\title{
PREPARATION OF PRE-SERVICE TEACHERS IN GHANA TO INTEGRATE INFORMATION AND COMMUNICATION TECHNOLOGY IN TEACHING MATHEMATICS
}

Douglas D. Agyei 
DOCTORAL COMMITTEE

Chairman Prof. dr. K.I. van Oudenhoven-Van der Zee - University of Twente

Promotor Prof. dr. J. M. Pieters - University of Twente

Assistant promotor Dr. J. M. Voogt - University of Twente

Members $\quad$ Prof. dr. J.J.H. van den Akker - University of Twente

Dr. S.E. McKenney - University of Twente

Prof. dr. H. Eijkelhof - University of Utrecht

Prof. dr. M. Cox - King's College London

Dr. P. Drijvers - University of Utrecht

Agyei, D.D.

Preparation of pre-service teachers in Ghana to integrate information and communication technology in teaching mathematics

Thesis University of Twente, Enschede.

ISBN 978-90-365-3369-0

DOI $10.3990 / 1.9789036533690$

Cover design: SeEPEC Graphics

Layout: Sandra Schele

Printer: Ipskamp Drukkers B.V. Enschede

CC Copyright, 2012, D.D. Agyei 


\title{
PREPARATION OF PRE-SERVICE TEACHERS IN GHANA TO INTEGRATE INFORMATION AND COMMUNICATION TECHNOLOGY IN TEACHING MATHEMATICS
}

\author{
DISSERTATION \\ to obtain \\ the degree of doctor at the University of Twente, \\ on the authority of the rector magnificus, \\ prof. dr. H. Brinksma, \\ on account of the decision of the graduation committee \\ to be publicly defended \\ on $28^{\text {th }}$ of June 2012 at 14.45 \\ by \\ Douglas Darko Agyei \\ born on $21^{\text {st }}$ of November 1974 \\ in Koforidua, Ghana
}


Promotor

Prof. dr. J. M. Pieters

Assistant promotor
Dr. J. M. Voogt

This dissertation has been approved by the promotor and assistant promotor. 


\section{TABLE OF CONTENTS}

LIST OF FIGURES AND TABLES vii

ACKNOWLEDGEMENTS $\quad$ xi

$\begin{array}{ll}\text { 1. INTRODUCTION } & \mathbf{1}\end{array}$

1.1 Problem definition 1

1.1.1 Mathematics education in Ghana 1

1.1.2 Teacher preparation programmes for teaching
mathematics in Ghana

1.1.3 Mathematics teacher preparation programme and ICT

$\begin{array}{ll}1.2 \text { Theoretical underpinning for the study } & 7\end{array}$

$\begin{array}{lll}\text { 1.2.1 Effective technology integration } & 7\end{array}$

1.2.2 The specific application of TPACK in the study 10

1.2.3 Learning ICT by collaborative design and pre-service teachers' design teams $\quad 14$

$\begin{array}{ll}1.3 \text { Research questions } & 16\end{array}$

1.4 Methodology 17

$\begin{array}{ll}\text { 1.4.1 Design-based research } & 17\end{array}$

$\begin{array}{ll}1.5 \text { Dissertation synopsis } & 19\end{array}$

2. ICT USE IN THE TEACHING OF MATHEMATICS: IMPLICATIONS FOR PROFESSIONAL DEVELOPMENT OF PRE-SERVICE TEACHERS IN GHANA

2.1 Introduction 21

2.2 Teacher preparation programmes for teaching mathematics in $\begin{array}{ll}\text { the senior high school } & 24\end{array}$

2.3 Potential of ICT for mathematics education 25 
2.4 Factors inhibiting ICT use in mathematics classrooms 26

2.5 Method 27

$\begin{array}{lll}2.5 .1 & \text { Participants } & 27\end{array}$

2.5.2 Research instruments $\quad 27$

2.5.3 Data collection and data analysis procedures 28

2.6 Results 29

2.6.1 Perceived barriers to ICT integration 29

2.6.2 Availability and accessibility of ICT 30

2.6.3 Current pedagogical practices 32

2.6.4 Levels of ICT use at the teacher education programme in UCC 33

2.6.5 Professional development and training needs 34

$\begin{array}{lll}2.7 & \text { Discussion and conclusions } & 38\end{array}$

3. EXPLORING THE POTENTIAL OF THE WILL, SKILL, TOOL MODEL IN GHANA: PREDICTING PROSPECTIVE AND PRACTICING TEACHERS' USE OF TECHNOLOGY 43

3.1 Introduction 44

3.2 A conceptual framework for the study: the will skill tool model 45

3.2.1 Computer attitudes 46

3.2.2 Technology competency 48

3.2.3 Access to technology tools 49

3.2.4 Technology integration $\quad 50$

$\begin{array}{ll}3.3 \text { Methods } & 50\end{array}$

3.3.1 Respondents $\quad 50$

$\begin{array}{ll}\text { 3.3.2 Research instruments } & 51\end{array}$

3.3.3 Data collection and data analysis procedures 54

3.4 Results $\quad 55$

3.4.1 Descriptive statistics $\quad 55$

3.4.2 Stages of adoption and teachers' related attitude,

3.4.3 A predictive model of technology integration using the will-skill-tool concept 59

$\begin{array}{ll}3.5 \text { Discussion } & 61\end{array}$

3.5.1 Practical implications $\quad 63$

$\begin{array}{lll}\text { 3.5.2 Limitation and further research } & 64\end{array}$

3.6 Conclusion 65 


\section{Developing Technological Pedagogical Content}

KNOWLEDGE IN PRE-SERVICE MATHEMATICS TEACHERS THROUGH COLLABORATIVE DESIGN

4.1 Introduction 68

4.2 Technology integration through collaborative design $\quad 70$

$\begin{array}{ll}4.3 \text { The professional development arrangement } & 73\end{array}$

4.4 Research questions and research design $\quad 74$

$\begin{array}{ll}4.5 \text { Methods } & 75\end{array}$

4.5.1 Participants 75

4.5.2 Instruments 76

$\begin{array}{ll}4.6 \text { Results } & 78\end{array}$

4.6.1 Experimental teachers' practice 78

4.6.2 Experimental teachers' reflection on their learning 80

4.6.3 The contribution of teacher design teams for experimental teacher learning $\quad 81$

4.6.4 The contribution of exemplary curriculum materials for experimental teacher learning $\quad 81$

$\begin{array}{ll}4.7 \text { Discussion } & 82\end{array}$

$\begin{array}{ll}4.8 \text { Conclusion } & 87\end{array}$

5. PRE-SERVICE MATHEMATICS TEACHERS' LEARNING AND TEACHING OF ACTIVITY-BASED LESSONS SUPPORTED WITH SPREADSHEETS

5.1 Introduction $\quad 89$

5.2 Theoretical underpinnings $\quad 91$

5.2.1 Activity-Based Learning in mathematics 91

5.2.2 TPACK and Mathematics 92

5.3 The professional development arrangement $\quad 95$

5.4 Research questions and research design 96

$\begin{array}{ll}5.5 \text { Methods } & 97\end{array}$

$\begin{array}{lll}\text { 5.5.1 Participants } & 97\end{array}$

5.5.2 Instruments 97

$\begin{array}{ll}5.6 \text { Results } & 102\end{array}$

$\begin{array}{lll}\text { 5.6.1 Lesson plans } & 102\end{array}$

5.6.2 Lesson enactment 105

5.6.3 Pre-service teachers' self-reported TPACK development 108

5.6.4 Student cognitive outcomes 111

$\begin{array}{lll}5.7 & \text { Discussion } & 112\end{array}$ 


\section{PRE-SERVICE TEACHERS' COMPETENCIES FOR TECHNOLOGY}

INTEGRATION: INSIGHTS FROM A MATHEMATICS-SPECIFIC INSTRUCTIONAL TECHNOLOGY COURSE

6.1 Introduction 116

6.2 Theoretical underpinnings

6.2.1 Technology integration in mathematics: Pre-service teachers competencies

6.2.2 Successful guidelines for technology integration in preservice teacher education

6.3 The mathematics-specific instructional technology (IT) course programme

6.4 Research questions 122

6.5 Method 122

6.5.1 Participants 122

6.5.2 Instruments 123

$\begin{array}{ll}\text { 6.6 Data analysis } & 127\end{array}$

6.7 Results 127

$\begin{array}{lll}\text { 6.7.1 Lesson plans } & 127\end{array}$

6.7.2 Lesson enactment 130

6.7.3 Pre-service teachers' perceived TPACK knowledge and skills 133

6.7.4 Pre-service teachers' attitudes toward technology 134

6.7.5 The contribution of the instructional technology course to pre-service teachers' technology integration competencies learning 135

$\begin{array}{ll}6.8 \text { Discussion } & 136\end{array}$

7. EXAMINING FACTORS AFFECTING BEGINNING TEACHERS' TRANSFER OF LEARNING IN PROFESSIONAL AND TEACHING PRACTICES IN GHANA 139

7.1 Introduction 139

7.2 Characteristics of the intervention: ICT-based innovation 141

7.3 Factors influencing transfer of teacher learning 142

7.3.1 Characteristics of the learner 143

7.3.2 School environment characteristics 145

$\begin{array}{ll}7.4 \text { Research questions } & 147\end{array}$ 
7.5 Methods

$\begin{array}{lll}7.5 .1 & \text { Participants } & 148\end{array}$

$\begin{array}{ll}\text { 7.5.2 Instruments } & 148\end{array}$

$\begin{array}{ll}\text { 7.6 Data analysis } & 150\end{array}$

$\begin{array}{ll}7.7 \text { Results } & 150\end{array}$

7.7.1 Transfer of learning of ICT-ABL and LTCD in beginning teachers' teaching practices. $\quad 150$

7.7.2 Factors influencing beginning teachers' transfer of learning of ICT-ABL and LTCD

7.7.3 Predicting teachers' transfer of ICT-ABL and LTCD in their teaching practices.

7.8 Discussion

7.8.1 Practical implications

\section{DISCUSSION AND REFLECTIONS}

8.1 Recapitulation: Aims and research questions 163

$\begin{array}{ll}8.2 \text { Research phases and results } & 165\end{array}$

8.2.1 First study: Feasibility of ICT use in teaching mathematics

8.2.2 Second study: Developing TPACK through collaborative design in a professional development scenario

8.2.3 Third study: Measuring competencies for ABL with technology

8.2.4 Fourth study: Evaluating guidelines in a mathematicsspecific instructional ICT course

8.2.5 Fifth study: Examining factors affecting beginning teachers' transfer of learning in professional and teaching practices in Ghana

8.2.6 Overall conclusion of the study 171

8.3 Reflecting on the research approach 172

$\begin{array}{ll}8.4 \text { Outcomes and reflections } & 174\end{array}$

8.4.1 Design guidelines for preparing pre-service teachers in mathematics teacher education $\quad 174$

8.4.2 Technological pedagogical content knowledge (TPACK) 175

8.4.3 Potential of spreadsheet and Activity-Based Learning 176

8.4.4 Potential of collaborative design in teams for the pre-service teacher programme

8.4.5 Ownership, transfer and practicability 
8.5 Recommendation

179

8.5.1 Recommendation for practice 179

8.5.2 Direction for future research 182

$\begin{array}{ll}\text { REFERENCES } & 185\end{array}$

$\begin{array}{ll}\text { ENGLISH SUMMARY } & 197\end{array}$

$\begin{array}{ll}\text { DUTCH SUMMARY } & 205\end{array}$

$\begin{array}{ll}\text { APPENDICES } & 213\end{array}$ 


\section{LIST OF FIGURES AND TABLES}

\section{FIGURES}

1.1 Framework of TPACK 9

1.2 Framework of TPACK used in the study 10

3.1 Teacher attitudes toward computers by stage of adoption of

$\begin{array}{lll}4.1 & \text { Framework of TPACK } & 71\end{array}$

5.1 Framework of TPACK use in the study 94

5.2 Graph of $y=a x^{2}+b x+k$ and Graph of $y=m x+k \quad 106$

6.1 Framework of TPACK used in the study 118

7.1 Hierarchical clustering dendrogram of conditions using Average Linkage

\section{TABLES}

2.1 Perceived barriers to ICT Integration by in-service and pre-service teachers

2.2 Availability of ICT Facilities in SHS's 31

2.3 Teaching strategies used in SHS's

2.4 Levels of ICT application in Instruction at the Teacher Education Programme in UCC

2.5 Overall perceptions of teachers towards ICT integration in delivery of mathematics lessons

2.6 Teachers' Professional development needs 36

3.1 Internal consistency reliability for six sub-scale of the TAC 52

3.2 Differences in attitudes based on TAC scores of practicing and prospective teachers

3.3 Differences in technology in education competencies of practicing and prospective teachers

3.4 Differences in accessibility of technology of practicing and prospective teachers 
3.5 Comparison of stages of adoption of technology between practicing and prospective teachers

3.6 Coefficients of predictors $\quad 60$

3.7 Coefficients of predictors 61

4.1 Relation between Design Team activities, TPACK framework and strategies for teacher learning $\quad 74$

4.2 Sample question for each TPACK knowledge type constructs $\quad 76$

4.3 Student-teachers' score on 3 sub-scales of the lessons 80

4.4 Results for pre- and post-test mean score responses for TPACK subscales

5.1 Overview of lessons designed and taught by the pre-service teachers

5.2 Pre-service teachers' knowledge and skill learning and classroom practices

5.3 Criteria for analysing spreadsheet supported ABL lesson plans 98

5.4 Sample items for each TPACK knowledge type construct 99

5.5 Sample question for each TPACK knowledge type constructs 101

5.6 Mean score responses for TPACK in lesson plans 104

5.7 Wilcoxon test results for peer teaching and classroom teaching mean score responses for TPACK Subscales

107

5.8 Wilcoxon test results for pre- and post-test mean score responses for TPACK subscales 108

5.9 Interview responses for designing and teaching ABL 109

5.10 Mean gain test score between spreadsheet-supported ABL and traditional approach

6.1 Outline of the instructional technology course and design guidelines for technology integration

6.2 Overview of instruments and their stages of administration. 123

6.3 Criteria for analyzing spreadsheet supported ABL lesson plans $\quad 124$

6.4 Sample items for each TPACK knowledge type construct 125

6.5 Sample question for each TPACK knowledge type constructs 126

6.6 Mid- and end-TPACK score of pre-service teachers' lesson plan
artefact

6.7 Descriptive statistics for end-TPACK score of pre-service teachers' lesson plan artefact 130

6.8 Activity-based lessons with the added value of spreadsheet 131

6.9 Descriptive statistics for end-TPACK score of pre-service teachers'
lesson observation

6.10 Perceived TPACK knowledge and skill for NPT and PT 133 
6.11 Differences in attitudes based on TAC scores of pre-service with and without teaching try-out experience

6.12 Pre-service teachers perceived usefulness of the design guidelines in IT course

7.1 Overview of the ICT-based innovation components

7.2 Beginning teachers' reported use of ICT-ABL and LTCD

7.3 Observation of beginning teachers' use of the ICT-ABL

7.4 Beginning teachers' perceptions of ICT-ABL and LTCD

7.5 Mean score and standard deviations for factors influencing beginning teachers transfer of learning

7.6 Coefficients of predictors: School environment characteristics, learner characteristics and perception about the ICT-based

7.7 Coefficients of predictors: School environment characteristics (SEC), learner characteristics (LEC) and perception about the ICTbased 


\section{ACKNOWLEDGEMENTS}

Earning Ph.D. requires extended study and intense intellectual effort; it is a long steep staircase that takes extreme perseverance to climb. The realization of this thesis is the fruit of total commitment to multiple years of hard work and determination. However, it would not have been possible without the kind support of many individuals and organizations. It is a pleasure to thank those who made this thesis possible.

I wish to express deep appreciation to my promotor Prof. Dr. Jules Pieters who gave me his unflinching encouragement, guidance and support, without which this research could neither have been started nor completed. I owe profound gratitude to my co-promotor, Dr. Joke Voogt, whose patience, constructive suggestions, critical questions and discussions enabled me to develop an understanding of the subject of study. She made available her support in various ways which led to the completion of this thesis before schedule.

My colleagues at the Department of Curriculum Design and Educational Innovation $(\mathrm{C} \& \mathrm{O})$ have contributed immensely to my personal and professional development at the University of Twente. Their constructive views and conversations, both formal and informal propelled me during this journey of constant challenges. I would like to thank Ms. Sandra Schele for making this book presentable and also for her ever willingness to provide administrative support.

My deepest appreciation goes to the principals and in-service mathematics teachers at various senior high schools, pre-service teachers and staff of the Science and Mathematics Education Department at the University of Cape Coast for their valuable support and ardent commitment during the interventions and data collection in Ghana. Thanks are due Prof. N.G. Mensah of the department of Mathematics and Statistics at University of Cape Coast for encouraging me to pursue doctoral studies. I have the pleasure to thank all other colleagues from the same department of whom I have great regard. 
Prof E. C. Quaye deserves special mention for his support and inspiration especially at the beginning of the programme.

I gratefully acknowledge the management of my home institution, University of Cape Coast, for giving me permission to commence this PhD study in the first instance and providing me with uninterrupted financial support throughout my absence for further studies.

I am also very much indebted to the Dutch Government who provided funding for the research through NUFFIC under the NPT-GHA-155 PRACTICAL Project: Strengthening Mathematics and Science Education in Ghana. My gratitude goes to the project partners at Vrije Universiteit, Amsterdam (Centre for International Cooperation). Particularly, Ms. Eek Dia always ensured timely financial disbursement and smooth travel and accommodation arrangements in and outside the Netherlands. I was honoured to have had Ms. Lieke Stoffelsma manage my funds as the project coordinator. Alongside her official responsibilities, she made other arrangements to make Enschede a home for me. Drs. Leo de Feiter deserves mention for his input, especially during the search for an institution to start my Ph.D. programme.

I am thankful to my many friends home and abroad for all the emotional support, camaraderie, interest and valuable hints and for assisting me in many diverse ways.

I am so grateful to Mark Boadu, for all his support and advice during this Ph.D. journey. I am truly humbled by his loyalty and I treasure our friendship. Crystal Mills Botchway shared my unrelenting enthusiasm for the research and spared time off her busy schedule to proof read my manuscripts. Seth Achia Addo also deserves special mention for his constant inspiration, support and prayers throughout this Ph.D. journey.

Last but not the least, I am thankful for encouragement and assistance that I received from all my family members- far too many to mention by names. They all made various contributions to this success story for which I am very thankful. I cherish their love, prayers and support in diverse ways. Kobby and Serena, my children, deserve special mention for their patience and sacrifices that have been my greatest strength to make this dream come true.

Douglas Darko Agyei, 2012 


\section{CHAPTER 1 \\ Introduction}

This first chapter provides a general introduction to the studies reported in this dissertation. The existing challenges at the onset of the study are described, followed by an overview of the specific context where the research was undertaken. Two concepts guided this study: Technological Pedagogical Content Knowledge and Learning Technology by Design. In this first chapter both concepts are introduced and elaborated as applied in this study. The research questions are introduced after which the overall research design is described. The chapter ends with an outline of the structure of the dissertation and an overview of the content of the subsequent chapters.

\subsection{PROBLEM DEFINITION}

\subsubsection{Mathematics education in Ghana}

The importance of mathematics in the development of a country cannot be underestimated as it plays a major role in the economy and the social life of its people. Due to its importance the government of Ghana is committed to ensuring the provision of high quality mathematics education. In spite of government efforts, learning mathematics has not undergone much change in terms of how it is structured and presented and among other reasons has resulted in consistently low achievement levels among mathematics students in high schools (e.g. see Mullis, Martin, \& Foy 2008; Ottevanger, Van den Akker, \& de Feiter, 2007). Ottevanger et al. (2007) indicated that the most frequently used strategy in mathematics classrooms is the teacher-centred (chalk and talk) approach in which teachers do most of the talking and intellectual work, while students are passive receptacles of the information provided. According to Ottevanger et al. (2007) this type of teaching is heavily dominated by teachers 
(while students are silent), involves whole class teaching, lots of notes being copied, and hardly any hands-on activities. In most instances, teachers rush to cover all the topics mechanically in order to finish on time for examinations rather than striving for in-depth student learning (Ottevanger et al., 2007).

Such teacher-centred instructional methods have been criticized for failing to prepare students to attain high achievement levels in mathematics (Hartsell, Herron, Fang, \& Rathod, 2009). Consequently, the emphasis on teaching mathematics in a way that is understandable to both the mathematics educators and the policy makers has been on the rise in the recent past. Numerous studies reiterate the impact of ICT use on the development of mathematical concepts in students and on their achievements (Beauchamp \& Parkinson, 2008; Bottino \& Robotti, 2007; So \& Kim, 2009). Guerrero (2010) indicated that one area that has seen dramatic growth in the influence and applications of ICT on the development of content and the evolution of instruction is mathematics. The American Association of Mathematics Teacher Educators (2006) stated that "ICT has become an essential tool for doing mathematics in today's world, and thus ... it is essential for the teaching and learning of mathematics" (p. 1). The government of Ghana shares this view, and considers ICT literacy as an engine for accelerated development outlined in the Ghana Information and Communication Technology for Accelerated Development (Ghana ICT4AD Policy document, 2003). Ghana introduced ICT as a tool for teaching into the school curriculum in September 2007 following the recommendations of the ICT4AD document and the Anamuah-Mensah National Education Review Committee Report (2002). Both documents highlight the importance of integrating ICT into the curriculum at all levels. The government and other institutions have invested huge sums of money in procurements of computers and establishment of computer labs in most senior high schools; accessibility problems however still exist in classroom.

Computer literacy is not only introduced as a new subject in the curriculum, but also as a tool to enhance teaching and learning. The new curriculum in mathematics at the senior high school encourages teachers to make use of the calculator and the computer for problem solving and investigations of real life situations, in order to help students acquire the habit of analytical thinking and the capacity to apply knowledge in solving practical problems (Ministry of Education (MOE), 2000; Ministry of Education, Science and Sports (MOESS), 
2007). However, there still exists a gap between this new concept of teaching with ICT as enumerated in curriculum and policy documents and the use of ICT in practice.

Teacher preparation programmes have not focussed on preparing pre-service teachers sufficiently for effective ICT integration in their teaching practice. Important questions such as: "what can teachers do with computers to promote integration of ICT in the curriculum or to extend instructional methods?" and "what can teachers do with computers to improve students' outcomes?" still remain. To realize this new orientation to teaching and learning including the use of computers by teachers more needs to be done than recommendations contained in syllabuses. Policy makers and teacher preparation programmes should advocate for radical changes in approaches of teaching in which teachers will adapt new roles. Teachers should be prepared to be innovative and creative in the integration of ICT in their classrooms, thus delivering concepts and theories easily to students and providing them with better education.

This study is being advocated to support teachers in this transition. The purpose of this research was to enhance professional development arrangements by providing opportunities and support in which pre-service teachers collaboratively design and use ICT-supported lesson teaching materials in mathematics instruction, in spite of limited ICT accessibilities. In the professional development arrangement, ICT is introduced as an instructional tool to promote student in-depth mathematical concept formation and Activity Based Learning approach, to make lessons less teacher-centred and more interactive. For pragmatic reasons the terms "ICT" and "technology" are used interchangeably in this report.

\subsubsection{Teacher preparation programmes for teaching mathematics in Ghana}

The Senior High School (SHS) mathematics curriculum in Ghana focuses on attaining one crucial goal: to enable all Ghanaian young persons to acquire the mathematical skills, insights, attitudes and values that they will need to be successful in their chosen careers and daily lives (MOESS, 2007). This curriculum is based on the premises that all students can learn mathematics and that all need to learn mathematics. The student is expected at the SHS level to develop the required mathematical competencies to be able to use his/her knowledge in solving real life problems and secondly, be well equipped to 
enter into further study and associated vocations in mathematics, science, commerce, industry and a variety of other professions (MOESS, 2007). The rationale of the curriculum has therefore a lot of implications on teaching strategies and the preparation of mathematics teachers for SHS's.

In Ghana mathematics teacher education for SHS's is offered by two main institutions, the University of Cape Coast (UCC) and University of Education, Winneba (UEW). These two universities are institutes for higher education that have the specific task to prepare teachers for the SHS's.

The main route in teacher education at both UCC and UEW is the Bachelor of Education qualification of 4 years duration. Three main components are present in these programmes: subject content courses, education courses and teaching practice. The education courses are further sub-divided into general ones and subject-specific ones (i.e. for individual school subjects, or categories of subjects like science). The latter are taught in the science and mathematics education departments and denoted as science or mathematics pedagogy courses.

At UCC in particular a mathematic-specific instructional course: Development of mathematics teaching materials, is offered to pre-service teachers in their final year for one semester. The course examines the nature of teaching and learning materials for secondary school mathematics and the criteria for their selection. In this course, materials for teaching major topics (e.g. Number, Algebra, Geometry) are supposed to be introduced and activities designed by students with specific objectives to enable pre-service teachers acquire the content of the curriculum as well acquire the knowledge and skills in developing and enacting learner-centred mathematics lessons. A careful study of the course description however showed that the content of the course was not sufficient and needed revision to ensure that pre-service teachers will be prepared to extend their instructional methods in an innovative and creative way and to improve their teaching after going through the programme. The general education courses are taught in other education departments, particularly Educational Foundations. Similarly for teaching practice placement in schools, the organisation is done by a general education department for all students from various subjects.

A major difference in the programmes between the two universities lies in the fact that most content in UCC is taught by the Faculty of Science, whilst at UEW 
this takes place in the Faculty of Science Education. The mathematics content courses (which cover the SHS curricula) at the first and second year undergraduate levels are the main basis for teacher education students.

Two main problems can be distinguished that put the quality of the programmes under pressure: reduced opportunities for interaction between lecturers and individual students (as a result of fast expansion of student numbers in universities) and lack of practical orientation. The later has roots in the educational tradition of the Ghana education system which emphasizes teacher-centred exposition as a main educational method (Adu-Gyamfi \& Smit 2007).This research was conducted within the context of the teacher education programme at UCC.

\subsubsection{Mathematics teacher preparation programme and ICT integration at UCC}

UCC is one of the rare sea front universities in the world. It was established in October, 1962 as a University College and placed in a special relationship with the University of Ghana, Legon. The University was established out of a dire need for highly qualified and skilled manpower in education to provide leadership and enlightenment. Its original mandate was therefore to prepare graduate professional teachers for Ghana's second cycle institutions, Teacher Training Colleges, and Technical Institutions.

The Faculty of Education is the largest faculty in the University of Cape Coast. It admits close to forty per cent of the total student population. The faculty has six departments, two centres and two institutes. Among the departments in the faculty is the Science and Mathematics education department which prepares science and mathematics teachers mainly for second cycle institutions in the country. A review of the courses offered within the 4-year mathematics teacher education programme unfolded two issues which were of major importance to this research: the status of ICT integration in teacher preparation and the different teaching methods adopted by instructors in the programme. The only ICT course (computing) offered to the students is during the first semester of the first year, taught as a subsidiary and optional subject by the computer science department of the university. In this course, students learn basic computing skills. 
Next to the computer literacy course the science teachers preparation programme also offers a course in Educational Technology; a two credit hour course in the second semester of year one. This course is mainly theoretical merely exposing students to various educational technologies. The mathematic-specific instructional course offered in the mathematics education department also does not include elements to prepare students to integrate ICT in their classrooms. This means that the programme does not give prospective teachers the chance to learn about ICT, and how to incorporate it into their own teaching. Consequently, pre-service teachers' experience to integrate ICT in teaching is limited. This leads to the question whether pre-service teachers are sufficiently prepared for new teaching methods which involve appropriate use of ICT.

Alongside concerns regarding the content of the programme with respect to ICT, instructors at the mathematics teachers' preparation programme have a limited use or in most case no use of ICT in their teaching process. Most instructors at this programme use lecture-based instruction by which teachers are doing most of the talking and intellectual works, while students are passive receptacles of the information provided. These instructors do not integrate ICT in their instruction due to lack of ICT integration skills. At best some instructors are knowledgeable about ICT applications, but do not have the skills to effectively integrate them in their courses. This is likely to have a ripple effect on the professional practice of these prospective teachers. Reasons which could explain instructors' limited implementation of new ICTs are the dependence on the traditional view of teaching and learning and limited access to ICT facilities. Becker (2001) concluded that teachers who believe in a more traditional transmission-oriented approach will find most computer applications incompatible with their instructional goals, and will therefore use a limited range of computer technology in their instruction. With a lack of attention on the integration of ICT in mathematics education and the current emphasis on teacher-centred education at the mathematics teacher preparation programme it is appropriate to explore possible ways to incorporate new teaching styles for active learning that use more supportive ICT resources in the mathematics teacher education programme. 


\subsection{THEORETICAL UNDERPINNING FOR THE STUDY}

\subsubsection{Effective technology integration}

The integration of ICT in education is a complex undertaking involving many stakeholders; teachers, however, are considered to play a core role (Voogt \& Knezek, 2008). Meaningful use of ICT in education requires teachers to develop knowledge and skills that enables them to integrate ICT with a suitable pedagogical approach for teaching specific subject matter in a certain context. Keating and Evans (2001) found that pre-service teachers felt comfortable with ICT in their schoolwork and daily practices, however felt unconfident to use ICT as an instructional tool in their classrooms. Lack of knowledge and skills about ways to integrate ICT in lesson might have been a possible reason for preservice teachers' inability to use ICT in their instructional practice.

Alongside the need to develop their knowledge and skills, also teachers' attitudes towards ICT integration need to be understood to appropriately determine competencies which pre-service teachers need to integrate ICT into their lessons. Christensen and Knezek (2008) indicated that teachers' attitude plays a key role in determining computer use as a learning tool and the likelihood that teachers will use ICT for teaching and learning. According to Myers and Halpin (2002), a major reason for studying teachers' attitudes is that it is a major predictor of future classroom integration of computers. Attitudes towards computers influence teachers' acceptance of the usefulness of technology, and also influence whether teachers integrate technology into their classroom (Clark, 2001; Van Braak, 2001; Paraskeva, Bouta, \& Papagianna, 2008). Studies by Fisher (2000), Khine (2001) and Van Braak, Tondeur, and Valcke (2004) have found significant relationships between computer attitudes and computer use in classrooms. Huang and Liaw (2005) also stated that among the factors considered to influence the successful integration of computers in the classroom, teachers' attitudes towards computers is a key factor and was the reason to assess pre-service teachers' attitudes in this study.

With regards to teacher knowledge required for ICT integration in their teaching practices, Technological Pedagogical Content Knowledge (TPCK) has been introduced by Mishra \& Koehler (2006) as a conceptual framework to understand the knowledge and skills that teachers' need to effectively integrate technology in their teaching. TPCK is derived from the concept pedagogical 
content knowledge (PCK) (Shulman, 1986) which highlights the importance of the complex interrelationships between teachers' knowledge about content and pedagogy, and the need for teachers to learn about variable ways of representing subject matter has been discussed by many researchers.

PCK is considered a unique feature that qualifies the teacher's profession: teachers are able to integrate domain knowledge with appropriate pedagogical approaches so that learners are able to understand the subject at stake (Voogt, Fisser, Pareja Roblin, Tondeur, \& Van Braak, 2012). In their analysis, Magnusson, Krajcik, and Borko (1999) stated that PCK includes knowledge of subject-specific strategies and topic-specific strategies. Subject-specific strategies are pedagogical methods that are unique to a given discipline, such as inquirybased learning in science, investigations in mathematics, or primary source research in social studies. Topic-specific strategies are "specific strategies that are useful for helping students comprehend specific concepts" (Magnusson et al., 1999, p. 111). Van Driel, De Vos, and Verloop (1998) indicated that there is also no universal agreement on what PCK entails, but Voogt et al. (2012) explained two key characteristics of what is common in PCK: PCK is about knowledge of representations of domain knowledge; and understanding of specific learning difficulties and student conceptions related to the teaching of particular topics of the domain.

T(PCK) as extended PCK is an emerging concept and has similar notion as PCK; it adds technology knowledge (TK) as an indispensable part of the teacher's profession (Voogt et al., 2012). The addition of " $T$ " is emphasized by different studies. Others used terms, such as information and communication technology (ICT)-related PCK (Angeli \&Valanides, 2005) or technology-enhanced PCK (Niess, 2005). In 2007, TPCK changed into TPACK, which stands for Technology, Pedagogy, and Content Knowledge and was described as the 'Total PACKage' for effectively teaching with technology (Thompson \& Mishra 2007). Cox and Graham (2009), referred to TPACK as teacher's knowledge of how to coordinate the use of subject-specific activities or topic-specific activities with topic-specific representations using emerging technologies to facilitate student learning. It is apparent that the role of " $T$ " in the framework cannot be overemphasized. Cox and Graham (2009) argue that there will always be a need for TPACK as long as there are new emerging technologies that have not yet become a transparent, ubiquitous part of the teaching profession's repertoire of tools. They further reiterated that it is only when technologies become 
ubiquitous in educational practice then TPACK will transform into PCK, and therefore, they referred to TPACK as a sliding framework.

The adaptation of the TPACK conceptual framework in the study can be explained in this direction. Incorporating ICT in teaching or learning is not common and an accepted practice among pre-service preparation and teacher education programmes in the context under consideration; TPACK may help to better understand the potential contributions of the emerging technologies. Secondly the added value of TPACK has the tendency to support students in learning conceptual and procedural knowledge of a particular subject (cf. Cox \& Graham 2009; Niess 2011) and impact on the curriculum. In this respect the TPACK concept seemed to be a useful framework for preparing these novice pre-service teachers to teach with ICT. The study in this dissertation focused on TPACK as developing from three contributing fields as proposed by Koehler and Mishra (2008) (see Figure 1.1).

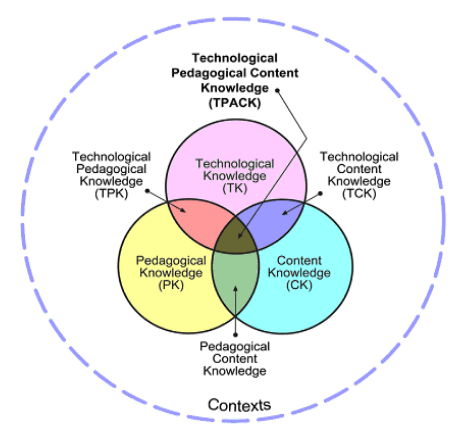

Figure 1.1 Framev

Koehler \& Mishra (2008) argue that effective ICT integration for teaching specific content or subject matter requires understanding of the relationships between three primary forms of knowledge that a teacher needs: Technological knowledge (TK), Pedagogical Knowledge (PK) and Content Knowledge (CK) as well as the interplay and intersections: Pedagogical Content Knowledge (PCK), Technological Content Knowledge (TCK), Technological Pedagogical Knowledge (TPK), and Technological Pedagogical Content Knowledge between them. PCK is the knowledge of teaching specific content as was addressed by Shulman (1986). TPK is an understanding of how teaching and learning changes when particular ICT application is used. TCK is an understanding of the manner in which ICT and content influence and constrain each other. TPACK is the intersection of all three knowledge areas (TK, CK and PK). Understanding of TPACK is above and beyond understanding of TK, CK, and PK in isolation. In the research TPACK 
has been used as a conceptual framework to examine the knowledge and skills pre-service math teachers developed about ICT, pedagogy and content.

The research described in this dissertation particularly focused on spreadsheets, which seemed a useful application (for instructional purposes) in enacting a guided activity-based pedagogical approach (referred to as Activity-Based Learning) as a strategy for teacher learning to develop pre-service teachers TPACK of teaching mathematics.

\subsubsection{The specific application of TPACK in the study}

In the research, pre-service teachers' knowledge and skills which are needed to teach spreadsheet supported ABL lessons in mathematics was operationalised as their TPACK. As shown in Figure 1.2, the technology (TKss) learned by the pre-service teachers were spreadsheet applications for mathematics and the pedagogical knowledge (PKABL), Activity-Based Learning (ABL). Content knowledge (CKmaths) was mathematics which was pre-service teachers' teaching subject area.

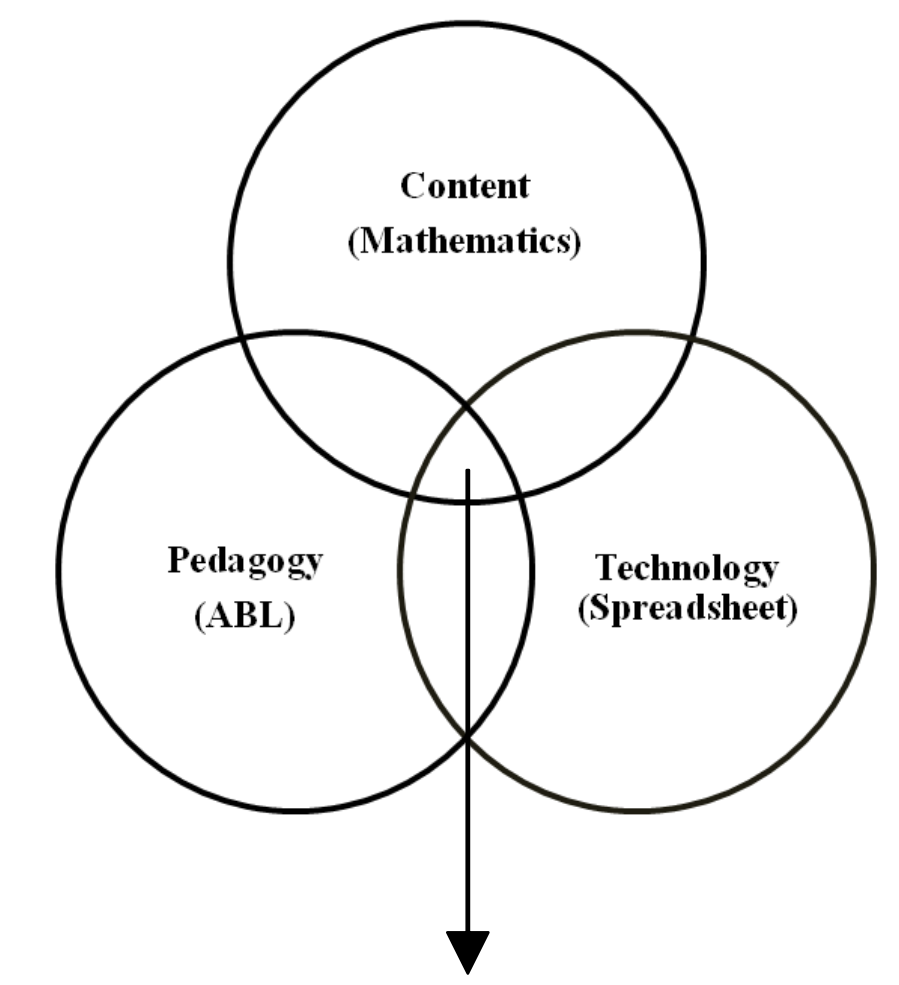

Technological Pedagogical Content Knowledge for spreadsheetsupported ABL in mathematics (TPACK)

Figure 1.2 Framework of TPACK used in the study 
The TPACK components as defined for this study consisted of the following specific knowledge and skills:

- Content knowledge ( $\left.C K_{\text {maths }}\right)$ : the knowledge about mathematical concepts.

- Pedagogical Knowledge $\left(P K_{A B L}\right)$ : knowledge and skills about applying ABL teaching strategies.

- Technological Knowledge ( $\mathrm{TK}_{\mathrm{ss}}$ ): knowledge and skills about use of spreadsheet its affordances and constraints.

- Pedagogical content knowledge (PCK $\left.K_{A B L}\right)$ : the knowledge and skills of how to apply ABL to teach particular mathematics content.

- Technological content knowledge $\left(T C K_{s s}\right)$ : the knowledge and skills of representing mathematical concepts in a spreadsheet.

- Technological Pedagogical Knowledge $\left(T P K_{A B L}\right)$ : The knowledge and skills of how to use spreadsheets in ABL.

- Technological pedagogical content knowledge (TPCK $\left.\mathrm{K}_{\text {maths}}\right)$ : the knowledge and skills of representing mathematical concepts with spreadsheet using $A B L$.

\section{Potential of spreadsheets for mathematics education}

Spreadsheets have been around since the early 1980s and, although not designed as an educational tool, have been used in mathematics classrooms since they first became available (Jones, 2005). Spreadsheets offer a technology readily available among classroom technologies with the potential for supporting students in meeting higher-order thinking skills in both the mathematics and science curricula. In particular, student development of dynamic spreadsheets supports them in learning important science/mathematics by exploring problems beyond their initial solution (Niess 2005). Niess, Sadri and Lee (2007) recognized advantages of using spreadsheets for solving complicated problems, motivating students, and providing opportunities for students to extend problems to additional hypothetical situations. According to Niess (2005) spreadsheets offer dynamic modeling capabilities that lead toward their use as a mathematical problem solving tool with the capacity for engaging students in higher-order thinking skills that supports them in exploring beyond initial solutions. According to Niess et al. (2007) teachers who are able to design and enact spreadsheet lessons engage their students in critical thinking to explore mathematical concepts and processes for accurate analysis. Jones (2005) indicated that one way to help learners move from a non-algebraic to an algebraic approach is through work with spreadsheets. He explained that in using such a tool, compared to using paper and pencil, learners appear to be able to learn 
more readily to express general mathematical relationships using the symbolic language in the spreadsheet environment. Dettori, Garuti and Lemut (2001) suggested that while using a spreadsheet may lead learners to solve problems using "trial and improvement", under the guidance of the teacher they can come to understand what it means to solve an equation, even before being able to handle equations. Rojano, (1996) showed more evidence of how the judicious use of spreadsheets can lead to algebraic understanding of learners.

In spite of its potential to support higher-order thinking skills, spreadsheet use is limited or even non-existent in most mathematics classrooms primarily because teachers have not been prepared to integrate them as teaching and learning tools; few teachers have used spreadsheets as tools for learning mathematics, leaving many of them unprepared to guide students in learning mathematics with spreadsheets (Niess, 2005). If spreadsheets are to be included as tools for learning mathematics, then mathematics teachers need opportunities to develop their personal knowledge and skills in using spreadsheets as tools for exploring and learning mathematics. They need support in redesigning the mathematics curriculum to include spreadsheets as tools for exploring mathematics while also guiding their students' development of knowledge and basic skills with spreadsheets (Niess et al., 2007).

The choice to use the spreadsheet in the context of the mathematics teacher education in Ghana was appropriate in the sense that the application was readily available, user friendly and had the potential of supporting students' higherorder thinking skills in mathematics at the Senior High Schools and in teacher Education Colleges. This also meant that the teachers will be able to use existing hardware and software in creative and situation-specific ways to design ICT resources to accomplish their teaching goals in future.

Previous research (Niess, Suharwoto, Lee, \& Sadri, 2006) in preparing teachers to teach with spreadsheets highlighted that a significant barrier affecting teachers' capacities for integrating spreadsheets in the curriculum was the difficulty in identifying appropriate topics and content in their own curriculum. Therefore, the research engaged pre-service teachers in collaborative investigations of their mathematic curriculum with the expectation that they plan their content curriculum to support students in building their knowledge and skills with spreadsheets concurrently with their mathematics knowledge and skills. 


\section{Activity-Based Learning (ABL)}

Previous studies (Bransford, Brown, \& Cocking, 1999; Lambert \& McComb, 1998; Mayer, 2004) have shown that there is merit in the constructivist vision of learning as knowledge construction. The constructivist revolution has brought new conceptions of learning and teaching (Marshall, 1996; Phillips, 1998; Steffe \& Gale, 1995) and has become the dominant view of how students learn (Mayer, 2004). Although constructivism takes many forms (Phillips, 1998), an underlying premise is that learning is an active process in which learners are active sense makers who seek to build coherent and organized knowledge (Mayer, 2004). According to Mayer, a common interpretation of the constructivist view of learning as an active process is that students must be active during learning. Furthermore, he explains that constructivist learning requires active teaching methods such as group discussions, hands-on activities, and interactive games.

The use of the ABL pedagogical approach in this research context, like other student-centered pedagogies, has been motivated by recognition of the failures of traditional instruction (Ottevanger et al., 2007) and is in line with the constructivist premise to make learning an active sense making process. Unlike traditional instruction, ABL actively engages the student in constructing knowledge. ABL describes a range of pedagogical approaches to teaching mathematics. Its core premises include the requirement that learning should be based on doing hands-on experiments and activities.

The idea of $\mathrm{ABL}$ is rooted in the common notion that students are active learners rather than passive recipients of information and that learning, especially meaningful learning, engages activity (Churchill \& Wong, 2002). Churchill (2004) argues that an active interaction with a learning object enables construction of learners' knowledge. Accordingly, he believes the goal of ABL is for learners to construct mental models that allow for 'higher-order' performance such as applied problem solving and transfer of information and skills. This suggests that in ABL approaches, learners are actively involved, the environment is dynamic, the activities are interactive and student centred and much emphasis is placed on collaboration and exchange of ideas. Mayer (2004) emphasizes on guidance, structure, and focused goals when using activitybased learning approach and recommends using guided discovery, a mix of direct instruction and hands-on activity, rather than pure discovery. HmeloSilver, Duncan and Chinn (2008) indicated that such guided inquiry approaches 
are not substituting content for practices; rather they advocate that content and practices are central learning goals. Hmelo-Silver, et al. (2008), argued that while it is challenging to develop instruction that fosters the learning of both theoretical frameworks and investigative practices of a discipline, such approaches provide the learner with opportunities to engage in scientific practices of questioning, investigation, and argumentation as well as learning content.

The research engaged pre-service teachers to develop the knowledge and skills needed to design and enact $\mathrm{ABL}$ lessons as a strategy for teacher learning and teachers' professional development. The expectation was that the pre-service teachers will be able to apply their knowledge and skills in enacting ABL lessons by employing a mix of direct instruction and hands-on activity to guide students through activities to enhance their learning.

\subsubsection{Learning ICT by collaborative design and pre-service teachers' design teams}

Teacher learning has become more pronounced in the education literature and associated with the implementation of planned change (Fullan, 2007). In view of that, there is broad consensus among teacher learning researchers that "reform oriented" professional development tends to be more effective than "traditional" course based professional development in bringing about change (LoucksHorsley, Hewson, Love \& Stiles, 1998; Penuel, Fishman, Yamaguchi, \& Gallagher, 2007; Putnam \& Borko, 2000).

Research on teacher professional development arrangements aiming to improve or change classroom practice, that aligns with views on teacher learning, emphasize that teacher professional development needs to provide opportunities for collaboration with peers and experts in attuning the practice to the local context (Ball \& Cohen, 1996; Borko, 2004; Elmore \& Burney, 1999; Garet, Porter, Desimone, Birman, \& Yoon, 2001; Penuel et al., 2007; Simmie, 2007). Bryk \& Schneider (2002) reiterated that studies that make extensive use of teacher collaboration are particularly successful in promoting implementation, in part because reforms have more authority when they are embraced by peers.

One way to comply with these features of effective teacher professional development is to embrace the ideas in preparing teachers to integrate ICT to 
teach. Numerous teacher preparation programmes have made extensive efforts to implement effective and meaningful use of ICT, however the strategies used to attain these goals are complex, diverse, often conflicting, and rarely evaluated well (Kay 2006). Such programmes have involved a wide range of approaches throughout the curriculum (based on Ottenbreit-Leftwich, Glazewski, Newby, \& Ertmer, 2010; Polly, Mims, Shepherd, \& Inan, 2010): information delivery of ICT integration content (e.g., lectures, podcasts), hands-on technology skill building activities (e.g., workshops), practice with ICT integration in the field (e.g., field experiences), and ICT integration reflections (e.g., electronic portfolios). Tondeur, et al. (2012) reviewed qualitative studies that focused on strategies to prepare pre-service teachers to integrate ICT into their lessons. Research has shown that needs-based collaborative professional development is effective in developing the competencies teachers need to adequately integrate ICT in classroom practice (e.g. Polly et al., 2010; MacDonald, 2008; Haughey, 2002).

Twelve key themes were identified that need to be in place to prepare pre-service teachers in ICT integration: (1) key themes explicitly related to the preparation of pre-service teachers (e.g., using teacher educators as role models, learning technology by design, scaffolding authentic technology experiences), and (2) key themes focusing on conditions necessary at the institutional level (e.g., technology planning and leadership, co-operation within and between institutions, training staff). Angeli and Valanides (2009) indicated that learning technology by design seeks to put pre-service teachers in roles as designers of ICT - enhanced learning activities and Jang (2008) explained that by actively collaborating, pre-service teachers are able to produce better designs than they would have done separately. Angeli and Valanides (2005) argued that such a design-based learning approach contribute to prepare future teachers to be competent to teach with ICT in ways that signify the added value of ICT. Polly et al. (2010) indicated that amongst others, the flexibility in such collaborations allow pre-service teachers to familiarize themselves with each other and the idea of ICT integration, and contributes to the success of curriculum design teams. So and Kim (2009) indicated that collaborative design help pre-service teachers to make intimate connections among content, pedagogy and technology in a collaborative way.

The reason for espousing collaborative design teams in the research was to provide opportunity for pre-service teachers to design ICT-enhanced curriculum 
materials to develop their knowledge and skills in ICT integration. By actively participating in the curriculum design process in teams, it is assumed that preservice teachers will build competencies that are sensitive to the subject matter (instead of learning ICT in general) and to specific instructional goals (instead of general ones) relevant for addressing the subject matter.

\subsection{ReseARCh QUESTIONS}

The teacher factor is considered one of the prominent reasons for students' poor achievement in mathematics in Ghana. The approach is mainly teacher centred which is characterized by transmittal techniques (dominated by teacher talk), making students to completely depend on teachers.

Recent research findings from mathematics education show that integration of ICT changed the nature of teaching and learning. But integrating ICT in teaching mathematics is a very complex and difficult task for mathematics teachers in Ghana. They have to learn to use new technologies appropriately and to incorporate it in lesson plans and lesson enactment. Professional development could facilitate the process of helping pre-service teachers develop the proper skills set and required knowledge.

The research focuses on enhancing professional development arrangements in which pre-service teachers collaboratively design and use ICT-supported lesson teaching materials. Based on this purpose, the main research question was formulated as:

How should collaborative design in design teams be applied in pre-service teacher education to prepare pre-service mathematics teachers for the integration of ICT in their future lessons?

The research approach applied in this dissertation to unearth responses to the main research question was design based research. Therefore, the main phases encompassing the design based research approach structured the studies in this thesis. 
The five main phases of the research were: context and needs analysis, two design and implementation studies, large scale implementation, and a transfer study. The following sub-research questions guided the research phases:

1. What are barriers, needs and opportunities of pre-and in-service mathematics teachers' use of ICT in teaching mathematics at SHS's in Ghana?

2. How do ICT attitudes, competencies and access of pre-and in-service mathematics teachers differ and to what extent do the parameters predict teachers' ICT integration levels?

3. What are pre-service mathematics teachers' experiences in developing and implementing technology-enhanced lessons through collaborative design teams?

4. How do pre-service teachers' knowledge and skills in designing and enacting spreadsheet supported ABL lessons develop and to what extent do the lessons impact on secondary school students learning outcomes?

5. Which impact does a mathematics specific course, in which pre-service teachers collaboratively design spreadsheet-supported mathematics lessons in teams, have on pre-service teachers' technology competencies (attitudes, knowledge and skills)?

6. To what extent is transfer of learning influenced by beginning teachers' learner characteristics, characteristics of the ICT-based innovation, and school environment characteristics in their professional and teaching practice?

\subsection{Methodology}

\subsubsection{Design based research}

Wang and Hannafin (2005) defined design-based research as a systematic but flexible methodology aimed to improve educational practices through iterative analysis, design, development, and implementation, based on collaboration among researchers and practitioners in real-world settings. According to Barab and Squire (2004), design-based research requires more than simply showing a particular design work but demands that the researcher move beyond a particular design exemplar to generate evidence-based claims about learning that address contemporary theoretical issues and further the theoretical knowledge of the field. Van den Akker, Gravemeijer, McKenney and Nieveen (2006) recommended design research approach to guide research projects because of its role to increase the 
relevance of research for educational policy and practice, develop empirically grounded theories through combined study of both the process of learning and the means that support that process and increase the robustness of design practice. The approach is iterative in nature involving analysis, design and evaluation. Analysis is conducted in order to understand how to target a design (McKenney, Nieveen \& Van den Akker, 2006). Cobb, diSessa, Lehrer, and Schauble (2003) further suggested that design-based research projects have a number of common features, including the fact that they result in the production of theories on learning and teaching, are interventionist (involving some sort of design), take place in naturalistic contexts, and are iterative. Evaluation is formative, performed to improve the quality of prototypes (McKenney, Nieveen \& Van den Akker, 2006) and /or summative to determine the impact of the intervention. These motives provide a stage for considering design based research.

This study drew on the multiple theoretical perspectives and research paradigms of design based research to build understandings of the nature and conditions of developing pre-service teachers' actual use of ICT resources to improve teaching mathematics using ICT. A context and needs analysis and a literature study were conducted as part of analysis at the first stage of the study. This provided empirically-based awareness about the problem in context as well as providing useful information for the formulation of the initial design guidelines that shaped a professional development arrangement. Based on the context, a professional development programme (using collaborative design teams) to engage pre-service teachers in ICT-rich design activities was implemented in three iterations of design, implementation, evaluation and refinement. Data collection during each iteration generated information on how to refine the programme and whether the professional development programme yielded desired impact, since design research integrates the development of solutions to practical problems in learning environments with the identification of reusable design principles (Reeves, 2006). Besides seeking to improve the programme, the evaluation also sought to determine the effectiveness of the technological professional development arrangement of the pre-service teachers on senior high school students' performance. Furthermore, a final study was conducted to ascertain the potential and conditions for transfer of knowledge and skills regarding the ICT innovation in pre-service teachers' professional or teaching practices. The design-based research approach appeared useful in finding realistic answers to the question posed for the research. 


\subsection{DISSERTATION SYNOPSIS}

The dissertation is structured in eight chapters. Chapter 2 and chapter 3 present research about the feasibility of teachers' ICT use in mathematics lessons. Whereas Chapter 2 sought to determine the features of ICT intervention that fit the realities in SHSs providing useful guidelines in designing a professional development arrangement for teachers' ICT integration, chapter 3 searched for a better understanding of mathematics teachers' attitudes, skills and ICT access levels and the extent to which these parameters influenced mathematics teachers' integration of ICT. Chapter 2 deals with the research question "What are barriers, needs and opportunities of pre-and in-service mathematics teachers' use of ICT in teaching mathematics at SHS's in Ghana?"

Chapter 3 focuses on "How do ICT attitudes, competencies and access of preand in-service mathematics teachers differ and to what extent do the parameters predict teachers' ICT integration levels?".

Chapter 4 reports results from the second study, which explored Technological Pedagogical Content Knowledge (TPACK) as a framework for developing preservice teachers' experiences in ICT integration. Particularly, the chapter presents results on teachers' experiences in developing and implementing ICTenhanced lessons using collaborative design teams as an approach to the professional development and addresses the research question: "What are preservice mathematics teachers' experiences in developing and implementing technology-enhanced lessons through collaborative design teams?".

The results from a follow-up study extending the arrangement of ICT integration programme to real classroom settings is reported in chapter 5.The research question that aided the conduct of the study in this chapter was: "How do pre-service teachers' knowledge and skills in designing and enacting spreadsheet supported ABL lessons develop and to what extent do the lessons impact on secondary school students learning outcomes?".

Chapter 6 integrates the findings from the studies reported in chapters 4 and 5 . This chapter reports a scale up study of the professional development arrangement into a mathematics-specific Instructional Technology course to foster adoption of the innovation by many pre-service mathematics teachers in 
the teacher preparation program. More specifically the study reports on how the IT course impacted on pre-service teachers' technology integration competencies. The research question was: which impact does a mathematics specific course, in which pre-service teachers collaboratively design spreadsheet-supported mathematics lessons in teams, has on pre-service teachers' technology competencies (attitudes, knowledge and skills)?

Chapter 7 reported on factors that influence or inhibit beginning teachers' transfer of knowledge and skills regarding the ICT innovation in their professional or teaching practices after several months of their preparation. The research question that guided this study was "To what extent is transfer of learning influenced by beginning teachers' learner characteristics, characteristics of the ICT-based innovation, and school environment characteristics in their professional and teaching practice?".

Chapter 8 brings together the findings of the subsequent chapters. It provides an overview of the answers to the questions formulated in this dissertation and presents integrated results and their practical implications. Finally it includes a discussion of the limitations of the studies and suggestions for future research. In the appendices are the data collection instruments for the phases in this research $^{1}$ as well as examples of coded lessons that were analyzed.

1 The soft copy of the instruments used in this study can be sent on request (dagyei@yahoo.com). 


\title{
CHAPTER 2
}

\section{ICT use in the teaching of mathematics: Implications for professional development of pre- service teachers in Ghana ${ }^{2}$}

\begin{abstract}
Included in the contemporary mathematics curricula in Ghana is the expectation that mathematics teachers will integrate technology in their teaching. However, importance has not been placed on preparing teachers to use ICT in their instruction. This paper reports on a study conducted to explore the feasibility of ICT use in mathematics teaching at senior high school levels in Ghana. Interviews and survey data were used for data collection. Preliminary results showed that mathematics teachers in Ghana do not integrate ICT in their mathematics instruction. Among the major perceived barriers identified were: Lack of knowledge about ways to integrate ICT in lesson and Lack of training opportunities for ICT integration knowledge acquisition. To overcome some of these barriers, opportunities of a professional development arrangement for pre-service mathematics teachers were explored. Findings from the study revealed specific features of a professional development scenario that matters for ICT integration in mathematics teaching in the context of Ghana.
\end{abstract}

\subsection{INTRODUCTION}

In Ghana, mathematics is a compulsory subject at all levels in pre-university education. Due to its importance the government is committed to ensuring the

2 This chapter has been published as: Agyei, D.D., \& Voogt, J. (2011). ICT use in the teaching of mathematics: Implications for professional development of pre-service teachers in Ghana. Education and Information Technologies, 16(4),423-439. Available: http://www.springerlink.com/openurl.asp?genre=article\&id=doi:10.1007/s10639-010-9141-9 
provision of high quality mathematics education. Various attempts have been made in the past to improve the achievement of mathematics in schools. The most recent is seen in the New Educational Reforms (Anamuah-Mensah National Education Review Committee Report, 2002) of which implementation started in September, 2007. The new curriculum in Mathematics at the Senior High School (SHS) places emphasis on skill acquisition, creativity and the arts of enquiry and problem solving. It aims at developing in the student the ability and willingness to perform investigations using various mathematical ideas and operations. As part of the reforms the curriculum places a lot of emphasis on Information and Communication Technology (ICT) as a tool for teaching mathematics (MOESS, 2007). It is therefore, designed to meet expected standards of mathematics in many parts of the world.

In spite of government efforts, mathematics has not undergone much change in terms of how it is presented. These reflect consistently in low achievement levels in mathematics among students at the high school levels. Results from the Trends in International Mathematics and Science Study (TIMSS) in 2003 and 2007 at the junior high school level (grade 8 equivalents) are instances of poor mathematics achievement in the country. In the aforementioned study, Ghana's eighth graders were ranked 43rd among 44th and 46th among 47 countries that participated in the study in 2003 and 2007 respectively (Mullis et al., 2004, 2008).

The situation is not too different in SHS's. For many years the failure rate in mathematics has been dramatically high in SHS's. The low scores of students' over the years in the Senior Secondary School Certificate Examination attest to this (Ottevanger et al., 2007). In Ghana not many studies have been conducted to explain such poor students' performance in mathematics. Ampiah et al. (2004) reported that both pre-service and in-service programmes in mathematics predominantly reflect teacher-centred approaches to learning. Curriculum documents in this context suggest that teachers should start every lesson with a practical problem to help students acquire the habit of analytical thinking and the ability to apply knowledge in solving practical problems (MOE, 2000) and also make use of the calculator and the computer for problem solving and investigations of real life situations (MOESS, 2007), but this orientation to teaching and learning requires more than recommendations contained in syllabuses. More particularly the report on Developing Science, Mathematics and ICT (SMICT) education in Sub-Saharan Africa suggested changes to the 
teacher's instructional role from presenter of knowledge and the use of drilloriented methods to participatory teaching and learning (Ottevanger et al., 2007). On a much broader note, research conducted in other Sub-Saharan Africa highlights some of the factors responsible for poor students' achievement in mathematics: poorly-resourced schools; large classes; a curriculum hardly relevant to the daily lives of students; a lack of qualified teachers; and inadequate teacher education programmes (Ottevanger et al., 2007).

The government of Ghana recognizes the need for teacher support for mathematics teachers in various ways. He considers ICT literacy as an engine for accelerated development outlined in the Ghana Information and Communication Technology for Accelerated development (Ghana ICT4AD Policy document, 2003). Ghana introduced ICT into the school curriculum in September 2007 following the recommendations of the ICT4AD document and the Anamuah Mensah National Education Review Committee Report (2002). Both documents highlight the importance of integrating ICT into the curriculum at all levels. As a result, the government and other institutions have invested huge sums of money in procurements of computers and establishment of computer labs in most SHS's, but it is still unclear whether these computers are being used effectively by teachers in their instruction. Thus the question of whether mathematics teachers need any further support to be able to integrate effectively the use of ICT in their daily teaching routines remains unanswered.

The overall goal of the present study was to explore the feasibility of ICT use in mathematics classrooms in Ghana as part of an on-going research project to design a professional development programme for pre-service teachers. The relevance of this study was to (1) provide an understanding of the context of mathematics teachers in the SHS's in Ghana regarding ICT integration in mathematics lessons and (2) determine the features of an ICT intervention that fits the realities in the SHS's that can prepare pre-service teachers to effectively design and implement ICT in teaching mathematics. The study was guided by the following questions:

1. What are the barriers of ICT use in teaching mathematics in SHS's in Ghana?

2. What are the needs of pre-service and in-service mathematics teachers in teaching mathematics with ICT in SHS's in Ghana?

3. What are the opportunities of ICT use in the teaching of mathematics in SHS's in Ghana? 


\subsection{TEACHER PREPARATION PROGRAMMES FOR TEACHING MATHEMATICS IN THE SENIOR HIGH SCHOOL}

The SHS mathematics curriculum in Ghana focuses on attaining one crucial goal: to enable all Ghanaian young persons to acquire the mathematical skills, insights, attitudes and values that they will need to be successful in their chosen careers and daily lives (MOESS, 2007). This curriculum is based on the premises that all students can learn mathematics and that all need to learn mathematics. It builds on the knowledge and competencies developed at the Junior High School level, placing a lot of emphases on the development and use of basic mathematical knowledge and skills. The student is expected at the SHS level to develop the required mathematical competencies to be able to use his/her knowledge in solving real life problems and secondly, be well equipped to enter into further study and associated vocations in mathematics, science, commerce, industry and a variety of other professions (MOESS, 2007). The rationale of the curriculum has therefore a lot of implications on teaching strategies and the preparing of mathematics teachers for SHS's.

In Ghana Mathematics Teacher education for Senior High Schools is offered by two main institutions, the University of Cape Coast (UCC) and University of Education, Winneba (UEW). These two universities are institutes for higher education that have the specific task to prepare teachers for the SHS's. The main route in the teacher education at both UCC and UEW is the Bachelor of Education qualification of 4 years duration. Three main components are present in these programmes: subject content courses, education courses and teaching practice. The education courses are further sub-divided into general ones and subject-specific ones (i.e. for individual school subjects, or categories of subjects like science). The latter are taught in the science and mathematics education departments and denoted as science or mathematics pedagogy courses. The general education courses are taught in other education departments, mostly Education Foundations. Similarly for teaching practice placement in schools, the organisation is done by a general education department for all students from various subjects.

A major difference between the two universities lies in the fact that most content in UCC is taught by the Faculty of Science, whilst at UEW this takes place in the Faculty of Science Education. The mathematics content courses (which cover the SHS curricula) at the first and second year undergraduate level are the main basis 
for teacher education students, but some further content courses at the third and fourth year levels are also in the programme. Two main problems can be distinguished that put the quality of the programmes under pressure: reduced opportunities for interaction between lecturers and individual students (as a result of fast expansion of student numbers in universities) and lack of practical orientation. The later has roots in the educational tradition of the Ghana education system which emphasizes teacher-centred exposition as a main educational method (Adu-Gyamfi \& Smit, 2007).

\subsection{POTENTIAL OF ICT FOR MATHEMATICS EDUCATION}

The use of ICT in the mathematics classroom has long been a topic for consideration by mathematics educators. Some examples of ICT use in mathematics include: portables, graphic calculators and computerized graphing, specialised software, programmable toys or floor robots, spreadsheets and databases. Studies have shown that a range of portable devices exists which allow pupils to collect data, and manipulate it using spreadsheets and databases for work in numeracy. Some portable equipment also enables the study of maths to move out of the classroom and to incorporate fieldwork investigations (Moseley \& Higgins, 1999).The use of graphic calculators and computerized graphing in mathematics speeds up the graphing process, freeing people to analyse and reflect on the relationships between data (Hennessy, 2000; Clements, 2000; Hennessy et al., 2001). Specialists software such as Computer Algebra Systems (CAS), Dynamic Geometry Systems (DGS) and Maths curriculum software improve pupils' skills and understanding in algebra, allow pupils to manipulate and measure shapes leading to higher level of learning among them (Hennessy et al., 2001; Clements, 2000). Programmable toys or floor robots controlled by instructions in programming languages (usually Logo) were one of the earliest applications of ICT to maths, and where used were the cause of significant changes in maths teaching (Becta, 2003). Logo encourages pupils to develop problem-solving skills, leads them to develop higher levels of mathematical thinking as well as learn geometric concepts (Clements, 2000).

According to Ittigson and Zewe (2003) ICT supports constructivist pedagogy, which allows students explore and reach an understanding of mathematical concepts. This approach promotes higher order thinking and better problem 
solving strategies (Ittigson \& Zewe, 2003). Becta (2003) reiterated that teachers can maximize the impact of ICT in maths teaching by using ICT as a tool in working towards learning objectives. For mathematics educators, defining the most effective uses of ICT in the teaching of mathematics can certainly be described as a "wicked problem," as represented by Mishra and Koehler (2006). A number of challenging instructional questions are associated within this wicked problem, such as: When should teachers incorporate calculators when teaching arithmetic? How should teachers incorporate the powerful new symbolic programmes within basic algebra instruction? Should teachers allow student use of the many new online homework assistance web sites for mathematics? Such instructional questions illustrate that the problem of effective ICT integration into the teaching of mathematics is a complex innovation for teachers. They do not only need to have competent knowledge of teaching mathematics but also need to be competent in the pedagogical use of ICT (AACTE, 2008; Voogt, 2008).

\subsection{FACTORS INHIBITING ICT USE IN MATHEMATICS CLASSROOMS}

Many studies have shown several obstacles that teachers experience in the integration of ICT in their classrooms. Jones (2004) found a number of barriers for the integration of ICT into lessons: (1) lack of confidence among teachers during integration, (2) lack of access to resources, (3) lack of time for the integration, (4) lack of effective training, (5) facing technical problems while the software is in use, (6) lack of personal access during lesson preparation and (7) the age of the teachers. Snoeyink and Ertmer (2002) have identified these or similar variations as widespread barriers: lack of computers, lack of quality software, lack of time, technical problems, teacher attitudes towards computers, poor funding, lack of teacher confidence, resistance to change, poor administrative support, lack of computer skill, poor fit with curriculum, scheduling difficulties, poor training opportunities, and lack of vision as to how to integrate ICT in instruction.

A study (Agyei \& Voogt, 2011b) conducted in Ghana among pre-service and inservice mathematics teachers explored the influence of computer attitudes, competencies and access of the teachers on their levels of ICT integration using the will, skill and tool concept. The study reported low levels of ICT integration 
levels as a result of low competencies and access levels of ICT. Furthermore, the study showed fairly high levels of positive computer attitudes and indicated among others to be a necessary condition to prepare teachers for new teaching methods which are flexible and involve appropriate use of ICT. Of equal importance to ICT integration is teacher preparation programmes. Research have shown that such programmes have not adequately modeled the use of technology in their method courses (Adamy \& Boulmetis, 2006) or incorporated effective approaches to technology integration into a single technology courses (Brown \& Warschauer, 2006).

\subsection{Method}

\subsubsection{Participants}

A total of 180 educators constituting of 60 in-service mathematics teachers and 120 pre-service mathematics teachers participated in the study. Mathematics teachers were used in the study because the mathematics curriculum in particular emphasizes the use of ICT in the teaching and learning process. The practicing teachers were selected from 16 Senior High Schools (SHS) ranging from government, mission, private and international schools. Schools were selected because they had a reasonable number of mathematics teachers as well as some kind of ICT infrastructure. The average age of these in-service teachers was approximately 39 ranging between 25 and 59 years. There were 52 males and only 8 females. The average teaching experience was approximately 12 years ranging from as low as 1 year to 37 years. The pre-service mathematics teachers were from the mathematics teacher education programme at University of Cape Coast (UCC), Ghana. 95 of them were males and 25 females aged between 19 and 43 years with an average age of nearly 26 years. The low representation of female teachers in this study is a reflection of the under-representation of females in science and mathematics in particular at all levels, from basic school to university. For instance, in 2006, female teachers constituted only $15 \%$ of the mathematics teachers in the country (Ottevanger et al., 2007). Six Principals and 14 Heads of departments (Hod's) in the mathematics section from the 16 SHS's were involved in the study. Also involved in the study were the Head of department of the teacher education programme and an officer from the ICT section of the Ghana Education Service (GES). 


\subsubsection{Research instruments}

\section{Questionnaire}

A questionnaire was used to collect data for this study. The first section of the questionnaire was used to collect demographic data. Following this were sections about availability and levels of ICT access, current pedagogical practices, perceived barriers in the use of ICT, and professional development and training needs.

Availability and accessibility of ICT. Variables indicating level of availability and accessibility of ICT facilities were used to measure ICT infrastructure available and also accessible by in-service mathematics teachers in the SHS. Respondents were supposed to indicate either "yes" or "no" to whether they had a facility available/ accessible in their various schools.

Current pedagogical practices, perceived barriers in the use of ICT, and professional development and training needs. Different variables were used to measure the current practices of in-service mathematics teachers from the SHS's and the instructors at the teacher education programme at UCC. Barriers teachers perceived in the use of ICT in instruction and perceptions of professional developments and training needs were also measured.

\section{Interviews}

Interviews were conducted for 6 principals and 14 Hod's from the SHS's that were involved in the study. Interview data was meant to provide in-depth elaborations for data collected through the questionnaire.

\subsubsection{Data collection and data analysis procedures}

The questionnaire was distributed to the pre-service teachers during the school after a lecture. For the in-service teachers it was sent to them in their various high schools with the help of principals and department heads. To analyze the data descriptive statistics was used. Interview data were audio taped and transcribed using data reduction technique (Miles \& Huberman, 1994). 


\subsection{Results}

\subsubsection{Perceived barriers to ICT integration}

What was perceived to be important barriers in integrating ICT in lessons was investigated in the study. Respondents were asked to indicate their levels of agreement on perceived barriers to ICT integration on a five-point Likert scale ( $1=$ strongly disagree, $5=$ strongly agree). The scores were interpreted as follows: one is the lowest possible score, which represents a negative attitude, while five is the highest possible score which represent a very strong positive attitude. Table 2.1 shows the mean values of the barriers as perceived by the teachers. The first two perceived barriers reported by the respondents centred on teachers' lack of ICT knowledge in integration: Lack of knowledge about ways to integrate ICT in lessons (in-service teachers $=3.88$, pre-service teachers $=4.28$ ) and Lack of training opportunities for ICT integration knowledge acquisition (inservice teachers $=3.87$, pre-service teachers $=4.18$ ). Lack of ICT infrastructure (inservice teachers $=3.80$, pre-service teachers $=4.17$ ) was also considered a barrier perceived high by the teachers (the following section elaborate further on the status of ICT infrastructure in the schools). The least identified perceived barrier was: Schools are not interested in integrating ICT in curriculum (in-service teachers $=2.18$, pre-service teachers $=2.12$, which suggested that most SHS's embrace the idea of integrating ICT in teaching mathematics.

Table 2.1 Perceived barriers to ICT Integration by in-service and pre-service teachers $(N=180)$

\begin{tabular}{|c|c|c|c|c|}
\hline \multirow[b]{2}{*}{ Perceived barrier } & \multicolumn{2}{|c|}{$\begin{array}{l}\text { In-service } \\
(\mathrm{n}=60)\end{array}$} & \multicolumn{2}{|c|}{$\begin{array}{l}\text { Pre-service } \\
(\mathrm{n}=120)\end{array}$} \\
\hline & $M$ & $S D$ & $M$ & $S D$ \\
\hline Lack of technical support regarding ICT integration & 3.77 & 1.24 & 4.09 & 1.00 \\
\hline Lack of support from administration & 3.48 & 1.32 & 3.93 & 1.17 \\
\hline $\begin{array}{l}\text { Lack of knowledge about ways to integrate ICT in } \\
\text { lessons }\end{array}$ & 3.88 & 1.21 & 4.28 & 1.02 \\
\hline $\begin{array}{l}\text { Lack of training opportunities for ICT integration } \\
\text { knowledge acquisition }\end{array}$ & 3.87 & 1.07 & 4.18 & 0.89 \\
\hline $\begin{array}{l}\text { Schools are unsure as to how effectively to integrate } \\
\text { ICT in teaching }\end{array}$ & 3.67 & 1.07 & 3.78 & 1.23 \\
\hline Teachers do not have sufficient time to integrate ICT & 3.52 & 1.20 & 3.71 & 1.22 \\
\hline $\begin{array}{l}\text { Lack of ICT infrastructure (i.e. computers, computer } \\
\text { lab, internet) in schools }\end{array}$ & 3.80 & 1.31 & 4.17 & 1.13 \\
\hline $\begin{array}{l}\text { Schools are not interested in integrating ICT in } \\
\text { curriculum }\end{array}$ & 2.18 & 1.05 & 2.12 & 1.22 \\
\hline $\begin{array}{l}\text { Curriculum does not allow enough time to integrate } \\
\text { ICT in teaching }\end{array}$ & 3.75 & 1.10 & 3.54 & 1.40 \\
\hline
\end{tabular}


In general the mean values for the pre-service teachers appear to be higher than the in-service teachers, but the differences were not huge.

\subsubsection{Availability and accessibility of ICT}

To ascertain the current situation in the SHS's, the 60 in-service teachers were asked if certain ICT facilities were available. Table 2.2 gives a summary of their responses. About $98 \%$ of the in-service teachers from the 16 SHS reported having at least one computer laboratory in their schools. The high responses in the availability of computer labs were confirmed by the officer from the ICT unit of the GES. In an interview with him, he reported that the Government of Ghana is committed to deployment of sufficient ICT infrastructure in all SHS's in Ghana. He purported:

As part of the New Reforms to introduce ICT at all level of Education in Ghana, it is the Governments' policy to provide ICT facility in all SHS. Some schools have already taken delivery of such support while the process is still on-going.

Some teachers also indicated that Parents-Teachers Association (PTA) had been helpful in providing computers in their schools. This apparently explains the establishments of computer lab(s) in all the schools. Further questions were asked to ascertain how accessible these facilities were. Relatively low figures: (Access to Computers (office/Computer Lab) $=21 \%$, Access to Computers (staff common room $/$ Library) $=13 \%$ and Internet Connectivity $=46 \%$ ) indicating low accessibilities of computer facilities were observed. The teachers indicated further that computer laboratories were used mainly for Information Technology (IT) lessons which were compulsory for all students, making it difficult to access facilities in computer lab for personal use or other purposes. Interview data from the Hod's and the principals of the various SHS's gave a better picture of the state of ICT availability and accessibility in the schools. The interview data (by the Hod's) indicated that schools lacked specialised software application (e.g. as derive, graphic calculus, geometer's sketchpad etc.) and did not use them at all in classrooms. Most of the Hod's (12 out of 14) confirmed that computer labs were mostly used by the IT departments to prepare students to acquire basic skills in computing and were not used for any other subject instruction. However, six of them pointed further that, the facility was available to all interested teachers (mainly after school) to prepare their lessons and also 
get information from the internet. One of the Hod's said that his school had a specialised Lab just for the teachers to enhance their preparation for a lesson.

Table 2.2 Availability of ICT Facilities in SHS's $(N=60)$

$\begin{array}{lc}\text { ICT Facility } & \text { \% yes } \\ \text { Computer Laboratory } & 98 \\ \text { Computers in the Library } & 40 \\ \text { Computers in the Staff common room } & 20 \\ \text { Computers in the mathematics department (office) } & 15 \\ \text { Computer in your office } & 23 \\ \text { Internet connectivity } & 47\end{array}$

Responding to the question whether the Lab could be used for mathematics lessons with their students, seven were of the view that it was possible to arrange to use the facility while the other seven said the lab was almost always busy. A teacher reiterated in the interview that:

Normally the time table is structured in such a way that it will be difficult for any other subject teaching in the Lab, because of the number of classes the Lab is always occupied. More computer Labs should be created so that other subject teaching could be possible.

Another indicated:

Hitherto mathematics teachers have not been using computers in their instruction so no such arrangement had been made, but with effort and planning with the IT unit it should be feasible.

All the principals on the other hand maintained strongly that any teacher who was willing to use the lab for a lesson could make an arrangement for it. One of them commented as below:

This is a facility that is made available for teaching. As an IT department it beholds on them to train the students in the use of the facility; but if a mathematics teacher wants to use the facility for his/her lesson, it is also available. Yes. So we use them interchangeably. The idea that the school must equip the students to acquire basic IT skills is one side, the teachers also willing to use it in their individual lesson is another side. 
Another head asserted:

The facilities are there; but the problem is with the teacher. The teacher should be in the position to use them. If the teachers are well equipped then they can integrate ICT in their teaching. The teachers being well equipped is a very crucial condition for student to benefit fully from the facilities.

\subsubsection{Current pedagogical practices}

Both in-service and pre-service teachers responded to this item, citing the teaching strategies they use and that which they have experienced in their SHS's respectively. In Table 2.3, list of teaching routines that teachers carry out or were experienced are presented. The results showed that the most frequently used teaching strategy in the SHS's is the "Chalk and Talk" approach (Lecture Method) (in-service $=3.33$, pre-service $=3.35$ ). Interview data confirmed this. All the Hod's stated emphatically during the interview that it was the main approach used by teachers in their departments. They explained that the approach allows the teachers to quickly convey lots of information to students because teachers do most of the talking and giving out of notes while students copy the notes. In so doing, they are able to cover a lot of topics in the curriculum before the students write their examinations.

Table 2.3 Teaching strategies used in SHS's (N=180)

\begin{tabular}{lcccc} 
Teaching Strategy & $\begin{array}{c}\text { In-service Teachers } \\
(\mathbf{n = 6 0 )}\end{array}$ & \multicolumn{2}{c}{$\begin{array}{c}\text { Pre-service Teachers } \\
(\mathbf{n = 1 2 0 )}\end{array}$} \\
& $M$ & $S D$ & $M$ & $S D$ \\
\hline Chalk and talk approach & 3.33 & 0.97 & 3.35 & 0.90 \\
Use of handouts/pamphlet & 2.57 & 1.03 & 2.09 & 0.93 \\
Individual assignments & 2.85 & 0.80 & 2.62 & 0.78 \\
Use of group/team work & 2.30 & 0.81 & 1.92 & 0.74 \\
Use of ICT & 1.57 & 0.90 & 1.38 & 0.62 \\
Use of demonstrations & 2.48 & 0.93 & 2.12 & 0.83
\end{tabular}

Note: $1=$ Never, $2=$ Sometimes, $3=$ often, $4=$ Nearly always, $M=$ Mean, $S D=$ Standard Deviation.

Two Hod's said mathematics teachers in their department occasionally gave assignments to students in groups to read on various topics to do individual presentations and one other said maths teachers in his department used demonstrations and experiments especially when teaching probability to their students. Table 2.3 shows that the "Use of ICT" is the teaching strategy which is the least used (in-service teachers $=1.57$, pre-service teachers $=1.38$ ). One of the interviewees' purported: 
We are not yet there. At best some mathematics teachers are able to type their own questions for student tests and examinations. They are able to get information they need from the internet either for their own purposes or to prepare their notes.

Responses depicted in Table 2.3 seem to suggest a similar trend for both groups of teachers although the mean values for pre-service teachers were relatively low.

\subsubsection{Levels of ICT use at the teacher education programme in UCC}

With regards to ICT application in instruction, pre-service teachers were asked to indicate the extent to which instructors in their department applied some ICT applications in teaching. They had to indicate one of these stages: (1) Not at all; (2) A little; (3) Somewhat and (4) A lot. Table 2.4 reveals that instructors (Mean $=1.32, \mathrm{SD}=0.73)$ in the department do not make use of ICT applications at all or at best just a little in their instruction.

Table 2.4 Levels of ICT application in Instruction at the Teacher Education Programme in UCC

\begin{tabular}{llc} 
& \multicolumn{2}{c}{$\begin{array}{c}\text { Pre-service teachers } \mathbf{( n = 1 2 0 )} \\
\text { Cronbach's Alpha=0.931 }\end{array}$} \\
& $M$ & $S D$ \\
\hline Word processing packages & 1.45 & 0.84 \\
\hline Database software & 1.29 & 0.77 \\
\hline Spreadsheet & 1.42 & 0.88 \\
\hline Presentation Software & 1.27 & 0.68 \\
\hline Graphical Application & 1.28 & 0.61 \\
\hline Graphical Calculators & 1.24 & 0.63 \\
\hline Application of multimedia & 1.24 & 0.65 \\
\hline Use of E-mail & 1.33 & 0.74 \\
\hline Internet & 1.37 & 0.80 \\
\hline Use of Java Applet & 1.31 & 0.68 \\
\hline Overall Mean & 1.32 & 0.73
\end{tabular}

Note: 1- Not at all; 2 - A little; 3 - Somewhat; 4 - A lot.

The Head of Department of the mathematics education programme reiterated this in an interview. He indicated that most of the content courses for the programme are not taught in the department. These are courses taught by the Mathematics and Statistics Department in the faculty of science (for both the pure sciences and the pre-service teachers); so little or no emphasis is placed onhands on approach type of teaching. He added that most instructors at the teacher 
education programme continue to use traditional tools for teaching without or with a limited integration of ICT due to two main reasons: courses are not designed to integrate ICT in its delivery and lack of technology integration skills (especially related to older staff members). He emphasized that there is the need to re-design courses in the programme that will involve pedagogical content knowledge and more hands-on activities. In commenting he said:

We need to change the focus of our courses we teach in the department; they are too traditional. My vision is to promote the redesigning of courses in the department to be hands-on to enable students think better and use their hands more. So my intention is for us to move away from the traditional way of teaching.

Responding to a question on whether ICT infrastructure availability and accessibility did not pose a problem for instructors' lack of ICT use, he asserted that although the department did not have an up-to-date computer lab for teaching mathematics, the faculty had one which was available to instructors (particularly mathematics and science education) and was heavily underutilized. He stated:

The computers are there! If you come to the faculty, we have a whole computer Lab which is rarely used. It is because lecturers have not designed their courses to use computers. It means we have a lot to do in this area. We need to encourage lecturers to incorporate the use of computers in their delivery; but for now, the same old traditional way of teaching dominates. So even though the computers are there they are not put into use.

It could be alleged from the results that the instructors' inability to use ICT in instruction is likely to have a ripple effect on these pre-service teachers in their profession since the former are their trainers.

\subsubsection{Professional development and training needs}

An investigation also aimed at determining mathematics teachers' overall perception towards ICT integration in lessons, training needs and willingness to participate in professional development programme that integrate ICT in instruction. Reporting on the overall perceptions of teachers' willingness to 
integrate ICT in lessons, an overwhelming majority of $96 \%$ (very willing $=68 \%$, willing $=28 \%$ ) pre-service and in-service teachers reported they were willing to integrate ICT in their future lessons. Only $1 \%$ said they were highly sceptical and 3\% neutral as far as ICT integration into future lessons were concerned. Table 2.5 shows the levels of perceptions as observed by the in-service and preservice teachers respectively.

Table 2.5 Overall perceptions of teachers towards ICT integration in delivery of mathematics lessons

$\begin{array}{lcc}\text { Perception } & \text { In-service teachers (\%) } & \text { Pre-service teachers (\%) } \\ \text { Highly Sceptical } & - & 2 \\ \text { Sceptical } & - & - \\ \text { Neutral } & 1 & 4 \\ \text { Willing } & 37 & 23 \\ \text { Very willing } & 62 & 71\end{array}$

The results showed that both in-service (98\%) and pre-service teachers (94\%) were very enthusiastic about integrating ICT in their future mathematics lessons. All the 14 Hod's were enthusiastic about integrating ICT in lessons at their various schools and confirmed that mathematics teachers in their department will embrace the idea very much. One of the Hod's explained:

I wish we could move from this chalk board approach to white board and effective use of ICT in instruction. It will make teaching easier and facilitate students' understanding.

The Head for the teacher education programme also expressed with much emphasis the need to incorporate into the programme courses which could help pre-service teachers acquire the skill of teaching with ICT in their future profession. Specifically, he proposed that a particular course "Preparing teaching aids for mathematics teaching" taught in the final year could be re-designed to include the component of ICT. With respect to whether teachers have had the opportunity to participate in any professional development activities or not and as to which professional development needs they would want to have, Table 2.6 gives a summary of responses. The table shows that barely few teachers have attended any course on pedagogical issues related to integrating ICT into teaching and learning mathematics (in-service teachers $=10 \%$, pre-service teachers $=5 \%$ ) suggesting that a professional development programme for these teachers will be a step in the right direction. Data in Table 2.6 is supported by interview data. The officer from the ICT unit of the GES indicated that: 
The ICT unit was responsible for organizing trainings for teachers at the SHS but it has not been very effective. Most of the trainings have not had a focus on use of ICT as an instruction in class. Most training has concentrated on how to help teachers get information on the internet and basic skills of computing. Again the unit is faced with the challenge of finances. As a result the TOT approach is used. This is the situation where few teachers are selected in a district to undergo training with the aim that these teachers will serve as trainers to other teachers in the same district. Unfortunately subsequent training in the various district most of the time do not take place due to improper planning.

Table 2.6 Teachers' Professional development needs

\begin{tabular}{|c|c|c|c|c|c|c|}
\hline \multirow[b]{2}{*}{$\begin{array}{l}\text { Professional Development } \\
\text { needs }\end{array}$} & \multicolumn{3}{|c|}{ In-service (\%) } & \multicolumn{3}{|c|}{ Pre-service (\%) } \\
\hline & $\begin{array}{l}\text { Yes } \\
\text { I have }\end{array}$ & $\begin{array}{l}\text { No, I } \\
\text { do not } \\
\text { wish to } \\
\text { attend }\end{array}$ & $\begin{array}{l}\text { No, I would } \\
\text { like to } \\
\text { attend if } \\
\text { available }\end{array}$ & $\begin{array}{l}\text { Yes } \\
\text { I have }\end{array}$ & $\begin{array}{l}\text { No, I } \\
\text { do not } \\
\text { wish to } \\
\text { attend }\end{array}$ & $\begin{array}{l}\text { No, I } \\
\text { would like } \\
\text { to attend if } \\
\text { available }\end{array}$ \\
\hline $\begin{array}{l}\text { Technical course for operating } \\
\text { and maintaining computer } \\
\text { system }\end{array}$ & 15.0 & 10.0 & 75.0 & 10.8 & 1.7 & 87.5 \\
\hline $\begin{array}{l}\text { Introductory course for Internet } \\
\text { use and general applications } \\
\text { (e.g., basic word-processing, } \\
\text { spread-sheets, databases, etc.) }\end{array}$ & 41.7 & 23.3 & 35.0 & 32.5 & 2.5 & 65.0 \\
\hline $\begin{array}{l}\text { Subject-specific training with } \\
\text { lear-ning software for specific } \\
\text { mathe-matics content goals (e.g., } \\
\text { tutorials, simulation, etc. }\end{array}$ & 10.0 & 8.3 & 81.7 & 6.7 & 3.3 & 90.0 \\
\hline $\begin{array}{l}\text { Course on pedagogical issues } \\
\text { related to integrating ICT into } \\
\text { teaching and learning } \\
\text { mathematics }\end{array}$ & 3.3 & 6.7 & 90.0 & 0.8 & 3.3 & 95.8 \\
\hline $\begin{array}{l}\text { Course on multimedia } \\
\text { operations (e.g., using digital } \\
\text { video and/or audio equipment } \\
\text { in mathematics }\end{array}$ & 5.0 & 8.3 & 86.7 & 0.8 & 5.5 & 93.7 \\
\hline
\end{tabular}

All the principals of the schools confirmed that the GES hardly organized training programmes for the schools but if they did, it focused on giving teachers basic ICT skills. The Hod's also explained that their schools did not provide any support of that kind to assist teachers integrate ICT in their instruction. Few (5 out of 14) of them however indicated that training 
programmes to assist teachers to acquire basic skills were offered. Two further indicated that, the training programmes were not timely and most of the time targeted fresh teachers. One of them said:

At the beginning of the academic year training is organized particularly for fresh teachers to become computer literate to equip them to be able to set their questions, key in students' results and get information from the internet.

Although responses from the teachers were high for course on multimedia (inservice teachers $=87 \%$, pre-service teachers $=94 \%$ ) and subject-specific training with learning software for specific mathematics content goals (in-service teachers = $82 \%$, pre-service teachers $=90 \%$ ) indicating that they would want to attend such courses if available, interview data from respondents were rather contrary to these views. The Hod's were of the view that more generalised software such as the spreadsheet which is user friendly could be adopted in any training to develop teachers to integrate ICT in teaching. Table 2.6 confirmed that the teachers (inservice $=42 \%$, pre-service $=33 \%$ ) had some knowledge in basics spreadsheet. They reported that apart from the problem of availability and accessibility of such software in the context under consideration, most mathematical applications were not known to the teachers. They concluded that the spreadsheet was known to them and can be tailored to the curriculum. One Hod explained:

It will be easy for the students too because they are taught basic excel in their IT lessons so it will not be a new environment for them.

The head of the teacher education programme was of the same view as the Hod's. When asked a similar question as to what application he will recommend for training of mathematics pre-service teachers in integrating ICT in their lessons, he said:

One that is not complex, easily available; the student can adopt and could be easily tailored to the curriculum.

Responding to their willingness to participate in training on how to design, develop and integrate ICT for teaching mathematics, the teachers were supposed to indicate "yes", "undecided" or "no, I like to have more information". The analyses revealed that $93 \%$ (both in-service and pre-service) were willing to participate in such training, whereas $5 \%$ and $2 \%$ indicated they were not 
decided and would want to have more information respectively. The Hod's said their department will welcome such an innovation. One of them vehemently stated:

I can confidently say yes. If there will be any problems, then it will be the very senior ones who are nearing retirement. The young ones are very enthusiastic and very interested. I am interested myself. So that much, I can give you the assurance that such a program will be well patronized.

\subsection{DISCUSSION AND CONCLUSIONS}

Despite the positive policy statements regarding the need for technology in Ghanaian Senior High Schools, and in the mathematics curriculum in particular, the implementation of technology in educational practice will be a major effort. In this study we explored the barriers, learning needs and opportunities for preparing mathematics teachers to integrate ICT in their instructions. We collected data from in-service teachers who were teaching in schools which had a relative good technology infrastructure. This choice was made because we expect that these schools (and their teachers) will be the first ones to implement the ambitions of the Ghanaian government regarding technology integration in the Senior High School. This is also confirmed by the school principals that were interviewed as part of the study. Also we collected data from pre-service teachers. To realize the implementation of technology, pre-service teachers need to be well prepared to use technology in their future teaching. For this reason we invited pre-service teachers from one of the two main teacher education institutions to participate in the study.

Although findings from this study cannot be generalized to Ghanaian in- and pre-service mathematics teachers, we believe that they provide information about conditions and opportunities to realize the first steps in the process of implementation of technology in Senior High Schools. Fullan (2007) indicated that school-based professional community can offer support and motivation to teachers as they work to overcome the tight resources, isolation, time constraints and other obstacles they commonly encounter in today's schools. He maintains that within a strong professional community, for example, teachers can work collectively to set and enforce standards of instruction and learning. 
The results showed a number of barriers identified to be reasons why mathematics teachers in this study did not integrate ICT in their instruction. Among others, lack of ICT knowledge in integration: lack of knowledge about ways to integrate ICT in lesson and lack of training opportunities for ICT integration knowledge acquisition (Ottevanger et al., 2007; Snoeyink \&Ertmer, 2002; Jones, 2004) were the major perceived barriers identified by both group of teachers.

Particularly, the pre-service teachers in this study reported fairly lower attitudes about knowledge of technology use in instruction than the in-service teachers. In-service training programmes organised for in-service teachers as was reported by school heads could explain this difference. Lack of ICT infrastructure (Snoeyink \& Ertmer, 2002; Jones, 2004) was also reported by the participant to be real challenges faced in the mathematics classrooms in Ghana.

The study showed that schools lacked common mathematical software (such as derive, graphic calculus, geometer's sketchpad etc.) used in teaching mathematics. It was particularly surprising to find that no classroom was identified to be web-based although few computer laboratories were supported by internet connectivity. Low ICT access levels as reported by the teachers are possible barriers for their inability to integrate ICT in instruction. Similar study conducted in Ghana (Agyei \& Voogt, 2011b) reported low levels of ICT integration of these teachers as a result of their low ICT competencies and access levels. Another barrier to ICT integration as reported by the teachers was the teaching strategy used in SHS's.

The most frequently used strategy for teaching as reported was the chalk and talk approach (Ottevanger et al., 2007; Ampiah et al., 2004); in which teachers did most of the talking and intellectual work, while students were passive receptacles of the information provided. Both in- and pre-service teachers barely differed in opinions on this subject. These teachers also have been taught in the same manner and for most of them effectively integrating ICT in their instruction is a complex innovation (AACTE, 2008; Voogt, 2008) which requires them to change their routines of teaching.

This was reiterated by the pre-service teachers who reported that most instructors at the teacher education programme were mainly dependent on lecture-based instruction. The programme also did not include courses where 
teachers were taught how to integrate ICT in their lessons (Adamy \& Boulmetis, 2006; Brown \& Warschauer, 2006).This means that the pre-service teachers' experience to integrate ICT in teaching is limited making the programme fall short of the practical approach. This leads to the big question whether the presently trained pre-service teachers are sufficiently prepared for new teaching methods which are flexible and involve appropriate use of technology.

The teachers also indicated that although schools are generally interested in ICT use, regular school practices did not promote ICT use in classrooms. Most inservice teachers reported that schools did not offer them sufficient time to manage and familiarise themselves with ICT. They maintained that as well as lack of time, schools did not provide support network for them to take up the challenges of using ICT in teaching. An additional barrier that could have contributed to these teachers use of ICT was the curriculum factor. Although the curriculum requires mathematics teachers to use ICT in instruction, some teachers (especially in-service ones) alleged that the current status of the curriculum presented serious threats to possibilities of teaching to integrate ICT in the classroom. As a result most of them reinforce the phenomenon of "teaching to the test" where they rush to cover all the topics mechanically in order to finish on time for examinations rather than striving for in depth student learning. Thus they contended that, to allow for meaningful teaching by integrating ICT, the concern of curriculum overload should be addressed.

In spite of the barriers, the study also showed several opportunities that existed for the teachers to be trained to be able to integrate ICT in their teaching. Curriculum (MOESS, 2007; MOE, 2000) and Policy documents (Ghana ICT4AD Policy, 2003) highlight the importance of integrating ICT to enhance teaching and learning. The teacher education programme and SHS's are open to any such ICT innovation. Both in- and pre-service teachers expressed the need for mathematics teachers to integrate ICT in their lessons. More importantly they showed a lot of enthusiasm to be part of any professional development programme related to integrating ICT in teaching and learning mathematics. It was encouraging to find that contemporary mathematics teachers appeared generally supportive and confident in wanting to use computers in their classrooms. Their overwhelming high perceptions (more especially the inservice teachers) to integrate ICT in an innovative way to improve teaching in their future lessons confirmed this. This is in line with similar study (Agyei \& 
Voogt, 2011b) which reported positive attitudes of these teachers towards ICT integration which is a necessary condition for teachers' willingness to participate in an ICT related programme and a predictor of future classroom integration (Agyei \& Voogt, 2011b).

Although the study reported overall low ICT infrastructure and accessibility in the schools, it could be argued that with computer numbers in schools having increased, the access difficulties identified are likely to stem from a situation in which demand outstrips supply rather than simply a shortage of hardware, although this may be the case in some SHS's in other parts of the country. This augurs well for the future with respect to the design of a professional development programme and anticipated levels of computer competence and its use among new, younger, mathematics teachers as they enter the profession.

The findings reported here highlight areas that require further attention to enable teachers use ICT in mathematics teaching. In particular, a professional development scenario that will assist pre-service and in-service teachers develop skills on ways to integrate ICT in their teaching processes was one of the significant issues identified by the researchers. Such a programme need not differ in content but in format for both groups of teachers. Bearing in mind the complexity of the problems most mathematics classroom in Ghana face in terms of ICT infrastructure and lack of application software, an environment with a more generalised application that offer a technology readily available and user friendly among mathematics classroom with the potential for supporting students' higher-order thinking in mathematics (such as spreadsheet) is proposed for use in professional development programmes. This will ensure that teachers will be able to use existing hardware and software in creative and situation specific ways to design ICT resources to accomplish their teaching goals. Thus this study is in line with SMICT study (Ottevanger et al., 2007) which discusses the lessons for improving teaching and learning mathematics in secondary education in Africa. Among their recommendations, effective use of ICT needs to be optimized through extensive programmes of teacher support to improve mathematics and science teaching in Sub-Saharan Africa. 


\section{CHAPTER 3}

\section{Exploring the potential of the will, skill, tool model in Ghana: predicting prospective and practicing teachers' use of technology ${ }^{3}$}

Research has shown that will (positive attitudes), skill (technology competency), and tool (access to technology tools) are all essential ingredients for a teacher to effectively integrate information technology into classroom practices. This study focuses on the will, skill and tool as essential measures for the predictability of technology integration, reported by the study participants and measured by stages of adoption of teachers in Ghana. Attempts are made to explore the extent to which these parameters differ among the teachers and also influence technology integration. Furthermore, the parameters are proposed for use in modeling the process of technology integration for these teachers. Well validated instruments spanning the areas of attitudes, competencies, access and technology integration proficiencies were used to collect data from 120 mathematics prospective teachers and 60 practicing mathematics teachers from Ghana. The data was analyzed using regression analysis. The results indicated that lack of teacher anxiety was the most important dimension of attitudes, and that skill is the strongest predictor of classroom integration of technology for the teachers. Significant differences existed between practicing and prospective teachers' computer anxieties, competencies, and access levels.

3 This chapter has been published as: Agyei, D. D., \& Voogt, J. (2011).Exploring the potential of the Will Skill Tool model in Ghana: Predicting prospective and practicing teachers' use of technology. Computers $\mathcal{E}$ Education, 56(1), 91-100. 


\subsection{INTRODUCTION}

Integration of technology in education has increasingly become an important concern in education not only in developed countries, but in developing countries as well. Tilya (2008) analyzed the development of technology in education policies in Sub-Saharan Africa. He found out that majority of Sub-Saharan Africa countries have a national policy on technology in education, including an implementation plan. In addition, some of these countries have organizational structure in place responsible for technology implementation. Ghana is one of the Sub-Saharan African countries with a national policy and implementation plan for technology in education. The government of Ghana considers technology literacy as an engine for accelerated development outlined in the Ghana Information and Communication Technology for Accelerated Development (Ghana ICT4AD Policy document, 2003). Ghana introduced technology into the school curriculum in September 2007 following the recommendations of the ICT4AD document and the Anamuah-Mensah National Education Review Committee Report (2002). Both documents highlight the importance of integrating technology into the curriculum at all levels. The government and other institutions have invested huge sums of money in procurements of computers and establishment of computer labs in most senior high schools. Computer literacy is not only introduced as a new subject in the Curriculum, but also as a tool to enhance teaching and learning.

The new curriculum in mathematics at the senior high school (Ministry of Education, Science and Sports, 2007) encourages teachers to make use of the calculator and the computer for problem solving and investigations of real life situations, in order to help students acquire the habit of analytical thinking and the capacity to apply knowledge in solving practical problems (MOE, 2000). However, to realize this new orientation to teaching and learning including the use of computers by teachers more needs to be done than recommendations contained in syllabuses. Therefore important questions such as "what can teachers do with computers to promote integration of technology in the curriculum or to extend instructional methods?" and "what can teachers do with computers to improve students' outcomes?" still remain. Many studies have shown that teachers have a decisive role in the integration of technology in the teaching and learning process 
(Law, 2008; Mumtaz, 2000; Voogt, 2003). Therefore teachers' responses to the questions posed above are critical for the implementation of technology in the classroom. With the recent impetus of technology, it is imperative that teacher education programmes, policy makers and researchers understand how teachers in Ghana relate to technology in particular with respect to teachers' attitudes and competencies. In this study we focus on mathematics teachers in particular as the study is part of an on-going study about the development of an appropriate professional development program for mathematics teachers to use technology in their classrooms. This study aims at contributing to a better understanding of mathematics teachers' attitudes and competencies towards technology.

\subsection{A CONCEPTUAL FRAMEWORK FOR THE STUDY: THE WILL SKILL TOOL MODEL}

There is no doubt that the use of computers in classrooms remains a challenge for most teachers in spite of many studies, which have focused on integrating technology in classroom teaching (Pamuk \& Peker, 2009; Smarkola, 2008; Tekinarslan, 2008). Since the early days of computer usage in schools back in the 1980s and 1990s teacher attitudes were considered an important factor for technology acceptance (Marshall \& Cox, 2008; Myers \& Halpin, 2002; Woodrow, 1992). In addition to teacher attitudes large scale international assessments of technology in education (e.g. Law, Pelgrum, \& Plomp, 2008; Pelgrum \& Anderson, 1999) found that teachers' technology competencies also are a basic condition for technology use in education. Pelgrum and Anderson (1999) concluded that an increasing number of teachers have been introduced to basic technology competencies, but most of them lack competencies related to the pedagogical use of technology.

Christensen and Knezek (2002, 2008) developed the Will Skill Tool model (WST model), in which teachers' will, skill and access to technology tools are all postulated to be necessary components for effective integration of technology into the teaching and learning environment of the classroom. The models' key elements are: will (which Christensen \& Knezek conceptualize as computer attitude) of the teacher, skill (which they conceive as technology competence), and tools (which needs to be understood as access to technology tools). The WST model predicts the 
level of technology integration as a function of attitude, competence and access to technology. Christensen and Knezek (2002) tested the model in 1999 with 39 teachers from the USA (Texas) using regression analysis, and they could explain $84 \%$ of the variance in technology integration. Morales (2006) used the WST model to predict integration of technology by teachers in a study of Mexican and US teachers. He found that measures of Will, Skill and Tool together were able to account for $90 \%$ of level of classroom technology use. In addition the Mexican teachers' access to technology (tool) was most important, while for the US teachers competence explained most of the variance. Since Ghana is, similar to Mexico (Ávila Munoz, 2008), a beginner of use of technology in education, the authors wanted to explore to what extent the WST model also would be useful to study teachers' integration of technology into the classroom in the context of Ghana.

Two research questions guided the study: "How do prospective and practicing mathematics teachers differ in their attitudes (will), competencies' (skill), access (tool) and their levels of technology integration?" and "To what extent do attitudes (will), competencies (skill) and access (tool) predict mathematics teachers' technology integration levels?". The best model fit involving these measures for the data set is also determined. To discuss the components of the WST model, studies from European countries and the United States were used to review literature, provided it could be assumed that the arguments were relevant in the Ghanaian context as well.

\subsubsection{Computer attitudes (will)}

The concept attitude can be divided into three components: affective, cognitive, and conative (Fishbein \& Ajzen, 1975). Attitudes towards computers influence teachers' acceptance of the usefulness of technology, and also influence whether teachers integrate technology into their classroom (Meelissen, 2008; Paraskeva, Bouta, \& Papagianna, 2008). Huang and Liaw (2005) also stated that among the factors considered to influence the successful integration of computers in the classroom, teachers' attitudes towards computers is a key factor. The study pointed out that no matter how sophisticated and powerful the state of technology is, the extent to which it is implemented depends on users having a positive attitude towards it (Huang \& Liaw, 2005). Many research studies confirmed that there are 
several factors affecting computer attitudes such as gender, socio-economic status and age. Recent studies about the effect of age on attitude towards computers have shown that younger people tend to have more positive attitudes towards the use of computers than their older peers (Christensen \& Knezek, 2006; Meelissen, 2008). This gives an indication that younger teachers are probable to use technology in instruction than the older ones.

Other related studies that have been conducted into attitudinal and motivation/personality factors towards technology in education contained attitude surveys consisting of questions about fear of computers, extent of liking technology, attitudes towards using technology in school, enjoyment in using computers, productivity/utility of computer, computer use for e-mails have shown strong links between pupils' and teachers' attitudes and the effect on technology use and learning (Marshall \& Cox, 2008). For example a number of studies have found "Computer anxiety" to be a consistent measurable construct present in teacher data sets on teachers' attitudes towards computers (Christensen \& Knezek, 2000a, 2001). According to Pamuk and Peker (2009) computer anxiety is the most important dimension of attitude towards computer scale, indicating that teachers who are anxious about computers tend to develop negative attitudes towards computers and express opposition to their use. Several research studies (e.g. Bozionelos, 2001; Durndell \& Haag, 2002) evaluated computer anxiety as a separate construct and found a high relationship between attitudes towards computers and computer anxiety. Few researches have also supported the view that computer enjoyment (see Bagozzi, Davis \& Warshaw, 1992) has positive effect on the intention to use technology in classrooms.

Other studies have demonstrated that the cognitive component of attitude is an important one. For example, Vankatesh (1999) and Davis and Wiedenbeck (2001) found that perceived usefulness of computers has a positive effect on computer attitudes. This is important in an individual's assessment of his/her productivity and describes the extent to which performance of an activity is instrumental in achieving valued outcomes (Vankatesh, 1999). The effect of the conative component of computer attitudes on computer use is also well addressed by some studies. Marshall and Cox (2008) found teachers with Internet access at home 
demonstrate more positive attitudes towards computers, and feel a greater need for computers in their lives. Christensen and Knezek (2001) found a similar trend and further confirmed that teachers without access to the Internet at home seldom become high integrators of technology in their classrooms.

\subsubsection{Technology competency (skill)}

Competence is usually defined as having the ability to perform a specific task. Research into computer competencies, also indicated with the terms computer performance, computer ability, or computer achievement, is in contrast to the large attention of studies in computer attitudes (Meelissen, 2008). Teachers' competencies in computer use is usually measured through self-report. One might argue that therefore teachers' competencies should be conceived as self-efficacy measures, which is defined as "confidence in one's competence" (Bandura, 1977). Numerous studies have showed that computer competencies are positively correlated with an individual's willingness to choose and participate in computerrelated activities, expectations of success in such activities, and persistence or effective coping behaviors when faced with computer-related difficulties (Looney, Valacich \& Akbulut, 2004; Sang, Valcke, Van Braak, \& Tondeur, 2010; Smarkola, 2008). Teachers with higher levels of technology competencies used computers more often and experienced less computer-related anxiety. On the other hand, teachers with lower levels of technology competencies become more frustrated and more anxious, and hesitate to use computers when they encounter obstacles (Sang et al., 2010). More recent studies about teachers' technology competencies differentiate between basic technology competencies and pedagogical technology competencies (Law et al., 2008). Also Smarkola (2008) argued that for effective integration of technology, teachers must move beyond being "computer literate" to "technology competent". Smarkola added that being technologically competent allows teachers to use computers as part of the curriculum and as a tool for authentic student engagement and learning. Research shows that computer competencies influence expectations and emotional reactions regarding the effective use of modern technologies (Looney et al., 2004). Thus attitudes towards information technology are linked to computer competencies since they are deemed to be significant factors in the interpretation of the frequency and success with which individuals use computers (Khorrami-Arani, 2001). Competencies and 
attitudes are clearly interrelated and there appears to be a universal agreement that competency in the use of technology is a predicting factor to successful employing technology in teaching and learning.

\subsubsection{Access to technology tools (tools)}

In many developed countries, access to computers seems to be no longer a relevant issue (Meelissen, 2008; Morales, 2006). Therefore discussion about the relation between computer access, computer competencies and computer attitudes seems to have been shifted from computer access to the 'quality' of computer experience (McIlroy, Bunting, Tierney, \& Gordon, 2001). This is an indication that access to technology tools is not a strong predictor in determining teachers' use of technology in instruction in these countries. This argument cannot be implied for developing countries. Gurcan-Namlu and Ceyhan (2003) discuss variables such as computer access level, usage frequency, computer ownership and amount and breadth of time in the use of computers as indicators of an individuals' level of technology use of computers.

Only a small proportion of the African population has access to computers (Murphy, Anzalone, Bosch \& Moulton, 2002) and 4\% has access to the Internet (Resta \& Laferrière, 2008). Aguti and Fraser (2006) in a study to integrate technology in Distant Education Program at the Makerere University of Uganda reiterated that lack of ready access to technologies by teachers is a key barrier to technology integration in most developing countries. Thus access levels could be influential factor in determining a teachers' use of technology in most African countries. Tekinarslan (2008) investigated computer anxiety and accessibility of personal computers between two groups of Dutch and Turkish students. The results of the study showed that the Dutch students had lower computer anxiety levels and for that matter higher levels of technology use than the Turkish students. This was explained by the relatively high levels of computer access and computer usage frequencies of the Dutch participants. These findings are consistent with findings of other studies (e.g., Christensen \& Knezek, 2001; Gurcan-Namlu \& Ceyhan, 2003). Thus in general, accessibility of technology as mentioned in the will skill tool model tends to affect attitudes and competencies and has a positive relationship with the level of technology use. 


\subsubsection{Technology integration}

Adoption of technology by teachers is considered a measure for technology integration. Adoption of technology is conceived as a process that develops through different stages. From being aware and informed about the possibilities of technology in education to a more routine utilization of technology in classroom practice and finally to creative uses of technology for teaching and learning (Christensen, 1997; Christensen \& Knezek, 2002; Sandholtz, Ringstaff, \& Dwyer, 1997).

\subsection{METHODS}

\subsubsection{Respondents}

\section{Teachers}

A total of 60 mathematics teachers (52 males and 8 females) who were purposively sampled from 16 Senior High Schools participated in this study. Schools ranging from government, mission, private and international schools, which had a reasonable number of mathematics teachers as well as some kind of technology infrastructure, were selected. The average age of the teachers was approximately 39 ranging between 25 and 59 years. The average teaching experience was approximately 12 years ranging from as low as 1 year to 37 years.

\section{Prospective teachers}

Second and third year prospective mathematics teachers from the Teacher education programme at the University of Cape Coast participated in the study. During their lessons, students were asked whether they wanted to participate in the research. As a result, 120 prospective teachers volunteered to fill out the questionnaire. There were 95 males and 25 females aged between 19 and 43 years with an average age of nearly 26 years. Out of the 120 prospective teachers, 72 of them were Certificate A holders meaning they were basic school teachers and had some teaching experience already in lower secondary education. 


\subsubsection{Research instruments}

A questionnaire was used to collect data for this study. The questionnaire had several sections. The first section of the questionnaire was used to collect data for demographical characteristics such as age, gender and experience or year of study. Following were sections about attitudes towards computers, technology skills and competencies, levels of technology access and technology integration. The instruments used in the different sections are presented below.

Teachers' attitudes towards computers (TAC)

The TAC has been developed based on existing computer attitudes scales (Christensen \& Knezek, 2000b). The TAC questionnaire is a 95-199 item Likert Differential instrument for measuring teachers' attitudes towards computers up to about 20 sub-scales. These measurement instruments are confirmed to be reliable by previous research (Knezek \& Christensen, 1998). Fifty items of the TAC Questionnaire (Knezek \& Christensen, 1998; Christensen \& Knezek, 2000b) were slightly modified and used to explore the attitudes of the practicing and prospective teachers in the study. Thirty-four of them were selected as high loadings on the extracted factors after an exploratory factor analysis. In all, 6 subscales were used: enjoyment (the pleasure someone experiences when using and talking about computers), anxiety (fear to use and talk about computers), benefit (perceived advantages of using computers in the class), interaction (willingness to use possible applications of computers for information dissemination), influence of computer use on the instructional productivity of users and possible professional enhancement in the use of computers. For all six sub-scales, a five-point Likert scale $(1=$ strongly disagree, $5=$ strongly agree $)$ was used. The scores are interpreted as follows: 1 is the lowest possible score, which represents a very strong negative attitude, while the 5 is the highest possible score which represents a very strong positive attitude. Rescaling of some items of the anxiety scale was done, so that a high score on computer anxiety could be interpreted as lack of anxiety. The TAC was administered to 120 prospective and 60 practicing teachers. Table 3.1 shows the internal consistency reliabilities for the TAC sub-scales and the factor loadings for the selected items as reported by the teachers. 
Table 3.1 Internal consistency reliability for six sub-scale of the TAC

\begin{tabular}{|c|c|c|c|}
\hline Sub-scale & $\begin{array}{l}\text { Cronbach's } \\
\text { alpha }\end{array}$ & Item $(\mathrm{N}=180)$ & $\begin{array}{l}\text { Factor } \\
\text { loadings }\end{array}$ \\
\hline \multirow[t]{5}{*}{ Lack of Anxiety } & \multirow[t]{5}{*}{0.75} & Working with a computer makes me nervous & 0.75 \\
\hline & & Using a computer is very frustrating & 0.71 \\
\hline & & Computers are difficult to use & 0.68 \\
\hline & & $\begin{array}{l}\text { I think that it takes a long time to finish a task } \\
\text { when I use a computer }\end{array}$ & 0.65 \\
\hline & & $\begin{array}{l}\text { I get a sinking feeling when I think of trying to } \\
\text { use a computer }\end{array}$ & 0.63 \\
\hline \multirow{9}{*}{$\begin{array}{l}\text { Instructional } \\
\text { Productivity }\end{array}$} & \multirow[t]{9}{*}{0.86} & Computers could enhance remedial instruction & 0.71 \\
\hline & & $\begin{array}{l}\text { Computers can help accommodate different } \\
\text { teaching styles }\end{array}$ & 0.70 \\
\hline & & $\begin{array}{l}\text { Computer can be used successfully with } \\
\text { courses which demand creative activities }\end{array}$ & 0.67 \\
\hline & & $\begin{array}{l}\text { Computers help to incorporate new teaching } \\
\text { methods }\end{array}$ & 0.65 \\
\hline & & $\begin{array}{l}\text { Teacher training should include instructional } \\
\text { applications of computers }\end{array}$ & 0.62 \\
\hline & & $\begin{array}{l}\text { Computers will relieve teachers of routine } \\
\text { duties }\end{array}$ & 0.61 \\
\hline & & $\begin{array}{l}\text { Computers can help incorporate new ways of } \\
\text { organizing student Learning }\end{array}$ & 0.61 \\
\hline & & $\begin{array}{l}\text { Computers can help teachers provide more } \\
\text { individualized feedback to students. }\end{array}$ & 0.57 \\
\hline & & $\begin{array}{l}\text { I believe that the roles of schools will be } \\
\text { dramatically changed because of the internet }\end{array}$ & 0.54 \\
\hline \multirow[t]{4}{*}{$\begin{array}{l}\text { Professional } \\
\text { Enhancement }\end{array}$} & \multirow[t]{4}{*}{0.86} & $\begin{array}{l}\text { If there is a computer in my future classroom, } \\
\text { It would help me to be a better teacher }\end{array}$ & 0.70 \\
\hline & & $\begin{array}{l}\text { I would like to have a computer for use in my } \\
\text { classroom }\end{array}$ & 0.67 \\
\hline & & $\begin{array}{l}\text { If there was a computer in my classroom it } \\
\text { would help me to be a better teacher }\end{array}$ & 0.63 \\
\hline & & $\begin{array}{l}\text { I believe that the more often teachers use } \\
\text { computers, the more I will enjoy school }\end{array}$ & 0.56 \\
\hline
\end{tabular}


Table 3.1 Internal consistency reliability for six sub-scale of the TAC (Continued)

\begin{tabular}{|c|c|c|c|}
\hline Sub-scale & $\begin{array}{l}\text { Cronbach's } \\
\text { alpha }\end{array}$ & Item $(\mathbf{N}=180)$ & $\begin{array}{l}\text { Factor } \\
\text { loadings }\end{array}$ \\
\hline \multirow[t]{6}{*}{ Enjoyment } & 0.65 & I concentrate on a computer when I use one & 0.74 \\
\hline & & I enjoy doing things on a computer & 0.72 \\
\hline & & $\begin{array}{l}\text { The challenge of learning about computers is } \\
\text { exciting }\end{array}$ & 0.69 \\
\hline & & I enjoy lessons on the computer & 0.62 \\
\hline & & I enjoy using new tools for instruction & 0.55 \\
\hline & & $\begin{array}{l}\text { I believe that it is very important for me to learn } \\
\text { how to use a computer }\end{array}$ & 0.52 \\
\hline \multirow[t]{4}{*}{ Interaction } & 0.67 & $\begin{array}{l}\text { I prefer e-mail to traditional class handouts as } \\
\text { an information disseminator }\end{array}$ & 0.79 \\
\hline & & $\begin{array}{l}\text { E-mail is an effective means of disseminating } \\
\text { class information and assignments }\end{array}$ & 0.76 \\
\hline & & $\begin{array}{l}\text { The use of e-mail provides better access to } \\
\text { instructor }\end{array}$ & 0.72 \\
\hline & & $\begin{array}{l}\text { Improvement of communication and } \\
\text { interaction between instructors and students, } \\
\text { and among students }\end{array}$ & 0.66 \\
\hline \multirow[t]{6}{*}{ Benefit } & 0.87 & $\begin{array}{l}\text { Lesson delivery is improved and enhanced } \\
\text { (efficiency) }\end{array}$ & 0.77 \\
\hline & & Enhances students learning (effectiveness) & 0.73 \\
\hline & & $\begin{array}{l}\text { Students can access courses, assignments, } \\
\text { course outlines etc. regardless of location and } \\
\text { time (flexibility in education) }\end{array}$ & 0.71 \\
\hline & & Improvement of feedback to students & 0.66 \\
\hline & & Provision of a better learning experience & 0.59 \\
\hline & & $\begin{array}{l}\text { The relationship between theory and practice is } \\
\text { strengthened (e.g. through simulations) }\end{array}$ & 0.53 \\
\hline
\end{tabular}

Technology in education competency survey (TECS)

The TECS (Knezek, Christensen, Miyashita \& Ropp, 2000) is a self-report measure of technology competence. The TECS was adopted to measure the self-efficacies of the respondents on a four point Likert scale ranging from 1 (not at all) to 4 (a lot). This instrument is a quick and reliable self-report measure for use in assessing teacher technology competencies. Christensen and Knezek (2000a) reported a Cronbach's alpha of 0.92. In this study TECS was used to determine practicing and prospective teachers' technology competencies. Two sub-scales: general purpose (application of technology for general purposes) and instructional purpose 
(application of technology to support teaching and learning) were used. Cronbach's alpha for TECS items were 0.89 and 0.90 respectively. The instrument items are presented in the results section, Table 3.3.

\section{Access to technology}

Three variables indicating level of access to technology tools were used in the study. These were (prospective and practicing teachers) access to Internet connectivity at school or in their office, whether or not they had access to a computer either in the office or at the computer laboratory or whether or not they had access to computers at staff common room or the library. Respondents were supposed to indicate either "yes" or "no" to whether they had access to each of the items. The instruments items are presented in the results section, Table 3.4.

Stages of adoption of technology (SoA)

SoA was used to measure the teachers' technology integration levels. The SoA provides a measure of the teachers' stage of adoption of technology use in educational practice (Christensen \& Knezek, 2000b, 2008).This instrument is a quick and reliable self-report measure for use in assessing technology integration. Since the SoA is a single item survey, internal consistency measures cannot be calculated for data gathered through it, however a high test-retest reliability estimates (0.91-0.96) was obtained from validation studies (Hancock, Knezek \& Christensen, 2007). The six stages related to adoption of technology are: Stage 1(Awareness), Stage 2 (Learning the process), Stage 3 (Understanding and application of the process), Stage 4 (Familiarity and confidence), Stage 5 (Adoption in other contexts) and Stage 6 (Creative applications in new contexts).

\subsubsection{Data collection and data analysis procedures}

The questionnaire was distributed to the prospective teachers during the school after a lecture. For the practicing teachers it was sent to them in their various high schools with the help of the principals and department heads. To analyze the data descriptive statistics, independent t-tests, correlation analysis and regression analysis were used. Effect size was calculated using Cohen's d (Cohen, 1969). Cohen (1969) provided tentative benchmarks for the interpretation of effect sizes. He considers $\mathrm{d}=0.2 \mathrm{a}$ small, $\mathrm{d}=0.5$ a medium and $=0.8$ a large effect size. 


\subsection{Results}

\subsubsection{Descriptive statistics}

A comparison between the two groups of participants was conducted in terms of their computer attitudes. The overall attitudes (practicing teachers $M=4.20$, prospective teachers $M=4.23$ ) seem to suggest high positive attitudes of the teachers towards computers. The t-test results shown in Table 3.2 indicated no significance difference in overall computer attitudes between the two groups.

Table 3.2 Differences in attitudes based on TAC scores of practicing and prospective teachers

\begin{tabular}{|c|c|c|c|c|c|c|}
\hline \multirow[b]{2}{*}{ Subscale } & \multicolumn{2}{|c|}{$\begin{array}{l}\text { Practicing teachers } \\
\qquad(n=60)\end{array}$} & \multicolumn{2}{|c|}{$\begin{array}{l}\text { Prospective teachers } \\
\qquad(n=120)\end{array}$} & \multirow[b]{2}{*}{ Sig } & \multirow{2}{*}{$\begin{array}{l}\text { Effect } \\
\text { size }\end{array}$} \\
\hline & $M$ & $S D$ & $M$ & $S D$ & & \\
\hline Lack of anxiety & 4.15 & 0.804 & 3.90 & 0.896 & $0.04^{\mathrm{a}}$ & 0.29 \\
\hline $\begin{array}{l}\text { Instructional } \\
\text { Productivity }\end{array}$ & 4.28 & 0.544 & 4.34 & 0.539 & 0.50 & -0.11 \\
\hline $\begin{array}{l}\text { Professional } \\
\text { Enhancement }\end{array}$ & 4.48 & 0.656 & 4.48 & 0.649 & 0.97 & 0.00 \\
\hline Enjoyment & 4.32 & 0.543 & 4.35 & 0.460 & 0.69 & -0.06 \\
\hline Interaction & 3.78 & 0.846 & 3.99 & 0.784 & 0.10 & -0.26 \\
\hline Benefit & 4.19 & 0.604 & 4.32 & 0.521 & 0.13 & -0.23 \\
\hline Overall attitude & 4.20 & 0.386 & 4.23 & 0.409 & 0.41 & -0.08 \\
\hline
\end{tabular}

Note: a $\mathrm{P}<.05$ - analyzed with t-test.

Very low effect size differences were observed for the various sub-scales. A significant difference was found with practicing teachers scoring higher on lack of anxiety (effect size $d=0.29$ ).

The TECS variables that were used to measure the teachers' technology competency revealed fairly low competencies. The practicing teachers in general seemed to be more competent or skilful in the use of technology than the prospective teachers. Table 3.3 shows an overall significant difference $(\mathrm{p}<0.001)$ with a medium effect size of 0.56 between the levels of competencies of the two groups. 
Table 3.3 Differences in technology in education competencies of practicing and prospective teachers

\begin{tabular}{lcccccc} 
& $\begin{array}{c}\text { Practicing teachers } \\
(\mathbf{n = 6 0 )}\end{array}$ & \multicolumn{2}{c}{$\begin{array}{c}\text { Prospective teachers } \\
(\mathbf{n = 1 2 0 )}\end{array}$} & \multicolumn{2}{c}{} & $\begin{array}{c}\text { Effect } \\
\text { size }\end{array}$ \\
TEC & $M$ & $S D$ & $M$ & $S D$ & Sig & sige \\
General purpose & 2.55 & 1.030 & 2.07 & 0.960 & $0.002^{\mathrm{b}}$ & 0.48 \\
Instructional purpose & 2.39 & 0.980 & 1.78 & 0.790 & $0.000^{\mathrm{b}}$ & 1.02 \\
Overall mean & 2.56 & 0.960 & 2.05 & 0.850 & $0.000^{\mathrm{b}}$ & 0.56
\end{tabular}

Note: $1=$ not at all, $2=$ a little, $3=$ somewhat, $4=\mathrm{a}$ lot; ${ }^{\mathrm{b}} \mathrm{p}<.05$.

Particularly very large effect size $(\mathrm{d}=1.02)$ was recorded for the differences in competencies which had to do with instructional purposes. Table 3.4 shows the distribution of the differences of the level of access across the teachers.

Table 3.4 Differences in accessibility of technology of practicing and prospective teachers

\begin{tabular}{|c|c|c|c|c|c|c|}
\hline & \multicolumn{2}{|c|}{$\begin{array}{l}\text { Practicing teachers } \\
\qquad(n=60)\end{array}$} & \multicolumn{2}{|c|}{$\begin{array}{l}\text { Prospective teachers } \\
\qquad(n=120)\end{array}$} & \multicolumn{2}{|r|}{$\begin{array}{l}\text { Effect } \\
\text { Size }\end{array}$} \\
\hline & $M$ & $S D$ & $M$ & $S D$ & Sig & \\
\hline $\begin{array}{l}\text { Access to Computers } \\
\text { (office/computer lab) }\end{array}$ & 1.23 & 0.427 & 1.19 & 0.395 & 0.21 & 0.11 \\
\hline $\begin{array}{l}\text { Access to } \\
\text { Computers(staff common } \\
\text { room/library) }\end{array}$ & 1.20 & 0.403 & 1.10 & 0.301 & $0.00^{c}$ & 0.28 \\
\hline Internet Connectivity & 1.77 & 0.427 & 1.31 & 0.464 & $0.03^{c}$ & 1.04 \\
\hline Overall mean & 1.40 & 0.419 & 1.20 & 0.387 & $0.00^{c}$ & 0.50 \\
\hline
\end{tabular}

Note: $1=$ no, $2=$ yes; ${ }^{c} \mathrm{p}<0.05$.

It is apparent that the practicing teachers have higher level of access to technology compared to the prospective teachers. This is more pronounced in the difference $(\mathrm{d}$ $=1.04, \mathrm{p}=0.03$ ) with accessibility to Internet connectivity. Although the means (practicing teachers $=1.40$, prospective teachers $=1.20$ ) do not show high access of technology, the difference $(d=0.50, p<0.001)$ is quite significant. Table 3.5 shows the results on practicing teachers and prospective teachers' stages of adoption of technology. The overall difference in means of the stages of adoption for the practicing teachers $(\mathrm{M}=3.92, \mathrm{SD}=1.45)$ and prospective teachers $(\mathrm{M}=3.28, \mathrm{SD}=$ $1.27)$ was significant with $(p=0.003)$ and a medium effect size $(d=0.47)$. 
Table 3.5 Comparison of stages of adoption of technology between practicing and prospective teachers

\begin{tabular}{lcccc} 
& Practicing teachers $\mathbf{( n = 6 0 )}$ & \multicolumn{2}{c}{ Prospective teachers (n=120) } \\
\cline { 2 - 4 } Stage of Adoption & Freq & $\%$ & Freq & $\%$ \\
\hline Awareness & 5 & 8.3 & 10 & 8.3 \\
\hline Learning the process & 3 & 5.0 & 29 & 16.7 \\
$\begin{array}{l}\text { Understanding and } \\
\text { application of the process }\end{array}$ & 17 & 28.3 & 20 & 36.7 \\
Familiarity and confidence & 11 & 18.3 & 44 & 10.8 \\
Adaptation to other contexts & 15 & 25 & 13 & 3.3 \\
$\begin{array}{l}\text { Creative application to new } \\
\text { contexts }\end{array}$ & 9 & 15 & 4 &
\end{tabular}

Thus, the practicing teachers seem to be higher than the prospective teachers when it comes to the levels of technology use. Interestingly $8.3 \%$ each of the total respondents for both practicing teachers and prospective teachers indicated that they were at the "awareness" (stage 1) stage of adoption of technology. At higher stages of technology adoption (Stages 5 and 6), the practicing teachers seem to be more than the prospective teachers; however at lower stages (1 and 2), the prospective teachers are more than the practicing teachers.

\subsubsection{Stages of adoption and teachers' related attitude (will), competencies (skill) and access (tool) to technology}

Figure 3.1 illustrates the relationship between the attitude scales measured by the $\mathrm{TAC}$, as teachers advance from lower to higher stages of adoption of technology. 


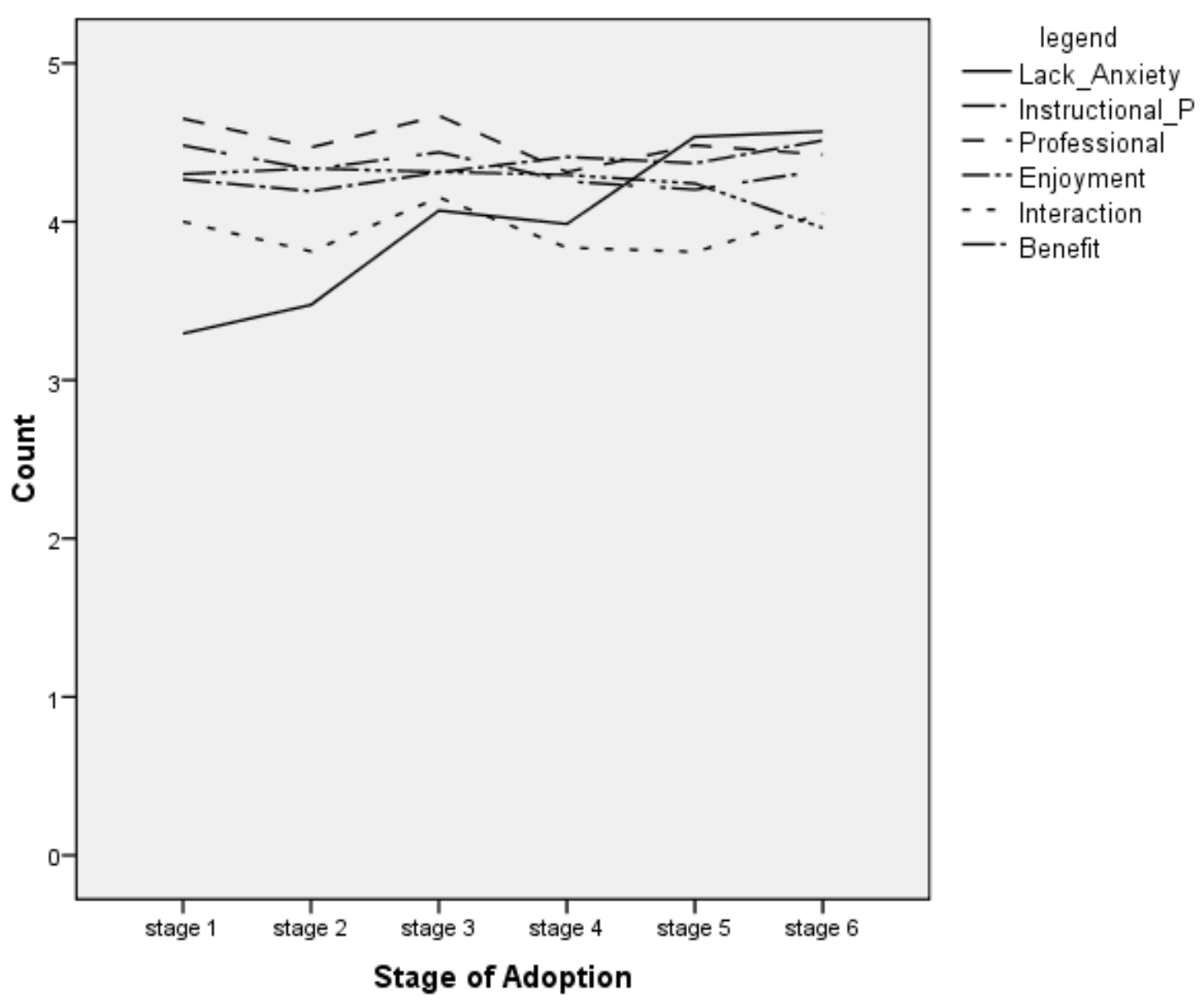

Figure 3.1 Teacher attitudes toward computers by stage of adoption of technology

There seems to be a strong relationship between lack of anxiety and stage of adoption. Perhaps this is an indication that lack of anxiety is a possible predictor of classroom integration for these teachers. The relationship between the other attributes and the stages of adoption seem not to be clearly defined (see Fig. 1). A Pearson product-moment correlation was calculated between the various attributes of computer use and the stages of adoption of technology. Correlations were significant for "lack of anxiety" $(\mathrm{r}=0.43, \mathrm{p}<0.001)$ and "enjoyment" $(\mathrm{r}=0.16, \mathrm{p}=$ 0.03 ) at 0.01 and 0.05 levels of significance respectively. However the productmoment correlation between the overall computer attitudes and the stages of adoption $(r=0.1, p=0.181)$ was found to be very weak. This seems to suggest that the overall attitudes of the respondents had a very weak correlation with the stages of adoption of technology. The two sub-scales (lack of anxiety and enjoyment) which had significant relation with the stages of adoption also had a significant correlation 
$(\mathrm{r}=0.41, \mathrm{p}<0.001)$ with the stages of adoption when they were combined. A significant association $(\mathrm{r}=0.63, \mathrm{p}<0.001)$ was found between technology competencies and stages of adoption of these teachers. Although there seems to be a week and linear association between the teachers' technology access and stage of adoption, the correlation $(r=0.23)$ was significant at the 0.01 level of significance.

\subsubsection{A predictive model of technology integration using the will-skill-tool concept}

A regression analysis model was used to explore how well will, skill and technology tools could predict an individuals' stage of adoption. The following are the results.

\section{Impact of will}

The R-square for the stage of adoption (0.01) predicted from the TAC attitude scales shows that only $1 \%$ of the variance in stage of adoption was found to be attributable to the "will" measures of the respondents. The F test: $\mathrm{F}=(1178)=1.80$, $p=0.181(p>0.01)$ associated with the independent variable was not significant indicating that the independent variable does not predict the dependent variable if only the "will "was considered in the model.

\section{Impact of will and skill combined}

Adding skill measures to the equation, the R2 for Stages of adoption predicted from the TAC attitude and TECS measures increased from 0.01 to 0.40 . This means that the predictability of stages of adoption of technology increases from $1 \%$ to approximately $40 \%$ when the skill measure is added. The F test: $F(2,177)=59.69, p$ $<0.001$ was significant for the model.

\section{Impact of will, skill and tool on technology integration}

Adding measures of tool of technology for the respondents increased the predictability of stages of adoption from $40 \%$ to $41 \%$. The regression equation with all the three predictors was significantly related to the stage of adoption index, $\mathrm{R}^{2}=$ 0.410 , adjusted $R^{2}=0.40, F(3,176)=40.71, p<0.001$. The standardized coefficients of the various predictors were $0.04,0.61$ and 0.09 for the will, skill (self-efficacy) and tool measures respectively. 
According to the standardized coefficients the regression model 1 is as follows:

$$
S O A_{\text {predicted }}=0.04 \text { will }+0.61 \text { skill }+0.09 \text { tool }
$$

As shown in the model, skill appeared to be a strong predictor of classroom integration for these teachers; tool quite acceptable and will $(\mathrm{r}=0.1, \mathrm{p}=0.181)$ was a weaker and perhaps an unacceptable predictor. A second model was investigated to further explore the extent of the teachers' computer attitude (particularly lack of anxiety attitude) as a predictor in the model. This analysis explored the relationship between teachers' lack of anxiety which had a significant association with the stage of adoption $(\mathrm{r}=0.427, \mathrm{p}<0.001)$ as teachers' will as against the other measures: skill and tool. Table 3.6 gives an over view of the results.

Table 3.6 Coefficients of predictors (Lack of anxiety (Will) against Skill and Tool measures of technology integration)

$\begin{array}{lcccccc} & \text { R } & \begin{array}{c}\text { R- } \\ \text { Square }\end{array} & \text { F (Sig) } & \begin{array}{c}\text { Standardized } \\ \text { Coefficients }\end{array} & \text { t } & \text { Sig } \\ \text { Impact of will (Lack of } & 0.427 & 0.183 & 39.76(0.000)^{\mathrm{d}} & 0.427(L) & 6.305 & 0.000 \\ \begin{array}{l}\text { anxiety) } \\ \text { Impact of will and skill }\end{array} & 0.651 & 0.424 & 65.09(0.000)^{\mathrm{d}} & 0.170(L) & 2.639 & 0.009 \\ \text { combined } & & & & 0.554(S) & 8.608 & 0.000 \\ \text { Impact of will, skill and } & 0.654 & 0.428 & 43.82(0.000)^{\mathrm{d}} & 0.158(L) & 2.426 & 0.016 \\ \text { tool on technology } & & & & 0.545(S) & 8.384 & 0.000 \\ \text { integration } & & & & 0.064(T) & 1.074 & 0.284\end{array}$

Note: ${ }^{\mathrm{d}} \mathrm{p}<0.05 ; \mathrm{L}=$ Lack of anxiety, $\mathrm{S}=\mathrm{Skill}, \mathrm{T}=$ Tool.

The regression analysis verified that approximately $18 \%$ of the variance in the stage of adoption is attributable to "will" measures of the teachers. Adding skill (self-efficacy) measures to the equation increased the predictability of the stages of adoption of technology from roughly $18 \%$ to approximately $42 \%$. Furthermore, predictability increased to approximately $43 \%$ when measures of tool were added to the equation. At all levels of the model, the F-values were significant indicating that the independent variables predict the dependent variable. According to the standardized coefficients the regression equation for this second model was:

$$
S O A_{\text {predicted }}=0.16 \text { will }+0.55 \text { skill }+0.06 \text { tool }
$$


Table 3.7 shows the results when the process is repeated for computer enjoyment attitude $(r=0.16, p=0.032$; no significant associations were found between the other TAC sub-scales and SOA) as an indicator of the teachers' "will" as against the other measures in the model.

Table 3.7 Coefficients of predictors (Computer Enjoyment (Will) against Skill and Tool measures of technology integration)

\begin{tabular}{|c|c|c|c|c|c|c|}
\hline & $\mathbf{R}$ & $\begin{array}{c}\text { R- } \\
\text { Square }\end{array}$ & F (Sig) & $\begin{array}{c}\text { Standardized } \\
\text { Coefficients }\end{array}$ & $t$ & Sig \\
\hline $\begin{array}{l}\text { Impact of will (Computer } \\
\text { Enjoyment) }\end{array}$ & 0.160 & 0.026 & $4.693(0.032)$ & $0.160(E)$ & 2.166 & 0.032 \\
\hline $\begin{array}{l}\text { Impact of will and skill } \\
\text { combined }\end{array}$ & 0.634 & 0.402 & $59.49(0.000)$ & $\begin{array}{l}0.030(E) \\
0.627(S)\end{array}$ & $\begin{array}{c}0.504 \\
10.554\end{array}$ & $\begin{array}{l}0.615 \\
0.000\end{array}$ \\
\hline $\begin{array}{l}\text { Impact on will, skill and } \\
\text { tools on technology } \\
\text { integration }\end{array}$ & 0.640 & 0.409 & $40.673(0.000)$ & $\begin{array}{l}0.033(E) \\
0.606(S) \\
0.089(T)\end{array}$ & $\begin{array}{l}0.533 \\
9.942 \\
1.489\end{array}$ & $\begin{array}{l}0.581 \\
0.000 \\
0.138\end{array}$ \\
\hline
\end{tabular}

Note: $\mathrm{p}<0.05 ; \mathrm{E}=$ Enjoyment, $\mathrm{S}=$ Skill, $\mathrm{T}=$ Tool.

The regression model 3 is as follows:

$$
S O A_{\text {predicted }}=0.03 \text { will }+0.61 \text { skill }+0.09 \text { tool }
$$

\subsection{DISCUSSION}

The study was designed to explore the computer attitudes, competencies, access and technology integration of prospective and practicing mathematics teachers in Ghana, using the will (attitudes towards computers), skill (technology competency), tool (access to technology tools) model. Prospective and practicing teachers demonstrated a positive attitude towards computers. But contrary to findings in other studies that younger people tend to have more positive attitudes towards the use of computers than their older peers (Christensen \& Knezek, 2006; Meelissen, 2008); the prospective teachers in this study showed more anxiety than the practicing teachers. The study reported fairly low technology competencies for the teachers. However, the practicing teachers were more technology competent than prospective teachers. The lower competencies, which was considered as a self-efficacy measure, of the prospective teachers coupled with their higher anxiety is consistent with findings of 
previous studies which suggest that computer skills and competencies are positively correlated with an individual's willingness to choose to participate in computerrelated activities, and that teachers with higher levels of competencies experienced less computer-related anxiety than teachers with lower levels of technology competencies (Looney et al., 2004; Sang et al., 2010).

A number of reasons might have accounted for the higher competencies of practicing teachers and the higher anxiety of the prospective teachers. One possible reason for this situation could have been the fact that the practicing teachers had more access to technology compared to the prospective teachers. Numerous studies have revealed that increase in computer experiences such as computer access, and computer usage frequencies leads to lower computer anxiety and higher technology competencies (Christensen \& Knezek, 2001; Gurcan-Namlu \& Ceyhan, 2003; Tekinarslan, 2008). Another reason which could explain why practicing teachers had higher technology competencies and showed less anxiety than prospective teachers could be attributed to in-service training organised for practicing teachers as was reported by school principals (Agyei \& Voogt, 2011a). Level of access and participation in in-service training could also explain the difference between prospective and practicing teachers in the levels of technology use. A body of literature on teachers' competencies and use of computers in instruction shows that teacher training programmes play a vital role in making teachers less anxious and more confident about the use of computers in instruction. Teachers who are more familiar with computers are more confident about using them for instruction and report more positive attitudes about the instructional effectiveness of computers (Christensen \& Knezek, 2008; KhorramiArani, 2001; Pamuk \& Peker, 2009).

In the study the overall attitudes of the teachers did not correlate with their SoA contrary to previous studies which suggest that teachers' attitude play a key role in determining computer use as a learning tool and determining the likelihood that the computer will be used in the future for teaching or learning (Huang \& Liaw, 2005; Paraskeva et al., 2008; Teo, 2008). Teachers' enjoyment and lack of anxiety towards computers in particular correlated significantly with SoA. This is in line with multiple studies (Christensen \& Knezek, 2001; Teo, 2008) which have been able to show a consistent decline in computer anxiety as teachers advance to 
higher SoA of technology. Teachers' technology competencies and access correlated significantly with their stages of adoption.

Finally, the findings of the study reported the extent to which the parameters will, skill and tool contribute to predicting teachers' classroom integration of technology. In predicting the stages of adoption, structured equation modeling (Knezek, Christensen, Hancock \& Shoho, 2000) would have been a better option; however it was not used because a much larger sample would have been needed. For this reason linear regression was used. Linear regression was applied on the whole data set, because similar patterns were observed when the data were treated for practicing and prospective teachers separately. Three models were discussed. The study showed that in all these models the "skill" of the teachers appeared to be the strongest predictor of classroom integration of computer use. This is different from the Mexican teachers (Morales, 2006) for whom access to technology explained most of the variance in technology integration. As already discussed the will of teachers, measured by their overall attitudes towards computers, showed no significant association with stage of adoption. This indicates that the first model was not the best fit for the data. In the second and the third models, the will of the teachers: "lack of anxiety" and "enjoyment" both showed significant association with teachers' stages of adoption with the former showing a much stronger correlation coefficient, indicating that the second model is the best fit for the data. This model explains $43 \%$ of the variance in stages of adoption of technology. This is consistent with literature that computer anxiety is the most important dimension of attitudes towards computers (Pamuk \& Peker, 2009). A number of studies (Bozionelos, 2001; Durndell \& Haag, 2002) have evaluated it as a separate construct and found a high relationship between attitudes and computer anxiety.

\subsubsection{Practical implications}

Several implications for professional development and teacher support for technology integration can be inferred from this study. The results of this study suggest that increasing teachers' technology competencies and decreasing their anxiety should be an integrated part of the design of professional development arrangements for prospective and practicing teacher education. It is believed that such arrangements can play a vital role in making teachers less anxious and 
consequently more confident about use of computers. Regarding technology integration by mathematics teachers in Ghana, attempts should be made to provide extensive professional development opportunities that focus on training practicing teachers to acquire skills on how to integrate technology effectively in their instruction - taking the context of the available technology infrastructure into account - and not just the acquisition of basic technology skills. Also teacher education institutions need to include courses on pedagogical issues related to technology integration in their curriculum. In this way prospective teachers' competencies will be enhanced and their experience to integrate technology in their future classes will increase. This will ensure that trained teachers are less anxious and sufficiently prepared for new teaching methods which are flexible and involve appropriate use of technology. The government of Ghana has put in place support systems in schools to facilitate access to computers. However, access probably will continue to be an issue in secondary schools in the coming years. In order to support government efforts, other stakeholders such as the Parent Teachers' Association, School Management and Boards must also put priority on the provision of technology facilities in schools to facilitate and increase access of teachers. Easy access to technology will certainly contribute to teachers' use of computers in the schools.

\subsubsection{Limitation and further research}

This study was not without some limitations. The best model had only $43 \%$ of the variance in stages of adoption of technology being accounted for by the latent variables as compared to over $90 \%$ from results of previous studies (Morales, 2006). This gives an indication that there could be other highly reliable indicators of technology integration in this context which have not been explored in the study. The fact that findings from a sample of mathematics teachers have been used is a limitation for the generalization of the findings. Although mathematics teachers form the highest number of all teachers in the senior high school (mathematics is taught both as a core subject for all students and as an elective subject for some programmes in the sciences, business and arts), involving other subject teachers in the study could have enhanced the extension of the findings and conclusions. The study which was conducted with only 60 practicing teachers from 16 schools which were sufficiently endowed with technology and 120 prospective teachers from one 
teacher education program provides no evidence to shed light on whether the findings of this study reflect the situation in the whole country.

\subsection{CONCLUSION}

The purposes of the study reported here were achieved in the modification and adoption of some measures: attitudes, competencies, access as predicting factors of level of technology use of prospective and practicing teachers. The prospective teachers in this study showed more anxiety and were less technology competent than the practicing teachers. Computer anxiety was identified as the most important dimension of attitudes towards computers consistent with literature of previous studies. The study showed that skill (competencies) was the strongest predictor of classroom integration of computers by these teachers. Notwithstanding the limitations, findings of this study provide directions for policy and practice about next steps that are necessary for a successful integration of technology in secondary education in Ghana. In addition the findings of this study may also inform similar initiatives on prospective and practicing teachers' use of technology in other sub-Sahara African countries. 


\title{
CHAPTER 4
}

\section{Developing Technological Pedagogical Content Knowledge in pre-service mathematics teachers through collaborative design ${ }^{4}$}

\begin{abstract}
Although many studies have shown the need to pay attention to teachers' preparation in the integration of technology in classroom practice, most teachers in Ghana have not had any preparation that develops their technology pedagogical content knowledge (TPACK). This paper presents a case study of four pre-service mathematics teachers from the University of Cape Coast, Ghana; who worked in two design teams to develop lessons and subsequently taught in a technology-based environment for the first time. It was evident from the findings that more systematic efforts are needed to engage pre-service teachers in technology-rich design activities, so as to develop aspects of their TPACK adequately. The study also showed the potential of TPACK as a new frame for developing preservice teachers' experiences in technology integration within initial teacher education particularly in Sub-Saharan African countries.
\end{abstract}

4 A previous version of this chapter was presented (and published) at SITE annual conference as: Voogt, J., Thompson, A., Mishra, P., Fisser, P., Allayar, G., Agyei, D.D, Koehler, M., Shin, T.S., Wolf, L.G., DeSchryver, M., Schmidt, D. \& Baran, E. (2010). Strategies for teacher professional development on TPACK, Part 2. In D. Gibson \& B. Dodge (Eds.), Proceedings of Society for Information Technology E Teacher Education International. The current version of this chapter has been published as: . Agyei, D \& Voogt, J. (2012). Developing Technological Pedagogical Content Knowledge in pre-service mathematics teachers, through Teacher Design Teams, Australiasian Journal of Educational Technology, 28(4), 547-564. 


\subsection{INTRODUCTION}

Integration of technology in education has increasingly become an important concern in education not only in developed countries, but in developing countries as well. Tilya (2008) analyzed the development of technology in education policies in Sub-Saharan Africa. He found that the majority of Sub-Saharan Africa countries have a national policy on technology in education, including an implementation plan. Ghana is one of the Sub-Saharan African countries with a national policy and implementation plan for technology in education. Ghana introduced ICT into the school curriculum in September 2007 following the recommendations of the Ghana Information and Communication Technology for Accelerated Development (Ghana ICT4AD Policy, 2003) policy document and the Anamuah-Mensah National Education Review Committee Report (2002). Both documents highlight the importance of integrating ICT into the curriculum at all levels. The new curriculum in mathematics at the Senior High School (SHS) encourages teachers to make use of the calculator and the computer for problem solving and investigations of real life situations, in order to help students acquire the habit of analytical thinking and the capacity to apply knowledge in solving practical problems (Ministry of Education, Science and Sports (MOESS), 2007). However, to realize this new orientation to teaching and learning including the use of computers by teachers more needs to be done than the current recommendations contained in syllabuses.

Few studies (Ottevanger, van den Akker, \& de Feiter, 2007; Agyei \& Voogt 2011a, b) conducted in Ghana report the poor state of mathematics teaching and technology use in secondary education in Ghana. Agyei and Voogt (2011a, b) showed that mathematics teachers do not integrate technology in their instruction in spite of government efforts in the procurement of computers and recent establishment of computer labs in most SHS's. They indicated that the major barriers to technology integration were the current teaching strategies used in SHS's and lack of teachers' and pre-service teachers' knowledge of ways to integrate technology in instruction. The most frequently used strategy in the SHS classrooms is the chalk and talk approach (Ottevanger et al 2007; Agyei \& Voogt, 2011a) in which teachers do most of the talking and intellectual work, while students are passive receptacles of the 
information provided. Agyei and Voogt (2011a) reported that these teachers also have been taught in the same manner and for most of them effectively integrating technology in their instruction is a complex innovation (cf. Koehler \& Mishra, 2008; Voogt, 2008) which requires them to change their routines of teaching. Agyei and Voogt $(2011 \mathrm{a}, \mathrm{b})$ further indicated that most instructors at the teacher education programme (responsible for training mathematics teachers in Ghana) are mainly dependent on lecture-based instruction. This programme also did not include Instructional Technology courses where teachers were taught how to integrate technology in their lessons. This means that the pre-service teachers' experience to integrate technology in teaching is limited making the programme fall short of the practical approach. This leads to the question whether the trained pre-service teachers are sufficiently prepared for new teaching methods which are flexible, student-centred and involve appropriate use of technology.

The study on Developing Science Mathematic and ICT (SMICT) education in Ghana (and other Sub-Saharan Africa) suggested changes to the teacher's instructional role from presenter of knowledge and the use of drill-oriented methods to participatory teaching and learning (Ottevanger, et al., 2007). More particularly it recommends effective use of equipment for practical work and ICT, which needs to be optimized through extensive programmes of teacher support (both in-service and pre-service). Agyei and Voogt (2011a, b) also found that mathematics teachers and pre-service mathematics teachers appeared generally supportive in wanting to use computers in their (future) classrooms in spite of the barriers to technology use in instruction. These teachers showed a lot of enthusiasm to be part of any professional development programme related to integrating technology in teaching and learning mathematics. In this study a professional development arrangement in which pre-service mathematics teachers collaboratively design and use technology rich teaching materials is carried out and evaluated, a first effort to develop a technology integration program for preservice mathematics teachers at the University of Cape Coast (UCC), one of the two main teacher education institutions in Ghana. The study builds on the findings of the previous study (Agyei and Voogt 2011a, b) and is part of an on-going study aiming at developing and integrating technology-rich design activities in the preservice mathematics teacher education curriculum at UCC. 


\subsection{TECHNOLOGY INTEGRATION THROUGH COLLABORATIVE DESIGN}

According to Koehler and Mishra (2009), at the heart of good teaching with technology are three core components: technology, pedagogy and content plus the relationships between them. Technological Pedagogical Content Knowledge (TPACK) was introduced to the educational research field as a theoretical framework for understanding teacher knowledge required for technology integration (Mishra \& Koehler, 2006).TPACK builds off on Schulman's concept of pedagogical content knowledge (Schulman 1986) which highlights the importance of the complex interrelationships between teachers' knowledge about content and pedagogy, and the need for teachers to learn about variable ways of representing subject matter. TPACK emphasizes the comprehensive set of competencies teachers need to successfully integrate technology in their educational practice (Koehler \& Mishra, 2008). The key to TPACK is the integration of multiple domains of knowledge in a way that support teachers in teaching their students the subject matter with technology (Margerum-Leys \& Marx 2004; Mishra \& Koehler 2006; Niess 2005). TPACK consists of 7 different knowledge areas: (i) Content Knowledge (CK), (ii) Pedagogical Knowledge (PK), (iii) Technology Knowledge (TK), (iv) Pedagogical Content Knowledge (PCK), (v) Technological Content Knowledge (TCK), (vi) Technological Pedagogical Knowledge (TPK), and (vii) Technological Pedagogical Content Knowledge (TPCK) (see Fig. 4.1).

Technology Knowledge (TK) broadly encompasses knowledge of standard technologies such as books and chalk and blackboard, as well as more advanced technologies such as the internet and digital video, and the different modalities they provide for representing information (Polly, Mims, Shepherd \& Inan, 2010). Technological Content Knowledge (TCK) refers to knowledge about how technology may be used to provide new ways of teaching content (Niess, 2005). Technological Pedagogical Knowledge (TPK) refers to knowledge about the affordances and constraints of technology as an enabler of different teaching approaches (Mishra \& Koehler, 2006). 


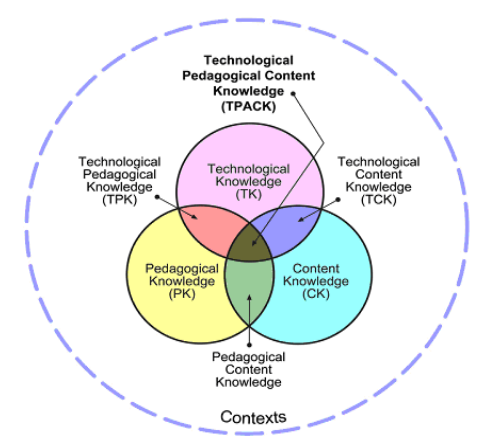

Figure 4.1 Framework of TPACK: (Koehler \& Mishra, 2008)

Technological Pedagogical Content Knowledge (TPACK) also refers to the knowledge and understanding of the interplay between CK, PK and TK when using technology for teaching and learning (Mishra \& Koehler, 2006).Considering the goal of engaging students in mathematical problem solving for example, a mathematics teacher's TPACK must focus on thinking strategically in planning, organizing, implementing, critiquing results and abstracting plans for specific mathematics content and diverse student needs (Niess, Sadri, \& Lee, 2007).Since this study describes and evaluates a professional development arrangement for pre-service mathematics teachers' development of TPACK, we particularly focus on those knowledge areas in which the ' $\mathrm{T}$ ' is involved: TK, TCK, TPK and TPCK and engage the teachers in a collaborative way to design technology-rich activities.

Several studies (Mishra \& Koehler 2003; Koehler \& Mishra, 2005; Koehler, Mishra \& Yahya, 2007; Polly et al., 2010; So \& Kim, 2009) have shown that collaborative design of technology enhanced curriculum materials support teachers in becoming TPACK competent. Mishra and Koehler (2003) indicated that a key to learning about TPACK is the "Learning Technology by Design" approach where pre-service teachers participate in "design teams". For instance, Koehler and Mishra (2005) and Koehler et al. (2007) used the Learning Technology by Design approach, describing it as a collaborative learning context in which a pre-service teacher is engaged to become "a practitioner, not just learning about practice" (p.135). Koehler and Mishra (2005) reported that participants who engaged in Learning Technology by Design were able to move from seeing technology, pedagogy, and content as separate constructs towards a more integrated and inter-related 
construct. Similarly, Angeli and Valanides (2005) argued that such design-based learning approach contribute to prepare future teachers to be competent to teach with technology in ways that signify the added value of technology. So and Kim (2009) indicated that collaborative designs help pre-service teachers to make intimate connections among content, pedagogy and technology in a collaborative way. According to Mishra, Koehler and Zhao (2007), learning technology through collaborative design seeks to put pre-service teachers on a common ground as they work collaboratively in small groups to develop technological solutions to authentic pedagogical problems.

In this study, the concept of Design Teams (DTs), which is defined as a group of pre-service teachers working collaboratively to design and develop technological solutions for authentic problems they face in teaching mathematics during their inschool training (adopted from Mishra \& Koehler 2003) was applied to actively involve pre-service teachers in the design of curriculum materials to develop their TPACK. It is expected that by working in DTs to design technological solutions, the pre-service teachers will begin to think about technology as a tool for achieving instructional objectives, rather than considering it as an end in itself. Again we expect that engaging pre-service teachers in DTs will promote active learning through collaboration with the different team members.

Because exemplary curriculum materials should speak to the teacher instead of through the teacher (Remillard, 2005), much emphasis was placed on exemplary curriculum materials that were specifically designed to help pre-service teachers learn through design and implementation of the innovation in the study. Several researchers have investigated the contributions of curriculum materials designed to support teacher learning (Van den Akker, 1988; Davis \& Krajcik, 2005; Voogt, McKenney, Smits \& Bustraan, submitted), referred to by Davis and Krajcik as "educative curriculum materials." Such studies have shown that exemplary curriculum materials provide teachers with an operational understanding of an innovation (van den Akker, 1988), prompt teachers decisions about how to proceed in the design of an innovation (cf Voogt, McKenney, Smits \& Bustraan, submitted); stimulate reflection (Davis \& Krajcik, 2005) and subject matter understanding (Ottevanger, 2001). According to Voogt (2010), exemplary materials can provide 
pre-service teachers with theoretical and practical insights of technologysupported learner-centered lessons and hands-on experience. In the study, the use of exemplary curriculum material was employed to support pre-service teachers' learning by: promoting a better understanding of what integrating technology in lessons is about, promoting pedagogical design capacity, providing concrete howto-do suggestions and facilitating a better implementation of the innovation.

\subsection{THE PROFESSIONAL DEVELOPMENT ARRANGEMENT}

The technology learned by the pre-service teachers (further addressed as experimental teachers) were spreadsheet applications for mathematics, because it was readily available in Senior High Schools and in teacher Education Colleges (Agyei \& Voogt 2011b), user friendly and had the potential of supporting students' higher-order thinking skills in mathematics ( Niess, Sadri \& Lee, 2007). Niess et al., (2007) indicated that during the process of design (in design teams) pre-service teachers experience elementary concepts of mathematical modelling, expand their own conceptions of teaching mathematics with spreadsheets, investigate and expand their knowledge of instructional strategies for integrating spreadsheet learning activities, and explore curricular materials that support learning with and about spreadsheets over an extended period of time.

The professional development arrangement in this study consisted of three stages: An introductory workshop for DTs, design of lessons in DTs and implementation of lessons by DT members. Table 4.1 presents an overview of the DT activities in relation to the TPACK framework. The workshop lasted for two weeks and was aimed at preparing the pre-service teachers by giving them the theoretical foundation/concepts as well as practical skills they needed to work successfully during the other stages (design and implementation) of the study. The exemplary materials consisted of two models of Spreadsheet-Supported Lessons (SSL) that were prepared by the researcher and appraised by an expert with ample experience in the use of technology in teaching mathematics. 
Table 4.1 Relation between DT activities, TPACK framework and strategies for teacher learning

\begin{tabular}{|c|c|c|}
\hline DT activities & Stage & $\begin{array}{l}\text { TPACK } \\
\text { frame-work }\end{array}$ \\
\hline Introduction to learning by design (collaboration) & $\mathrm{w}$ & - \\
\hline Introduction to computer skills(including spreadsheet basics) & $\mathrm{w}$ & TK \\
\hline Introduction to TPACK concept & $\mathrm{w}$ & TPACK \\
\hline $\begin{array}{l}\text { Introduction/demonstration of spreadsheet-based lesson } \\
\text { (exemplary material) and discussion }\end{array}$ & $\mathrm{w}$ & TPACK \\
\hline $\begin{array}{l}\text { Scouting spreadsheet techniques that support mathematics } \\
\text { teaching }\end{array}$ & $\mathrm{w} / \mathrm{d}$ & TPK \\
\hline Development of mathematics SSL activities by teachers & $\mathrm{d}$ & TCK \\
\hline $\begin{array}{l}\text { Teaching of SSL to colleagues/peers/researcher } \\
\text { (Use of teachers' developed lesson materials) }\end{array}$ & $\mathrm{w} / \mathrm{i}$ & TPACK \\
\hline Revision of the developed lesson materials based on feedback & $\mathrm{w} / \mathrm{d} / \mathrm{i}$ & TPACK \\
\hline
\end{tabular}

Note: $\mathrm{w}=$ workshop; $\mathrm{d}=$ design; $\mathrm{i}=$ implementation.

Based on their experiences, the DTs developed and modelled their own lessons (lesson plans and students' worksheet) after the exemplary materials during the design stage (which lasted for 3 weeks). These, they taught first as a micro-teaching among themselves and later among their peers (further addressed as studentteachers) in a designed classroom situation during implementation. Each member of the DT taught one out of the four lessons (which lasted for 80 minutes each) although they had worked in teams to design them. The student teachers (who served as students in the classrooms) appraised the lessons. The lessons were done in a classroom with a LCD projector and a laptop (PC) available to each teacher. The results and insights learned from the teaching try-outs (micro-teaching and classroom implementation) served as necessary inputs for the teachers in revising their designs. The researcher acted mainly as a facilitator, coach and observer in different stages of the study.

\subsection{RESEARCH QUESTIONS AND RESEARCH DESIGN}

The study examined the impact of collaborative design of technology-enhanced lesson materials in design teams on experimental teachers' classroom practices, and their learning of TPACK. The main research question that guided the study was: What are pre-service mathematics teachers' experiences in developing and 
implementing technology-enhanced lessons through collaborative design teams? The following sub research questions guided the study (1) how did the experimental teachers implement the developed technology-enhanced lesson materials in their teaching; (2) how did student-teachers experience the technology-enhanced lessons; (3) how did experimental teachers' learning of TPACK develop; and (4) how did the experimental teachers perceive the contribution of DTs and exemplary lesson materials to their learning? A case study of 4 pre-service teachers was applied (Yin, 1993). The study focused on an in-depth investigation of the pre-service teachers' development of TPACK as well as their perceptions on how DTs contributed to their TPACK development. Consequently the units of analysis were the pre-service teachers and the case was the professional development arrangement which was organised within the context of the mathematics teacher education program at the University of Cape Coast. The study employed mixed method of quantitative and qualitative evidence.

\subsection{MeTHODS}

\subsubsection{Participants}

Four pre-service mathematics teachers (experimental teachers) and their student peers $(\mathrm{N}=125)$ (student-teachers) participated in the study. Both groups of participants were in their final year of the teacher education (BEd Mathematics) programme at UCC. The BEd (Mathematics) is a 4-year programme which will allow them to teach at Junior and Senior High School when they graduate. In the study the experimental teachers: Isaac, Nat, Kobby and Serena (fictitious name) worked in teams (Nat and Isaac; Kobby and Serena) to develop and teach SSL (to the student-teachers).These experimental teachers have not had any experience in a technology-supported lesson: neither as part of their training nor in their preuniversity education at the SHS. The student-teachers, who volunteered to be part of the study, were 90 males and 35 females. Just like the experimental teachers, the student teachers had no experiences with technology-supported lessons. The participants were aged between 19 and 37 with the average age of nearly 26 years. 


\subsubsection{Instruments}

\section{Experimental teacher interview}

Interview data was collected after each peer teaching session. This interview focused on teachers' experiences and opinions of the SSL; reflecting their views from the planning and preparation stage to the actual implementation of lessons as well as a post- review of the teaching. Interview data was also taken at the end of the arrangement to seek the teachers' opinion on aspects of the programme impacting on their professional development. All interviews were audio-taped and transcribed using pattern coding techniques (Miles \& Huberman, 1994).

\section{Experimental teacher evaluation questionnaire}

Since the study aimed at enhancing teachers' technological pedagogical content knowledge (TPACK), the questionnaire included items that addressed the experimental teachers' self-assessment toward TPACK adapted from Schmidt, Baran, Thompson, Mishra, Koehler \& Shin (2009). Construct validity analysis of the items of the framework ranges from 3.67 to 9.00 of the knowledge types with five of the seven types scoring 7.88 (Schmidt, Seymour, Baran, \& Thompson, 2009). Cronbach's alpha reliability estimates of this instrument ranges from 0.75 to 0.93 (Schmidt et al., 2009) suggesting that the instrument is reliable and could be used with confidence. Items were adapted to address the integration of spreadsheets in mathematics teaching in particular. The focus was teachers' knowledge related to technology integration: TK, TPK, TCK and TPACK (see also Table 4.2).

Table 4.2 Sample question for each TPACK knowledge type constructs

$\begin{array}{ll}\text { Knowledge Type } & \text { Sample Question For Each Knowledge Type } \\ \begin{array}{ll}\text { Technology Knowledge (TK) } \\ \text { Technology Pedagogical Knowledge }\end{array} & \begin{array}{l}\text { I frequently play around with spreadsheets } \\ \text { I can choose spreadsheets application that enhance the } \\ \text { teaching approaches of a lesson }\end{array} \\ \begin{array}{ll}\text { Technology Content Knowledge } \\ \text { (TCK) }\end{array} & \begin{array}{l}\text { I know about spreadsheet applications that I can use } \\ \text { for understanding and doing mathematics }\end{array} \\ \begin{array}{ll}\text { Technology, Pedagogy and Content } \\ \text { Knowledge (TPACK) }\end{array} & \begin{array}{l}\text { I can teach lessons that appropriately combine } \\ \text { mathematics concepts, spreadsheet applications and } \\ \text { teaching approaches }\end{array}\end{array}$


The questionnaire contained items on a five-point Likert scale ( 1 = strongly disagree, 5 = strongly agree) about teachers' self-efficacy toward technology use. Bandura (1977) presented self-efficacy as one's perceived ability to perform an action that will lead successfully toward a specific goal. The questionnaire was administered twice: before and after the intervention. Teachers' responses in the pre-post survey delineated expressed teachers' disposition toward on-going evolving understanding and mastery of spreadsheets (TK), possibilities of teaching and learning with spreadsheets (TPK), how to use spreadsheets to increase understanding of mathematics concepts (TCK) and their understanding of how teaching and learning mathematics change with the application of spreadsheets (TPACK).

Student-teachers' experiences with the Spreadsheet-Supported Lessons (SSL)

A questionnaire consisting of 23 items on student-teachers' opinions of the SSL was administered immediately after each lesson implementation. Possible answers to an item were on a five point Likert scale $(1=$ strongly disagree, $5=$ strongly agree). Seventeen of the items were selected as high loadings on extracted factors after an exploratory factor analysis. In all, 3 sub-scales were reported. They were: Interest (how appealing/motivating/exciting and attention-grabbing a lesson was), Clarity (students' comprehension/understanding of the concepts of the lesson) and Presentation (the practice of showing and explaining content of the topic to the learners using technology). The reliability co-efficient observed for the scales were Interest $(\alpha=0.74)$, Clarity $(\alpha=0.71)$ and Presentation $(\alpha=0.70)$. Following the administration of the questionnaire, a guided group discussion with 6 to 9 student-teachers was conducted to seek further clarifications of their opinions about the SSL in general and their learning and usefulness of the exemplary materials. The discussions were audio-taped and transcribed using data reduction techniques (Miles \& Huberman, 1994).

\section{Researcher's logbook}

The researchers' log book was used to maintain a record of activities and events occurring during the classroom implementation of the SSL's as well as contributions of components of the arrangement in enhancing experimental teachers' TPACK. Information recorded in the logbook was analyzed qualitatively using data reduction technique. (Miles \& Huberman, 1994). 


\subsection{RESULTS}

\subsubsection{Experimental teachers' practice}

\section{Spreadsheet-Supported Lesson implementation}

The first research question dealt with how the experimental teachers implemented the developed technology-enhanced lesson materials in teaching. A major aspect of the professional development arrangement was the SSL designed by the experimental teachers. Although the lessons were in lecture form, they were less teacher-centred, as all four SSL's were executed with an "interactive demonstration" in a spreadsheet environment in which the technology was used as a tool to help students explore mathematics concepts and perform authentic tasks. For instance, Kobby taught a topic on Linear functions and just as Isaac (who taught a lesson on quadratic functions) he used spreadsheet to guide his students to explore patterns (see how changes in parameters affect graphs) to assist them in making generalizations from the observed patterns. Furthermore, graphic representations from the use of the spreadsheet made it relatively easy for the teachers to guide their students in identifying properties of families of functions such as linear functions (as in Kobby's lesson) and quadratic functions (as in Isaac's lesson). All teachers introduced fundamental concepts of their lessons by using spreadsheet and gradually engaged their students to develop higher concepts as lessons progressed. Student-teachers confirmed having discovered new things during the lessons. For instance during Serena's lesson (quadratic in the vertex form), most student-teachers identified that the basic second-degree curve $\left(y=a x^{2}\right)$ gives a thinner parabola if $|a|$ is increased and a flatter parabola if $|a|$ is decreased (which they did not know before the lesson). The experimental teachers used the students' worksheet a great deal during the lessons. Activities were carried out in groups (2-3 student-teachers) on the worksheets and this promoted healthy interactions among students and also between students and the teacher. In most cases, experimental teachers asked representatives of groups to share and discuss their findings. Nevertheless, little time (Kobby) or no time at all (Nat, Isaac and Serena) was allotted for students to reflect on the differences and similarities that occurred in the outcomes of their activities. Time management was a setback for the experimental teachers during their lessons. They all found some difficulty in completing lessons within the stipulated time. In most cases, the introduction of the lesson took more time. In spite 
of this limitation, results of the classroom observations reflect a positive impact of the in-service arrangement on the experimental teachers' classroom practice of the SSL taking into account that these teachers had never been exposed to technology use in classroom prior to the arrangement.

Student-teachers experiences with the SSL lessons

The results of the study showed that student-teachers were satisfied with various aspects of the lesson. Most of them had the view that the lessons were learnercentred and applicable to real life situations. Some student-teachers indicated during the guided group discussion that they had better understood certain mathematical concepts which they ought to have learnt in SHS's. The following were some of their responses:

The lesson was a great scaffolding exercise. It gradually unfolded the content of quadratic in the vertex form. In fact I never knew there was an expression for determining the y-coordinate of a parabola in the vertex form; but today I have learnt something new (S11);

I was thinking of how certain concepts could have been developed for students to understand the way we did without the graphs, but the spreadsheet activities helped us to explore the effect of the parameters on the graphs (S23);

I had the opportunity to teach linear equations during my off-campus teaching practice at the SHS; reflecting on what I did and what I just witnessed there is a very big difference. This lesson really brought out the effect of changes on the parameters clearly whereas it was very difficult to get this concept across to the students during my lesson (S25).

The student-teachers pointed further that the lessons were very interesting and practical and presentations were attention grabbing promoting class participation. In general they were fascinated by the lessons and asserted that the integration of spreadsheet in learning mathematics is a good idea and should be extended to the SHS. The student-teachers' questionnaire responses (see Table 4.3) further confirmed their experiences with SSL. The overall means of aspects of the lesson 
reported by the students were very high; Clarity (Mean $=4.45, \mathrm{SD}=0.35$ ), Interest $($ Mean $=4.43, \mathrm{SD}=0.37)$ and Presentation (Mean $=4.35, \mathrm{SD}=0.36)$. A one-way ANOVA test was conducted to evaluate to what extent differences between their perceptions for the four lessons were significant across the three subscales. The ANOVA was significant $(F(3,121)=4.77, p=0.004)$ for the Clarity construct and Interest $(F(3,121)=2.80, p=0.043)$. With respect to the practice of showing and explaining content of the topic using the technology (Presentation), the learners did not identify significant differences across the lessons.

Table 4.3 Student-teachers' score on 3 sub-scales of the lessons

\begin{tabular}{|c|c|c|c|c|c|c|c|c|c|c|}
\hline \multirow[b]{2}{*}{ Sub-scale } & \multicolumn{2}{|c|}{ Isaac $(N=30)$} & \multicolumn{2}{|c|}{ Nat $(\mathbf{N}=30)$} & \multicolumn{2}{|c|}{$\begin{array}{l}\text { Kobby } \\
(\mathrm{N}=31)\end{array}$} & \multicolumn{2}{|c|}{$\begin{array}{l}\text { Serena } \\
(\mathrm{N}=34)\end{array}$} & \multicolumn{2}{|c|}{ ANOVA TEST } \\
\hline & M & SD & $\mathrm{M}$ & $\mathrm{SD}$ & M & SD & $\mathrm{M}$ & SD & $\mathrm{F}$ & $\mathrm{p}$ \\
\hline Clarity & 4.39 & 0.40 & 4.29 & 0.42 & 4.58 & 0.22 & 4.53 & 0.26 & 4.77 & $0.004^{*}$ \\
\hline Interest & 4.41 & 0.39 & 4.31 & 0.40 & 4.57 & 0.32 & 4.45 & 0.35 & 2.80 & $0.043^{*}$ \\
\hline Presentation & 4.36 & 0.38 & 4.27 & 0.43 & 4.44 & 0.37 & 4.35 & 0.28 & 1.07 & 0.363 \\
\hline
\end{tabular}

Note: * Significant at 0.05 level.

The level of difficulty of the various topics taught by the teachers might have contributed to the differences in the lessons for the clarity and interest constructs. In spite of their enthusiasm about the SSL, student teachers pointed out some challenges in teaching a SSL. They speculated that it requires one lots of skills and expertise to design and prepare to teach a SSL. They also expressed concerns about accessibility of technological facilities problems in secondary school where they were being trained to teach.

\subsubsection{Experimental teachers' reflection on their learning}

Looking back at lesson implementation

The experimental teachers had the opportunity to clarify their opinion about the SSL in a reflective interview after teaching their lessons. They reported several challenges with the process of design SSL itself. Isaac indicated having taught a similar lesson in quadratics once in the SHS during his off- campus teaching practice. Responding to how different the preparation of the lesson was compared to what he had taught before he explained: 
Here it was more difficult and time consuming to prepare (than the one I taught before). Whereas in the former I only prepared a lesson plan and few questions, now we had to prepare a student worksheet in addition to the lesson plan, set up the spreadsheet environment, prepare slides and eventually teach the whole lesson to ourselves before the actual teaching was done.

His team mate added:

It was difficult to think of authentic student activities that tied with the learning objectives in the preparation of the worksheet (Nat).

Kobby vehemently stated that his team also had some problems when designing the lesson. He indicated:

The challenge was to identify and integrate appropriate spreadsheet resources having in mind our learning objectives.

The experimental teachers further indicated having problems designing suitable interactive activities with spreadsheet to guide students develop higher concepts. However, they believed the lessons were more student-centred and the development of the mathematics concepts more deductive. When asked what encouraged them to select the topics they taught in their lessons, the teachers explained that it was easier for them to develop lessons in which concept formation could be facilitated by using spreadsheets. Reflecting on their experiences and how comfortable they were teaching the SSL; the teachers said they built their confidence over time and it was easier for them to explain certain concepts with the approach. Isaac indicated:

Some concepts I thought would be difficult to develop was made much easier for me to explain than I would have done before...

The experimental teachers believed that the SSL approach of teaching caught the attention of the students and engaged them throughout the lesson giving them a different role from what they experienced in their normal lessons. They were of the 
view that their lessons incorporated more student activities making it more student-led rather than teacher-led. The four teachers contended that their students enjoyed the lessons and their conceptual understanding of the various topics that were taught had improved tremendously in spite of the fact that they were teachers supposed to be teaching these topics they learnt several years ago.

\section{Experimental teachers' development of TPACK}

Table 4.4 gives a summary of the results of the pre-post survey delineated by the teachers' expressed self-efficacy of the TPACK components.

Table 4.4 Results for pre-and post-test mean score responses for TPACK subscales

\begin{tabular}{|c|c|c|c|c|c|}
\hline & Isaac & Nat & Kobby & Serena & $\begin{array}{c}\text { Overall } \\
\text { Mean }\end{array}$ \\
\hline \multicolumn{6}{|l|}{ TK } \\
\hline Pre & 4.38 & 3.65 & 4.25 & 3.63 & 3.98 \\
\hline Post & 4.64 & 4.33 & 4.74 & 4.42 & 4.53 \\
\hline Change in TK & 0.26 & 0.68 & 0.49 & 0.79 & 0.55 \\
\hline \multicolumn{6}{|l|}{ TPK } \\
\hline Pre & 4.01 & 3.22 & 3.89 & 3.45 & 3.64 \\
\hline Post & 4.51 & 4.20 & 4.64 & 4.38 & 4.43 \\
\hline Change in TPK & 0.50 & 0.98 & 0.75 & 0.93 & 0.79 \\
\hline \multicolumn{6}{|l|}{ TCK } \\
\hline Pre & 2.55 & 2.13 & 2.35 & 2.04 & 2.27 \\
\hline Post & 4.76 & 4.18 & 4.48 & 4.39 & 4.45 \\
\hline Change in TCK & 2.21 & 2.05 & 2.23 & 2.35 & 2.18 \\
\hline \multicolumn{6}{|l|}{ TPACK } \\
\hline Pre & 2.33 & 1.98 & 2.22 & 1.89 & 2.11 \\
\hline Post & 4.36 & 3.63 & 4.21 & 4.09 & 4.07 \\
\hline Change in TPACK & 2.03 & 1.65 & 1.99 & 2.20 & 1.96 \\
\hline
\end{tabular}

Overall the results indicated that there were appreciable increments between the respondents' pre- and post-test means for all four TPACK sub-scales. The largest area of change between the teachers' pre- and post-test mean differences was for the subscale TCK (2.18), followed by TPCK (1.96). Changes in TK and TPK were from approaching agree to agree (in both cases) for the pre to post mean scores. The teachers' prior experiences with spreadsheets knowledge (especially Kobby and Isaac) as indicated in interview responses confirmed this. Experimental teachers reported that the arrangement gave them the experience in learning their subject 
matter better and thus expanding their own conceptions of teaching with spreadsheet. For instance, Isaac said he intends to explore other topics in the SHS curriculum while Kobby and Serena indicated they were already in the process of extending the TPACK to topics in Statistics and Simultaneous Equations. They mentioned having expanded their knowledge on instructional strategies to teach the subject matter with spreadsheet. They considered the intervention useful as it had increased their confidence and competence in teaching mathematics with technology.

\subsubsection{The contribution of teacher design teams for experimental teacher learning}

The experimental teachers indicated that they enjoyed working in DTs and participated actively in their teams. Specifically the teachers liked the collaborations on team discussions on how to improve lessons, co-plan their lessons and share ideas. They were of the view that the support offered in DTs increased their confidence in designing mathematics lessons. More importantly it helped them improve their teaching performance through sharing experiences and expertise with their immediate colleagues. In addition, they were able to identify their individual strengths and weaknesses. Despite appreciating the importance of design teams and the role it played in enhancing their TPACK, the experimental teachers admitted encountering some challenges when working in teams. The major ones were the time factor and punctuality at design meetings. Again different views among members within teams posed challenges during lesson designs and discussions. However they believed through discussions and negotiations they always came to a compromise. Thus, experimental teachers concluded that by working in design teams, they learnt how to tolerate one another's view, how to cope with colleague's ideas on different issues and how to compromise and develop common understanding.

\subsubsection{The contribution of exemplary curriculum materials for experimental teacher learning}

All four teachers considered the exemplary teaching materials as very useful in various reasons: enhanced their skills for teaching SSL (Nat and Kobby), provided a better understanding of the SSL's (All), suggested suitable classroom activities 
(Isaac and Kobby), facilitated step-by-step suggestions on how to proceed with their own designs (Kobby, Serena and Nat) and provided new knowledge on the topics (All). They emphasized the effectiveness of the exemplary materials in designing their own lesson materials. Experimental teachers mentioned using the materials they had modelled themselves (following the exemplary ones) in their future lessons. The various reasons for using such materials were: promoting student-centred learning, arousing interest of students, enhancing understanding of the topic and promoting full participation in the teaching and learning process.

\subsection{Discussion}

The study aimed at exploring the impact of collaborative design teams on preservice (experimental) teachers' TPACK development and their teaching with technology. Pre-service mathematics teachers worked in design teams to plan and organize for teaching mathematics with spreadsheets (supported by exemplary materials) within a mathematics classroom context. The results of the study showed that the pre-service teachers reported appreciable levels of growth in components of TPACK (TK, TPK, TCK and TPACK) (with pronounced changes in TCK and TPACK) as shown in Table 4.4. What was common was that all the preservice teachers moved from thinking discretely about technology, pedagogy, and content, to thinking and speaking about them as hardly separable constructs. For instance, the pre-service teachers reported having expanded their knowledge of instructional strategies for integrating spreadsheet learning activities in lessons. Again the results showed improved subject matter of pre-service teachers which consequently impacted their presentation of certain concepts they would have found difficult to develop (cf. Niess, et al., 2007). Student-teachers experiences confirmed that the lessons were great scaffolding exercises and more learnercentred that gave them deeper insights to certain concepts they ought to have learnt earlier when they were in secondary school and exclaimed that if such lessons are extended into their future classroom at the SHS, it will promote participatory teaching and learning and consequently improve achievement of students in mathematics. 
On the whole while the study showed that pre-service teachers had acquired technology integration skills and had adopted some elements of learnercentredness approach in their teaching, it was not without some difficulties. The pre-service teachers indicated that generating authentic activities and ill-structured problems for their chosen topics was one of the challenges. They also experienced difficulties in finding and integrating appropriate spreadsheet applications for the learning activities. Apparently confining to spreadsheet tools (as the only technology for designing lessons) in this study could have contributed to this problem. Challenges with time management (in various sections) of lesson implementations were evident in the study. As a result lesson conclusions were in a rush and teacher driven. Possibly, lessons were overloaded with activities in some cases and estimating appropriate times with this new experience was a possible challenge for the others. One possible reason which could explain preservice teachers' difficulties in designing and teaching the SSL was their limited repertoires for teaching mathematics with technology in a student centred approach. Furthermore student-teachers speculated that it requires a lot of efforts and expertise to prepare and teach a SSL. These findings illuminate that the teachers needed more time to practice this new approach to mathematics teaching to develop their TPACK in a more desirable way. This is similar to findings from Fishman and Davis (2006) which explains that building a knowledge base of TPACK should be viewed as a long term trajectory that goes beyond pre-service teacher education in formal settings. Fishman and Davis argued that as teachers gain more experience, they can continue to expand their knowledge base and to strengthen the connection between content, pedagogy and technology.

In spite of the drawbacks, the overall findings of the study suggest that the arrangement that was developed contributed to growth in TPACK and the subsequent implementation of technology-supported mathematics lessons of the pre-service teachers.

A number of factors accounted for the positive impact of DTs. Clearly, collaborative design was a useful support for pre-service teachers' development of TPACK. The targeted teachers were enthusiastic about working in design teams. Consistent with research evidence, (e.g. Mishra et al., 2007; Penuel, Fishman, 
Yamaguchi \& Gallagher, 2007), the pre-service teachers indicated that they benefited from the collaboration in the design teams and confirmed that the support helped them to enhance their TPACK and in achieving their goal throughout the programme. They were of the view that collaboration in the teams helped them to achieve more than they would have done individually with the same task and also provided them with opportunities for active involvement during the design and development of the SSL.

Along with working in DTs, the exemplary materials supported the pre-service teachers by giving a clearer picture of what to design as well as their learning goals. According to the teachers, these materials provided a theoretical as well as practical insight of SSL, hands-on experience and prompted their decisions on how to proceed with their own designs (cf. Voogt, 2010). Consequently, the development and use of exemplary materials to support teachers during collaborative design is a promising strategy for DTs in the Ghanaian context).

Although findings from this study do not allow for broad generalizations due to the limited scope and specific context, we believe that they provide information about conditions and opportunities of developing experiences of future teachers' integration of technology, pedagogy and content in teacher education programmes in Ghana. As Voogt (2010) explains, gaining more in-depth knowledge in specific contexts can be considered complementary to findings of large scale studies such as those conducted by Penuel et al. (2007) and may result in more specific design guidelines for professionals, who are in charge of teacher professional development aiming at technology integration. In the light of this, the following design guidelines are proposed from the study for use in developing TPACKcompetent pre-service mathematics teachers in our context and other regions with similar context (e.g. Sub-Saharan Africa): 1. Collaborative Design Teams are an important means to stimulate and support teacher learning. This approach of technology integration will move pre-service teachers from being passive learners and consumer of technological resources to being more active learners and producer/designer of technology resources thereby increasing user involvement and local ownership; 2. Exemplary curriculum materials are an important means as they can inspire teachers to learn and provide a better understanding of an 
innovation; 3. For more effective collaboration with the use of the exemplary materials and working in DTs, an orientation programme is important. The orientation is intended to prepare pre-service teachers by giving them the theoretical foundation/concepts (furnishing teachers with the concept of TPACK, a learner-centred approach of teaching and technology-based possibilities of teaching mathematics) as well as practical skills (basic technology acquisition skills, demonstrations of technology-based lesson examples, team co-plan and discussion of lessons and micro/peer teaching) they need to work successfully in teams; 4. Adaption of technology that is readily available and user friendly with the potential of supporting students' higher-order thinking skills in mathematics is key to a successful intervention in integrating technology. This will ensure that pre-service teachers will be designers of technological resources by learning how to use existing hardware and software in creative and situation specific ways to accomplish their teaching goals. Next to this, they can integrate available technology in their daily lesson plans and into traditional classroom practice; and 5. A complete arrangement to develop pre-service mathematics teachers TPACK should encompass technology, both as a tool for learning mathematics content and process as well as a topic for instruction in itself. It is therefore necessary to take small steps and carefully formulate the aims of the arrangement so as to enhance teachers' growth of technology use in instruction.

\subsection{CONCLUSION}

This study supported the contention (Mishra \& Koehler, 2006) that TPACK is a useful analytic lens for studying teachers' integration of technology, content, and pedagogical knowledge as it develops over time in "learning technology by design" settings. Although the study showed the potential of TPACK to be a new frame for developing experiences for future teachers, it cannot be said that the professional development arrangement fully developed the teachers' TPACK. Further opportunities to experience learning about the affordances of technology applications are necessary for teachers to explore further topics and concepts in their mathematics curriculum to develop their TPACK much better. Another challenge is for teachers to extend the initial knowledge, beliefs and dispositions 
for teaching with technology as they contend with the real school barriers of time, access and infrastructure. This will be the focus of our next study; to extend this study on pre-service teachers in the real classroom situation. 


\section{CHAPTER 5}

\section{Pre-service mathematics teachers' learning and teaching of activity-based lessons supported with spreadsheets 5}

In this study 12 pre-service mathematics teachers worked in teams to develop their knowledge and skills in designing and enacting activitybased lessons supported with spreadsheets. Pre-service teachers' lesson plans, their instruction of the lessons designed and the impact of their lesson enactment on students' learning outcomes were examined. The preservice teachers in the study were able to develop and demonstrate their knowledge and skill adequately in designing and enacting activity-based mathematical lessons supported with spreadsheets. The results also showed that, the activity-based lessons supported with spreadsheets served a useful pedagogical approach, impacted on student learning outcomes and has the potential of improving teaching and learning mathematics in secondary education.

\subsection{INTRODUCTION}

In Ghana, mathematics is a required subject at all levels in pre-university education. Due to its importance the government is committed to ensuring the

5 A previous version of this chapter was presented (and published) at SITE annual conference as: Agyei, D.D. \& Voogt, J. (2011). Determining teachers' TPACK through observations and self-report data. In Proceedings of Society for Information Technology E Teacher Education International Conference 2011 (pp. 23142319). Chesapeake, VA: AACE. Available: http://www.editlib.org/p/36652. The current version of this chapter has been submitted as: Agyei, D. D., \& Voogt, J. Pre-service mathematics teachers' learning and teaching of activity-based lessons supported with spreadsheets. Technology Pedagogy and Education. 
provision of high quality mathematics education. Various attempts have been made in the past to improve its success in schools. In spite of government efforts, learning mathematics has not undergone much change in terms of how it is structured and presented and has resulted in consistently low achievement levels among mathematics students in high schools (e.g. see Mullis, Martin, \& Foy 2008; Ottevanger, van den Akker, \& de Feiter, 2007). Among the reasons for these low achievements, the method of teaching mathematics is considered one prominent factor. The most frequently used strategy in mathematics classrooms is the teachercentred (chalk and talk) approach (Ottevanger et al, 2007; Agyei \& Voogt 2011a) in which teachers do most of the talking and intellectual work, while students are passive receptacles of the information provided. This type of teaching is heavily dominated by teachers (while students are silent), involves whole class teaching, lots of notes being copied, and hardly any hands-on activities, where teachers rush to cover all the topics mechanically in order to finish on time for examinations rather than striving for in-depth student learning (Ottevanger et al, 2007). Such teacher-centred instructional methods have been criticized for failing to prepare students to attain high achievement levels in mathematics (Hartsell, Herron, Fang, \& Rathod; 2009). Although these teacher-centred approaches still dominate in mathematics classrooms, curriculum and policy documents in this context suggest student-centred constructivist teaching methods in which learners construct and internalize new knowledge from their experiences (MOE, 2000). For example, the new curriculum in Mathematics at the Senior High School (SHS) places emphasis on skill acquisition, creativity and the arts of enquiry and problem solving (MOESS 2007); but many teachers in Ghana do not have the background knowledge and proper skill set to teach mathematics in this way.

Keong, Horani and Daniel (2005) recommended a constructivist pedagogical approach in teaching mathematics and explained that such an approach is easily supported by technology, where students use technology to explore and reach an understanding of mathematical concepts by concentrating on problem solving processes rather than on calculations related to the problems. So and Kim (2009) indicated that technology can play a critical role in representing subject matter to be more comprehensible and concrete, helping students correct their misconceptions on mathematical concepts, providing cognitive and metacognitive scaffolding, and ultimately improving learning outcomes. Other studies (e.g. 
Beauchamp \& Parkinson, 2008; Bottino \& Robotti, 2007) have reported positive effects of incorporating technology in teaching mathematics to enhance motivation and improve student achievement. In spite of the numerous advantages that come with technology, many maths teachers do not feel proficient in teaching mathematics lessons that take advantage of technology-rich environments.

Technology simply being present in the classroom is not enough (National Council of Teachers of Mathematics, 2000), and the use of technology ultimately is the responsibility left to mathematics teachers. But integrating technology in teaching mathematics is a very complex and difficult task for mathematics teachers. They have to learn to use new technologies appropriately and to incorporate it in lesson plans and lesson enactment. Professional development is therefore critical towards helping pre-service teachers to develop the proper skill set and required knowledge before such instructional change can occur. In this study, a professional development arrangement in which pre-service teachers collaboratively design and use technology -supported lesson teaching materials is carried out for pre-service mathematics teachers. In the study, technology is presented as a tool for enacting a guided activity-based pedagogical approach (referred to as Activity-Based Learning) of teaching mathematical concepts to develop pre-service teachers' knowledge and skills in teaching with technology, in particular spreadsheets, and measure the impact of the lesson enactment on students' learning outcomes.

\subsection{THEORETICAL UNDERPINNINGS}

\subsubsection{Activity-Based Learning (ABL) in mathematics}

$\mathrm{ABL}$ describes a range of pedagogical approaches to teaching mathematics. Its core premises include the requirement that learning should be based on doing hands-on experiments and activities. The idea of ABL is rooted in the common notion that students are active learners rather than passive recipients of information and that learning, especially meaningful learning, engages activity (Churchill \& Wong, 2002). Churchill (2004) argues that an active interaction with a learning object enables construction of learners' knowledge. Accordingly, he believes the goal of ABL is for learners to construct mental models that allow for 'higher-order' performance such 
as applied problem solving and transfer of information and skills. This suggests that in ABL approaches, learners are actively involved, the environment is dynamic, the activities are interactive and student centred and much emphasis is placed on collaboration and exchange of ideas.

Mayer (2004) explains that a basic premise in constructivism is that meaningful learning occurs when the learner strives to make sense of the presented material (or activities) by selecting relevant incoming information, organizing it into a coherent structure, and integrating it with other organized knowledge. Thus Mayer places much emphasis on cognitive activity and learning by thinking instead of depending solely on learning by doing or learning by discussion. He emphasizes on guidance, structure, and focused goals when using an activity-based learning approach and recommends using guided discovery, a mix of direct instruction and hands-on activity, rather than pure discovery. Hmelo-Silver, Duncan and Chinn (2008) indicated that such guided inquiry approaches are not substituting content for practices; rather they advocate that content and practices are central learning goals. Hmelo-Silver, et al., (2008), argued that though it is challenging to develop instruction that fosters the learning of both theoretical frameworks and investigative practices in the development of guided learning environments, such approaches provide the learner with opportunities to engage in scientific practices of questioning, investigation, and argumentation as well as learning content in a relevant and motivating context. Furthermore they indicated that guided inquiry approaches involve the learner with appropriate scaffolding, in the practices and conceptualizations of the discipline in a way that promotes construction of knowledge. This implies that the teachers' role is critical in designing and enacting an activity-based lesson. Their roles should include prompting and facilitating discussion, focusing on guiding students by asking questions and designing activities that will lead learners to develop their own conclusions on mathematical concepts.

\subsubsection{TPACK and Mathematics}

According to Niess, van Zee, and Gillow-Wilese (2010-11), most teachers learned mathematics using paper and pencil, which limited the use of data for exploration and required time to calculate averages and create charts for every change in the variables. With the potential of technologies in maths education however, there is 
need for teachers to create innovative learning experiences that truly engage the power of technology to involve students in higher-order thinking tasks. Thus mathematics teachers are still confronted with challenges and questions of how and when to incorporate such technologies for teaching and learning various subject matter topics (Niess, 2011). For this reason teachers' knowledge and skills for teaching with technology need to be developed (Niess, 2008).

Mishra and Koehler outlined the Technological Pedagogical Content Knowledge (TPACK) framework (Koehler \& Mishra, 2008; Mishra \& Koehler, 2006) in an effort to explain the types of knowledge teachers need to integrate technology into their teaching. TPACK emphasizes the comprehensive set of knowledge and skill teachers need to successfully integrate technology in their instructional practice (Koehler \& Mishra, 2008). Niess (2011) indicated that TPACK strategic thinking includes knowing when, where and how to use domain-specific knowledge and strategies for guiding students' learning with appropriate information and communication technologies. Considering the goal of engaging students in mathematical problem solving for example, a mathematics teacher's TPACK must focus on thinking strategically in planning, organizing, implementing, critiquing results and abstracting plans for specific mathematics content and diverse student needs (Niess, Sadri, \& Lee, 2007).This framework explicitly acknowledges that effective pedagogical uses of technology is deeply influenced by the content domain in which they are situated. Thus the TPACK framework for using technology strategically in classroom instruction does not encourage technology as being a "stand alone" support to mathematics teacher education but as a tool specifically and uniquely applied to mathematics instruction. Subject-specific technological software, such as spreadsheets have been used as pedagogical tool for teaching and learning and have depicted potentials which effective teachers can maximise to develop students' understanding and increased proficiency in mathematics . Niess et al (2010-11) indicated that spreadsheets contain features for modeling and analyzing change; providing teachers with tools that rely on mathematics concepts and processes for accurate analysis. According to Niess et al (2007) teachers who are able to design and enact spreadsheet lessons experience elementary concepts of mathematical modelling, expand their own conceptions of teaching mathematics with spreadsheets, investigate and expand their knowledge of instructional strategies for integrating spreadsheet learning activities, 
develop their own knowledge and skills of spreadsheets as tools for exploring and learning mathematics, and explore curricular materials that support learning with and about spreadsheets over an extended period of time. This redirection exposes the importance of teachers' strategic thinking and actions with respect to integrating technologies as learning tools in mathematics instruction. In this study TPACK has been used as a conceptual framework to examine the knowledge and skills pre-service math teachers developed about technology, pedagogy, and content as they designed and enacted activity-based lessons supported with spreadsheets. As shown in Figure 5.1, the pedagogical knowledge examined in this study was ABL ( $\left.\mathrm{PK}_{\mathrm{ABL}}\right)$.

The technological knowledge $\left(\mathrm{TK}_{\mathrm{ss}}\right)$ learned by the pre-service teachers were spreadsheet applications for mathematics, because it was readily available in SHSs and in teacher Education Colleges (Agyei \& Voogt, 2011a, b), user friendly and had the potential of supporting students' higher-order thinking skills in mathematics (Agyei \& Voogt, 2012; Niess et al., 2007). Content knowledge ( $\mathrm{CK}_{\text {maths }}$ ) was mathematics which was the pre-service teachers teaching subject area.

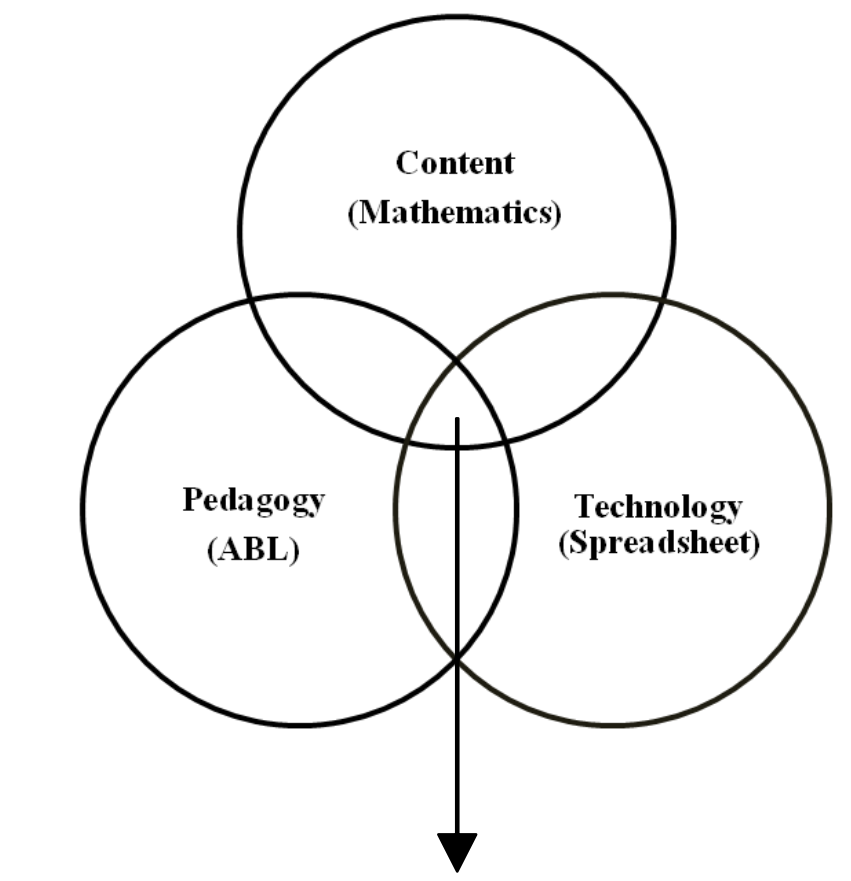

Technological Pedagogical Content Knowledge for spreadsheetsupported $\mathrm{ABL}$ in mathematics (TPACK)

Figure 5.1 Framework of TPACK used in the study 
In the study, pre-service teachers' knowledge and skills which are needed to teach spreadsheet supported ABL lessons in mathematics was operationalised as their TPACK, and consists of the following specific knowledge and skills:

- Content knowledge ( $\left.C K_{\text {maths }}\right)$ : the knowledge about mathematical concepts.

- Pedagogical Knowledge $\left(P K_{A B L}\right)$ : knowledge and skills about applying ABL teaching strategies.

- Technological Knowledge (TK $\left.{ }_{\mathrm{ss}}\right)$ : knowledge and skills about use of spreadsheet its affordances and constraints.

- Pedagogical content knowledge $\left(P C K_{A B L}\right)$ : the knowledge and skills of how to apply ABL to teach particular mathematics content.

- Technological content knowledge $\left(T C K_{s s}\right)$ : the knowledge and skills of representing mathematical concepts in a spreadsheet.

- Technological Pedagogical Knowledge (TPK $K_{A B L}$ ): The knowledge and skills of how to use spreadsheets in ABL.

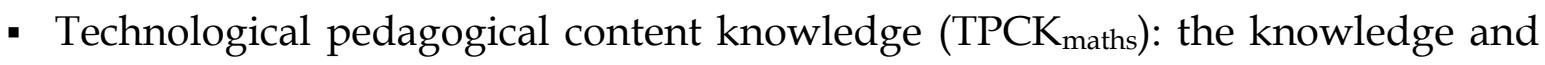
skills of representing mathematical concepts with spreadsheet using $A B L$

\subsection{THE PROFESSIONAL DEVELOPMENT ARRANGEMENT}

The professional development arrangement (PD) was based on 'learning technology by design' (Mishra \& Koehler, 2006) and has been described extensively in Agyei and Voogt (2012). In the PD Pre-service teachers collaboratively designed and enacted spreadsheet-support ABL lessons. The PD consisted of three stages: An introductory workshop for Design Teams (DTs), design of lessons in DTs and implementation of lessons by DT members. The workshop lasted for two weeks and prepared the pre-service teachers by giving them the theoretical foundation/concepts as well as practical skills. Exemplary materials consisting of two models of activity-based lessons supported with spreadsheet that were prepared by the researcher and appraised by an expert with ample experience in the use of technology in teaching mathematics were a necessary component of the PD arrangement. Based on their experiences, the teachers worked in teams of two to develop and model their own lessons (in suitable mathematics topics from the SHS curriculum) after the exemplary 
materials during the design stage (six weeks). In the implementation stage (five weeks) each lesson was enacted by teaching to their peer pre-service teachers and in three secondary high schools. Consequently six activity-based lessons supported with spreadsheet were developed and enacted two times each at different stages of implementation. Table 5.1 gives an overview of the lessons designed and enacted by the pre-service teachers.

Table 5.1 Overview of lessons designed and taught by the pre-service teachers

\begin{tabular}{|c|c|c|c|c|c|}
\hline \multirow[b]{2}{*}{ Lesson } & \multirow{2}{*}{$\begin{array}{c}\text { Peer } \\
\text { Teaching }\end{array}$} & \multicolumn{3}{|c|}{$\begin{array}{l}\text { Actual Classroom } \\
\text { try-outs (SHS) }\end{array}$} & \multirow{2}{*}{$\begin{array}{c}\text { Lesson } \\
\text { Duration } \\
\text { (min) }\end{array}$} \\
\hline & & School & Form & $N$ & \\
\hline Transformation by a Vector (TBV) & 30 & B & 3 & 35 & 80 \\
\hline $\begin{array}{l}\text { Distance between two given points of a line } \\
\text { (DBTGP) }\end{array}$ & 32 & A & 1 & 43 & 40 \\
\hline Trigonometric Functions (TRIG) & 32 & $\mathrm{C}$ & 3 & 42 & 80 \\
\hline Quadratic in Vector Form (QVF) & 34 & B & 2 & 36 & 80 \\
\hline Quadratic in Polynomial Form (QPF) & 31 & A & 2 & 44 & 80 \\
\hline Graphs of Linear Equations (GLE) & 31 & $\mathrm{C}$ & 1 & 25 & 40 \\
\hline
\end{tabular}

Each lesson document comprised a teachers' support or guide to help set up the environment, a plan for lesson implementation and a student worksheet which promoted hands-on activities during lesson implementation. All lessons were taught in a classroom with a computer and a LCD projector available to the teacher. The researcher acted mainly as a facilitator, coach and observer in different stages of the study.

\subsection{RESEARCH QUESTIONS AND RESEARCH DESIGN}

The main research question of the study was: To what extent do pre-service teachers' knowledge and skill in designing and enacting spreadsheet supported ABL lessons develop and impact on secondary school students learning outcomes? The following sub research questions guided the study:

1. To what extent do pre-service teachers demonstrate the knowledge and skills needed to design and enact spreadsheet supported ABL lessons in mathematics? 
2. How do pre-service teachers perceive their own development in the knowledge and skills needed to design and enact spreadsheet supported ABL lessons in mathematics?

3. What was the impact of the spreadsheet-supported ABL mathematics lesson as enacted by the pre-service teachers on secondary school students learning outcomes?

This study was an in-depth investigation of the knowledge and skill needed to design and enact spreadsheet supported ABL lessons of pre-service mathematics teachers in which both quantitative and qualitative data were used. To investigate the impact of the spreadsheet-supported ABL lessons on their students' outcomes, a pre-post test experimental control group design was used.

\subsection{Methods}

\subsubsection{Participants}

Twelve pre-service mathematics teachers participated in the study. The pre-service teachers were in their final year of the mathematics teacher education programme at University of Cape Coast (UCC) in Ghana. The 4-year teacher training programme, allows pre-service teachers to teach at Junior and Senior High School when they graduate. The average age of these pre-service teachers was 26 years. The senior high school students $(n=297)$ who participated in the study were from 3 different high schools. These high school students (from year 1, 2 and 3) were taught lessons by the pre-service teachers. Two hundred and twenty-five of them participated in the activity-based lessons supported with spreadsheet, while 72 of them were taught with the traditional approach and served as a control group.

\subsubsection{Instruments}

In Table 5.2 an overview of the data collecting instruments measuring how pre-service teachers' perceive as well as demonstrate their knowledge and skill and the impact on students for the activity-based lessons supported with spreadsheet is presented. 
Table 5.2 Pre-service teachers' knowledge and skill learning and classroom practices

\begin{tabular}{|c|c|c|c|c|c|c|}
\hline & & & Instr & nents & & \\
\hline $\begin{array}{l}\text { Research } \\
\text { Questions }\end{array}$ & $\begin{array}{l}\text { Lesson } \\
\text { Plan } \\
\text { Rubric }\end{array}$ & $\begin{array}{c}\text { Observation } \\
\text { Rubric }\end{array}$ & $\begin{array}{l}\text { TPACK } \\
\text { Survey }\end{array}$ & $\begin{array}{l}\text { Teacher } \\
\text { Interview }\end{array}$ & $\begin{array}{c}\text { Researcher's } \\
\text { Logbook }\end{array}$ & $\begin{array}{c}\text { Student } \\
\text { Test }\end{array}$ \\
\hline RQ1 & $\begin{array}{c}\checkmark \\
\text { (post) }\end{array}$ & $\begin{array}{c}\checkmark \\
\text { (post) }\end{array}$ & & & $\checkmark$ & \\
\hline RQ2 & & & $\begin{array}{c}\checkmark \\
\text { (pre- } \\
\text { post) }\end{array}$ & $\begin{array}{c}\checkmark \\
\text { (post) }\end{array}$ & & \\
\hline RQ3 & & & & & & $\begin{array}{c}\checkmark \\
\text { (pre- } \\
\text { post) }\end{array}$ \\
\hline
\end{tabular}

Lesson Plan Rubric

A TPACK lesson Plan rubric was adapted from the Technology Integration Assessment Rubric (TIAR) which Harris, Grandgenett, and Hofer (2010) created and tested and found to be a valid and reliable instrument to assess TPACK evident in teachers' written lesson plans. While TIAR is a general rubric to determine TPACK in lesson plans, adaptations were made to fit to TPACK for spreadsheet supported ABL in mathematics. The rubric consisted of seven different criteria (Table 5.3), and was scored as: Not at all (1), Minimal (2) and Strong (3). Interrater reliability (Cohen's $\mathrm{K}=0.91$ ) was calculated using a sample of three lesson plans by two raters. The lessons were first coded (based on the TPACK constructs) and then assessed using the rubric. See Appendix G for an example.

Table 5.3 Criteria for analysing spreadsheet supported ABL lesson plans Appropriately spelt out subject matter of mathematics lesson $\left(C K_{\text {maths }}\right)$

ABL strategies support to mathematics learning ( $\mathrm{PK}_{\mathrm{ABL}}$ )

Clearly designed spreadsheet techniques that can support transfer of knowledge $\left(T K_{s s}\right)$

Support of ABL strategies to mathematics lesson goals $\left(P C K_{A B L}\right)$

Alignment of spreadsheet techniques to mathematics lesson goals $\left(T C K_{s s}\right)$

Support of spreadsheet to ABL strategies (TPK $\left.K_{A B L}\right)$

Fit of mathematics content, ABL strategies and spreadsheet techniques together within the instructional plan (TPCK $\left.K_{\text {maths }}\right)$ 


\section{TPACK Observation Rubric}

The Observation Rubric was adapted from a valid and reliable TPACK-based Technology Integration Observation Instrument (Hofer, Grandgenett, Harris, Swan; 2011) which was developed and used to assess TPACK in observed instruction. Adaptations were made to be able to observe TPACK for spreadsheet supported ABL in mathematics. The observation instrument consisted of 20 items, which could be scored as not at all $=1$, partly observed $=2$ and observed $=3$. The interrater reliability (Cohen's $\mathrm{\kappa}$ ) assessed for two observed lessons was $\mathrm{K}=0.94$. Table 5.4 gives an overview of sample items for each TPACK knowledge type construct that was assessed in lesson three (TRIG).

\section{Table 5.4 Sample items for each TPACK knowledge type construct}

\begin{tabular}{|c|c|c|c|c|}
\hline Sample items & Example of observed or partly & & & \\
\hline Subject matter ( $\left.\mathrm{CK}_{\text {maths }}\right)$ & observed practice & 3 & 2 & 1 \\
\hline $\begin{array}{l}\text { Clearly introducing mathematics } \\
\text { topic and learning goals of lesson }\end{array}$ & $\begin{array}{l}\text { Teacher assisted students to form the } \\
\text { concept of negative angles and to } \\
\text { establish the following relations: } \\
\sin (-\theta)=\sin \left(360^{\theta}-\theta\right)=-\sin (\theta) \\
\cos (-\theta)=\sin \left(360^{\theta}-\theta\right)=\cos (\theta) \\
\tan (-\theta)=\tan \left(360^{\theta}-\theta\right)=-\tan (\theta)\end{array}$ & $\checkmark$ & & \\
\hline \multicolumn{5}{|l|}{ Pedagogical knowledge (PK $\left.{ }_{\mathrm{ABL}}\right)$} \\
\hline $\begin{array}{l}\text { Engaging students in solving } \\
\text { authentic problems using } \\
\text { teaching mathematics } \\
\text { activities(worksheet) }\end{array}$ & $\begin{array}{l}\text { Teacher encouraged students (in teams) } \\
\text { to use calculators and specific values } \\
\text { from (worksheet) to verify } \\
\text { trigonometric solutions. }\end{array}$ & $\checkmark$ & & \\
\hline \multicolumn{5}{|l|}{ Technological knowledge $\left(\mathrm{TK}_{\mathrm{ss}}\right)$} \\
\hline $\begin{array}{l}\text { Demonstrating developed } \\
\text { knowledge in spreadsheet skills }\end{array}$ & $\begin{array}{l}\text { Entering and editing data in cells } \\
\text { allowed for changes in the graphs. }\end{array}$ & $\checkmark$ & & \\
\hline \multicolumn{5}{|l|}{$\begin{array}{l}\text { Pedagogical content knowledge } \\
\left(\text { PCK }_{\mathrm{ABL}}\right)\end{array}$} \\
\hline $\begin{array}{l}\text { Applying ABL approach to } \\
\text { stimulate students interest in } \\
\text { solving mathematics problem }\end{array}$ & $\begin{array}{l}\text { Designed activities assisted students to } \\
\text { find solutions to trigonometric } \\
\text { equations giving them greater } \\
\text { opportunity to consider general rules } \\
\text { test and reformulate hypotheses. }\end{array}$ & $\checkmark$ & & \\
\hline
\end{tabular}


Table 5.4 Sample items for each TPACK knowledge type construct (Continued)

\begin{tabular}{|c|c|c|c|c|}
\hline Sample items & Example of observed or partly & & & \\
\hline Subject matter ( $\left.\mathrm{CK}_{\text {maths }}\right)$ & observed practice & 3 & 2 & 1 \\
\hline $\begin{array}{l}\text { Technological pedagogical } \\
\text { knowledge }\left(\mathrm{TPK} \mathrm{ABL}_{\mathrm{AL}}\right)\end{array}$ & & & & \\
\hline $\begin{array}{l}\text { Engaging students in spreadsheet } \\
\text { based ABL activities }\end{array}$ & $\begin{array}{l}\text { "Zooming" in and out allowed in-depth } \\
\text { investigation and stimulated students' } \\
\text { discussions on worksheet. }\end{array}$ & & $\checkmark$ & \\
\hline $\begin{array}{l}\text { Technological Content } \\
\text { knowledge }\left(\mathrm{TCK}_{\mathrm{ABL}}\right)\end{array}$ & & & & \\
\hline $\begin{array}{l}\text { Introducing fundamental } \\
\text { mathematical concepts by } \\
\text { spreadsheet incorporation }\end{array}$ & $\begin{array}{l}\text { Spreadsheet representations of } \\
\text { trigonometric functions allowed for } \\
\text { demonstrations of a wide range of } \\
\text { graphs and immediate feedback making } \\
\text { learners to concentrate more on } \\
\text { mathematical relationships rather than } \\
\text { on the mechanics of construction. }\end{array}$ & & $\checkmark$ & \\
\hline $\begin{array}{l}\text { Technological Pedagogical and } \\
\left.\text { Content Knowledge } \text { (TPCK }_{\text {maths }}\right)\end{array}$ & & & & \\
\hline $\begin{array}{l}\text { Proper choice of spreadsheet } \\
\text { technique in relation to } \\
\text { mathematical concepts and ABL } \\
\text { pedagogy }\end{array}$ & $\begin{array}{l}\text { Spreadsheet allowed for investigating } \\
\text { the nature of graphs of trigonometric } \\
\text { functions and graphically providing a } \\
\text { visual link between graphs of } \\
\text { trigonometric functions and their } \\
\text { solution sets (making it easy for } \\
\text { students to match graphs of } \\
\text { trigonometric functions and their } \\
\left.\text { solutions on worksheet)( } T P C K_{\text {maths }}\right) \text {. }\end{array}$ & & $\checkmark$ & \\
\hline
\end{tabular}

\section{Pre-service- teachers' TPACK questionnaire}

The questionnaire included items that addressed the pre-service teachers' selfefficacy of their TPACK, adapted from Schmidt, Baran, Thompson, Mishra, Koehler \& Shin (2009) on a five-point Likert scale format (from 1-strongly agree to 5 -strongly disagree). Cronbach's alpha reliability estimates of this instrument ranges from 0.75 to 0.93 (Schmidt et al., 2009).The instrument was adapted and administered two times- before and after the intervention. 
Table 5.5 Sample question for each TPACK knowledge type constructs

\begin{tabular}{|c|c|}
\hline Knowledge & \\
\hline Type & Sample Question For Each Knowledge Type \\
\hline $\mathrm{TK}_{\mathrm{ss}}$ & I frequently play around with spreadsheets \\
\hline $\mathrm{CK}_{\text {maths }}$ & I have sufficient knowledge about mathematics. \\
\hline $\mathrm{PK}_{\mathrm{ABL}}$ & I can adapt ABL teaching style to different learners. \\
\hline $\mathrm{PCK}_{\mathrm{ABL}}$ & $\begin{array}{l}\text { I know how to select effective ABL teaching approaches to guide student } \\
\text { thinking and learning in mathematics. }\end{array}$ \\
\hline TCK $_{\mathrm{ABL}}$ & $\begin{array}{l}\text { I know about spreadsheet applications that I can use for understanding and } \\
\text { doing mathematics }\end{array}$ \\
\hline $\mathrm{TPK}_{\mathrm{ABL}}$ & I can choose spreadsheets application that enhance ABL approaches of a lesson \\
\hline TPCK maths & $\begin{array}{l}\text { I can teach lessons that appropriately combine mathematics concepts, } \\
\text { spreadsheet applications and ABL teaching approaches }\end{array}$ \\
\hline
\end{tabular}

Teachers' responses in the pre-post survey delineated their own development in the perceived knowledge and skills needed to design and enact spreadsheet supported ABL lessons.

\section{Teacher Interviews}

To explore pre-service teachers' knowledge and skills needed to design and enact spreadsheet-supported ABL, interviews were conducted after each teaching session. The interviews were transcribed and coded using the following coding schemes: usefulness of spreadsheet-supported ABL lessons, impact of spreadsheetsupported ABL lessons, lesson design challenges and lesson enactment challenges of activity-based lessons supported with spreadsheet. Two raters coded the interview data using a sample of 5 interviews (from 5 teachers).The interrater reliability (Cohen's $\mathrm{\kappa})$ was $\mathrm{K}=0.92$.

\section{Researcher's Logbook}

The researchers' log book was used to maintain record of activities and events occurring during the design and enactment of the activity-based lessons supported with spreadsheet. The logbook entries complemented findings from the other data collection instruments. Information recorded in the logbook was analyzed qualitatively using data reduction techniques in which major themes (students' participation; teachers' role; use of lesson materials and challenges in enacting activity-based lessons supported with spreadsheet) were identified and clustered (Miles \& Huberman, 1994). 


\section{Student test}

For each of the designed lessons a test was developed by the pre-service teachers, and reviewed by the researcher, to determine student learning outcomes. The same test was conducted pre and post to ascertain the impact of the activity-based lessons supported with spreadsheet during each of the six lessons enacted at the SHS classrooms. Furthermore, two pre-service teachers developed the same lessons $(Q V F$ and $T B V)$ and taught them in a teacher-centred approach without using the spreadsheet-supported ABL pedagogical approach in the same school for comparison purposes.

\subsection{RESULTS}

\subsubsection{Lesson plans}

The teacher's support or guide gave step by step instructions on how to set up the environment (before a lesson is conducted); mainly regarding knowledge and skills about use of spreadsheet (TKss) in inputting numerical data and viewing a plot of the data. For example lessons in GLE and QPF outlined:

Define the values of $\mathrm{m}$ as 1 and $\mathrm{k}$ as 0 in cells B4 and B5 respectively. (This is done by clicking in cell B4... (GLE).

Make up an equation in the form $y=a^{*}(X 1)^{\wedge} 2+b^{*}(X 1)+k$, and enter the formula in cell $\mathrm{Y} 1$ (or in the first cell of the next column you chose). Then use the Fill Down command... (QPF).

The lesson documents made links between the students' worksheet and the activities on the lesson plan to be implemented by the teachers. Examples are:

In this activity, ask students to indicate (by tick $(\sqrt{ })$ ) the features of the equations as shown on the Worksheet (without plotting or solving them) $\left(\mathrm{PCK}_{\mathrm{ABL}}\right)(\mathrm{QVF})$ 
Set the value of $m$ to be zero and continue decreasing the value of $m$ in the cell to negative numbers as students record the changes in the graph on their worksheet $\left(\mathrm{TPK}_{\mathrm{ABL}}\right)(\mathrm{DBTGP})$.

Analysis of the document also showed that specific roles were identified for the teachers as well as the students. Most lessons showed various tasks to be done by students (i.e. observing, recording, exploring etc.) whiles teachers were to guide and instruct during the lesson. These were enumerated in the various lessons:

Get students to observe how the graph changes when a is altered on the spreadsheet (TPCK $\mathrm{maths}_{\text {) }}$ (QVF).

Begin with the graph of the standard function: $\mathrm{y}=\mathrm{x}$ on the spreadsheet and guide students to observe and record how the graph changes when $\mathrm{m}$ changes (TPCK $K_{\text {maths }}$ (GLE).

Prepare students for the following activities (Activities: 1.0 - 3.0) by organizing them in small groups.... (PK $\mathrm{ABL}_{\mathrm{AL}}$ (TBV).

The results of the analysis of the lesson plans are presented in Table 5.6. The highest number of codes (Cds) for TPACK (per lesson) was found in $\mathrm{CK}_{\text {maths }}$ (12) with the total number of codes (TCds) being 67. The analysis showed fairly high TPACK evidence in the teachers' lesson plans documents with the highest mean scores in $\mathrm{PK}_{\mathrm{ABL}}(2.56,0.131)$ and $\mathrm{CK}_{\text {maths }}(2.53,0.084)$ and least mean scores in $\operatorname{TPK}_{\mathrm{ABL}}(2.42,0.028)$. 
Table 5.6 Mean score responses for TPACK in lesson plans $(N=6)$

\begin{tabular}{|c|c|c|c|c|c|c|c|c|c|c|c|c|c|c|}
\hline & \multicolumn{2}{|c|}{ TBV } & \multicolumn{2}{|c|}{ DBTGP } & \multicolumn{2}{|c|}{ TRIG } & \multicolumn{2}{|c|}{ QVF } & \multicolumn{2}{|l|}{ QPF } & \multicolumn{2}{|c|}{ GLE } & \multicolumn{2}{|c|}{ All Lessons } \\
\hline & $C d s$ & $M(S D)$ & $C d s$ & $M(S D)$ & $C d s$ & $M(S D)$ & $C d s$ & $M(S D)$ & $C d s$ & $M(S D)$ & $C d s$ & $M(S D)$ & $T C d s$ & $M(S D)$ \\
\hline TKss & 7 & $2.40(.414)$ & 8 & $2.55(.512)$ & 10 & $2.50(.434)$ & 9 & $2.45(.547)$ & 9 & $2.47(.444)$ & 8 & $2.50(.535)$ & 51 & $2.48(.051)$ \\
\hline $\mathrm{CK}_{\text {maths }}$ & 11 & $2.48(.404)$ & 11 & $2.50(.453)$ & 12 & $2.50(.511)$ & 11 & $2.45(.499)$ & 10 & $2.60(.567)$ & 12 & $2.67(.492)$ & 67 & $2.53(.084)$ \\
\hline $\mathrm{PK}_{\mathrm{ABL}}$ & 8 & $2.46(.557)$ & 9 & $2.45(.349)$ & 9 & $2.49(.475)$ & 9 & $2.60(.541)$ & 10 & $2.55(.486)$ & 9 & $2.80(.447)$ & 54 & $2.56(.131)$ \\
\hline $\mathrm{PCK}_{\mathrm{ABL}}$ & 6 & $2.44(.561)$ & 7 & $2.48(.500)$ & 7 & $2.43(.544)$ & 9 & $2.40(.343)$ & 7 & $2.44(.576)$ & 7 & $2.57(.535)$ & 43 & $2.46(.060)$ \\
\hline $\mathrm{TPK}_{\mathrm{ABL}}$ & 5 & $2.46(.449)$ & 5 & $2.40(.511)$ & 5 & $2.45(.436)$ & 6 & $2.39(.321)$ & 6 & $2.42(.438)$ & 5 & $2.40(.548)$ & 32 & $2.42(.028)$ \\
\hline $\mathrm{TCK}_{\mathrm{ss}}$ & 5 & $2.38(.467)$ & 5 & $2.56(.487)$ & 5 & $2.44(.422)$ & 6 & $2.41(.436)$ & 7 & $2.41(.551)$ & 4 & $2.50(.577)$ & 32 & $2.45(.068)$ \\
\hline $\mathrm{TPCK}_{\text {maths }}$ & 6 & $2.40(.500)$ & 6 & $2.42(.442)$ & 6 & $2.44(.345)$ & 7 & $2.46(.444)$ & 7 & $2.48(.431)$ & 6 & $2.50(.548)$ & 38 & $2.45(.037)$ \\
\hline
\end{tabular}

$C d s=$ Number of codes, TCds $=$ Total Number of codes 


\subsubsection{Lesson enactment}

During lesson enactment, the teachers used their lesson plans to guide class instruction using "interactive demonstration" in a spreadsheet environment. All teachers introduced the fundamental concepts of their lessons by using spreadsheet and gradually engaged their students to develop higher concepts as lessons progressed. For instance in the QVF lesson teachers were able to demonstrate a wide range of examples of graphs by changing variables in cells (on the spreadsheet) without having to draw them physically; learners were able to explore many graphs in a shorter time, giving them greater opportunity to consider general rules and test and reformulate hypotheses. In the TRIG lesson, visual representations of trigonometric functions allowed for immediate feedback, allowing learners to concentrate more on mathematical relationships rather than on the mechanics of construction. The analysis also showed that teachers used the spreadsheet environment and the student worksheet to engage their students in different learning related activities. In the TBV lesson for example, students view presentation, collected data (on coordinates of an object) and made predictions of the image location when the object was rotated by a vector. With the QPF lesson, students collaborated to explore the properties of quadratic functions and presented their work to their peers in teams for peer assessment. The teachers who taught their peers found some difficulty using the spreadsheet to develop mathematical concepts well to support their students 'understanding. For instance it was a struggle for the teacher (lesson QPF, Figure 5.2) to demonstrate that the basic second-degree curve $y=a x^{2}+b x+k$ gives a thinner parabola if $|a|$ is increasing and a flatter parabola if $|a|$ is decreasing. It was also difficult to illustrate that as the absolute value of $m$ increases the graph of $y=m x+k$ become steeper and vice -versa in the lesson on GLE (Figure 5.3). Apparently, what was difficult for the students was to connect the resulting changes in the graph (which is wider or steeper?) to changes in the numerically values (teachers displayed graph after graph on the same spreadsheet when the co-efficients were altered). Such similar difficulties were encountered in the other lessons as well. The corresponding subsequent lessons for secondary school students were less of a struggle. The teachers were able to present the concepts better by demonstrating the different values of the co-efficients with their respective graphs on the same spreadsheet as shown below for lessons QPF and GLE. 

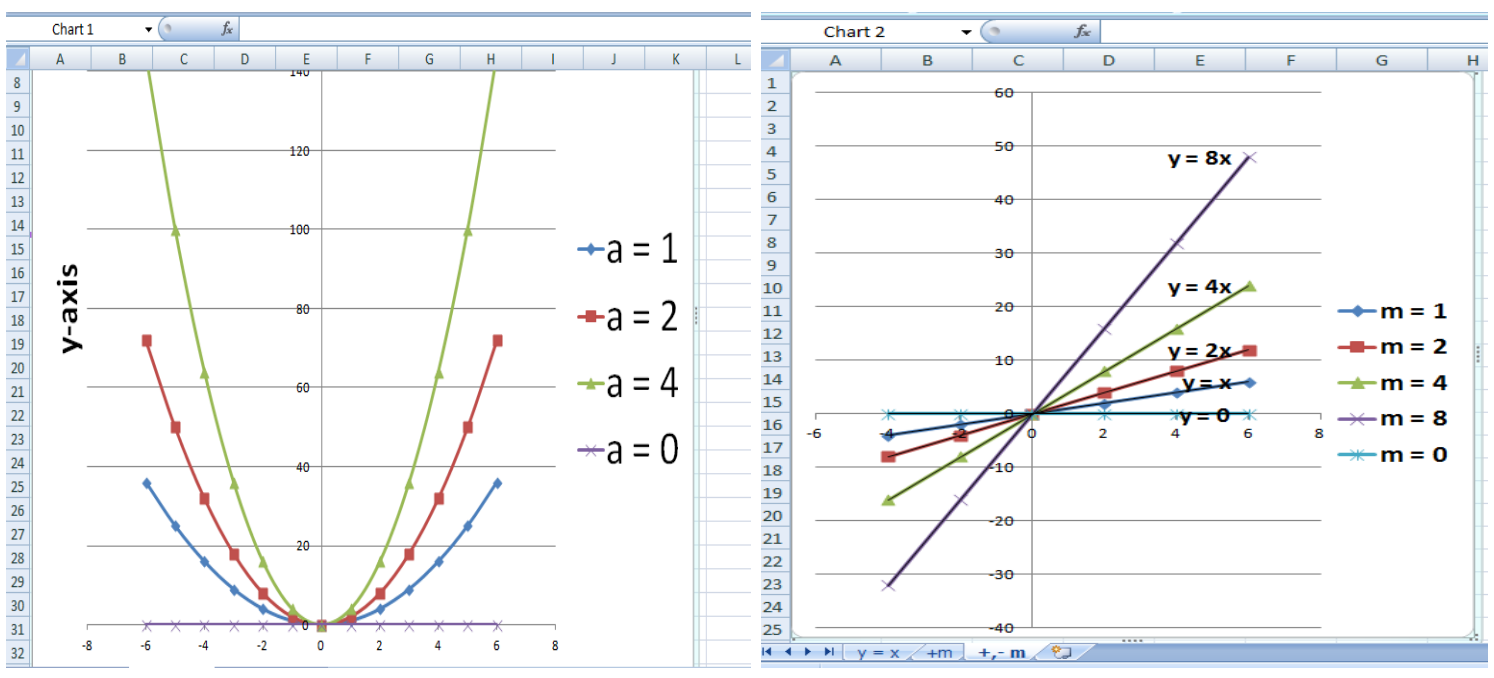

Figure 5.2 Graph of $\mathrm{y}=\mathrm{ax} \mathrm{x}^{2}+\mathrm{bx}+\mathrm{k} \quad$ Graph of $\mathrm{y}=\mathrm{mx}+\mathrm{k}$

This suggests that the results and insights learned from the teaching try-outs (peer teaching) served as necessary inputs for the classroom teachers in revising and implementing their designs particularly in spreadsheet-related constructs: $\mathrm{TK}_{\mathrm{ss}}$, $\mathrm{TPK}_{\mathrm{ABL}}, \mathrm{TCK}_{\mathrm{ABL}}$ and $\mathrm{TPCK}_{\text {maths. }}$ As a result their final designs reflected relatively high scores for $\mathrm{TK}_{\mathrm{ss}}, \mathrm{TPK}_{\mathrm{ABL}}, \mathrm{TCK}_{\mathrm{ABL}}$ and $\mathrm{TPCK}_{\text {maths }}$ (see Table 5.7). Table 5.7 shows that differences in this constructs $\mathrm{TK}_{\mathrm{ss}}, \mathrm{TPK}_{\mathrm{ABL}}, \mathrm{TCK}_{\mathrm{ABL}}$ and $\mathrm{TPCK}_{\text {maths }}$ for the peer teachers and classroom teachers were significant $(p=0.021,0.019,0.006$ and 0.005) with large effect sizes. 
Table 5.7 Wilcoxon test results for peer teaching and classroom teaching mean score responses for TPACK Subscales $(N=6)$

\begin{tabular}{|c|c|c|c|c|c|c|c|c|c|}
\hline & TBV & DBTGP & TRIG & QVF & QPF & GLE & Overall & Sig & Effect \\
\hline $\mathrm{TK}_{\mathrm{ss}}$ & Mean(SD) & Mean(SD) & Mean(SD) & Mean(SD) & Mean(SD) & Mean(SD) & Mean(SD) & $(\mathrm{P})$ & Size \\
\hline CT & $2.33(0.712)$ & $2.45(0.654)$ & $2.33(0.489)$ & $2.29(0.543)$ & $2.33(0.312)$ & $2.40(0.442)$ & $2.35(0.057)$ & $0.021^{* *}$ & 2.2 \\
\hline PT & $2.23(0.357)$ & $2.33(0.567)$ & $2.33(0.457)$ & $2.30(0.359)$ & $2.22(0.352)$ & $2.24(0.349)$ & $2.27(0.052)$ & & \\
\hline \multicolumn{10}{|c|}{$\mathrm{CK}_{\text {maths }}$} \\
\hline $\mathrm{CT}$ & 2.57(0.389) & 2.65 (0.444) & $2.57(0.383)$ & $2.57(0.374)$ & $2.62(0.546)$ & $2.64(0.534)$ & $2.61(0.039)$ & \multirow[t]{2}{*}{0.970} & \multirow[t]{2}{*}{0.03} \\
\hline PT & $2.57(0.459)$ & $2.64(0.453)$ & $2.57(0.309)$ & $2.57(0.446)$ & $2.62(0.443)$ & $2.63(0.453)$ & $2.60(0.034)$ & & \\
\hline \multicolumn{10}{|c|}{$\mathrm{PK}_{\mathrm{ABL}}$} \\
\hline $\mathrm{CT}$ & $2.47(0.462)$ & $2.62(0.435)$ & $2.53(0.432)$ & $2.54(0.415)$ & $2.60(0.472)$ & $2.62(0.531)$ & $2.56(0.059)$ & \multirow[t]{2}{*}{0.938} & \multirow[t]{2}{*}{0.065} \\
\hline PT & $2.50(0.301)$ & $2.62(0.421)$ & $2.52(0.377)$ & $2.53(0.501)$ & $2.59(0.401)$ & $2.61(0.654)$ & $2.56(0.050)$ & & \\
\hline \multicolumn{10}{|c|}{$\mathrm{PCK}_{\mathrm{ABL}}$} \\
\hline $\mathrm{CT}$ & $2.36(0.430)$ & $2.51(0.440)$ & $2.38(0.444)$ & $2.40(0.523)$ & $2.41(0.569)$ & $2.46(0.476)$ & $2.42(0.055)$ & \multirow[t]{2}{*}{0.940} & \multirow[t]{2}{*}{-0.05} \\
\hline PT & $2.36(0.521)$ & $2.52(0.421)$ & $2.39(0.435)$ & $2.40(0.528)$ & $2.42(0.529)$ & $2.45(0.555)$ & $2.42(0.057)$ & & \\
\hline \multicolumn{10}{|c|}{$\mathrm{TPK}_{\mathrm{ABL}}$} \\
\hline $\mathrm{CT}$ & $2.25(0.628)$ & $2.42(0.528)$ & $2.25(0.458)$ & $2.21(0.436)$ & $2.33(0.514)$ & $2.38(0.625)$ & $2.30(0.082)$ & \multirow[t]{2}{*}{$0.019^{* *}$} & \multirow[t]{2}{*}{1.7} \\
\hline PT & $2.19(0.309)$ & $2.15(0.409)$ & $2.22(0.432)$ & $2.18(0.459)$ & $2.11(0.613)$ & $2.27(0.556)$ & $2.19(0.055)$ & & \\
\hline \multicolumn{10}{|c|}{$\mathrm{TCK}_{\mathrm{ss}}$} \\
\hline $\mathrm{CT}$ & $2.25(0.652)$ & $2.44(0.772)$ & $2.26(0.656)$ & $2.22(0.552)$ & $2.38(0.543)$ & $2.33(0.452)$ & $2.31(0.086)$ & \multirow[t]{2}{*}{$0.006^{*}$} & \multirow[t]{2}{*}{2.5} \\
\hline PT & $2.19(0.313)$ & $2.11(0.613)$ & $2.21(0.546)$ & $2.18(0.624)$ & $2.19(0.524)$ & $2.09(0.513)$ & $2.16(0.049)$ & & \\
\hline \multicolumn{10}{|c|}{ TPCK $_{\text {maths }}$} \\
\hline $\mathrm{CT}$ & $2.25(0.852)$ & $2.42(0.652)$ & $2.25(0.657)$ & $2.20(0.605)$ & $2.30(0.652)$ & $2.38(0.654)$ & $2.30(0.085)$ & \multirow[t]{2}{*}{$0.005^{*}$} & \multirow[t]{2}{*}{2.08} \\
\hline PT & $2.01(0.708)$ & $2.12(0.568)$ & $2.15(0.507)$ & $2.14(0.567)$ & $2.25(0.654)$ & $2.11(0.564)$ & $2.13(0.076)$ & & \\
\hline
\end{tabular}

Note: ${ }^{*}=\mathrm{p}<.01,{ }^{* *}=\mathrm{p}<.05, \mathrm{CT}=$ Classroom teaching, $\mathrm{PT}=$ Peer teaching. 


\subsubsection{Pre-service teachers' self-reported TPACK development}

Table 5.8 gives a summary of the results of the respondents' pre- and post-test means for all seven TPACK sub-scales in a one-tailed Wilcoxon test.

Table 5.8 Wilcoxon test results for pre- and post-test mean score responses for TPACK subscales $(N=12)$

\begin{tabular}{|c|c|c|c|c|}
\hline TPACK Sub-scales & Mean (SD) & $\mathbf{Z}$ & $\mathbf{P}$ & Effect size \\
\hline \multicolumn{5}{|l|}{$\mathrm{TK}_{\mathrm{ss}}$} \\
\hline Pre-test & $2.93(0.712)$ & -3.06 & $0.002^{*}$ & 2.40 \\
\hline Post-test & $4.27(0.357)$ & & & \\
\hline \multicolumn{5}{|l|}{$\mathrm{CK}_{\text {maths }}$} \\
\hline Pre-test & $4.14(0.389)$ & -2.21 & $0.027^{* *}$ & 0.70 \\
\hline Post-test & $4.44(0.459)$ & & & \\
\hline \multicolumn{5}{|l|}{$\mathrm{PK}_{\mathrm{ABL}}$} \\
\hline Pre-test & $4.05(0.462)$ & -2.55 & $0.011^{* *}$ & 1.15 \\
\hline Post-test & $4.50(0.301)$ & & & \\
\hline \multicolumn{5}{|l|}{$\mathrm{PCK}_{\mathrm{ABL}}$} \\
\hline Pre-test & $4.00(0.430)$ & -2.45 & $0.014^{* *}$ & 1.05 \\
\hline Post-test & $4.50(0.521)$ & & & \\
\hline \multicolumn{5}{|l|}{$\mathrm{TPK}_{\mathrm{ABL}}$} \\
\hline Pre-test & $3.18(0.628)$ & -2.94 & $0.003^{*}$ & 2.62 \\
\hline Post- test & $4.48(0.309)$ & & & \\
\hline \multicolumn{5}{|l|}{$\mathrm{TCK}_{\mathrm{ss}}$} \\
\hline Pre-test & $3.17(0.652)$ & -3.02 & $0.003^{*}$ & 2.61 \\
\hline Post-test & $4.50(0.313)$ & & & \\
\hline \multicolumn{5}{|l|}{$\mathrm{TPCK}_{\text {maths }}$} \\
\hline Pre-test & $2.63(1.052)$ & -3.06 & $0.002^{*}$ & 2.38 \\
\hline Post-test & $4.47(0.308)$ & & & \\
\hline
\end{tabular}

Note: ${ }^{*}=\mathrm{p}<.01,{ }^{* *}=\mathrm{p}<.05$.

The results showed significant changes in all components of TPACK with largest areas of change occurring in subscales related to technology integration knowledge and skills: $\mathrm{TPK}_{\mathrm{ABL}}\left(\right.$ gain = 2.62), $\mathrm{TCK}_{\mathrm{ss}}$ (gain = 2.61), $\mathrm{TK}_{\mathrm{ss}}$ (gain = 2.40) and $\mathrm{TPCK}_{\text {maths }}$ (2.38). The next two sub-scales with the highest change were $\mathrm{PK}$ ABL (gain = 1.15) and $\mathrm{PCK}_{\mathrm{ABL}}$ (gain =1.05), and both differences were statistically significant at 0.05 level. The teachers' responses in CK maths (gain=0.70) reported a fairly low gain, but was also significant at 0.05 level. A possible reason for the relatively low gains in the teachers' $\mathrm{PK}_{\mathrm{ABL}}, \mathrm{PCK}_{\mathrm{ABL}}$ and $\mathrm{CK}_{\text {maths }}$ compared to $\mathrm{TK}_{\mathrm{ss}}, \mathrm{TCK}_{\mathrm{ss}}, \mathrm{TPK}_{\mathrm{ABL}}$ and $\mathrm{TPCK}_{\text {maths }}$ was the difficulty in assessing their own abilities needed to design and enact ABL lessons. Apparently, the pre-service teachers initially rated themselves high on the 
$\mathrm{PK}_{\mathrm{ABL}}$ and PCK $\mathrm{ABL}$ scales (because of their perceived knowledge and skills on pedagogical issues and its application in teaching mathematics content), while this was not the case with the technology-related subscales which they perceived as new; they basically realized that $\mathrm{PK}{ }_{\mathrm{ABL}}$ and $\mathrm{PCK}_{\mathrm{ABL}}$ were also new. Furthermore, the teachers initially rated their $\mathrm{CK}_{\text {maths }}$ as high, but might have expanded their knowledge about some mathematical concepts not because it was new, but because they realized they did not yet completely understand these concepts. These observations were reiterated in the interview data. For instance three teachers indicated:

and my understanding in quadratics was broadened as we explored the teaching activities we had designed in our lesson ( $\left.\mathrm{CK}_{\text {maths }}\right)$ (T52).

I have learnt a great deal of activity-based pedagogical approach of teaching mathematics and I hope to use it extensively in my future lessons $\left(\mathrm{PK}_{\mathrm{ABL}}\right)(\mathrm{T} 41)$.

By observing how changes in the variables had immediate feedback on the graph, I got first-hand information on the role played by each part of the equation ( $\left.\mathrm{PCK}_{\mathrm{ABL}}\right)(\mathrm{T} 44)$.

In the interview teacher reported on the usefulness, impact and several challenges in designing and enacting spreadsheet-supported ABL lessons. The teachers indicated that spreadsheet-supported ABL served a useful pedagogical approach for a number of reasons (Table 5.9).

Table 5.9 Interview responses for designing and teaching ABL (N=12)

\begin{tabular}{|c|c|c|}
\hline Question & Response & $f$ \\
\hline \multirow{3}{*}{$\begin{array}{l}\text { What are your } \\
\text { reflections on the } \\
\text { spreadsheet-supported } \\
\text { ABL lessons? }\end{array}$} & Promotes collaborative learning & 12 \\
\hline & Promotes active learning & 12 \\
\hline & $\begin{array}{l}\text { Allow teachers more time to reflect on the learning } \\
\text { that is taking place }\end{array}$ & 8 \\
\hline \multirow{3}{*}{$\begin{array}{l}\text { How, do you think the } \\
\text { approach helped your } \\
\text { students to learn? }\end{array}$} & $\begin{array}{l}\text { Helped student evaluate their own work and that } \\
\text { of others }\end{array}$ & 10 \\
\hline & Helped students share their evaluations & 9 \\
\hline & $\begin{array}{l}\text { Helped students to be responsible for their own } \\
\text { learning }\end{array}$ & 9 \\
\hline
\end{tabular}


According to them, spreadsheet demonstrations of the mathematical concepts generated active interactions among their students and in most cases supported their students to develop their own knowledge in higher concepts. Two teachers explained in an interview:

Indeed I have been taught trigonometric functions before and I taught a similar lesson during my off-campus teaching practice; but the use of the spreadsheet in this lesson made it more practical promoting students' involvement (T41).

......to me it was far better than the normal teaching in the SHS classroom because the lesson was more practical and the concepts were easier to develop (T11).

While pre-service teachers in the study understood the importance of using the spreadsheet-supported ABL approach, they indicated that implementing spreadsheet-supported ABL could be time consuming. A number of them found difficulty in completing lessons within the stipulated time.

Another challenge the pre-service teachers faced had to do with the design process itself. They reported the following problematic and difficult areas they had experienced during the design of their lesson: designing authentic learning activities for their chosen topics as well as selecting and matching appropriate integrating spreadsheet tools and relevant resources in designing mathematics learning activities. The pre-service teachers also reported that it was time consuming to develop activity-based lessons supported by spreadsheet. For example in team two, a member indicated:

In designing the learning activities for our students' worksheet, we went through a lot of thoughts. We had difficulty designing a task that will promote active learning and at the same time help student consolidate their learning (T21).

The second member of the same team also indicated:

We had to strike a balance between making the activities suitable for collaborative learning and at the same time meeting the learning 
objectives. In addition, the activities had to be innovative and creative, so it took us a long time in accomplishing this task (T22).

The following responses confirmed teachers' challenges in selecting appropriate integrating spreadsheet tools and relevant resources in their designing activities:

With the options of spreadsheet capabilities, it was difficult for us to select the appropriate applications in designing the teaching activities in our lesson (T11);

It was difficult to think of appropriate spreadsheet applications that tied in with the topic (Trigonometric functions) we taught (T32);

Deciding on what concepts that needed the incorporation of spreadsheet application was a struggle in our case..., (T51).

In spite of this, pre-service teachers were of the view that implementation of the spreadsheet-supported ABL reflected good practices of learner-centredness in their classrooms.

\subsubsection{Student cognitive outcomes}

A paired sample t-test showed significant $(\mathrm{p}<0.0001)$ difference in the learning outcomes of the pre- and post-test scores with large effect sizes (ranging from 1.19 - 4.47) for all six lessons. For two lessons (QVF and TBV) it was possible to compare the mean gains test scores for students following the spreadsheetsupported ABL (SSL) lesson and those of the traditional approach (TM). Table 5.10 provides an overview of the results.

Table 5.10 Mean gain test score between spreadsheet-supported ABL (SSL) and traditional approach (TM)

\begin{tabular}{|c|c|c|c|c|c|c|}
\hline \multirow[b]{2}{*}{ Lessons } & \multicolumn{2}{|c|}{ SSL } & \multicolumn{2}{|c|}{ Traditional(TM) } & \multirow{2}{*}{$\begin{array}{l}\text { Effect } \\
\text { Size }\end{array}$} & \multirow{2}{*}{$\begin{array}{c}\text { Sig } \\
P\end{array}$} \\
\hline & $\begin{array}{l}\text { Mean } \\
\text { Gain }\end{array}$ & SD & $\begin{array}{l}\text { Mean } \\
\text { Gain }\end{array}$ & SD & & \\
\hline QVF (SSL=36, TM=34) & 4.28 & 1.523 & 3.15 & 1.258 & 0.81 & $0.001^{*}$ \\
\hline TBV $(\mathrm{SSL}=35, \mathrm{TM}=38)$ & 1.86 & 1.258 & 1.08 & 1.399 & 0.59 & $0.015^{*}$ \\
\hline Overall (SSL=71, TM=72) & 3.08 & 1.849 & 2.06 & 1.686 & 0.58 & $0.001^{*}$ \\
\hline
\end{tabular}

Note: ${ }^{*} \mathrm{p}<0.05$. 
Table 5.10 indicated high mean gains for the lesson on QVF. A possible reason which explains the relatively high mean values was that the lesson was taught the second time in the classes involved. Differences in both lessons (QVF = $0.001, \mathrm{TBV}=0.015)$ proved to be significant with effect sizes ( $\mathrm{QVF}=0.81$, $\mathrm{TBV}=0.59)$. The overall difference between the means $(\mathrm{SSL}=3.08, \mathrm{TM}=2.06)$ for both lessons was significant $(p=0.001)$ with effect size 0.58 indicating that the spreadsheet-supported ABL lessons impacted more positively on the students' outcomes. Figure 5.3 shows the mean different gains between the two approaches: SSL's and TM lessons.

\subsection{DiscussiON}

In this study, pre-service mathematics teachers collaboratively designed and used spreadsheet teaching materials to enact an ABL within a mathematics classroom context. In particular, the study sought to measure the extent to which the pre-service teachers were able to develop and demonstrate the knowledge and skill needed to design and enact spreadsheet-supported ABL lessons and the impact of pre-service teachers' enactment of the lessons on secondary school students learning outcomes. The lesson documents and lesson enactment showed that the pre-service teachers employed a mix of direct instruction and hands-on activity to guide students through activities in which the students explored, conjectured, verified, generalized, and applied results to other settings and realistic mathematical problems consistent with other studies (Mayer, 2004; Hmelo-Silver, et al., 2008). The teachers used spreadsheet extensively to give greater opportunity to verify results and consider general rules, make links between spreadsheet formula, algebraic functions and graphs, analyse and explore number patterns and graphs within a shorter time and allow for many numerical calculations simultaneously, helping their students explore mathematics concepts and perform authentic tasks. This confirms similar studies (Özgün-Koca, Meagher \& Edwards 2010), that pre-service teachers' understanding of technology shifts from viewing technology as a tool for reinforcement into viewing technology as a tool for developing student understanding of mathematical concepts.

The study also showed that the ABL approach prompted clearly defined roles for both students and teachers. Students worked collaboratively in groups, had 
the opportunity to evaluate their own work and that of others sharing their evaluations. The role of the teachers on the other hand, depicted them more as facilitators than dispensers of knowledge; managing the context and setting and assisting students in developing mathematical concepts through activities.

The teachers demonstrated knowledge and skills in designing and enacting activity-based lessons supported with spreadsheet in their lesson plan products and observed instruction. This was confirmed by their perceived development in the knowledge and skill needed to design and enact spreadsheet-supported $\mathrm{ABL}$ lessons as were observed by significant gains in all the TPACK components of the teachers' self -reported data.

In particular, the teachers perceived that their knowledge and skills had developed more in areas which the ' $\mathrm{T}$ ' is involved compared to their $\mathrm{PK}_{\mathrm{ABL}}$, $\mathrm{CK}_{\text {maths }}$ and $\mathrm{PCK}_{\mathrm{ABL}}$. A possible reason for the relatively low gains in the teachers' $\mathrm{PK}_{\mathrm{ABL}}$ and $\mathrm{PCK}_{\mathrm{ABL}}$ was the difficulty in assessing their own abilities in an unknown knowledge/skill domain. The teachers' initially rated themselves high on $\mathrm{PK}_{\mathrm{ABL}}$ and $\mathrm{PCK}_{\mathrm{ABL}}$, but after having experienced the potential of $\mathrm{ABL}$ lessons they might have realized that they never had considered other pedagogical approaches than the ones they were used to. The findings also illuminate that, the teachers initially rated their $\mathrm{CK}_{\text {maths }}$ as high, but expanded their own understanding of mathematical concepts as they explored the spreadsheet-supported ABL lessons pedagogical approach. Thus, findings of the study suggest that as novice teachers, the new experience with spreadsheet and ABL impacted on their knowledge and skills regarding all the TPACK constructs.

In spite of the advantages of the pedagogical approach, the teachers reported some difficulties in applying their knowledge and skill designing and enacting activity-based lessons supported with spreadsheet. The areas they identified to be particularly challenging and difficult included: selecting and integrating appropriate spreadsheet tools and relevant spreadsheet application in designing authentic learning activities for selected topics. It is apparent that the range of spreadsheet capabilities is limited and that for many mathematics concepts spreadsheet applications are not relevant. As a result, most teachers might have experienced difficulty in making spreadsheet application choices and in matching learning activities which they employed in their instructional plans. The context-sensitive factor in which pre-service teachers have been deep-rooted in teacher-centered learning approach could have influenced their thinking and 
practices. The concern of time was reiterated by the teachers; indicating that conducting a spreadsheet-supported ABL lessons involved a lot of time and required a kind of subject-specific training with technology. These drawbacks notwithstanding, the spreadsheet-supported ABL impacted their secondary students learning outcomes. The test pre-post test scores for the lessons had improved significantly in all the lessons. The mean gains in the spreadsheetsupported ABL approach compared to the traditionally taught lessons showed significance difference with an medium to high effect size which confirms previous studies (cf. Keong, Horani \& Daniel, 2005) that technology use improves the way mathematics is taught and enhances students' understanding of basic concepts and have positive effect on student achievement in mathematics (cf. Bottino \& Robotti, 2007; Beauchamp \& Parkinson, 2008).

Findings of the study showed that $\mathrm{ABL}$ pedagogy can play a vital role in enhancing pre-service teachers' skill and their experience to integrate technology in their future classes. Furthermore the study supports arguments that spreadsheet-supported ABL approach fostered learner-centered classroom practices and has potential of improving mathematics achievement in senior high schools. The results also indicated that in spite of design challenges, exposing teachers to activity-based learning supported with spreadsheet is a good way to help pre-service teachers develop deeper connections between their subject matter, instructional strategy and spreadsheet application fostering knowledge base of TPACK. Such a conclusion poses a question on TPACK's applicability in different context and technologies to assess teachers on a more generic level. Therefore, the study contends that for teachers to understand and develop knowledge/skill related to TPACK in a valid and reliable way, it is important for them to focus on a specific content as well as specific pedagogical approach in which a specific technology can be integrated. This aligns to Shulman (1986) idea of a teachers' PCK characterized as: knowledge of the most regularly taught topics in one's subject area, the most useful forms of representation of those ideas, the most powerful analogies, illustrations, examples, explanations, and demonstrations ... including an understanding of what makes the learning of specific concepts easy or difficult ( $p$. 9).A possible next step of this study will be to scale up the professional development approach to the institutional level to foster adoption of the innovation by many pre-service teachers. Accordingly, a mathematicsspecific Instructional Technology course, incorporating findings of this study, to develop pre-service teachers' knowledge and skill in teaching mathematics with technology using ABL pedagogical approach is recommended. 


\section{CHAPTER 6}

\section{Pre-service teachers' competencies for technology integration: Insights from a mathematics-specific instructional technology course ${ }^{6}$}

The study aimed at exploring design guidelines to develop pre-service teachers' spreadsheet integration competencies in teaching mathematics. In this respect, 104 pre-service mathematics teachers from one of the major pre-service teacher preparation programmes in Ghana enrolled in an instructional technology course for one semester. The following guidelines aligning theory and practice, collaborative design, learning technology by design, modeling how to use technology and scaffolding authentic technology experiences were applied in designing the mathematic-specific course. The teachers' competencies were assessed in their learning outcomes (lesson plans and lesson implementation), their self-reported TPACK, and their attitudes towards technology. Findings showed that in spite of design challenges, their technology integration competencies improved as were reported in their selfreported and learning outcome measures after the teachers' participation in the semesters' IT course. In particular, the learning outcome data provided information, in which pre-service teachers demonstrated spreadsheet integration competencies by providing specific information and concrete representations of what they could actually do with technology. Evidence from the study showed that all guidelines were considered important, but in particular, scaffolding

6 A previous version of this chapter was presented (and published) at SITE annual conference as: Agyei, D. \& Voogt, J. (2012). Pre-service teachers' competencies for technology integration: Insights from a mathematics-specific instructional technology course. In P. Resta (Ed.), Proceedings of Society for Information Technology \& Teacher Education International Conference 2012 (pp. 1094-1099). Chesapeake, VA: AACE. Available: http://www.editlib.org/p/39722. The current version of this chapter has been submitted as: Agyei, D. D., \& Voogt, J. Pre-service teachers' competencies for technology integration: Insights from a mathematics-specific instructional technology course. Educational Technology Research and Development. 
authentic technology experiences including feedback from teaching tryouts made a significant contribution to the teachers' developed technology integration competencies.

\subsection{INTRODUCTION}

In spite of positive impact of the use of technology on students' mathematics achievement (Beauchamp \& Parkinson, 2008; Bottino \& Robotti, 2007), evidence suggests that pre-service teachers do not feel prepared to effectively use technology in their classrooms (e.g. Kay 2006). Recent calls have indicated that to prepare pre-service teachers for effective technology integration, teacher education programmes need to help pre-service teachers to build knowledge of sound pedagogical practices, technology skills, and content knowledge, as well as how these knowledge domains relate to one another (Koehler \& Mishra, 2008; Mishra \& Koehler, 2006). Kay (2006) indicated that there is no consolidated picture on how to effectively introduce technology to pre-service teachers. A comprehensive description and evaluation of strategies is a necessary step to guide researchers and educators. The purpose of this paper is to explore the impact of design guidelines applied in a designing mathematicsspecific instructional technology course on pre-service teachers' competencies to integrate technology in their lessons. The study has been conducted in one of the major pre-service teacher preparation programmes in Ghana.

\subsection{THEORETICAL UNDERPINNINGS}

\subsubsection{Technology integration in mathematics: Pre-service teachers competencies}

With the potential of technology, there is need for (pre-service) mathematics teachers to redefine classroom environments to create learning experiences that engage the power of technology to involve students in learning mathematics. Pre- service mathematics teachers feel confronted with challenges and questions on how to develop their knowledge and skills for teaching and learning mathematics topics with technology (Niess, 2011). Alongside the need to develop their knowledge and skills, also teachers' attitudes towards technology 
integration need to be understood to appropriately determine competencies which (pre-service) mathematics teachers need to integrate technology into their lessons. A body of literature on teachers' use of computers in instruction shows that attitude plays a key role in determining computer use as a learning tool and determining the likelihood that teachers will use technology for teaching and learning (Agyei and Voogt, 2011b; Christensen \& Knezek, 2008).To determine the type of knowledge and skills teachers need to integrate technology into their instructional practice, Mishra and Koehler introduced the technological pedagogical content knowledge (TPACK) framework (Koehler \& Mishra, 2008; Mishra \& Koehler, 2006). The framework explicitly acknowledges that effective pedagogical use of technology is deeply influenced by the content domain in which they are situated. In this study TPACK has been used as a conceptual framework to examine the knowledge and skills pre-service mathematics teachers develop as they design and enact activity-based lessons supported with technology as part of an instructional technology course. As shown in Figure 6.1, the technology $\left(\mathrm{TK}_{\mathrm{ss}}\right)$ learned by the pre-service teachers were spreadsheet applications for mathematics. Spreadsheet software is readily available in Ghana's senior high schools. Niess, van Zee \& Gillow-Wilise (201011) indicated that spreadsheets contain features for modelling and analyzing change, providing teachers with tools that support mathematics concepts and processes for accurate analysis. The pedagogical knowledge ( $\mathrm{PK}_{\mathrm{ABL}}$ ) examined in this study was Activity-Based Learning (ABL). The idea of ABL is rooted in the common notion that students are active learners rather than passive recipients of information (Churchill \& Wong, 2002). ABL was used to ensure that teaching and learning was based on hands-on activities. Content knowledge ( $\left.\mathrm{CK}_{\text {maths }}\right)$ was mathematics which was pre-service teachers' teaching subject area. 


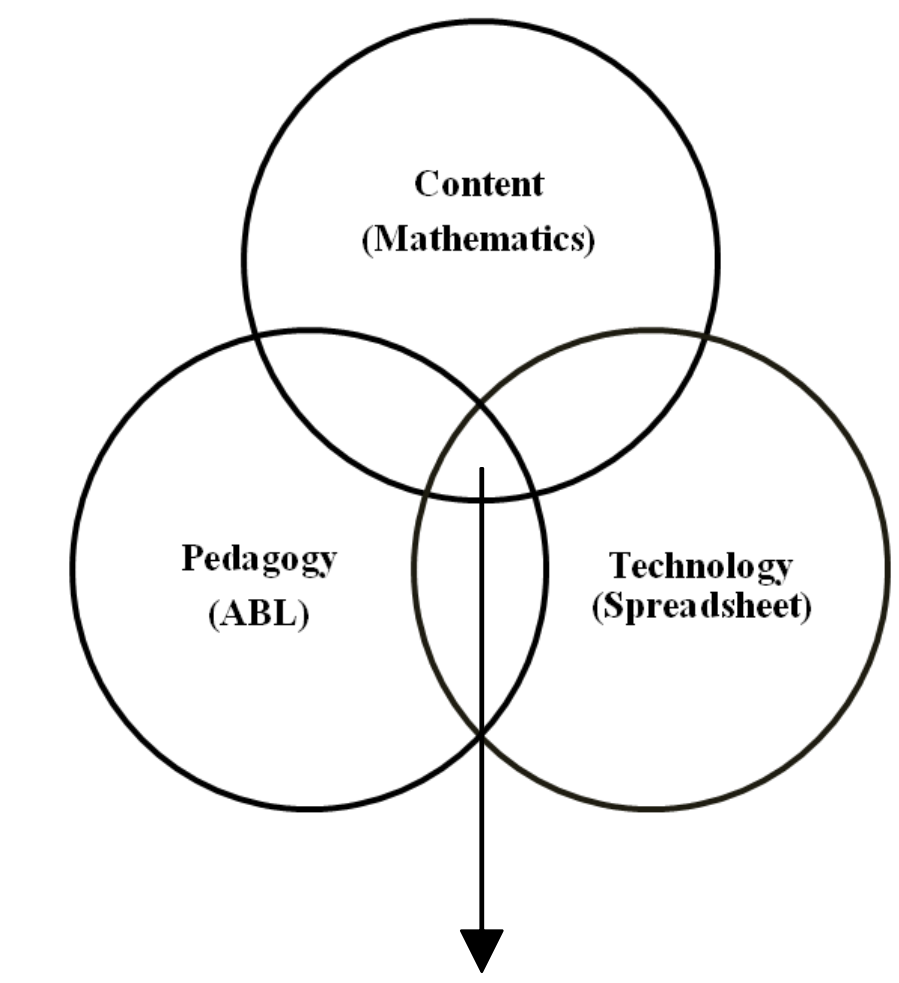

Technological Pedagogical Content Knowledge for spreadsheetsupported ABL in mathematics (TPACK)

Figure 6.1 Framework of TPACK used in the study

In this study, the TPACK components are defined as follows:

- Content knowledge ( $\left.C K_{\text {maths }}\right)$ : the knowledge about mathematical concepts.

- Pedagogical Knowledge $\left(P K_{A B L}\right)$ : knowledge and skills about applying ABL teaching strategies.

- Technological Knowledge ( $\mathrm{TK}_{\mathrm{ss}}$ ): knowledge and skills about use of spreadsheet its affordances and constraints.

- Pedagogical content knowledge $\left(P C K_{A B L}\right)$ : the knowledge and skills of how to apply ABL to teach particular mathematics content.

- Technological content knowledge $\left(T C K_{s s}\right)$ : the knowledge and skills of representing mathematical concepts in a spreadsheet.

- Technological Pedagogical Knowledge (TPK $\left.K_{A B L}\right)$ : The knowledge and skills of how to use spreadsheets in ABL.

- Technological pedagogical content knowledge (TPCK $\mathrm{T}_{\text {maths }}$ ): the knowledge and skills of representing mathematical concepts with spreadsheet using $A B L$. 


\subsubsection{Successful guidelines for technology integration in pre-service teacher education}

Teacher education programmes have struggled with selecting and implementing the most effective guidelines on how to prepare pre-service teachers to integrate technology in their future lessons (Goktas, Yıldırım, \& Yıldırım, 2008). Numerous teacher education programmes have made extensive efforts to implement effective and meaningful use of technology, however the guidelines used to attain these goals are complex, diverse, often conflicting, and rarely evaluated well (Kay 2006). Teacher education programmes have involved a wide range of approaches throughout the curriculum (based on Ottenbreit-Leftwich et al., 2010; Polly et al., 2010): information delivery of technology integration content (e.g., lectures, podcasts), hands-on technology skill building activities (e.g., workshops), practice with technology integration in the field (e.g., field experiences), and technology integration reflections (e.g., electronic portfolios). Tondeur et al., (2012) reviewed qualitative studies that focused on guidelines to prepare pre-service teachers to integrate technology into their lessons. They identified 12 key themes that need to be in place in the teachers' education program in preparing pre-service teachers in technology integration. The key themes were either related to the preparation of pre-service teachers (e.g., using teacher educators as role models, learning technology by design, scaffolding authentic technology experiences), or to conditions necessary at the institutional level (e.g., technology planning and leadership, co-operation within and between institutions, training staff).This study applied the first set of key themes as guidelines in the design of the instructional technology course (IT course):

- Guideline 1: aligning theory and practice. Studies (e.g., Brush et al., 2003; Jang, 2008) have shown that in preparing teachers to use technology (e.g., how to use specific software), it seems better to link conceptual or theoretical information to practice so that pre-service teachers can understand the reasons behind using ICT rather than presenting the content in isolation. In the IT course, a combination of theory during lectures and practice during lab sessions was employed to provide learning experiences in which knowledge/skill gained can be applied.

- Guideline 2: collaborating with peers. According to Angeli and Valanides (2009), collaboration with peers appeared to provide a time effective, highchallenge, low threat learning environment for pre-service teachers. It also makes pre-service teachers aware of the fact that in order to evaluate others, they first had to reflect on their own performance and evaluate themselves 
(Tearle \& Golder, 2008). In this IT course collaborative design teams was used to stimulate teacher learning.

- Guideline 3: learning technology by design. Research suggests that the opportunity to (re-) design technology-enhanced curriculum materials was a promising strategy for pre-service teachers technology integration (e.g. Polly et al., 2010), which was the reason to have collaborative design teams in the IT course.

- Guideline 4: modeling how to use technology. According to Voogt (2010), exemplary materials can provide pre-service teachers with theoretical and practical insights of technology- supported learner-centred lessons and hands-on experience. Similarly, Brush et al. (2003) and Haydn and Barton (2007) described how pre-service teachers adopted the strategies modelled to them during their pre-service education. In the IT course exemplary curriculum materials and demonstration lessons were used to model appropriate technology use.

- Guideline 5: scaffolding authentic technology experiences. Tondeur et al (2012) found the importance of applying their knowledge about educational technology in authentic technology experiences .Tearle and Golder (2008) stressed that "watching" technology being used could not substitute for "doing". In this respect, teaching-tryout by pre-service teachers was an important component of the IT course to provide them with hands-on technology experiences.

\subsection{THE MATHEMATICS-SPECIFIC INSTRUCTIONAL TECHNOLOGY COURSE PROGRAMME}

This research was conducted in the context of the department of science and mathematics education in a major teacher preparation program in Ghana. Based on the design guidelines described above and experiences with the approach in two small pilot studies (Agyei and Voogt, 2012; submitted) in the same context, the IT course was redesigned and taught for the first time during the spring semester for final year pre-service mathematics teachers. The 14-week course required pre-service teachers to attend one-two hours lectures and one-two hours laboratory sessions per week. Table 6.1 presents an overview of the activities in the IT course in relation to design guidelines for developing TPACK. 
Table 6.1 Outline of the instructional technology course and design guidelines for technology integration

\begin{tabular}{|c|c|c|c|c|}
\hline DT activities & Activity & Guideline & $\begin{array}{l}\text { Integration } \\
\text { competencies }\end{array}$ & $\begin{array}{l}\text { Time } \\
\text { frame }\end{array}$ \\
\hline $\begin{array}{l}\text { Introduction to technology-based } \\
\text { possibilities of teaching mathematics }\end{array}$ & $1 / \mathrm{ls}$ & 1 & $\mathrm{TPCK}_{\text {maths }}$ & \multirow{6}{*}{4 weeks } \\
\hline $\begin{array}{l}\text { Introduction to learning by design } \\
\text { (collaboration) }\end{array}$ & 1 & 1 & - & \\
\hline $\begin{array}{l}\text { Introduction to computer skills(and } \\
\text { spreadsheets in particular) }\end{array}$ & $1 / 1 \mathrm{~s}$ & 1,2 & $\mathrm{TK}_{\mathrm{ss}}$ & \\
\hline Introduction to TPACK concept & 1 & 1 & $\mathrm{TPCK}_{\text {maths }}$ & \\
\hline $\begin{array}{l}\text { Introduction to learner centred } \\
\text { approaches (and ABL of teaching } \\
\text { maths) }\end{array}$ & 1 & 1 & $\begin{array}{l}\mathrm{PK}_{\mathrm{ABL}} \\
/ \mathrm{PCK}_{\mathrm{ABL}}\end{array}$ & \\
\hline $\begin{array}{l}\text { Introduction/demonstration of activity- } \\
\text { based lessons supported by spreadsheet } \\
\text { (exemplary material) and discussion }\end{array}$ & $1 / 1 \mathrm{~s}$ & 1,4 & $\mathrm{TPCK}_{\text {maths }}$ & \\
\hline $\begin{array}{l}\text { Scouting spreadsheet techniques that } \\
\text { support mathematics teaching }\end{array}$ & ls & $1,2,3,4$ & $\mathrm{TPK}_{\mathrm{ABL}}$ & \multirow[t]{2}{*}{5 weeks } \\
\hline $\begin{array}{l}\text { Development of mathematics activities } \\
\text { supported by spreadsheets and lesson } \\
\text { development }\end{array}$ & ls & $1,2,3,4$ & $\mathrm{TCK}_{\mathrm{ss}}$ & \\
\hline $\begin{array}{l}\text { Teaching of activity-based lessons } \\
\text { supported by spreadsheets to } \\
\text { peers/researcher }\end{array}$ & ci & 1,5 & $\mathrm{TPCK}_{\text {maths }}$ & \multirow[t]{2}{*}{5 weeks } \\
\hline $\begin{array}{l}\text { Revision of the developed lesson } \\
\text { materials based on feedback }\end{array}$ & $\mathrm{ci} / \mathrm{ls}$ & 1,3 & $\mathrm{TPCK}_{\text {maths }}$ & \\
\hline
\end{tabular}

Note: 1 = lecture; $1 \mathrm{~s}=$ laboratory session; $\mathrm{ci}$ = classroom implementation.

The lectures were meant to update the students on theoretical foundation/concepts (e.g. TPACK framework, collaborative teacher design, ABL and the pedagogical task). Two technology-based lesson models (designed by the researcher) were taught by the researcher as demonstration lessons and discussed in class during two lecture periods. Other lecture periods included interactive discussions on readings, class assignments and projects. A typical lab session included small group components in which design teams worked on their assignments and project. Implementation of lessons in which teams taught their peers during teaching try-outs was a necessary component. To complete their semester's long project, the pre-service mathematics teachers worked in teams of four to identify mathematics topics (concept) from the senior high school curriculum to be taught with technology, identified appropriate spreadsheet applications for the topic; designed and developed appropriate 
learning activities based on ABL; incorporated activities in lesson plans and taught (in teaching try-outs) their lessons accordingly. Each lesson document comprised a teacher guide to help set up the environment, a plan for lesson implementation and a student worksheet which promoted hands-on activities during lesson implementation. Eight teams presented their lessons in the middle of the course (6-7th week) and at the end to their peers and instructors. The lessons were taught in a classroom with a computer and a LCD projector. The same teams and eight others presented their lessons at the end $\left(12-14^{\text {th }}\right.$ week) of the IT course. Two instructors, the researcher and the original course instructor, were involved. The researcher's role was demonstrative during the lecture sessions and consultative during the lab sessions. The other instructor helped the researcher and supported students during lab sessions.

\subsection{RESEARCH QUESTIONS}

The main research question of the study is: Which impact does a mathematics specific course, in which pre-service teachers collaboratively design spreadsheet-supported mathematics lessons in teams, has on pre-service teachers' technology competencies (attitudes, knowledge and skills)?

\subsection{METHOD}

\subsubsection{Participants}

Pre-service mathematics teachers ( $\mathrm{N}=104 ; 70$ males and 34 females) participated in the study. The pre-service teachers were in their final year of the mathematics teacher education program. The pre-service teachers have not had any experience in technology-supported lesson; neither as part of their training nor in their pre-university education. The average age was nearly 25 years. As a result, twenty-four lessons were developed by twenty-six teams. A random sample of eight teams was selected of which the lessons plans and teaching tryouts were presented at the middle and at the end of the course. Another random sample of eight teams presented their end products at the end of the course. All twenty-four teams were involved in the self-reported survey before and end of the IT course. 


\subsubsection{Instruments}

Table 6.2 gives a general overview of the different instruments used, the purpose and their stage of administration during the IT course.

Table 6.2 Overview of instruments and their stages of administration

\begin{tabular}{|c|c|c|c|c|c|c|c|}
\hline \multirow[b]{2}{*}{ Instrument } & \multirow[b]{2}{*}{ Construct } & \multirow{2}{*}{$\begin{array}{l}\text { Measurement } \\
\text { Type }\end{array}$} & \multicolumn{2}{|c|}{ TPACK data } & \multicolumn{3}{|c|}{$\begin{array}{l}\text { Stage of } \\
\text { Administration }\end{array}$} \\
\hline & & & Source & Type & $B$ & $M$ & E \\
\hline $\begin{array}{l}\text { Lesson Plan } \\
\text { Rubric }\end{array}$ & $\begin{array}{l}\text { spreadsheet } \\
\text { integration } \\
\text { competence }\end{array}$ & $\begin{array}{l}\text { Performance } \\
\text { assessment }\end{array}$ & Team & Artefact & & $\checkmark$ & $\checkmark$ \\
\hline $\begin{array}{l}\text { TPACK } \\
\text { Observation } \\
\text { Rubric }\end{array}$ & $\begin{array}{l}\text { spreadsheet } \\
\text { integration } \\
\text { competence }\end{array}$ & $\begin{array}{l}\text { Performance } \\
\text { assessment }\end{array}$ & Team & Observable & & $\checkmark$ & $\checkmark$ \\
\hline $\begin{array}{l}\text { Design Team } \\
\text { Reports }\end{array}$ & $\begin{array}{l}\text { developing } \\
\text { spreadsheet } \\
\text { Integration } \\
\text { Competence }\end{array}$ & Reports & Team & Artefact & & & $\checkmark$ \\
\hline $\begin{array}{l}\text { TPACK } \\
\text { Survey }\end{array}$ & $\begin{array}{l}\text { self-confi- } \\
\text { dence of } \\
\text { spreadsheet } \\
\text { integration } \\
\text { competence }\end{array}$ & Survey & $\begin{array}{l}\text { Individ } \\
\text { ual }\end{array}$ & Self-report & $\checkmark$ & & $\checkmark$ \\
\hline TAC Survey & $\begin{array}{l}\text { self-belief of } \\
\text { spread-sheet } \\
\text { inte-gration } \\
\text { competence }\end{array}$ & Survey & $\begin{array}{l}\text { Individ } \\
\text { ual }\end{array}$ & Self-report & $\checkmark$ & & $\checkmark$ \\
\hline
\end{tabular}

Note: ${ }^{*} \mathrm{~B}=$ Before, $\mathrm{M}=\mathrm{Mid}, \mathrm{E}=$ End of Instructional technology course.

TPACK Lesson Plan Rubric (TLPR)

A TPACK lesson Plan rubric was adapted from the Technology Integration Assessment Rubric (TIAR) which Harris, Grandgenett, and Hofer (2010) created and tested and found to be a valid and reliable instrument to assess TPACK evident in teachers' written lesson plans. While TIAR is a general rubric to determine TPACK in lesson plans, adaptations were made to fit to TPACK for spreadsheet supported ABL in mathematics. The rubric consisted of seven different criteria (see Table 6.3); each criterion was scored as: not at all (1), minimal (2) and strong (3) with a minimum score of 7 and maximum 21. In analysing the documents, coding based on categories of TPACK was done for each lesson. Each code was then assessed based on criteria of the rubric, after which the average score for each category was determined. To find TPACK 
evidence in the document, the sum of all the categories of TPACK was determined. Eight lesson documents were analysed twice: at the middle and the end of the program; and another eight at the end of the course. Interrater reliability (Cohen's $\mathrm{k}=0.86$ ) was calculated using a sample of three lesson plans (see the Appendix for an example of an analysed document).

Table 6.3 Criteria for analyzing spreadsheet supported ABL lesson plans

Appropriately spelt out subject matter of mathematics lesson $\left(C K_{\text {maths }}\right)$

ABL strategies support to mathematics learning ( $\mathrm{PK}_{\mathrm{ABL}}$ )

Clearly designed spreadsheet techniques that can support transfer of knowledge $\left(T K_{s s}\right)$

Support of ABL strategies to mathematics lesson goals $\left(P C K_{A B L}\right)$

Alignment of spreadsheet techniques to mathematics lesson goals $\left(\mathrm{TCK}_{s s}\right)$

Support of spreadsheet to ABL strategies $\left(T P K_{A B L}\right)$

Fit of mathematics content, $\mathrm{ABL}$ strategies and spreadsheet techniques together within the instructional plan (TPCK $\left.K_{\text {maths }}\right)$

\section{TPACK Observation Rubric}

The Observation Rubric was adapted from a valid and reliable TPACK-Based Technology Integration Observation Instrument (Hofer, Grandgenett, Harris, \& Swan; 2011) which was developed and used to assess TPACK evidence in observed instruction. Adaptations were made to be able to observe TPACK for spreadsheet supported ABL in mathematics. The observation instrument consisted of 20 items, which could be scored as not at all=1, partly observed $=2$ and observed $=3$ with a minimum score of 20 and maximum 60 . To analyse a lesson, the total score (TPACK score) was obtained for all the 20 items. Eight lessons were observed at the mid and end of the program respectively; and another eight at the end of the course. Cohen's $\mathrm{k}$ for two independent raters 0.84. Table 6.4 gives an overview of sample questions for each TPACK knowledge type construct that was assessed in the lesson: Enlargement with scale factor $k$. 
Table 6.4 Sample items for each TPACK knowledge type construct

Sample items
Subject matter (CK $\left.\mathbf{K}_{\text {maths }}\right)$
Clearly introducing mathematics
concept and learning goals of
lesson.

\section{Sample items}

Pedagogical knowledge (PK $\left.{ }_{\mathrm{ABL}}\right)$

Engaging students in solving authentic problems using teaching mathematics

activities(worksheet)

\section{Technological knowledge (TK $\mathrm{Ts}_{\mathrm{ss}}$}

Demonstrating developed

knowledge in spreadsheet skills
Example of observed or partly

observed practice

The scale factor $\boldsymbol{k}$ is the ratio of the image to the object.

$\left(k=\frac{\text { image size }}{\text { object size }}\right)$.

Teacher encouraged students (in teams)

to draw the images of plane figures

under enlargement from the

origin for given scale factors on

worksheets

Entering and editing data in cells

allowed for changes in the image size of

a plane shape

\section{Pedagogical content knowledge (PCK $\left.\mathrm{PBL}_{\mathrm{AB}}\right)$}

Applying AB approach to Designed activities assisted students to

stimulate students interest in

find images of plane figures under

solving mathematics problem

enlargement from the origin for given scale factors.

\section{Technological pedagogical knowledge (TPK $\left.{ }_{\mathrm{ABL}}\right)$}

Engaging students in spreadsheet "Zooming" in and out allowed in-depth

based ABL activities investigation and stimulated students' discussions on worksheet.

\section{Technological Content knowledge (TCK $\left.\mathrm{ABL}_{\mathrm{AL}}\right)$}

Introducing fundamental mathematical concepts by spreadsheet incorporation

Changes in the scale factor (in the cells) allowed for demonstrations of a wide range of images (of given object) and immediate feedback making learners to concentrate more on mathematical relationships (of the scale factor, image and object size) rather the mechanics of construction.

Technological Pedagogical and Content Knowledge $\left(\right.$ TPCK $\left._{\text {maths }}\right)$

Proper choice of spreadsheet technique in relation to mathematical concepts and ABL pedagogy
Spreadsheet allowed for determining how changes in the scale factor affect the orientation/size of the image providing a visual link between the object and changes in its image (giving students greater opportunity to consider general rules, test and reformulate and relationships among the scale factor $(\mathrm{k})$, the object size and the image size on worksheet)( TPCK $\left.K_{\text {maths }}\right)$. 


\section{TPACK Survey}

The TPACK survey measured teachers' self-reported development in their TPACK. The questionnaire was adapted from Schmidt, et al (2009) and had a five-point Likert scale format (from 1-strongly agree to 5-strongly disagree). The instrument was administered twice: before and after the IT course.

Table 6.5 Sample question for each TPACK knowledge type constructs

\begin{tabular}{|c|c|c|c|}
\hline $\begin{array}{l}\text { Knowledge } \\
\text { Type }\end{array}$ & Sample Question For Each Knowledge Type & $\begin{array}{l}\text { Cronbach's } \\
\text { a pre }\end{array}$ & $\begin{array}{l}\text { Cronbach's } \\
\text { a post }\end{array}$ \\
\hline $\mathrm{TK}_{\mathrm{ss}}$ & I frequently play around with spreadsheets & 0.89 & 0.91 \\
\hline $\mathrm{CK}_{\text {maths }}$ & I have sufficient knowledge about mathematics. & 0.84 & 0.83 \\
\hline $\mathrm{PK}_{\mathrm{ABL}}$ & $\begin{array}{l}\text { I can adapt ABL teaching style to different } \\
\text { learners. }\end{array}$ & 0.79 & 0.79 \\
\hline $\mathrm{PCK}_{\mathrm{ABL}}$ & $\begin{array}{l}\text { I know how to select effective ABL teaching } \\
\text { approaches to guide student thinking and } \\
\text { learning in mathematics. }\end{array}$ & 0.70 & 0.69 \\
\hline $\mathrm{TCK}_{\mathrm{ABL}}$ & $\begin{array}{l}\text { I know about spreadsheet applications that I can } \\
\text { use for understanding and doing mathematics }\end{array}$ & 0.84 & 0.81 \\
\hline $\mathrm{TPK}_{\mathrm{ABL}}$ & $\begin{array}{l}\text { I can choose spreadsheets application that } \\
\text { enhance ABL approaches of a lesson }\end{array}$ & 0.83 & 0.85 \\
\hline $\mathrm{TPCK}_{\text {maths }}$ & $\begin{array}{l}\text { I can teach lessons that appropriately combine } \\
\text { mathematics concepts, spreadsheet applications } \\
\text { and ABL teaching approaches }\end{array}$ & 0.88 & 0.91 \\
\hline
\end{tabular}

\section{Teachers' attitudes towards computers (TAC)}

The TAC (Christensen \& Knezek, 2000b) measures pre-service teachers' attitudes towards technology. Six sub-scales of the TAC questionnaire instrument were used: Enjoyment (Cronbach's a=0.73), the pleasure someone experiences when using and talking about computers; Anxiety (Cronbach's $\mathrm{a}=72$ ), fear to use and talk about computers; benefit (Cronbach's $\mathrm{a}=0.88$ ), perceived advantages of using computers in the class; interaction (Cronbach's $\mathrm{a}=0.83$ ), willingness to use possible applications of computers for information dissemination; influence of computer use on the instructional productivity (Cronbach's $\mathrm{a}=0.86$ ) of users and possible professional enhancement (Cronbach's a $=0.79$ ) in the use of computers. All sub-scales had a five-point Likert scale $(1=$ strongly disagree, $5=$ strongly agree $)$, with 1 as the lowest possible score representing a strong negative attitude, and 5 as the highest possible score representing a strong positive attitude. The TAC was administered before and after the IT course. 


\section{Design Team Reports}

Each design team maintained a record of activities and events occurring during the IT course in a report. The report entries complemented findings from the other data collection instruments.

\subsection{DATA ANALYSIS}

To analyze the data descriptive statistics, $t$-tests (paired and independent), and non-parametric statistics (Wilcoxon signed rank test and Mann-Whitney U- test) were used. Effect size was calculated using Cohen's d (Cohen, 1988). Cohen (1988) provided tentative benchmarks for the interpretation of effect sizes. He considers $\mathrm{d}=0.2$ a small, $\mathrm{d}=0.5$ a medium and $\mathrm{d}=0.8$ a large effect size. Information recorded in the design team reports was analyzed qualitatively using data reduction techniques in which major themes (e.g. importance of collaboration; use of exemplary materials; learning technology by doing and challenges in instructional design in teams) were identified and clustered (Miles \& Huberman, 1994).

\subsection{RESUlTS}

\subsubsection{Lesson plans}

The guides that the pre-service teachers had designed gave step by step instructions on how to set up the lesson environment; mainly showing the knowledge and skills needed to use spreadsheets (indicating $\mathrm{TK}_{\mathrm{ss}}$ ) in inputting data and viewing a plot of the data. For example the study guide for the lessons in Enlargement and Statistics outlined:

Set the cursor over cell X2 and cell Y2 to note the formulas. You should see: $=k^{*} X 1$ and $=k^{*} Y 1$ respectively. (The symbol * must be used for multiplication)(Enlargement).

Highlight the cells that contain the data and use the chart command to create an $x-y$ scatter plot in the second window, make sure to use the data from column 1 as $x$-data (Statistics). 
The lesson plan made links between the students' worksheet and the lesson activities of the teachers. Examples are:

Guide students to carry out different activities with concrete objects to identify the images (by matching on their worksheet) of an object by a given vector ( $\left.\mathrm{PCK}_{\mathrm{ABL}}\right)$ (Plane Geometry)

Alter the value of $k$ (say $k=1,2,3$, 4 etc.) and guide students to observe and record the sum of interior angles of the different polygons on their worksheet (TPK ${ }_{\mathrm{ABL}}$ ) (Regular Polygons).

Analysis of the lesson plan documents also showed that specific roles were identified for teachers and students. Most lessons showed various tasks to be done by students (i.e. observing, recording, exploring etc.) while teachers were to guide and instruct during the lessons. For example:

Begin with two linear graphs on the same axes on the spreadsheet and guide students to observe and record the values of $x$ on their worksheet (as you alter the value of $\mathrm{x}$ ) which satisfy the two equations simultaneously and their corresponding values of y (TPCK maths (Simultaneous Linear Equations).

Guide students to carry out different activities by organizing them in small groups.... (PK $\left.\mathrm{PBL}_{\mathrm{AL}}\right)$ (Matrices).

The analysis of the eight lesson plans (used for try-outs during mid and end of the course) is presented in Table 6.6 The table shows relatively high TPACK score in pre-service teachers' lessons plans used for second teaching try-out. These final lesson plans reflected clearly spelt out lesson objectives ( $\left.\mathrm{CK}_{\text {maths }}\right)$, well defined roles for both the teacher and students $\left(P K_{A B L}\right)$, and well mapped up support of spreadsheet application technique to student worksheet activities (TPK ${ }_{\mathrm{ABL}}$ ) and clearly defined use of spreadsheet technique to stimulate student thinking in solving mathematics problems (TCK $\left.{ }_{\mathrm{ABL}}\right)$. 
Table 6.6 Mid-and end-TPACK score of pre-service teachers' (PTs) lesson plan artefact $(n=8)$

\begin{tabular}{|c|c|c|c|c|}
\hline \multirow[b]{3}{*}{ Lesson } & \multicolumn{2}{|c|}{ Mid of Course } & \multicolumn{2}{|c|}{ End of Course } \\
\hline & & \# TPACK & TPACK & \# TPACK \\
\hline & TPACK Score & Codes & Score & Codes \\
\hline Enlargement & 14.25 & 46 & 15.30 & 48 \\
\hline Statistics & 15.75 & 50 & 16.70 & 54 \\
\hline Simultaneous Linear & & & & \\
\hline Equations & 15.00 & 44 & 16.00 & 48 \\
\hline Sum of Interior Angles & 15.67 & 43 & 17.00 & 43 \\
\hline Matrices & 14.43 & 42 & 15.50 & 43 \\
\hline Straight lines & 15.00 & 51 & 16.50 & 56 \\
\hline Plane Geometry & 15.00 & 44 & 16.00 & 44 \\
\hline Linear Equations & 16.76 & 54 & 18.00 & 59 \\
\hline All lessons & 15.23 & 374 & 16.38 & 395 \\
\hline
\end{tabular}

Note: Minimum score $=7$, Maximum score $=21$.

Wilcoxon one-tailed test results showed that the overall TPACK mean score was significant $(p=0.004)$ (with significant more TPACK codes $(p=0.015$, $\mathrm{d}=0.49)$ ) and a large effect size $(d=1.36)$ for pre-service teachers' lesson artefact used for second teaching try-out. This suggests that the insights learned by the pre-service teachers (feedback peers and researcher) during their first teachingtry-out served as necessary input for them in revising their design as was reflected in the final teaching documents. To further examine the impact of peer and researcher feedback on teachers' demonstration of TPACK in their lesson documents the TPACK scores were compared to final lesson documents (which were not used in the teaching try-out). Table 6.7 shows the means and standard deviations between the lesson plans that were provided with midterm feedback and those that were not. 
Table 6.7 Descriptive statistics for end-TPACK score of pre-service teachers' lesson plan artefact

\begin{tabular}{|c|c|c|c|c|c|}
\hline & \multicolumn{2}{|c|}{$\begin{array}{l}\text { Lessons (with peer } \\
\text { teaching) }(\mathrm{n}=8)\end{array}$} & & \multicolumn{2}{|c|}{$\begin{array}{c}\text { Lessons (without peer } \\
\text { teaching) }(n=8)\end{array}$} \\
\hline Lessons & $\begin{array}{l}\text { TPACK } \\
\text { Score }\end{array}$ & $\begin{array}{l}\text { \#TPACK } \\
\text { Codes }\end{array}$ & Lessons & $\begin{array}{l}\text { TPACK } \\
\text { Score }\end{array}$ & $\begin{array}{l}\text { \# TPACK } \\
\text { Codes }\end{array}$ \\
\hline Enlargement & 15.30 & 48 & Pie Chart & 14.30 & 44 \\
\hline Statistics & 16.70 & 54 & $\begin{array}{l}\text { Logarithmic } \\
\text { Functions }\end{array}$ & 15.30 & 50 \\
\hline $\begin{array}{l}\text { Simultaneous } \\
\text { Linear } \\
\text { Equations }\end{array}$ & 16.00 & 48 & $\begin{array}{l}\text { Linear } \\
\text { Programming }\end{array}$ & 15.30 & 43 \\
\hline $\begin{array}{l}\text { Regular } \\
\text { Polygons }\end{array}$ & 17.00 & 48 & $\begin{array}{l}\text { Modular } \\
\text { Arithmetic }\end{array}$ & 14.70 & 44 \\
\hline Matrices & 15.50 & 43 & $\begin{array}{l}\text { Quadratic } \\
\text { Functions }\end{array}$ & 14.00 & 46 \\
\hline Straight lines & 16.50 & 52 & Trigonometry & 14.90 & 46 \\
\hline Plane Geometry & 16.00 & 48 & Bearings & 15.00 & 44 \\
\hline $\begin{array}{l}\text { Linear } \\
\text { Equations }\end{array}$ & 18.00 & 54 & Rotation & 16.80 & 47 \\
\hline $\begin{array}{l}\text { All lessons } \\
\text { (mean) }\end{array}$ & 16.38 & 395 & All lessons(mean) & 15.03 & 362 \\
\hline
\end{tabular}

Note: Minimum score $=7$, Maximum score $=21$.

The results indicate relatively high TPACK score (with more TPACK codes) for lesson artefacts in which the teachers did a peer teaching as compared to artefacts in which no peer teaching was done. A Mann-Whitney U-test confirmed significant $(p=0.008)$ difference between the two lesson categories: lesson with peer teaching $(M=16.38, S D=0.807)$ and lesson without peer teaching without peer teaching $(M=15.03, S D=0.845)$ with a large $(d=1.55)$ effect size. Specific feedback from peers and instructors during teaching-tryout was a possible reason for improved scores of pre-service teachers who taught their peers. Another possible reason was the authentic technology experience itself as a result of the hands-on teaching try-out by these teachers.

\subsubsection{Lesson enactment}

As was observed, the 8 teams of teachers who taught their peers at mid-term (referred to hereafter as peer teachers (PT) (and also at the end of the course) used their lesson plans to guide class instruction using "interactive demonstration" in a spreadsheet environment. The use of the spreadsheet gave students greater opportunities to verify results and consider general rules, make links between spreadsheet formula, algebraic functions and graphs, 
analyse and explore number patterns and graphs within a shorter time. The analysis showed that the teachers used the spreadsheet environment and the student worksheet to engage their students in different learning related activities. Table 6.8 shows the added value of spreadsheet use in different lessons to engage their student in different learning activities.

Table 6.8 Activity-based lessons with the added value of spreadsheet

\begin{tabular}{|c|c|c|}
\hline Lesson & $\begin{array}{l}\text { Teaching and learning } \\
\text { activities }\end{array}$ & Added value of spreadsheet use \\
\hline $\begin{array}{l}\text { Polynomial } \\
\text { Functions } \\
\text { (Year 2) }\end{array}$ & $\begin{array}{l}\text { Collaboration in teams } \\
\text { to explore patterns, } \\
\text { team presentations and } \\
\text { peer assessment }\end{array}$ & 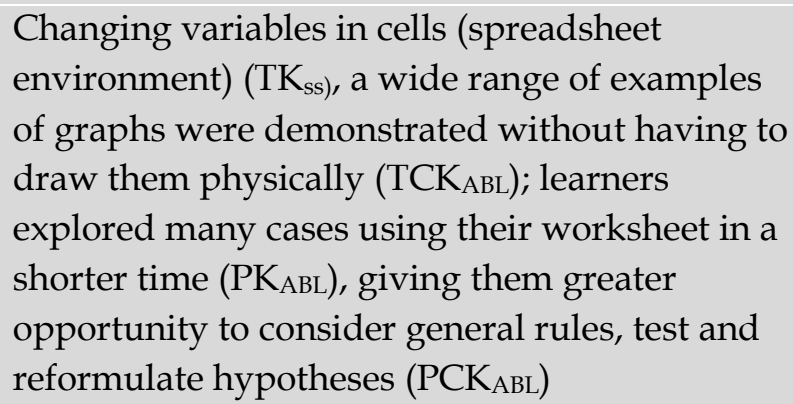 \\
\hline $\begin{array}{l}\text { Plane } \\
\text { Geometry } \\
(\text { Year 1) }\end{array}$ & $\begin{array}{l}\text { Interactive } \\
\text { demonstration with } \\
\text { students, collaboration } \\
\text { in teams to explore } \\
\text { relationships/properties } \\
\text { of figures. }\end{array}$ & $\begin{array}{l}\text { Technology use in an interactive demonstrative } \\
\text { lecture stimulated students' discussions with } \\
\text { worksheet }\left(\mathrm{TPK}_{\mathrm{ABL}}\right) \text {. Visual representations of } \\
\text { geometrical figures allowed for immediate } \\
\text { feedback (TCK } \mathrm{TBBL}_{\mathrm{AB}} \text { ), allowing learners to } \\
\text { concentrate more on mathematical relationships } \\
\text { rather than on the mechanics of construction } \\
\left(\mathrm{TCK}_{\mathrm{ABL}}\right)\end{array}$ \\
\hline $\begin{array}{c}\text { Statistics } \\
\text { (Year 2) }\end{array}$ & $\begin{array}{l}\text { Students view } \\
\text { presentation, make } \\
\text { predictions, collect data } \\
\text { and interpret them in } \\
\text { teams }\end{array}$ & $\begin{array}{l}\text { Using the spreadsheet allowed for many } \\
\text { numerical calculations simultaneously (TCK } \mathrm{ABL}) \text {, } \\
\text { easy tabulation of numerical data, graphical } \\
\text { representation of the data, analyses and } \\
\left.\text { exploration of number patterns ( } \mathrm{CK}_{\text {maths }}\right)\end{array}$ \\
\hline $\begin{array}{l}\text { Simultaneous } \\
\text { Linear } \\
\text { Equations } \\
\text { (Year 1) }\end{array}$ & $\begin{array}{l}\text { Interactive } \\
\text { demonstration with } \\
\text { students, group tasks } \\
\text { and group presentations }\end{array}$ & 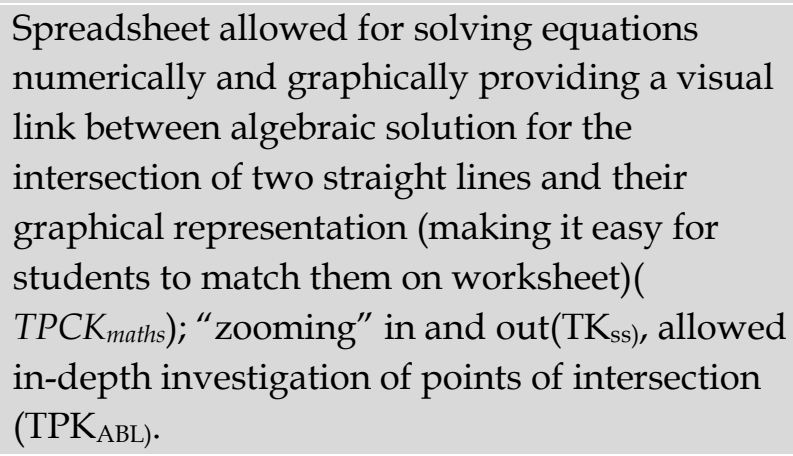 \\
\hline
\end{tabular}

The PTs however, found lots of difficulty using the spreadsheet to develop mathematical concepts well to support their students 'understanding especially during the mid-term (first teaching try-out lessons). For instance it was difficult 
to illustrate that as the absolute value of $m$ increases the graph of $y=m x+k$ become steeper and vice -versa in the lesson on Linear Equations. Apparently, what was difficult for the students was to connect the resulting changes in the graph (which is wider or steeper?) to changes in the numerically values (teachers displayed graph after graph on the same spreadsheet when the parameters were altered). In the lesson on Straight lines, it was a struggle for students to read coordinates of the mid-point of a line segment joining two given points from the spreadsheet on the slides. As a result teachers were compelled to readout the values whiles students did the recording on their worksheets. Another difficulty observed during the lesson on simultaneous equation was students' verifying graphical solution set (from the spreadsheets) of two linear equations in two variables by solving them algebraically either by the method of elimination or substitution. The graphical solution sets appeared approximated and in most cases did not match answers from the students' algebraic solutions of the same set of equations. Such similar difficulties were encountered in the other lessons as well. The corresponding subsequent lessons implemented at the end (second teaching try-out) of the IT course were less of a struggle. For instance on Linear equations, the teacher was able to present the concepts better by demonstrating the different graphs with corresponding changing values of the parameters on the same spreadsheet. Zooming out on the co-ordinates of mid-points was an improved way to allow students read and record their own values during the lesson on Straight lines and using the "Increase decimal" button on the spreadsheet helped to show more precise values to verify algebraic solution sets in the lesson on Simultaneous equations.

In spite of challenges, the analysis of the lesson observations at end of term suggest that the PTs' knowledge and skills developed and improved more than their counterparts without peer teaching experience (further referred to as teachers without peer teaching (NPT)) (Table 6. 9). A Mann-Whitney one-tailed $\mathrm{U}$ test results showed an overall significant $(p<0.0001)$ difference with large effect size $(d=2.53)$ for PTs TPACK Observation score. The relatively high TPACK score suggest that the results and insights (feedback from peers and researcher) learned from the first teaching try-out as well as authentic technology experienced gained from the teaching might have served as necessary inputs for the teachers in revising and implementing their designs in the second try-out. 
Table 6.9 Descriptive statistics for end-TPACK score of pre-service teachers' lesson observation

\begin{tabular}{|llll|}
$\begin{array}{l}\text { Lessons (with peer } \\
\text { teaching) } \mathbf{( n = 8 )}\end{array}$ & TPACK Score & $\begin{array}{l}\text { Lessons (without } \\
\text { peer teaching) } \mathbf{( n = 8 )}\end{array}$ & $\begin{array}{l}\text { TPACK } \\
\text { Score }\end{array}$ \\
\hline $\begin{array}{l}\text { Enlargement } \\
\text { Statistics }\end{array}$ & 41.81 & $\begin{array}{l}\text { Pie Chart } \\
\text { Logarithmic }\end{array}$ & 40.10 \\
& 42.29 & $\begin{array}{l}\text { Functions } \\
\text { Linear Programming }\end{array}$ & 41.00 \\
\hline $\begin{array}{l}\text { Simultaneous Linear } \\
\text { Equations }\end{array}$ & 43.10 & Modular Arithmetic & 41.05 \\
Sum of Interior Angles & 43.50 & Quadratic Functions & 40.40 \\
\hline Matrices & 41.61 & Trigonometry & 39.54 \\
\hline Straight lines & 41.39 & Bearings & 41.00 \\
\hline Plane Geometry & 42.00 & Rotation & 41.20 \\
\hline Linear Equations & 43.40 & All lessons & 40.54 \\
\hline All lessons & 42.39 & &
\end{tabular}

Note: Minimum score $=20$, Maximum score $=60$.

\subsubsection{Pre-service teachers' perceived TPACK knowledge and skills}

A paired sample t-test to compare the teachers reported knowledge and skills (preand post) showed significant $(\mathrm{p}<0.0001)$ difference in all subscales with large gains in: $\mathrm{TK}_{\mathrm{ss}}($ gain $=2.31), \mathrm{TPK}_{\mathrm{ABL}}($ gain $=2.31)$, $\mathrm{TCK} \mathrm{ABL}($ gain $=2.44)$ and $\mathrm{TPCK}_{\text {maths }}$ $($ gain $=2.80)$.The teachers' overall computer attitudes pre $(M=3.29, S D=0.562)$ and post $(M=4.40, S D=0.142)$ showed significance difference $(\mathrm{p}<0.0001)$ with a large effect size $(d=2.92)$. This seems to suggest that the teachers' knowledge and skills developed and improved during the IT course. To compare the development of TPACK for the two categories of teachers (of 8 teams consisting of 32 pre-service teachers each): PT and NPT, an independent t-test of TPACK post test scores was conducted. The results showed that significant differences existed in mean scores in all constructs in favour of the teachers who did a teaching try-out with peers.

Table 6.10 Perceived TPACK knowledge and skill for NPT and PT

$\begin{array}{lllll} & \text { PT }(\mathbf{n}=32) & \text { NPT }(\mathbf{n}=32) & & \\ \text { Factor } & \text { Mean }(S D) & \text { Mean }(S D) & \text { P } & \text { Effect size } \\ \text { TK } & 4.13(0.301) & 4.41(0.399) & 0.005^{*} & 0.79 \\ \text { CK }_{\text {maths }} & 4.44(0.577) & 4.52(0.400) & 0.049^{*} & 0.15 \\ \text { PK }_{\text {ABL }} & 4.33(0.322) & 4.50(0.430) & 0.027^{*} & 0.45 \\ \text { PCK }_{\text {ABL }} & 4.36(0.459) & 4.48(0.552) & 0.031^{*} & 0.24 \\ \text { TCK }_{\text {ABL }} & 4.10(0.309) & 4.34(0.410) & 0.008^{*} & 0.67 \\ \text { TPK }_{\text {ABL }} & 4.21(0.291) & 4.45(0.309) & 0.001^{*} & 0.80 \\ \text { TPCK }_{\text {maths }} & 4.15(0.277) & 4.43(0.340) & 0.001^{*} & 0.90\end{array}$

Note: " Significant at the 0.05 level. 
It appears the peer teaching experience in which the teachers engaged themselves in additional planning and preparation informed their knowledge and skill and this was pronounced in spreadsheet-related constructs: $\mathrm{TK}_{\mathrm{ss}}$ $(d=0.79), \operatorname{TPK}_{\mathrm{ABL}}(\mathrm{d}=0.80), \mathrm{TCK}_{\mathrm{ABL}}(0.67)$ and $\mathrm{TPCK}_{\text {maths }}(0.90)$ which required teachers to revise the role of the spreadsheet in their designs for successful implementation.

\subsubsection{Pre-service teachers' attitudes toward technology}

A paired sample t-test result indicated significance differences $(\mathrm{p}<0.0001, \mathrm{~d}=0.80)$ in overall computer attitudes (pre $(M=4.10, S D=0.370)$, post $(M=4.39, S D=$ $0.352)$ ) of teachers before and after the IT course. The highest mean gain $(d=0.89)$ was reported for teachers' perceived computer interaction followed by instructional productivity $(\mathrm{d}=0.87)$. The lowest mean gain $(\mathrm{d}=0.32)$ was reported in their perceived lack of anxiety attitudes. Comparing the attitudes between the two groups of participants (PT and NPT) an independent t-test was conducted. Table 6.11 indicated no significance difference in overall computer attitudes (peer teaching $M=4.37$, without peer teaching $M=4.32$ ) between the two groups.

Table 6.11 Differences in attitudes based on TAC scores of pre-service with and without teaching try-out experience: ( $M, S D$, p-value and effect size)

\begin{tabular}{|c|c|c|c|c|c|c|}
\hline \multirow[b]{2}{*}{ Subscale } & \multicolumn{2}{|c|}{ NPT $(n=32)$} & \multicolumn{2}{|c|}{ PT (n=32) } & \multirow[b]{2}{*}{ Sig. } & \multirow{2}{*}{$\begin{array}{c}\text { Effect } \\
\text { size } \\
\text { (d) }\end{array}$} \\
\hline & $M$ & $S D$ & $M$ & $S D$ & & \\
\hline Lack of anxiety & 4.05 & 0.588 & 4.22 & 0.583 & $0.041^{*}$ & 0.29 \\
\hline $\begin{array}{l}\text { Instructional } \\
\text { productivity }\end{array}$ & 4.35 & 0.511 & 4.44 & 0.414 & $0.049^{*}$ & 0.19 \\
\hline $\begin{array}{l}\text { Professional } \\
\text { enhancement }\end{array}$ & 4.35 & 0.674 & 4.40 & 0.683 & 0.130 & 0.07 \\
\hline Enjoyment & 4.46 & 0.507 & 4.43 & 0.523 & 0.452 & -0.06 \\
\hline Interaction & 4.47 & 0.589 & 4.47 & 0.506 & 0.952 & 0.00 \\
\hline Benefit & 4.47 & 0.431 & 4.49 & 0.447 & 0.240 & 0.04 \\
\hline Overall attitude & 4.37 & 0.434 & 4.41 & 0.483 & 0.122 & 0.09 \\
\hline
\end{tabular}

Note: ${ }^{*} \mathrm{P}<0.05$ - analyzed with independent t-test.

However, significant differences were found with peer teachers scoring higher on the subscales: lack of anxiety $(d=0.29)$ and instructional productivity $(d=0.19)$. 


\subsubsection{The contribution of the instructional technology course to pre-service teachers' technology integration competencies learning}

The teachers enumerated various reasons that contributed to their development of technology integration competencies (See Table 6.12). Table 6.12 shows that both PT and NPT considered the contribution of all strategies approximately equal, apart from teaching try-out usefulness (NPT=44.4\%; PT=100\%) with technology and usefulness of feedback from peers and instructors in lesson revision (NPT= 72.2\%; PT=100\%). Apparently, the authentic technology experience PT acquired during the teaching try-outs including feedback on the lessons made a significant difference on their TPACK development unlike their NPT counterparts.

Table 6.12 Pre-service teachers perceived usefulness of the design guidelines in IT course ( $N=26$ teams)

\begin{tabular}{|c|c|c|}
\hline & NPT $(\mathbf{N}=18)$ & \\
\hline Strategy & $(100 \%)$ & PT $(\mathrm{N}=8)(100 \%)$ \\
\hline $\begin{array}{l}\text { Importance of Collaborative Design Team } \\
\text { strategy in lesson design }\end{array}$ & $17(94.4 \%)$ & $8(100 \%)$ \\
\hline $\begin{array}{l}\text { Usefulness of Learning technology by doing } \\
\text { approach in developing competencies }\end{array}$ & $15(83.3 \%)$ & $7(87.5 \%)$ \\
\hline $\begin{array}{l}\text { Effectiveness of mixture of theory during } \\
\text { lectures and practical during labs }\end{array}$ & $16(88.8 \%)$ & $7(87.5 \%)$ \\
\hline Teaching try-out usefulness with technology & $8(44.4 \%)$ & $8(100 \%)$ \\
\hline $\begin{array}{l}\text { Usefulness of feedback from peers and } \\
\text { instructors in lesson revision }\end{array}$ & $13(72.2 \%)$ & $8(100 \%)$ \\
\hline $\begin{array}{l}\text { Use of exemplary materials in enhancing } \\
\text { technology competencies }\end{array}$ & $18(100 \%)$ & $8(100 \%)$ \\
\hline $\begin{array}{l}\text { Use of demonstration by the lecturer was a } \\
\text { good example and gave practical insight of } \\
\text { what to design }\end{array}$ & $16(88.8 \%)$ & $7(87.5 \%)$ \\
\hline
\end{tabular}

Despite appreciating the importance of the guidelines in the IT course and the role they played in enhancing their TPACK, the teachers admitted encountering some challenges in the instructional design process. The teachers reported that, although the opportunity to learn technology by doing was a useful strategy, they reported having difficulty in applying their own abilities in an unknown skill domain as novice teachers in technology use. As a result most teams might have adopted strict use of the exemplary materials and explains the relatively high values reported (NPT=16; PT=8). The following problematic and difficult areas they had experienced during the design of their lesson were also reported: designing authentic learning activities for their chosen topics (NPT=11; PT=4) as well as selecting and matching appropriate integrating spreadsheet tools and 
relevant resources in designing mathematics learning activities (NPT=13; $\mathrm{PT}=6$ ). For example in one report (from NPT), the team indicated:

Our first and second meetings to design our lesson on Polygons were held on 17th and 24th of February. In both meetings we had problems designing spreadsheet activities to determine the sum of interior angles so we had to reschedule the meetings. In our next meeting which was on the 28th, the group agreed to change the topic of Rotation....

The issue of time and punctuality at design meetings was also reiterated. Again different views among members within teams posed challenges during lesson designs and discussions. However they indicated solving such problems through discussions and negotiations.

\subsection{Discussion}

The study aimed at exploring the impact of design guidelines applied in a mathematic specific IT course on pre-service teachers' technology integration competencies. The impact of the IT course on the pre-service teachers' competencies was reflected in the increase of their attitude towards technology, their self-reported TPACK development, and their lesson plans and lesson implementation. The impact of the IT course differed between pre-service teachers who were involved in the teaching try-out (PT) and those you were not (NPT). Teachers involved in the teaching try-out had less anxiety and more enjoyment, a higher increase in their self-reported TPACK, and lesson plans which better reflected TPACK, than pre-service teachers not involved in the midterm teaching try-out. The pre-service teachers involved in the mid-term lesson try out demonstrated in their lesson plans that they were able to spell out lesson objectives, define roles for both the teacher and students, map spreadsheet applications to student worksheet activities and clearly define the use of spreadsheets to stimulate student thinking in solving mathematics problems. Also in their lesson implementation the pre-service teachers involved in the midterm try-out showed their ability to integrate technology in teaching mathematics in a sound way at the end of term, much more than their peers who did not have the opportunity to teach the lesson for peers and instructors at mid-term. For example, the end of term lessons improved based on the feedback provided 
during the mid-term teaching try-out employed extensive use of spreadsheets to give greater opportunity to students to verify results and consider general rules, make links between spreadsheet formula, algebraic functions and graphs, analyse and explore number patterns and graphs within a shorter time and allow for many numerical calculations simultaneously, which assisted students in exploring mathematics concepts and perform authentic tasks.

Thus, although both group of teachers (PT and NPT) developed and improved their competencies in the IT course, the evidence showed that pre-service teachers involved in the mid-term teaching try-out developed the competencies better. One obvious reason for developed and improved competencies (particularly with the PTs) was the pedagogical integration of technology experience (which promoted more hands-on experience) they acquired during the teaching try-out; these teachers engaged themselves in additional planning and preparation needed to teach the technological lessons. This is consistent with other studies (e.g. Barton \& Haydn, 2006; Tearle \& Golder, 2008) that acknowledge the importance of applying teacher's competencies about technology integration in authentic settings. The contribution of feedback from peers and instructors during the try-outs was an added advantage for improved competencies of PTs. Based on evidence collected from the study, several other strategies used in the IT course accounted for developed and improved technology integration competencies of the pre-service teachers. It seems that observing an instructor using technology (both groups) was an important motivator for the pre-service teachers to integrate technology into their own practices (e.g., Haydn \& Barton, 2007).

Consistent with studies (e.g. Voogt, 2010), the pre-service teachers indicated that the exemplary materials provided them with theoretical and practical insights of technology- supported learner-centred lessons and hands-on experience. Pre-service teachers also acknowledged the importance of Collaborative Design Teams in stimulating and enhancing their TPACK throughout the program. According to them collaborative experiences provided them with opportunities to explore and practice technology application in a supportive environment consistent with previous studies (e.g. Angeli \&Valanides, 2009). The teachers also reported that, the opportunity to learn technology by doing offered in the IT course was a useful strategy in developing their TPACK. Finally, the programme which combined a mixture of 
short lectures and practical work was a good approach to sustain pre-service teachers' interest and focus in developing their competencies. In this respect, it seems to be important that pre-service teachers have the possibility to see and experience the pedagogical integration of technology in the classroom during their training experiences, by observing good examples and being able to implement such practices themselves (Enochson \& Rizza, 2009).

Pre-service teachers also experienced some difficulties applying their knowledge and skill in designing spreadsheet-supported lessons in the IT course. As novice teachers in technology, they experienced difficulty applying their own abilities in an unknown skill domain during the instruction design. As a result some teams made extensive use of the exemplary materials (replicating the instructor's example with slight changes). This action has the tendency to reduce the opportunity of pre-service teachers to construct their own technology-based lessons. Other areas they identified to be particularly challenging and difficult included: selecting and integrating appropriate spreadsheet tools and relevant spreadsheet application in designing authentic learning activities for selected topics.

In spite of the drawbacks, the study provides useful guidelines for the design of a subject-specific teacher education programme to prepare pre-service teachers in Ghana to integrate technology in teaching. Programme designers should deliberately create experiences in which: i. conceptual or theoretical information would be linked to practice so as to provide pre-service teachers a learning experience in which knowledge/skill acquired can be applied; ii. collaborative design (in which pre-service teachers work with peers) would be useful support for teachers to develop their competencies; iii. scaffolds and authentic technology experience such as teaching tryouts would be included; such an activity has the tendency to reduce pre-service teachers' anxieties about computers thereby increasing their enthusiasm to use them in instruction. In instances where large classes hinder implementation of teaching try-outs for all participants (such as in the context of Ghana), micro-teaching within teams should be encouraged; iv. opportunities where teacher can learn technology by design would be created; and v. modeling how to use technology would be a component of the arrangement; using demonstrations and exemplary materials are options, but caution should be taken to ensure that exemplary materials provide meaningful and effective technology examples. 


\section{ChAPTER 7}

\section{Examining factors affecting beginning teachers' transfer of learning in professional and teaching practices in Ghana ${ }^{7}$}

This study examined 100 beginning teachers' transfer of learning in utilizing an ICT-based innovation consisting of two related components: (1) learning of technology by collaborative design of (2) ICT-enhanced activity-based lessons. Transfer of learning was postulated as characteristics of: the ICT-based innovation, beginning teachers' and school environment. Beginning teachers held positive views about active learning and ICT use developed during the ICTbased innovation, which seemed to have impacted transfer of their learning. Although school environment characteristics were not a significant predictor of transfer of learning, qualitative data indicated that teachers were faced with constraints. Implications of these findings are discussed.

\subsection{INTRODUCTION}

Formal training typically involves learning new knowledge, skills and attitudes in one environment (the training situation) that can be applied or used in another environment (the performance situation) (Goldstein \& Ford, 2002). However, several studies have shown that a common experience is that learning from a formal training programme is often not or in a limited way applied on the job (e.g.Georgensen, 1982; Saks, 2002; Yamnill \& McLean, 2001). Since Baldwin and Ford's (1988) highly recognized review of the "transfer

7 The current version of this chapter has been submitted as: Agyei, D. D., \& Voogt, J. Examining factors affecting beginning teachers' transfer of learning in professional and teaching practices in Ghana. International Journal of Educational Development. 
problem" in training research, an outpouring of conceptual and research-based suggestions have focused on how to lessen the gap between learning and sustained workplace performance (Goldstein \& Ford, 2002; Yamnill \& McLean, 2001; Burke \& Hutchins, 2007).

Baldwin and Ford (1988) define the positive transfer of training "as the degree to which trainees effectively apply the knowledge, skills and attitudes gained in a training context to the job" (p. 63). To be able to bridge the gap between learning and sustained workplace performance, it is important to understand the dynamics of transfer in order to look for ways to minimize transfer losses while improving the yield from any training programme. Baldwin and Ford (1988) identified taxonomy of major conceptual factors influencing transfer. They divided these factors into three groups of characteristics which directly or indirectly influence trainees' learning and the transfer of training: trainee characteristics, training characteristics, and work environment characteristics. Trainee characteristics refer to internal factors (e.g. ability, personality, and motivation) whereas training characteristics involve training design factors (e.g. principles of learning, sequencing, and training content). Baldwin and Ford referred to work environment characteristics as external factors which directly and indirectly affect trainees' learning and the transfer of training. Many of these characteristics of the work environment can be related to the 'transfer climate'. According to Burke and Baldwin (1999, p. 229), "transfer climate refers to those perceptions describing characteristics of the work environment that may facilitate or inhibit the use of trained skills".

While the question of transferability of training has been present in various disciplines (management, human resource development, adult learning, performance improvement, applied psychology), there is no much evidence of comprehensive transfer studies in teacher education involving the transfer of learning of pre-service teachers.

The purpose of this study was to attain understanding of factors that influence beginning mathematics teachers' transfer of learning of an ICT-based innovation in their professional and teaching practice. The study has followed pre-service mathematics teachers, who have started their career as mathematics teachers in various senior high schools in Ghana. 
In the study factors are explored that influence transfer of learning of an ICTbased innovation offered in the final year of the pre-service preparation programme. In this paper we used Baldwin and Ford's (1988) model to analyze beginning teachers' transfer of learning. First we describe the ICT-based innovation. Potential factors that might impact transfer of learning derived from the literature are presented related to the characteristics of the beginning teachers and of the school environment.

\subsection{CHARACTERISTICS OF THE INTERVENTION: ICT-BASED INNOVATION}

As indicated earlier, this transfer study grew out of a programme of research to introduce ICT as a tool to improve teaching and learning of mathematics in preservice teacher education in Ghana. In two iterative arrangements (in 2009 and 2010) a professional development programme (Agyei \& Voogt, 2012; submitted) based on "learning technology by design" was developed. Pre-service teachers worked in design teams to develop spreadsheet-enhanced activity based learning activities. In early 2011, the approach was applied into a regular mathematics-specific instructional technology course.

Findings from the arrangements showed that the pre-service mathematics teachers developed competencies to design and enact ICT-enhanced activitybased mathematics lessons. Of much relevance to this study is the potential of transfer which depends on the quality and depth of learning that occurred during the professional development; Burke and Hutchins (2007) indicated that the intervention design and delivery is an important factors that influence transfer directly or indirectly.

In this study, the ICT-based innovation had two components. The process of learning was characterized by learning technology by collaborative design (LTCD). The focus of pre-service teachers' learning was the design and enactment of ICT-enhanced activity-based learning activities (ICT-ABL). Thus pre-service teachers (here after referred to as beginning teachers) worked collaboratively in design teams (DTs) to design and enact ICT-enhanced ABL solutions for authentic problems they face in teaching mathematics concepts. Spreadsheets (because they were readily available) were employed as a tool for enacting a guided activity-based pedagogical approach to help students explore mathematics concepts and perform authentic tasks. 
Table 7.1 presents an overview of the components for the ICT-based innovation (see also Agyei \& Voogt 2012; submitted).

Table 7.1 Overview of the ICT-based innovation components

\begin{tabular}{|l|l|}
$\begin{array}{l}\text { Learning technology by collaborative } \\
\text { design (lesson design) }\end{array}$ & $\begin{array}{l}\text { ICT-enhanced activity-based learning } \\
\text { (lesson enactment) }\end{array}$ \\
\hline $\begin{array}{l}\text { Use of Design teams to develop } \\
\text { worksheets, spreadsheet techniques and } \\
\text { lesson plans }\end{array}$ & $\begin{array}{l}\text { Use of activity-based pedagogical } \\
\text { approach (ABL) through worksheets }\end{array}$ \\
\hline $\begin{array}{l}\text { Use of exemplary materials (or resources } \\
\text { from internet) }\end{array}$ & Use of teamwork among students \\
\hline $\begin{array}{l}\text { Support from facilitator } \\
\text { Learning by doing (by exploring } \\
\text { spreadsheet techniques activities) }\end{array}$ & $\begin{array}{l}\text { Use of spreadsheet techniques to support } \\
\text { the learning of mathematical concepts }\end{array}$ \\
\hline $\begin{array}{l}\text { Interactive demonstration of spreadsheet } \\
\text { techniques use in class }\end{array}$ \\
\hline
\end{tabular}

\subsection{FACTORS INFLUENCING TRANSFER OF TEACHER LEARNING}

If research-based ICT related innovations are not transferrable, to utilize skills and knowledge learned in pre-service preparation setting to a real world work situation, then there is little expectation that investment and efforts made during the preparation will have a deep and lasting effect on education. Mumtaz (2000) in a review study mentions three factors that impact teachers' continued use of ICT: institution, resources and the teacher. Ely (1999) formulated eight conditions for the implementation of an educational innovation. This study related Mumtaz'(2000) factors to Ely's (1999) (see Table 7.2) Conditions for Change model to examine the potential of beginning teachers' transfer of the ICT-based innovation in their work places.

Table 7.2 Factors form Muntaz (2000) and Ely (1999)

$\begin{array}{ll}\frac{\text { Mumtaz }}{\text { - Teachers }} & \begin{array}{l}\text { Dly } \\ \text { skissatisfaction warticipation the status quo, sufficient knowledge and }\end{array} \\ \text { - Resources } & \text { Availability of resources, availability of time } \\ \text { - Institutions } & \text { Rewards or incentives, commitment and leadership }\end{array}$


Ely's conditions have been demonstrated to apply to both technological and non-technological innovations; they have also been shown to traverse institutional and cultural boundaries (Ely, 1999; Surry \& Ensminger, 2003; Ensminger \& Surry, 2008). In the study we applied Ely's conditions (slightly adapted) to two of the components of Baldwin and Ford's (1988) model of factors influencing transfer. In particular the categorization applied to two factors namely: characteristics of the learners or trainees (Dissatisfaction with the status quo, sufficient knowledge and skills, commitment and availability of time) and work environment characteristics (Availability of resources, participation, Rewards or incentives and school culture). The third component, the characteristics of the professional development intervention, has been described in section 2

\subsubsection{Characteristics of the learner}

Dissatisfaction with the status quo: The views that teachers hold about teaching, learning and ICT itself form an important foundation stone as to whether a teacher may use ICT -based innovations such as ICT-ABL, in their practices. For example, teachers with views about learning that emphasize collaboration may choose to explore the transformative potential of ICT, building their knowledge base and reflecting upon their own practices in the light of the communicative opportunities that ICT might present (Bate, 2010). Teachers with this orientation may see students' engagement with ICT as an intellectual partnership in which ICT is used as a cognitive tool (Jonassen, 2002) to extend students' learning and creativity. Other teachers may hold views about learning that emphasizes the importance of the teacher as an efficient means of distributing knowledge. In these circumstances it is likely that ICT is equated with productivity (Maddux, LaMont Johnson \& Willis, 2001), as an opportunity to complement or amplify existing teaching approaches (Hughes, Thomas \& Scharber, 2006), or simply as a reward for early finishers.

In this study, the assumption of transfer of learning of ICT-ABL is that beginning teachers are not satisfied with existing teaching approaches and see a need to change these towards approaches that support students' active learning. This is also likely to influence beginning teachers' transfer of LTCD which is the process of learning ICT-ABL.

Sufficient knowledge and skills: In order to make an implementation succeed, "the people who will ultimately use the innovation must possess sufficient knowledge 
and skills to do the job" (Ely, 1999). This is especially the case when the innovation involves the use of a certain tool or a technique. Without enough preparation to use the tool or technique, the innovation will die out soon. According to Webb and Cox (2004), one of the reasons for the unenthusiastic response to ICT- based innovation amongst teachers might be that technological knowledge and skills is either absent or lacking in the processes that underpins teachers' planning. This idea has recently been developed by Mishra and Koehler (2006) and Harris, Mishra and Koehler (2009), who propose that there is a tendency for teachers not to synergise their content and pedagogical knowledge with their technological knowledge, and that this can result in mundane ways in which ICT-based innovations are implemented in the classroom.

In this study, the beginning teachers who are implementers of the ICT-based innovation have been involved in professional development to learn technology by collaborative design (LTCD) to design and enact ICT-enhanced activity-based learning activities (ICT-ABL). It is expected that the knowledge and skills acquired during their professional development will reflect in the way beginning teachers currently design their lessons and teaching practices, which was the reason to examine whether sufficient knowledge and skill about the innovation is a necessary factor for beginning teachers' transfer of LTCD and ICT-ABL.

Commitment: Since ICT-based innovation design and use take a great deal of endeavors and time, the people who are involved in the use need to make commitment to their efforts and time. Thus commitment of the teacher is an essential ingredient to a successful implementation of an educational innovation. Riel and Becker (2008) indicated that, teachers who have strong commitments to their pupils' learning and their own professional learning will evidently integrate ICT-based innovations within their teaching. In this study beginning teachers' commitment was measured by their dedication to their students' learning, in particular through ICT-ABL, and to their own developments as teachers, in particular through collaboration with their colleagues in the form of LTCD.

In this study, it is expected that strong commitments of beginning teachers will increase the amount of transfer of their willingness to us LTCD for professional learning and ICT-ABL for improving their students' learning. 
Availability of time: The adoption of the innovation takes time. As Ely (1999) explained, implementers of an innovation must have time to learn, adapt, integrate, and reflect on what they are doing. The adoption of the innovation does not necessarily bring forth the change (Fullan, 2007). It needs time for the people to understand the innovation and develop the abilities to adapt the innovation. Inadequate or insufficient time is recognized as a barrier to implementation of technology in higher education (Ebersole \& Vorndam, 2003). Beginning teachers need time to collaboratively design (LTCD) and practice their designed ICT-enhanced activity-based learning (ICT-ABL) lessons before enacting them in real classroom situations.

In the study, availability of time refers not only to beginning teachers willingness to devote learning time in LTCD but also time to become educated and skilled in how to use ICT-ABL before actual teaching; availability of time to design and practice during pre-lesson preparations is likely to influence beginning teachers' transfer of LTCD and ICT-ABL.

\subsubsection{School environment characteristics}

Availability of resources: According to Mumtaz (2000), limited resources within schools are a great impediment to the take-up of technology. For instance, lack of computers and software in classroom can seriously limit transfer of both the process of beginning teachers learning of technology (LTCD) and the focus (ICT-ABL) as well. Studies have shown that only a small proportion of the African population has access to computers (Murphy, Anzalone, Bosch \& Moulton, 2002) and $4 \%$ has access to the Internet (Resta \& Laferrière, 2008). Aguti and Fraser (2006) reiterated that lack of ready access to technologies by teachers is a key barrier to technology integration in most developing countries. Other researchers (Snoeyink \& Ertmer 2002; Benson \& Palaskas, 2006) have identified resources as an important part of implementation of an innovation.

In the study, adequate resources refer to the amount of resources currently available and accessible to the beginning teachers to successful transfer their use of LTCD for their own and their colleagues learning and their ability to design and enact ICT-ABL lessons.

Reward or incentives: People need to be encouraged in their performance of innovation or use of innovations. Extrinsic or intrinsic rewards can add some 
value of the innovation, and thus, promote its implementation. These rewards can vary significantly from user to user. Additionally, the innovation itself may be perceived as reward or the anticipated outcomes from the use of the innovation may serve an incentive (Ely 1999, 1990). Stockdill and Morehouse (1992) identified rewards as a significant factor in "organizational capacity" (p. 57). Burkman (1987) discusses the use of rewards as part of "moral support" during implementation (p. 450).

In the study the existence of incentives or rewards provided by school management is presumed to motivate beginning teachers' use of LTCD for professional learning and ICT-ABL to foster their students' learning and was the reason to examine whether incentive is a necessary factor for beginning teachers' transfer of learning.

Participation: Participants in the implementation should be encouraged to involve in decision-making. Participation may take the form of user group representatives if it is difficult to get feedback from all potential users (Ely 1990, 1999). Varkking (1995) states "participation in the design phase is in fact the first step of implementation" (p. 35). Participation was defined to include beginning teachers' involvement in decision making with regards to decisions that relate to the planning and design of the innovation in the school setting either through working committees or general staff meetings. With the opportunities to communicate their ideas and opinions, beginning teachers LTCD could contribute to beginning teachers' sense of the ownership of ICT-ABL in their school.

School Culture: Another characteristic emerging from the literature regarding ICT integration is "school culture" (e.g., Bate, 2010; Tearle, 2003), which can be defined as "the basic assumptions, norms and values, and cultural artifacts that are shared by school members" (Maslowski, 2001, p. 8-9). A school's culture sets the conditions for ICT practices at the level of the organization (Bate,2010).These meanings and perceptions can be linked to the "readiness" of a school to adopt the planned change (Tearle, 2003), as well as to teachers' actual take-up of ICT (Bennett et al., 2000). In the present study, three underlying aspects of school culture were considered to assist (or hinder) beginning teachers' use of LTCD and ICT-ABL lesson enactment: "School resistant to change" (Mumtaz, 2000), "importance of leadership in managing ICT, providing support and encouragement to users, as well as role modeling 
use of the innovation" (McGarr \& Kearney, 2009) and "provision of training opportunities" (Galanouli, Murphy \& Gardner, 2004). Mumtaz (2000) explained that due to schools resistant to change, institutions give little time to teachers to manage and familiarize themselves with ICT-based innovation and classroom timetabling does not allow time for teaching with ICT. Several studies (e.g.,Bate, 2010; Dawson \& Rakes 2003; McGarr \& Kearney, 2009;) also support the claim that leadership promoting change is a key factor when it comes to merging ICT and instruction. Baylor and Ritchie (2002) concluded that training has an important influence on how well ICT is embraced in the classroom.

The study advocates that favourable school culture will promote beginning teachers to successful transfer LTCD in their school and to design and enact collaboratively ICT-ABL lessons.

\subsection{RESEARCH QUESTIONS}

The study examined the extent to which beginning teachers were able to transfer knowledge and skills gained in the two components of the ICT-based innovation: learning of technology by collaborative design (LTCD) and ICTenhanced activity-based learning (ICT-ABL). The main research question that guided the study was: To what extent is transfer of learning influenced by beginning teachers' learner characteristics, characteristics of the ICT-based innovation, and school environment characteristics in their professional and teaching practice?

The following sub-research questions were formulated to answer the main research question.

1. To what extent is transfer of learning influenced by beginning teachers' perceptions of the characteristics of LTCD and ICT-ABL?

2. To what extent is transfer of learning influenced by beginning teachers' perceptions of their learner characteristics?

3. To what extent is transfer of learning influenced by beginning teachers' perceptions about their school environment characteristics?

Thus the study hypothesized transfer (ICT-ABL $L_{\text {transfer }}$ and LTCD $_{\text {transfer) }}$ (dependent variables) of the ICT-based innovation( ICT-ABL and LTCD) as functions of the beginning teachers perceptions of their learner characteristics 
(LEC), perceptions about their school environment characteristics (SEC) and perceptions (ICT-ABL perceptions, LTCD perceptions) about the ICT-based innovation (ICT-ABL and LTCD)(the independent variables). Transfer of the ICT-based innovation was reported in beginning teachers' actual use and observed enactment of the ICT-ABL and LTCD. Beginning teachers' perception of the ICT-based innovation, learner characteristics and school environment characteristics were self-reported. The study employed embedded mixed method research design (Creswell, Plano Clark, Gutmann \& Hanson, 2003); including the collection of quantitative and qualitative data.

\subsection{MethodS}

\subsubsection{Participants}

One hundred beginning mathematics (66 male, 34 female) teachers were involved in the transfer study. The beginning teachers had participated in a preparatory programme during their final year at the teacher education programme at the University of Cape Coast (UCC) to collaboratively design and enact ICT-enhanced activity based learning for the first time. Approximately six or eighteen or twenty-eight months after the third, second and first arrangements respectively, the pre-service mathematics teachers who participated in the study were posted into various senior high schools and were pursuing their careers as mathematics teachers. All 100 participants responded and completed a questionnaire survey which was administered through email. A random sample of 20 participants was interviewed and 6 of them were voluntarily observed to provide an authentic depiction of the way in which beginning teachers used the ICT-based innovation or its components in their naturalistic classroom.

\subsubsection{Instruments}

Three different instruments were used in the study. The questionnaire was used to assess beginning teachers' perceptions regarding the extent to which they used the ICT-based innovation and factors influencing their actual use, interview data provided in-depth elaborations for data collected through the questionnaire. The observation data provided information, in which beginning teachers demonstrated actual use or transfer of the ICT-based innovation as well as a record of prevailing factor in the schools. 


\section{Questionnaire}

The questionnaire was developed based on instruments developed by Surry \& Ensminger (2004) and Zhu \& Engels (in press). Teachers' perception and actual use of ICT-ABL (Perception: 5 items; Cronbach's a $=0.91$; use: 5 items, Cronbach's a=0.78) and LTCD (Perception: 4 items; Cronbach's a $=0.89$; use: 4 items, Cronbach's a=0.74).

A five point Likert scale was used for teachers' use (where $5=$ always, $4=$ often, $3=$ sometimes, $2=$ hardly, $1=$ never)(see Table 7.2$)$ and teachers' perception $(1=$ strongly disagree, $5=$ strongly agree)(see Table 7.4). The scores were interpreted as follows: 1 is the lowest possible score, which represents a very strong negative attitude, while the 5 is the highest possible score which represents a very strong positive attitude. The questionnaire also contained 30 statements representing reasons for beginning teachers' use (inability to make use) of the ICT-based innovation. The items could be classified under 8 subscales: availability of resources (Cronbach's a $=0.79$ ), availability of time (Cronbach's a $=0.80$ ), commitment (Cronbach's $\alpha=0.79$ ), participation (Cronbach's a $=0.69$ ), rewards or incentives (Cronbach's $a=0.73$ ), school cultures (Cronbach's $a=0.74$ ), knowledge and skill (Cronbach's $a=0.81$ ) and dissatisfaction with status que (Cronbach's a=0.77).

Further analysis grouped these subscales into two clusters: learner characteristics (beginning teachers' personal factors that are important to ensuring successful transfer of learning) and school environment characteristics (school-related factors which directly and indirectly influence beginning teachers' transfer of learning). For all these items, a five-point Likert scale ( $1=$ strongly disagree, $5=$ strongly agree) was used.

\section{Teacher interview}

To explore the teachers' use of the ICT-based innovation in their specific settings, interviews were conducted. The following coding schemes were generated: value of the ICT-based innovation (and its components), use of the ICT-based innovation (and its components), support for the ICT-based innovation implementation, hindrances to the ICT-based innovation use, and suggestions for ICT-based innovation use. 


\section{Observation checklist}

An observation checklist developed by the researcher was used to help focus and standardize observations. During visits to schools, the researcher used the observation checklist to assess 6 beginning teachers' actual use of the ICT based innovation or its components. Table 7.3 shows the assessment for the teachers' usage levels of the ICT-based innovation. Data were also collected on the infrastructure and equipment that was available to the teachers who were being observed.

\subsection{DATA ANALYSIS}

To analyze the quantitative data descriptive statistics, hierarchical cluster analysis, and regression analysis were conducted in SPSS. Effect size was calculated using Cohen's d (Cohen, 1988). Cohen (1988) provided tentative benchmarks for the interpretation of effect sizes. He considers $d=0.2$ a small, $\mathrm{d}=0.5$ a medium and $\mathrm{d}=0.8$ a large effect size. The interviews were transcribed and coded using Atlas-ti. Two raters coded the interview data using a sample of 5 interviews. The interrater reliability (Cohen's $\mathrm{k}$ ) was $\mathrm{\kappa}=0.90$.

\subsection{RESULTS}

\subsubsection{Transfer of learning of ICT-ABL and LTCD in beginning teachers' teaching practices.}

Beginners' teachers reported use of ICT-ABL and LTCD

A major question dealt with in the study was whether beginning teachers were able to transfer their knowledge and skill in designing and enacting the ICTbased innovation (or its components) in the way they currently design their lessons and teaching practices. Table 7.3 presents the results of their reported use of ICT-ABL and LTCD. With regards to ICT-ABL beginning teachers reported being able to transfer various aspects: use of teamwork among their students $(M=4.53, S D=0.489)$, use of lesson notes in guiding lessons $(M=4.63$, $\mathrm{SD}=0.489)$ and use of activity-based pedagogical approach $(\mathrm{M}=4.50, \mathrm{SD}=0.50)$ during instructions while other aspects: use of "interactive demonstration" of spreadsheet techniques $(\mathrm{M}=3.06, \mathrm{SD}=0.653)$ and spreadsheet techniques to 
support mathematical concepts formation $(\mathrm{M}=3.18, \mathrm{SD}=0.599)$ appeared to be a challenge. Lack of ICT infrastructure might have been the strongest barrier constraining the teachers in their transfer; successful use or transfer of those aspects of the ICT-based innovation required ICT facilities.

Beginning teachers explained this in their interview data. Two of them indicated:

In my school, there is only one computer lab which is used for teaching basic ICT for all the students from year 1 to year 4.And the only projector in the school is used by the ICT teachers (T14).

...but the major problem that hinder my use of the ICT-based innovation has been lack of resources. There is no mathematics lab and the computer lab is used purposely for ICT teaching. The projection devices are used mainly for entertainment (T11).

To what extent beginning teachers continued LTCD within the existing support structures in their school settings was also reported. The results showed that collaboration in design teams $(\mathrm{M}=1.86, \mathrm{SD}=0.521)$ is hardly used by the beginning teachers.

Table 7.3 Beginning teachers' reported use of ICT-ABL and LTCD $(N=100)$

\begin{tabular}{llc}
\hline ICT-based innovation components & Mean & SD \\
\hline $\begin{array}{l}\text { ICT-enhanced activity-based learning } \\
\begin{array}{l}\text { Activity-driven pedagogical approach (through worksheet) to support } \\
\text { student learning }\end{array}\end{array}$ & 4.50 & 0.500 \\
\hline $\begin{array}{l}\text { Spreadsheet techniques to support mathematical concepts formation } \\
\text { Use of teamwork among students }\end{array}$ & 3.18 & 0.599 \\
\hline $\begin{array}{l}\text { Use of "interactive demonstration" of spreadsheet techniques in class } \\
\text { Use of lesson plan to guide lesson implementation }\end{array}$ & 3.06 & 0.489 \\
\hline $\begin{array}{l}\text { Learning technology by collaborative design } \\
\text { I collaborate in design teams to design worksheets, spreadsheet techniques } \\
\text { and lesson plans in mathematics }\end{array}$ & 1.86 & 0.653 \\
\hline $\begin{array}{l}\text { I use exemplary curriculum materials during lesson design } \\
\text { I use a facilitator/resource person to help me in designing mathematics } \\
\text { lessons }\end{array}$ & 4.49 & 0.521 \\
\hline $\begin{array}{l}\text { I use "learning - by -doing" approach to design spreadsheet supported } \\
\text { lessons }\end{array}$ & 4.84 & 0.530 \\
\hline
\end{tabular}

Note: $5=$ always, $4=$ often, $3=$ sometimes, $2=$ hardly. $1=$ never. 
According to them, though some of their senior colleagues valued the ICTbased innovation, they were unwilling to collaborate to design ICT-based lessons. It appears individual teacher characteristics and pedagogical views (particularly between beginning and veteran teachers) could be possible reasons. Such observations were reiterated in interview data. For example one of the beginning teachers indicated:

In my school I am the only guy who can teach using ICT-based innovation. My peers who also teach mathematics do not have the expertise to do that and are not enthusiastic about designing ICT lessons with me. In fact they rather bring your moral down... (T13).

The beginning teachers indicated they would have collaborated better if their design team mates or perhaps others who participated in the preparatory programme were teaching in the same schools as they were. The low mean scores $(\mathrm{M}=1.05, \mathrm{SD}=0.221)$ for beginning teachers' use of facilitators or resource persons in designing lessons is an indication that the teachers were able to learn successfully from the preparatory programme. Table 7.2 also showed that teachers still appreciate the contribution of exemplary materials in designing similar lessons. They indicated that they developed new lessons following exemplary materials used in the preparatory program (as well as their own lessons developed during the preparatory program). Many of them further indicated using resources from the internet to beef up designs of students activities when developing their lesson plans.

\section{Beginners' teachers' observed enactment of ICT-ABL and LTCD}

Of the 6 beginning teachers, Felix, Joel, Mark, Gifty, Rene and Joe (pseudonyms used) who were observed, two (Mark \& Gifty) were from deprived ICT environments (without any ICT infrastructure whatsoever); the other four were situated in modest ICT settings (with a minimum of one computer lab with at least 40 computers). Mark had just gained appointment in a regional secondary school. The school itself was remote comprising of a largely indigenous population. In his lesson, he used components of the ICT-ABL (activities on a worksheet, students working in teams) that did not require ICT facilities. He sees himself as one of the leaders in the school in terms of his ICT knowledge and skills in teaching, but exhibited frustration with the lack of ICT and support. 
Gifty, who found herself in a similar environment as Mark, used lesson plans to guide her lesson, in which students worked in teams using the worksheet to do various activities but did not use ICT as an instructional tool. She expressed similar frustrations in what she termed as poor leadership in supporting ICTbased innovations and remarked on becoming somewhat de-skilled because of her lack of access to ICT facilities.

Felix, Rene, Joel and Ike had some kind of ICT infrastructure in their school but had struggles accessing them for use in their classrooms. For example Rene conducted her lesson without any computer available to her (nor her students) in the classroom. She emphasized the possibility of having access to the computer lab once a week, but was hampered by what she sees as an apathetic school culture; in which timetabling was strictly adhered to leaving little or no room for changes. Felix admitted having his own laptop computer which he could use in class but explained that with the current class size of forty-five students, it was impossible to use the computer meaningfully for any studentdirected activity without any projection device. Joel and Ike on the other hand were able to implement all components of the ICT-based innovation for teaching their lessons, yet were not without struggles. In observing Joel, he used his own laptop to enact his lesson (by rotating groups of students around his computer) to explore the potential of spreadsheets giving students' opportunity to discover mathematics concepts and perform authentic because he did not have access to a projector. Ike's students also turned up in groups around his computer but had a difficult time in his lesson because the class size was large, 50. Table 7.4 shows the ICT-based innovation components that the teachers used as were assessed by the researcher.

Table 7.4 Observation of beginning teachers' use of the ICT-ABL $(n=6)$

\begin{tabular}{lcccccc} 
ICT-based innovation components & Felix & Joel & Mark & Gifty & Rene & Ike \\
\hline $\begin{array}{l}\text { Activity-driven pedagogical approach to } \\
\text { support student }\end{array}$ & $\checkmark$ & $\checkmark$ & $\checkmark$ & $\checkmark$ & $\checkmark$ & $\checkmark$ \\
$\begin{array}{l}\text { Spreadsheet techniques to support } \\
\text { mathematical concepts formation }\end{array}$ & & $\checkmark$ & & & & $\checkmark$ \\
\hline $\begin{array}{l}\text { Use of teamwork among students } \\
\text { Use of "interactive demonstration" }\end{array}$ & $\checkmark$ & $\checkmark$ & $\checkmark$ & $\checkmark$ & $\checkmark$ & $\checkmark$ \\
\hline $\begin{array}{l}\text { Use of lesson plan to guide lesson } \\
\text { implementation }\end{array}$ & $\checkmark$ & $\checkmark$ & & $\checkmark$ & $\checkmark$ & $\checkmark$ \\
\hline
\end{tabular}




\subsubsection{Factors influencing beginning teachers' transfer of learning of ICT- ABL and LTCD}

\section{Beginning teachers' perception of the ICT-based innovation}

The beginning teachers in the study reported their perceptions and how they valued the ICT-based innovation and its components. The results showed positive high perceptions of teachers to collaboratively design and enact ICTenhanced activity based learning as reported in Table 7.5.

Table 7.5 Beginning teachers' perceptions of ICT-ABL and LTCD (N=100)

\begin{tabular}{|c|c|c|}
\hline ICT-based innovation components & Mean & $S D$ \\
\hline \multicolumn{3}{|l|}{ ICT-enhanced activity-based learning (ICT-ABL) } \\
\hline $\begin{array}{l}\text { I believe the use of the activity-based pedagogical approach } \\
\text { supports student learning }\end{array}$ & 5.00 & 0.000 \\
\hline $\begin{array}{l}\text { I believe that the use of spreadsheet techniques supports } \\
\text { mathematical concepts formation }\end{array}$ & 4.88 & 0.331 \\
\hline $\begin{array}{l}\text { I believe that the use of teamwork among students promote } \\
\text { collaborating learning }\end{array}$ & 4.88 & 0.332 \\
\hline $\begin{array}{l}\text { I believe that the use of "interactive demonstration" helps to } \\
\text { encourage teachers to be facilitators of students' learning }\end{array}$ & 5.00 & 0.000 \\
\hline $\begin{array}{l}\text { I believe that the use of a lesson plan help to guide a proper } \\
\text { implementation of a mathematics lesson }\end{array}$ & 4.88 & 0.329 \\
\hline \multicolumn{3}{|l|}{ Learning technology by collaborative design (LTCD) } \\
\hline $\begin{array}{l}\text { I believe that it is important to design mathematics lessons in a team } \\
\text { with colleagues }\end{array}$ & 4.63 & 0.489 \\
\hline $\begin{array}{l}\text { I believe that exemplary curriculum materials helps to get a better } \\
\text { understanding on what a spreadsheet-supported activity-based } \\
\text { mathematics lesson could be provided }\end{array}$ & 4.75 & 0.439 \\
\hline Support from the facilitator was helpful in the design process & 4.88 & 0.328 \\
\hline $\begin{array}{l}\text { Learning - by -doing was a useful strategy in learning to design the } \\
\text { spreadsheet-supported activity based mathematics lessons }\end{array}$ & 5.00 & 0.000 \\
\hline
\end{tabular}

Note: 5 = strongly agree, 1 = strongly disagree.

Both components of the ICT-based innovation: ICT-ABL $(\mathrm{M}=4.93, \mathrm{SD}=0.141)$ and LTCD $(M=4.81, S D=0.267)$ were highly valued by the beginning teachers indicating that approximately six, eighteen or twenty-eight months after the professional development programme the beginning teachers held strong positive pedagogical views about the ICT-based innovation (and its components). This was evident that the preparatory programme had impacted on the teachers' views about teaching and learning with ICT which could be central in influencing their use of the ICT-based innovation in their professions or teaching practice. 
Beginning teachers' reported learner characteristics (LEC) and School environmental characteristics (SEC)

Analysis of results from the questionnaire responses indicate that beginning teachers' perceived LEC and SEC factors for the transfer of ICT-ABL and LTCD innovations differently. Based on the Hierarchical cluster analysis, eight factors influencing transfer (as reported by the teachers) were distributed in two clusters (see Figure 7.1): learner characteristics (LEC) (factors related to teachers' knowledge and skill, commitment, availability of time and their dissatisfaction with the status quo) as cluster 1 and school environment characteristics (SEC) (factors related to school culture, availability of resources, rewards and incentives and participation in decision making) as cluster 2.

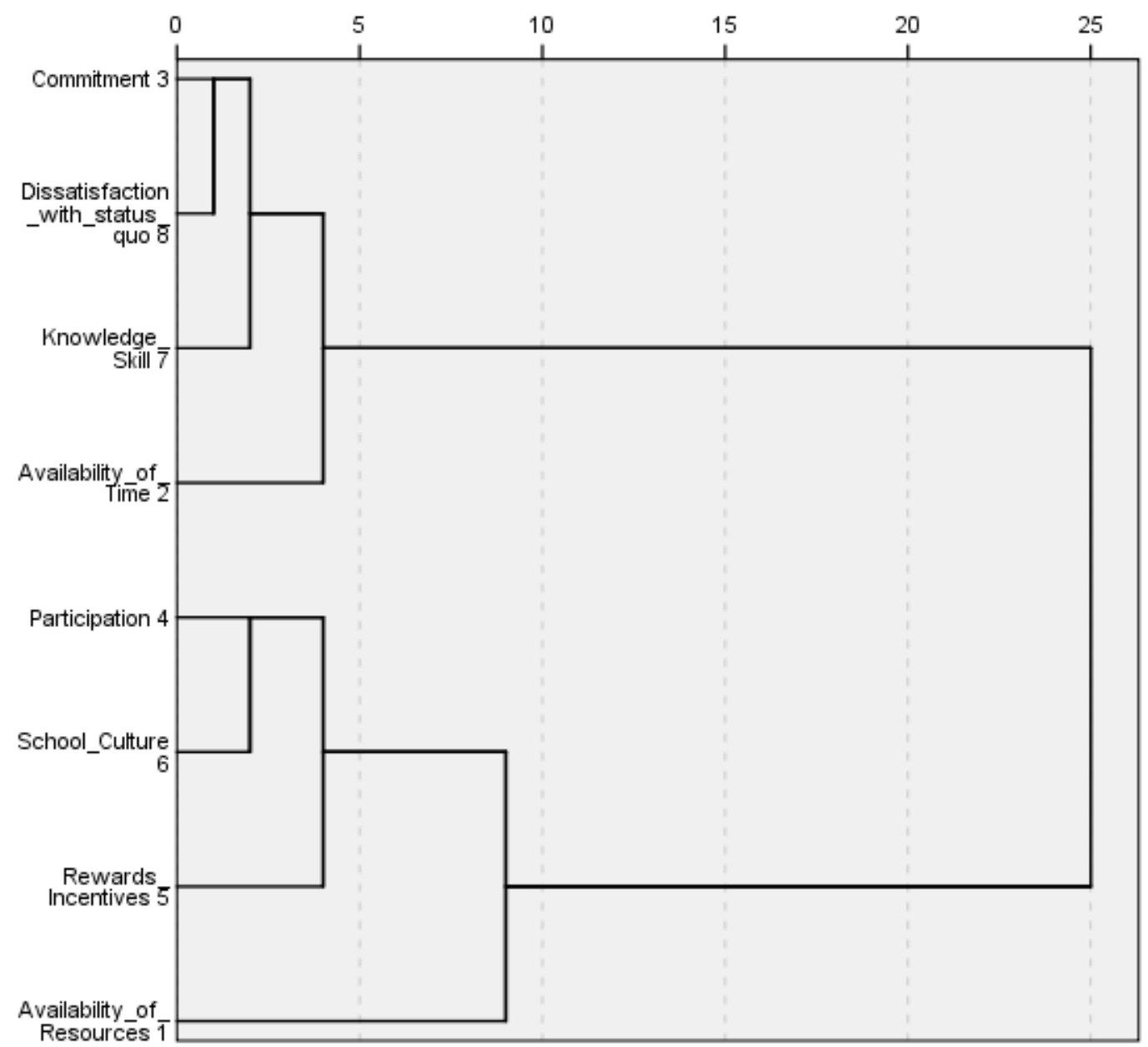

Figure 7.1 Hierarchical clustering dendrogram of conditions using Average Linkage

Cronbach's alpha was calculated for the four items comprising each cluster as shown in figure 7.2 and results were .71 for cluster 1 (LEC) and .79 for cluster 2 
(SEC) which is acceptable according to guidelines provided by DeVellis(1991). Beginning teachers tended to agree strongly to LEC cluster $(M=4.20, S D=0.451)$, while they disagreed on the SEC cluster $(M=2.48, S D=0.155)$.

In addition the standard deviation for SEC is very small, indicating that the beginning teachers did not differ much in their opinion about the SEC cluster. The differences between the mean scores of the clusters were statistically significant ( $p<0.0001$ ) for both scale scores, with a large effect size $(d=3.17)$. This seems to suggest that learner characteristics were influential in the teachers' transfer or use of the ICT-based innovation. Table 7.6 shows the ranking of the factors with their means and standard deviations as were reported by the teachers for each factor.

Table 7.6 Mean score and standard deviations for factors influencing beginning teachers transfer of learning $(N=100)$

\begin{tabular}{lcc} 
Conditions & Mean & Std Dev \\
\hline LEC & & \\
\hline Skills and knowledge & 4.57 & .355 \\
\hline Dissatisfaction with status quo & 4.48 & .383 \\
Commitment & 4.21 & .287 \\
\hline Availability of Time & 3.75 & .562 \\
\hline SEC & & \\
\hline Rewards and Incentives & 3.17 & .137 \\
Participation & 3.02 & .103 \\
\hline School Culture & 2.05 & .292 \\
\hline Resources & 1.71 & .011 \\
\hline
\end{tabular}

Overall, knowledge and skills was the most valued factor reported; indicating the beginning teachers knowledge and skilled' acquired during the preparatory programme was the most influential factor for successful transfer of the ICTbased innovation. This was followed by beginning teachers' dissatisfaction with status quo. Beginning teachers expressed their dissatisfaction on the existing methods of instruction and reiterated the need to change the existing teaching approaches. Table 7.5 also indicates that the teachers' commitment and availability of time were important factors that contributed to their use of the ICT-based innovation.

The availability of ICT resources, school culture and teachers participation in decision-making however, were weak in promoting the teachers' use of the ICT- 
based innovation. As a matter of fact, lack of ICT resources and an unfavorable school culture especially were perceived as barriers which hindered the teachers' use of the ICT-based innovation. The teachers expressed their frustrations regarding these observations in the interview data in various ways:

Very few resources are available. Apart from the problem with ICT resources, there are also problems with timetabling. The period for teaching mathematics with ICT is very short whereas the workload is huge (T03).

The leadership of the school does not afford a high enough priority to ICT planning and implementation. As far as leadership goes in the school, use of ICT-based innovation is not a large focus so there is little I can do (T10).

My school did not organise any in-service training and time table structure do allow precise considerations to access computer labs for teaching (T04).

\subsubsection{Predicting teachers' transfer of ICT-ABL and LTCD in their teaching practices.}

The study postulates transfer of learning (ICT-ABLtransfer and $L T C D_{\text {transfer }}$ ) as a function of beginning teachers reported learner characteristics (LEC), their school environment characteristics (SEC) and their perceptions about the characteristics of ICT-ABL (ICT-ABLperceptions) and LTCD (LTCD perceptions).The exact weights of each parameter and relations between them were determined empirically.

Table 7.7 shows the results of the co-efficient of the factors for predicting the teachers' transfer of learning of the ICT- based innovation. The results (model 1) indicates that the $\mathrm{R}^{2}$ for transfer of learning regarding learning technology in collaborative design predicted from the teachers' perception about LTCD showed that $28 \%$ of the variance in the transfer of LTCD in teaching practices was found to be attributable to the LTCD innovation characteristics.. The $F$ test ( $F=(1,98)=37.91, p<0.001)$ associated with the independent variable

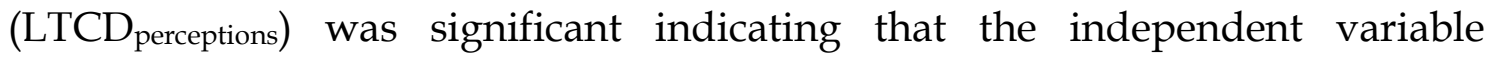
predicted the dependent variable if only the "LTCD perception" scale was 
considered in the model. Adding the LEC measure increased the predictability for $L T C D_{\text {transfer }}$ from approximately $28 \%$ to approximately $45 \%$. Although the

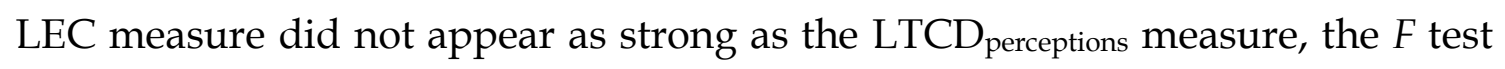
$(F(2,97)=14.65, p=0.043)$ was significant (at 0.05$)$ for the model; the SEC measure was an unacceptable predictor $(F=(3,96)=0.34, p=0.982)$.

Similar to model 1 , the ICT-ABLperceptions $(r=0.46, p<0.001)$ scale in model 2 appeared to be the strongest predictor for teachers transfer of learning in enacting ICT-ABL; SEC was an unacceptable predictor. Thus in both models, beginning teachers' positive perceptions about the ICT-based innovation seemed to have had the strongest impact on teachers' transfer learning and use of the ICT-based innovation.

Table 7.7 Coefficients of predictors: School environment characteristics (SEC), learner characteristics (LEC) and perception about the ICT-based

\begin{tabular}{|c|c|c|c|c|c|}
\hline & $\mathbf{R}$ & $\begin{array}{l}\text { R- } \\
\text { square }\end{array}$ & $F($ Sig) & $\begin{array}{l}\text { Standardized } \\
\text { coefficients }\end{array}$ & Sig \\
\hline \multicolumn{6}{|l|}{ Model 1: $L T C D_{\text {transfer }}$} \\
\hline Impact of $\mathrm{LTCD}_{\text {perceptions }}$ & 0.53 & 0.28 & $37.91(0.000)^{*}$ & $0.44(p)$ & $0.0001^{* *}$ \\
\hline Impact of LTCD $_{\text {perceptions and LEC }}$ & 0.67 & 0.45 & $\begin{array}{l}14.65 \\
(0.043)^{*}\end{array}$ & $\begin{array}{l}0.41(p) \\
0.24(t)\end{array}$ & $\begin{array}{l}0.0001^{*} \\
0.009^{*}\end{array}$ \\
\hline Impact of $\mathrm{LTCD}_{\text {perceptions, LEC and SEC }}$ & 0.67 & 0.45 & $0.34(0.982)$ & $\begin{array}{l}0.39(p) \\
0.21(t) \\
-0.04(s)\end{array}$ & $\begin{array}{l}0.0001^{* *} \\
0.011^{*} \\
0.284\end{array}$ \\
\hline \multicolumn{6}{|l|}{ Model 2: ICT-ABL transfer } \\
\hline Impact of ICT-ABL perceptions & 0.46 & 0.21 & $\begin{array}{l}28.58 \\
(0.000)^{*}\end{array}$ & $0.39(p)$ & $0.0001^{* *}$ \\
\hline Impact of ICT-ABL perceptions and LEC & 0.65 & 0.42 & $\begin{array}{l}17.56 \\
(0.000)^{*}\end{array}$ & $\begin{array}{l}0.36(p) \\
0.28(t)\end{array}$ & $\begin{array}{l}0.0001^{\text {** }} \\
0.005^{*}\end{array}$ \\
\hline $\begin{array}{l}\text { Impact of ICT-ABL perceptions, LEC and } \\
\text { SEC }\end{array}$ & 0.65 & 0.43 & $0.56(0.811)$ & $\begin{array}{l}0.34(p) \\
0.24(t) \\
-0.10(s)\end{array}$ & $\begin{array}{l}0.0001^{* *} \\
0.010^{*} \\
0.312\end{array}$ \\
\hline
\end{tabular}

Note: ${ }^{* *} \mathrm{p}<0.0001 ;{ }^{*} \mathrm{p}<0.05 ; \mathrm{p}=$ perception of beginning teachers, $\mathrm{t}=\mathrm{TEC}, \mathrm{s}=\mathrm{SEC}$.

\subsection{Discussion}

This study examined the extent to which beginning teachers were able to transfer their knowledge and skills to utilize an ICT-based innovation, existing of two components: learning of technology by collaborative design (LTCD) and 
ICT-enhanced activity-based learning (ICT-ABL) which they learnt in their final year of their pre-service preparation education programme. In particular, the study sought to attain an understanding of how beginning teachers reported learner characteristics, school environment characteristics and characteristics of the ICT-based innovation itself, influenced transfer of learning in teachers' professional and teaching practice.

Results of the study showed that beginning teachers continued to employ aspects of the ICT-based innovation in their professional and teaching practice. With regards to the first component of the ICT-based innovation, Learning Technology by Design (LTCD), the beginning teachers reported using the "learning - by -doing" approach and the exemplary materials extensively in designing their own lessons. The teachers had no longer the support from resource persons to their disposal when designing their lessons, but that apparently did not hinder them. Collaboration in design teams to design lessons was no longer a practice among the teachers. It appears that disparity between the beginning teachers and their other colleagues hindered collaboration between these groups of teachers. In most cases, their colleagues (senior teachers) were un willing to collaborate to design ICT related lessons. The beginning teachers also indicated to what extent they continued using the ICT-ABL innovation when enacting lessons within the existing support structures of their respective schools.

It was apparent that use of teamwork among their students, use of lesson notes in guiding lessons and use of activity-based pedagogical approach were common practices among the beginning teachers. On the other hand, use of "interactive demonstrations using spreadsheets" and use of spreadsheet techniques as an instructional tool to support mathematical concepts formation appeared to be an on-going challenge. Beginning teachers reported factors which facilitated or inhibited their continued use of different aspects of the ICT-based innovation.

The results showed that, after several months of finishing their teacher education preparatory programme, beginning teachers hold strong positive pedagogical views about the ICT-based innovation; which seemed the most influential factor on teachers' transfer and use of the ICT-based innovation. Results from the regression analysis showed that the second most influential factor affecting teachers' use of the ICT-based innovation were their learner 
characteristics. A significant amount of variance attributed to the teachers' learner characteristics explained differences in the level of transfer of the ICTbased innovation in LTCD and ICT-ABL. The most critical learner characteristics which were reported were knowledge and skills. It was encouraging to note that most beginning teacher's reported to have sufficient knowledge and skills which indicates how well the preparatory programme contributed to teachers' professional learning.

The second most critical condition: teachers' dissatisfaction with the status quo shows that the teachers saw the need to change existing teaching approaches towards approaches which support ICT-based innovations. This also suggests those teachers' views about teaching or existing teaching approaches were central in influencing their transfer of learning of ICT-based innovations in their professional and teaching practice.

Furthermore, the teachers' commitment factor was also reported by beginning teachers to have promoted transfer of learning. Riel and Becker (2008) indicated that, teachers who are motivated and have strong commitments to their pupils' learning and their own professional development as teachers will evidently integrate ICT-based innovations, such as ICT-enhanced activity-based learning more easily within their teaching.

Regarding the school environment characteristics, both models of the regression analysis indicated that they were not significant in determining transfer of learning for beginning teachers' use of the ICT-based innovation. This contradicts with studies conducted in the Western world (Snoeyink \& Ertmer 2002;Benson \& Palaskas, 2006; Mumtaz, 2000; Bate 2010) that have identified school-related factors as important in implementing an ICT-based innovation. A possible reason which could explain this phenomenon was the small standard deviation in the school-related factors, as was also confirmed by the interview data. Conditions regarding school-related factors did not seem to differ much across schools and in most cases were perceived as hindrances. The lesson observations confirmed that participants faced a complex mix of schoolrelated constraints that when combined, contributed to a lack of creativity in using certain components, particular those that required ICT facilities, of the ICT-based innovation. Particularly, lack of access to the ICT infrastructure and an unenthusiastic school culture were pronounced. Although some schools in 
this study achieved success in equipping and maintaining their school, in most cases ICT facilities were not accessible in classrooms. This impacted on creative use of ICT-enhanced activity-based learning, particularly in large classes. Often, even the most enthusiastic teachers could do little more than rotate students through teachers' personal computers in their classrooms. In situations where a centralized computer laboratory was available, participants struggled to gain appropriate and timely access. This state of affairs is also common in the literature (Groff \& Mouza, 2008) and also supports the contention that the specific positioning of computers in the school can foster or hinder ICT-based innovation use in teaching and learning (Tondeur, Valcke, \& Van Braak, 2008). Thus although attempts were made to explain the non-significance level of the school environment characteristics in the regression models, further investigation of school environment characteristics in similar contexts as the teacher preparation programme in Ghana seems warranted.

\subsubsection{Practical implications}

Although the findings of the study showed that a significant amount of variation in the transfer of learning and the utilization of the ICT-based innovation could be attributed to the teacher-related factors, the study does not underrate the role of school environment characteristics in influencing transfer of learning in beginning teachers professional and teaching practice. It is therefore important that Parent Teachers' Association, School Management and Boards put priority on the provision of ICT facilities in Ghanaian schools (e.g. mathematics laboratories, computers and projection devices in classrooms) to facilitate and increase access of teachers.

The culture of teaching and the organization of schools served as obstacles to the effective use of the ICT-based innovation. This means that at the school level, there is an urgent need to promote innovative school cultures such as: schoolbased in-service professional development opportunities, flexibility of classroom timetable and willingness to change exiting traditional approaches. A big challenge therefore is to figure out what suite of support principles and school leadership for schools in this context need to help them provide the type of pedagogical leadership in ICT integration and support that will inspire new teachers (as well as other staff) to push the boundaries of using ICT-based innovations. One solution is for providers of pre-service education, to have collaborative programmes with the schools. Apart from providing support for 
the school leadership, such a "symbiotic" partnership will help in addressing the realities of specific teaching contexts; provide a forum for school and pre-service providers to think together about the learning needs of beginning teachers.

The study also unveiled that lack of support in the face of a wide range of responsibilities was a compelling challenge for beginning teachers' use of the ICT-based innovation in their practice. For instance while ensuring that the curriculum was covered was particularly important to the beginning teachers in this study, questions like: "how teachers could balance the demands of a crowded curriculum with providing students with opportunities to explore mathematical concepts using ICT in ways that embrace the principles of lifelong learning" and "how effective models of ICT use that cut across curricula and timetable constraints could be addressed" were concerns raised by the beginning teachers. According to Feiman-Nemser (2001) these multiple challenges of teaching alone for the first time can discourage new teachers from trying ambitious pedagogies and that good induction support could keep novices from abandoning these approaches in favor of what they may perceive as safer, less complex activities. This study has implications in this direction, to advocate for the introduction of induction programmes for beginning teachers in the context of Ghana and similar contexts. Such a programme will serve as a short term support to ease new teachers' entry into the teaching profession and to help them cope with their first year on the job.

One way to make this possible is for providers of pre-service education to extend pre-service preparation through the early years of teaching for beginning teachers. In Ghana, the teacher education institution together with the Ghana Education service could spearhead the design and implementation of such a programme. It is therefore important to emphasize that if the goal of transforming teaching and learning through ICT-based innovations is to move beyond rhetoric, and then there are many bridges to cross at the teacher and school levels as well as teacher preparation institutions and other stakeholders. In conclusion the study draws attention to the importance of transfer of learning particularly in the situation of the development and implementation of educational innovations in developing countries to help lessen the gap between learning and sustained work performance for the reason that many innovations in this context are very vulnerable and fail to be transferred. 


\title{
CHAPTER 8 \\ Discussions and reflections
}

\begin{abstract}
In this final chapter, the results from the different studies of the previous chapters are discussed. The chapter starts with a general overview of the research stating the aims and research questions. Next, a summary of the research phases and results is presented, followed by a reflection on the research approach. Thereafter the outcomes of the entire study are reflected upon and discussed. The chapter ends with recommendations for practice and directions for future research.
\end{abstract}

\subsection{RECAPITUlation: AIMS AND RESEARCH QUESTIONS}

Meaningful use of ICT in education requires teachers to develop attitudes, knowledge and skills that enable them to integrate ICT with a suitable pedagogical approach for teaching specific subject matter in a certain context. Mathematics teachers in Ghana do not have the background knowledge and proper skills set to engage the power of ICT and to involve students in learning while teaching mathematics. To prepare prospective teachers for technology integration, the teacher preparation programme at the University of Cape Coast (UCC) in Ghana embarked on a set of studies with the aim to design and implement a professional development arrangement for the integration of ICT in teaching mathematics for pre-service teachers.

The professional development arrangement was based on the assumption of Koehler \& Mishra (2008) that effective ICT integration for teaching specific content or subject matter requires Technological Pedagogical Content Knowledge (TPACK), an understanding of the relationships between three primary domains of knowledge that a teacher needs: Technological knowledge (TK), Pedagogical Knowledge (PK) and Content Knowledge (CK) as well as the interplay and intersections. In this study Technological knowledge was operationalized as 
spreadsheets, a specific ICT application, which could contribute to higher order thinking skills in mathematics and was readily available in Ghana's senior high schools and in the teacher education programme.

To actively involve pupils in their learning of mathematics Activity Based Learning was used as pedagogical approach. In the research, pre-service teachers collaboratively designed and enacted spreadsheet-based lesson materials to prepare pre-service mathematics teachers to teach specific mathematics content enriched with spreadsheets. The reason for espousing collaborative design teams in the research was to provide opportunity for pre-service teachers to develop their attitudes, knowledge and skills in ICT integration through the design and enactment of ICT-based curriculum materials.

The central question for the research was framed as follows:

How should collaborative design in design teams be applied in pre-service teacher education to prepare pre-service mathematics teachers for the integration of spreadsheets in their future lessons?

In order to find answers to the main question, the following sub-research questions guided the research phases:

1. What are barriers, needs and opportunities of pre-and in-service mathematics teachers' use of ICT in teaching mathematics at senior high schools in Ghana?

2. How do ICT attitudes, competencies and access of pre-and in-service mathematics teachers differ and to what extent do the parameters predict teachers' ICT integration levels?

3. What are pre-service mathematics teachers' experiences in developing and implementing technology-enhanced lessons through collaborative design teams?

4. How do pre-service teachers' knowledge and skills in designing and enacting spreadsheet supported activity-based lessons develop and to what extent do the lessons impact on secondary school students learning outcomes?

5. Which impact does a mathematics specific course, in which pre-service teachers collaboratively design spreadsheet-supported mathematics lessons in teams, have on pre-service teachers' technology competencies (attitudes, knowledge and skills)? 
6. To what extent is transfer of learning influenced by beginning teachers' learner characteristics, characteristics of the ICT-based innovation, and school environment characteristics in their professional and teaching practice?

\subsection{RESEARCH PHASES AND RESULTS}

\subsubsection{First study: Feasibility of ICT use in teaching mathematics}

At the initial stage of the research a context and needs analysis study was conducted among pre-service and in-service mathematics teachers, principals (from senior high schools), heads (from the teachers education programme at UCC and a representative from the curriculum and ICT section, Ghana Education service, to explore the feasibility of ICT use in mathematics teaching in Ghana (see also chapters 2 and 3).

The purpose of this study was to provide an understanding of the context of mathematics teaching in the Senior High Schools (SHS's) and to inform and support the development of ICT integration in the UCC teacher preparation programme. By assessing the perceptions of the various stakeholders regarding the current mathematics curriculum, especially in relation to the use of ICT, chapter 2 reported on challenges and perceived barriers in integrating ICT. ICT training needs of mathematics teachers, opportunities that existed to prepare preservice teachers to effectively design and implement ICT in teaching mathematics were also reported. Findings of the study revealed that, mathematics teachers in Ghana do not integrate ICT in their mathematics instruction, and that the most frequently used pedagogical strategy by the teachers was the teacher-centred approach in which teachers do most of the talking and intellectual work, while students are passive receptacles of the information provided. Among the major perceived barriers which hindered use of ICT were: lack of knowledge and skills about ways to integrate ICT in lessons and lack of opportunities for both pre-and in-service teachers to learn and practice ICT integration.

The results revealed that the development of teachers' knowledge and skills in the integration of ICT in mathematics education was a major need. This however, was not part of the teacher preparatory programme at UCC. The study also revealed that secondary high schools lacked common mathematical software 
(such as derive, graphic calculus, geometer's sketchpad etc.) which can be used for teaching mathematics in the classrooms; but most schools had computer labs.

In conclusion, chapter 2 reported that in spite of challenges, it was encouraging to find that in-service and pre-service mathematics teachers appeared generally supportive indicating positive attitudes to use ICT as an instructional tool in their classrooms.

Chapter 3 reported an in-depth analysis of pre-service and in-service teachers' will (attitudes), skill (technology competency), and tool (access to technology tools) as essential ingredients for a teacher to integrate ICT into classroom practices. The results indicated fairly low ICT competencies with significant differences existing between pre-service and in-service teachers. The pre-service teachers in this study showed more anxiety and were less ICT competent than the in-service teachers. It was also identified that computer anxiety was the most important dimension of attitudes towards ICT use and that skill was the strongest predictor of classroom integration of ICT for the pre- and in-service teachers. The results of the study suggested that increasing pre- and in-service teachers' ICT skills and decreasing their anxiety should be an integrated part of the design of professional development arrangements for pre- and in-service teacher education.

The study (as reported in chapters 2 and 3) concluded by recommending design professional development opportunities that focus on preparing pre-service teachers to acquire skills on how to integrate technology effectively in their instruction - taking the context of the available ICT infrastructure into account.

\subsubsection{Second study: Developing TPACK through collaborative design in a professional development programme}

Based on the outcomes of the context and needs analysis study, a professional development programme based on 'learning technology by design' was piloted. TPACK was used as a conceptual framework to examine the knowledge and skills pre-service math teachers developed about ICT, pedagogy and content (see also chapter 4 ).

The arrangement involved four pre-service teachers who worked collaboratively in design teams (DTs) to design and develop ICT solutions for 
authentic problems they face in teaching mathematics concepts. The technology learned by the pre-service teachers was spreadsheet applications because it has the potential of supporting students' higher-order thinking in mathematics and is readily available.

Pre-service teachers were asked to carefully choose instructional strategies they felt will be useful in supporting their lessons. Exemplary curriculum materials were used to provide pre-service teachers with the theoretical and practical insights of spreadsheet-supported lessons and hands-on experiences. The DTs developed and modelled their own lessons after the exemplary materials and subsequently taught their peers in an ICT-based environment for the first time.

Pre-service teachers' participation in collaborative design teams increased their knowledge and skills to design and use ICT-enhanced mathematics lessons. Pre-service teachers enhanced their knowledge in their subject matter and were able to make intimate connections among their specific content, pedagogy and technology in a collaborative way.

The results showed that collaborative design was a useful approach for preservice teachers' development of TPACK. Along with working in DTs, the exemplary materials supported the pre-service teachers by: promoting a better understanding of what integrating technology in lessons is about, promoting pedagogical design capacity, providing a concrete how-to-do suggestions and facilitating a better implementation of the innovation.

Although the study showed the potential of TPACK to be a new frame for developing experiences for future teachers, it cannot be said that the professional development programme in the study fully developed the teachers' TPACK.

Further opportunities to experience learning about the affordances of technology applications were necessary for teachers to explore further topics and concepts in their mathematics curricular to develop their TPACK much better. Lessons from the study supported the contention that TPACK is a useful analytic lens for studying teachers' integration of technology, content, and pedagogical knowledge and skills as it develops over time in "learning technology by design" settings. 
Finally, the study proposed design guidelines (discussed further in section 8.4.1) for developing TPACK-competent pre-service teachers in the context of Mathematics pre-service education in Ghana.

\subsubsection{Third study: Measuring competencies for Activity Based Learning with technology}

A third study was conducted in the same University but extending the professional development programme to real classroom settings in various senior high schools (see chapter 5).

In the study, ICT, spreadsheets in particular, was presented as a tool for enacting a guided activity-based pedagogical approach, referred to as ActivityBased Learning (ABL) of teaching mathematical concepts. Twelve pre-service teachers participated in this study. The teachers worked in teams of two to develop and model their own spreadsheet-supported lessons, for suitable mathematics topics from the SHS curriculum, based on the exemplary materials. Six activity-based mathematics lessons supported with spreadsheets were developed and enacted twice: first by teaching their peer pre-service teachers and later by teaching senior high school students.

Results of the study indicated that the pre-service teachers enacted their lessons using an activity-based instructional approach in which spreadsheets were integrated to help students explore mathematics concepts and perform authentic tasks. In their lesson plans and during observed instruction the preservice teachers demonstrated knowledge and skills in designing and enacting activity-based lessons supported with spreadsheets. This was confirmed by the self-reported development of the knowledge and skills needed to design and enact spreadsheet-supported ABL lessons as were observed by significant gains in all the TPACK components.

To assess the impact of the spreadsheet-supported ABL mathematics lessons on secondary school students' learning outcomes, two pre-service teachers taught their lesson in the spreadsheet-supported ABL pedagogical approach (experimental group) and in a common teacher-centred approach (control group). Significant differences with large effect sizes were found between preand post-mean gains on a performance test in favour of students who followed the spreadsheet-supported ABL approach compared to the teacher-centred taught lessons. 
The findings supported arguments that the spreadsheet-supported ABL approach fosters learner-centred classroom practices, is a useful pedagogical approach and has potential to improve mathematics teaching, learning and achievement in secondary education.

It was concluded that exposing teachers to activity-based learning supported with spreadsheets through collaborative design teams is a good way to help pre-service teachers develop deeper connections between their subject matter, instructional strategy and spreadsheet application to enhance their TPACK.

\subsubsection{Fourth study: Implementing design guidelines in a mathematics- specific instructional ICT course}

This study reports on the integration of the professional development programme (developed and applied in the previous studies and reported in chapters 4 and 5) into a regular mathematics-specific instructional technology course in the mathematics teacher preparation programme of the University of Cape Coast.

The design guidelines used and reported in chapters 3 and 4 were applied in the design of the mathematic-specific course to develop pre-service teachers' spreadsheet integration competencies (see also chapter 6). In addition to those design guidelines, opportunities for scaffolding authentic ICT experiences were also created for pre-service teachers. The importance of authentic teaching experiences with ICT was demonstrated in teaching try-outs in which preservice teachers put into practice their designed lessons.

One hundred and four pre-service mathematics teachers from the teacher preparation programme at UCC enrolled in the course for one semester to develop their ICT integration competencies in teaching mathematics. As was the case in the previous studies pre-service teachers collaborated in design teams to design spreadsheet-enhanced activity-based lessons for mathematics. Two groups of pre-service teachers were distinguished; those who were involved in a try-out (PT) of their designed lessons by teaching their peers and those who did not have any teaching try-outs experience (NPT).

Findings showed that the impact of the IT course on the pre-service teachers' competencies for both PT and NPT was reflected in the increase of their attitude towards technology, their self-reported development in TPACK, and their lesson plans and lesson enactment. 
The impact of the IT course however differed between pre-service teachers who were involved in the teaching try-out (PT) and those were not (NPT). Teachers involved in the teaching try-out had less anxiety and more enjoyment, a higher increase in their self-reported TPACK, and lesson plans which better reflected TPACK than pre-service teachers not involved in the teaching try-out. The preservice teachers involved in the lesson try out demonstrated in their lesson plans and lesson enactment their ability to integrate technology in teaching mathematics in a sound way, much more than their peers who did not have the opportunity to teach the lesson for peers and instructors.

Thus, although both groups of teachers (PT and NPT) developed and improved their competencies in the IT course, the evidence from the study showed that pre-service teachers involved in the teaching try-out developed their competencies better. One obvious reason for developed and improved competencies, particularly with the PTs, was the authentic technology experiences they acquired during the teaching try-outs. Furthermore, the contribution of feedback from their peers and the researcher during the try-out was an added advantage for improved competencies of PTs.

\subsubsection{Fifth study: Examining factors affecting beginning teachers' transfer of learning in professional and teaching practices in Ghana.}

Approximately six, eighteen, and twenty-eight months after the third, second and first interventions respectively, the pre-service mathematics teachers who participated in the study had been posted into various senior high schools and were pursuing their careers as mathematics teachers.

This study employed an embedded mixed method research design to examine the extent to which 100 of the beginning teachers' were able to transfer their knowledge and skills to utilize the ICT-based innovation.

The ICT-based innovation consisted of two related components: (1) learning of technology by collaborative design (LTCD) (process) of (2) ICT-enhanced activity-based lessons in mathematics (ICT-ABL) (product). Based on Baldwin \& Ford (1998), this study postulated transfer of learning as a function of: 1) characteristics of the ICT-based innovation; 2) beginning teachers' learner characteristics and 3) school environment characteristics. 
The study sought to attain an understanding of how these characteristics influenced transfer of learning in the teachers' professional and teaching practice.

The findings showed that the beginning teachers still hold positive pedagogical views developed during collaborative design in teams in their pre-service teacher preparation programme, and this seemed to be the most influential factor on teachers' transfer and use of the innovation. The second most influential factor affecting teachers' use of the ICT-based innovation was their learner characteristics. A significant amount of variance attributed to the teachers' learner characteristics explained differences in the level of transfer of the ICT-based innovation.

The most critical learner characteristics which were reported were knowledge and skills. It was encouraging to note that most beginning teacher's reported to have sufficient knowledge and skills which indicates how well the preparatory programme contributed to teachers' professional learning. School environment factors were not a significant predictor of transfer of learning, probably because of lack of variation in the school-related factors across the schools. However, interview and observation data indicated that teachers were faced with constraints related to their school environment that contributed to lack of creativity in using certain components of the ICT-based innovation. Particularly, lack of access to the ICT infrastructure and an unenthusiastic school culture were mentioned as hindering the use of ICT-ABL.

In conclusion, the study reported that although a significant amount of variation in the transfer of learning and the utilization of the ICT-based innovation could be attributed to the teacher-related factors in the context, the role of school environment characteristics in influencing transfer of learning in beginning teachers' professional and teaching practice must not be underrated and may need further research to explore its impact on transfer better.

\subsubsection{Overall conclusion of the study}

Based on responses and experiences of the pre-service teachers, the research demonstrated that pre-service teachers TPACK developed and that they felt prepared to effectively use ICT in their classroom. 
The outcomes of the research showed that collaborative design in design teams in pre-service teacher education is a viable and effective approach to prepare preservice mathematics teachers for the integration of technology and activity-based learning in mathematics lessons. Because pre-service teachers had to design and enact ICT-enhanced mathematics lessons opportunities were provided to develop their knowledge and skills and make intimate connections between technology (spreadsheets), content (mathematics) and pedagogy (activity-based learning). While pre-service teachers collaborated during design and enactment, knowledge and attitudes about ICT and activity-based learning became explicit, which helped them to reflect on their experiences, and hence fostered learning.

\subsection{REFLECTING ON THE RESEARCH APPROACH}

Design-based research has been adopted and served a suitable approach to this research in the Mathematics pre-service education in Ghana. Its capability to develop creative approaches for solving performance or teaching/learning problems and at the same time constructing a body of design guidelines that informs theory that could be used to guide efforts in future developments of pre-service teachers' experiences in technology integration (cf. Reeves, 2006) was a reason for adopting design-based research. Wang and Hannafin (2005) indicated that design-based research leads to contextually-sensitive design principles and theories.

Although some scholars use the term design principles (Reeves, 2006; Wang \& Hannafin, 2005, Van den Akker, Gravemeijer, McKenney \& Nieveen, 2006), this study has adopted the term design guidelines to characterise the design of the professional development programme. Through literature review, a needs- and context analysis and (formative) evaluation valid, practical and effective guidelines for the design of mathematic-specific professional development programmes to prepare pre-service teachers to teach with technology were derived, which yielded positive results in the specific context of the mathematics education programme in UCC.

A discussion on the details of the design guidelines, a major outcome of this research, is presented in section 8.4.1. 
Concerns relating to sustainability of outcomes of design-based research, such as the ICT-based innovation in this study, have not often been addressed in designbased research (Van den Akker et al., 2006). For this reason Van den Akker et al. (2006) proposed that 'sustainability' is an important aspect of the quality of designbased research. However, they did not give an indication of how 'sustainability' could be determined. In this study, transfer of learning has been used as an indicator of sustainability to assess how pre-service teachers continued to employ aspects of the ICT-based innovation in their professional and teaching practice. Chapter 7 provides details on how transfer of learning was measured.

By being a faculty member at UCC, it was easier for the researcher to gain understanding and insights of the context and the associated research problems. This also aided the process of ICT integration and made it possible for the data collection activities to be seamlessly integrated into the teacher education programme.

Typical for design-based research, and as was the case in this research project, was how to account for the role of the researcher and the associated threats to internal validity that come with it. In this study the researcher had to play overlapping roles: facilitator (demonstrative, during lecture sessions and workshop organizations and consultative during the design sessions); observer (during design and participants' teaching try-outs) and researcher (during data collection sessions). Caution was taken to ensure that results reported were honest and accurate reflecting valid scientific conclusions without biases. For example, careful steps were taken to ensure triangulation through the use of multiple data sources; multiple data methods and involvement of multiple coders in the analysis of qualitative data to ensure validity and reliability of results (cf. Cohen, Manion, \& Morrison, 2007). The return of the researcher during the transfer study, which followed up on pre-service teachers who participated in research, also helped to attain a better understanding of the results of this research. 


\subsection{OUTCOMES AND REFLECTIONS}

\subsubsection{Design guidelines for preparing pre-service teachers in mathematics teacher education}

One major outcome of applying design-based research in this project has been the constructing of a body of design guidelines that could be used to guide efforts in future developments of pre-service teachers' experiences in technology integration.

Based on this research the following design guidelines have been formulated:

- Collaborative Design Teams, in which pre-service teachers work with peers, are an important means to stimulate and support teacher learning. This approach of ICT integration will improve interaction and interdependence among preservice teachers; making them discover how to share knowledge and ideas as well to brainstorm on relevant information relating to their designs.

- Exemplary curriculum materials are an important means as they can inspire teachers to learn and provide a better understanding of an innovation (cf. Van den Akker, 1988). Exemplary curriculum materials will promote a better understanding of what integrating technology in lessons is about, promote pedagogical design capacity, provide a concrete how-to-do suggestions and facilitate a better implementation of ICT-based innovations.

- For more effective collaboration with the use of the exemplary materials and working in design teams, an orientation programme is important. Such an orientation programme for pre-service teachers should provide a learning experience where conceptual and theoretical information could be linked to a practical application.

- Adoption of technology that is readily available with the potential of supporting students' higher-order thinking in mathematics is key to a successful intervention in integrating technology. By learning how to use existing hardware and software in creative and situation-specific ways to accomplish their teaching goals, pre-service teachers will be prepared to use ICT in their professional and daily classroom practices.

- Scaffolds and authentic technology experiences, such as teaching try-outs with peers should be an integrated part of a pre-service teacher preparation programme aiming to develop pre-service teachers' technology integration competencies. This allows pre-service teachers to put into practice their designed lesson plans and that through feedback from peers, scaffolds are provided. 
It is also evident that observing an ICT-based lesson being modelled is an important motivator for pre-service teachers to integrate technology into their own practices (cf. Haydn and Barton 2007), but caution should be taken to ensure that such exemplary lessons provide meaningful and effective technology examples. Secondly, over reliance of exemplary materials can ruin the creative thinking of pre-service teachers, to construct their own ICT-based lessons since they will tend to replicate what has been designed and modelled to them.

The research demonstrated that these design guidelines account for developing and improving, technology integration competencies, but scaffolding authentic technology experiences including feedback from teaching try-outs particularly plays the most significant contribution to pre-service teachers' development of technology integration competencies. The importance of authentic teaching experiences with technology contributes to the reduction of pre-service teachers' anxieties thereby increasing their enthusiasm to use technology in instruction.

\subsubsection{Technological Pedagogical Content Knowledge (TPACK)}

In this research TPACK has been used as a conceptual framework in preparing pre-service teachers for ICT integration because it seemed an interesting and useful framework to better understand what knowledge base teachers need to incorporate ICT in teaching. TPACK is often assessed on a more generic and abstract level measuring perceived knowledge which is not tailored towards specific content knowledge, specific pedagogical knowledge or specific technological knowledge as was in the case of this research project.

The research described in this dissertation particularly focused on specific spreadsheets applications in enacting a guided activity-based pedagogical approach to develop pre-service teachers TPACK in teaching mathematics.

The research demonstrated that pre-service teachers' TPACK was developed as a result of the intervention in the three studies (chapters 4, 5 and 6). The research provided insights about how ABL as a pedagogical approach (representing the " $\mathrm{P}$ " in the TPACK model) and spreadsheets applications (representing the " $\mathrm{T}$ ") needs to be designed in close relationship to each other to create a learning environment in which mathematics content could be taught. The focus on the affordance of a specific technology (spreadsheets) and a specific pedagogy (ABL) to foster high order thinking skills in mathematics as a specific operationalisation 
of TPACK is closer to the original conception of Schulman's (1986) ideas of Pedagogical Content Knowledge, than the general way TPACK is used in many studies (Voogt, Fisser, Pareja Roblin, Tondeur \& Van Braak, 2012).

The results of this study has shown this specific focus helped pre-service teachers to develop deep connections between their subject matter, the instructional strategy and the ICT application, fostering their TPACK.

It appears that the explicit focus on ABL use and spreadsheet in particular raises questions on whether the pre-service teachers will develop their TPACK in similar initiatives using other ICT applications and pedagogical approaches. The researcher contend that once pre-service teachers understand their contextspecific, strategies and representations in which new technologies are integrated (cf. Harris, Mishra \& Koehler, 2009; Koehler et al. 2007) they will further develop knowledge and skills related to TPACK in a valid and reliable way.

It is also apparent that using multiple data sources is a good way to assess preservice teachers TPACK. The research enhanced better understanding and nature of the pre-service teachers' TPACK development through the multiple data measures: while the self-reports assessed what the pre-service teachers think they know about teaching spreadsheet supported ABL lessons but not necessarily that they can indeed teach (cf. Kereluik, Casperson \& Akcaoglu, 2010; Alayyar, 2011), the assessment of their lesson plans and lesson enactment provided specific information and concrete representation of what pre-service teachers could actually do with spreadsheets to develop their TPACK (cf. Alayyar, 2011).

Alongside the need to use TPACK as a conceptual framework to develop preservice teachers' knowledge and skills, it is important that teachers' attitudes towards technology integration be understood to appropriately determine their competencies, understood as the integration of knowledge, skills and attitudes, which pre-service mathematics teachers need to integrate technology into their lessons.

\subsubsection{Potential of spreadsheet and Activity-Based Learning}

In this research spreadsheets were used because they are readily available on most computers and are an ICT application that is relevant for developing mathematics pre-service teachers TPACK. Activity Based Learning (ABL) was 
applied as a pedagogical environment for the use of spreadsheets. ABL assumes that students are actively involved in their learning process.

The pre-service teachers were challenged to select mathematics topics suitable for teaching with spreadsheets, and to make use of the affordances of the technology to design learning activities that fosters higher order thinking in mathematics. It was expected that the combination of a specific pedagogy (ABL) and a specific technology (spreadsheets) will encourage the pre-service teachers to apply their knowledge and skills in designing and enacting ABL lessons by employing a mix of direct instruction and hands-on activity to guide students through activities with spreadsheets to enhance student learning.

The spreadsheet environment appeared useful to engage pre-service teachers in the design of learning activities to support mathematics learning of students, such as: discussing presentations, collecting data (e.g. on the co-ordinates of an object), working in teams, making predictions. This variety of learning activities offered the pre-service teachers to orchestrate student learning in various ways (cf. Drijvers, Doorman, Boon, Reed \& Gravemeijer, 2010). This is the kind of pedagogical reasoning (cf. Webb \& Cox, 2004) that pre-service teachers need to undertake in their planning and teaching of ICT-enhanced lessons.

\subsubsection{Potential of collaborative design in teams for the pre-service teacher programme}

Polly, Mims, Shepherd, and Inan (2010) indicated that amongst others, collaborative design teams allow pre-service teachers to familiarize themselves with each other and the idea of ICT integration, and contributes to the success of curriculum design teams. The reason for espousing collaborative design teams in the research was to provide opportunity for pre-service teachers to design ICT-enhanced curriculum materials to develop their knowledge and skills in ICT integration.

In this study collaborative design in teams helped pre-service teachers to undertake the kind of pedagogical reasoning that is necessary to design lessons to effectively integrate technology in their lessons. In particular the need to collaborate in lesson design required the pre-service teachers to share knowledge and ideas and to explicitly reason and convince their peers about issues such as why certain topics coulds best be taught with spreadsheets and why they expect that certain learning activities contribute to students' learning. 
This research demonstrated that collaborative design in teams is a viable and effective approach for learning about technology integration. The mathematics teacher education programme at UCC therefore decided to continue with this approach and currently employ collaborative design teams in the preparation of pre-service teachers to integrate technology in education.

\subsubsection{Ownership, transfer and practicability}

The essence of the research project was to foster effective adoption and adaptation of collaborative design in design teams to support the integration of ICT in mathematics education. To realize this the study aimed to design and implement a professional development arrangement that had concrete artefacts as (one of its) outputs; developed ownership in pre-service teachers regarding the integration of ICT in mathematics teaching and resulted in transfer of learning to the professional and teaching practice of pre-service teachers.

In view of this the research aimed to prevent failure of implementation of the ICT-based innovation. In this realm three concepts were considered important:

- Ownership, which refers to pre-service mathematics teachers and educators claiming responsibility, for actions regarding collaboration in design teams to support ICT integration in teaching mathematics;

- Transfer of learning, referring to whether new knowledge, skills and attitudes acquired by pre-service teachers during the pre-service programme were being applied or used in their professional and teaching practices; and

- Practicability, referring to how feasible collaborative design in design teams can be used to support ICT integration by teachers in the classroom situations.

The research demonstrated ownership regarding collaboration in design teams in the sense that the mathematics teacher education programme at UCC continue with this approach in the preparing pre-service teachers to integrate technology in education.

Transfer of learning was demonstrated in pre-service teachers' high enthusiasm to apply the new knowledge and skills about collaborative design in design teams to support the integration of ICT in their professional and teaching practice.

Findings from the transfer study (chapter 7) showed that, after several months of finishing their teacher education preparatory programme, the pre-service 
teachers who had just begun their professional careers still held strong positive pedagogical views about collaboration in design teams to support ICT integration and make attempts to employ aspects of it in their professional and teaching practices.

This research demonstrated that applying collaborative design in design teams to support ICT integration in the classroom situations was a challenge. Findings showed that these practicability problems resulted from a complex interaction of several variables. However, it appeared that the underpinning factor had to do with passive involvement of various stakeholders, in particular outside the pre-service teacher preparation programme, such as principals and practicing teachers at the senior high schools.

Although SHS principals and practicing teachers were involved in the first stage of this study (see chapters 2 and 3), they were minimally involved in the design and implementation of the pre-service professional development programme. This might partly account for the problems pre-service teachers encountered when they as beginning teachers wanted to enact what they had learned in the pre-service programme. In addition to the design of an induction programme for beginning teachers to smoothen the transition from teacher preparation to teaching in practice, more attention in this research could have been given to the involvement of senior high schools during the formative evaluations of the professional development arrangement.

\subsection{RECOMMENDATIONS}

Based on the outcomes of this research, recommendations are provided for continued exploration of effective adoption and adaptation of collaborative design in design teams to support the integration of ICT in mathematics education.

\subsubsection{Recommendation for practice}

Effective pre-service teacher preparation for ICT integration

In this study a professional development programme was designed to prepare pre-service teachers to integrate ICT in teaching within a subject-specific teacher 
education programme. The characteristics of the professional development arrangement programme are also useful for future initiatives in other subject areas or teacher education programmes in Ghana and sub-Saharan Africa.

In replicating such an arrangement, programme designers should deliberately create learning experiences in which:

- Conceptual or theoretical information is linked to the application of knowledge and skills; Collaborative design, in which pre-service teachers design ICT-enhanced lessons with peers, are applied as strategy to develop competencies needed to integrate ICT and reflect on the experiences;

- Scaffolds and authentic technology experiences, such as teaching try-outs are an integrated part of the arrangement. Teaching try-outs have the tendency to reduce pre-service teachers' anxieties about ICT thereby increasing their enthusiasm to use ICT in instruction. In instances where large classes hinder implementation of teaching try-outs for all participants (such as in the context of Ghana) , micro- teaching within teams can be applied;

- Modeling, through demonstrations and exemplary materials on how to use technology should be a component of the arrangement; caution should be taken to ensure that exemplary materials provide meaningful and effective technology examples.

\section{Transition from teacher preparation to teaching practice}

- The study unveiled that lack of support, associated with beginning teachers' completion of university, in the face of a wide range of responsibilities was a compelling challenge for beginning teachers' use of the innovation in their practices.

The study advocates for the introduction of induction programmes for beginning teachers. Such a programme will serve as a short term support to ease new teachers' entry into the teaching profession and to help them cope with their first year on the job. The importance of a good induction support in this context would be to keep novices from abandoning ICT-based innovation approaches in favor of what they may perceive as safer, less complex activities.

- This study found that the transfer of learning of technology by collaborative design of ICT-enhanced activity-based lessons from the teacher preparation programme to the real classroom setting in the SHS's was problematic, in particular with respect to unfavorable school environmental factors. 
To smoothen the transition from the teacher preparation programme to the schools, it is recommended that collaborative programmes between providers of pre-service education and schools be advocated. In this way principals and school leaders will be supported to provide the type of pedagogical leadership in ICT integration that will inspire new teachers to push the boundaries of using ICT-based innovations.

- Apart from providing support for school leadership, such a "symbiotic" partnership will help in addressing the realities of specific teaching contexts; provide a forum for school- and pre-service providers to think together about the learning needs of beginning teachers and attend to multiple challenges of teaching alone for the first time that can discourage new teachers from trying ambitious pedagogies with ICT-based innovations.

The potential of collaborative design in teams

- The use of collaborative design teams employed in this research emerged a useful approach in developing pre-service teachers' competencies in designing and enacting ICT-enhanced activity-based mathematics lessons. Learning technology by collaborative designs in design teams should be embraced by providers of pre-service education because it creates the platforms for teachers to interact with one another thereby sharing their professional competencies to develop ICT-solutions to authentic pedagogical problems and encourage local ownership.

- The outcomes of this study showed that collaborative design in design teams contributed positively in pre-service teachers' preparation to integrate technology in their lessons and to adopt an activity based approach to mathematics learning. Literature shows that collaborative design in design teams is also promising to prepare practicing teachers in the integration of technology.

This study therefore recommends the introduction of learning technology by collaborative design in teams as a viable and effective approach for practicing teachers to design and enact ICT-enhanced activity-based lessons in mathematics lessons to school leadership. This will ensure that activities of design teams are made part and parcel of schools schemes.

Towards sustainable integration of ICT in Ghanaian education

- At school level, there is an urgent need to resolve difficult dilemmas in the terrain of ICT and technological pedagogical knowledge; innovative school 
culture such as: school-based in-service education opportunities, flexibility of classroom timetable and willingness to change existing traditional approaches should be promoted.

The study therefore recommends that Ghana Education Service strengthen and enforce policies regarding the practical use of ICT for educational practices in the curriculum. A clear articulation of policy within the framework of the teacher education institution and Ghana Education service could ensure better grounding of learning of technology by collaborative design of ICT-enhanced activity-based lessons in mathematics and other related subjects in secondary education in Ghana.

- In the midst of lack of ICT facilities, teachers must make choices about the continued use of ICT-based innovative materials within their existing support structures and school environment conditions. The study recommends that principals and school leaders provide supervisory and the necessary pedagogical leadership in ICT integration. They should also provide motivation (e.g. award schemes) to promote the use of ICT-based innovations in schools.

- At the teacher level, conscious efforts to use existing hardware and software in creative and situation specific ways to design and enact ICT-enhanced activity-based learning activities to accomplish teaching goals are to be encouraged. It is recommended that school management lend their support by providing opportunities for teachers to learn technology by collaborative designs. In-service trainings could be a means to provide such a support.

- Parent Teachers' Association, School Management and Boards must join forces and put priority on the provision of ICT facilities in Ghanaian schools (e.g. mathematics laboratories, computers and projection devices in classrooms) to facilitate and increase access to ICT of teachers. Easy access to ICT facilities will certainly contribute to teachers' use of ICT innovations in schools.

\subsubsection{Direction for future research}

In this study TPACK has been used as a conceptual framework to examine and develop the knowledge and skills pre-service math teachers from the University of Cape Coast need to teach mathematics using ICT. Developing the teachers TPACK was done through "Learning Technology by Design", an approach in which teachers were involved in collaborative authentic problem solving tasks with ICT. 
In the study, spreadsheet was presented as a tool for enacting a guided activitybased pedagogical approach of teaching mathematical concepts to develop preservice teachers' knowledge and skills in teaching with ICT. By actively participating in the design process, teachers build competencies that are sensitive to the subject matter and to specific instructional goals relevant for addressing the subject matter.

The pre-service teachers in the study were able to develop and demonstrate their knowledge and skills adequately in designing and enacting activity-based mathematical lessons supported with spreadsheets. The results also showed that the activity-based lessons supported with spreadsheets as an instructional tool served a useful pedagogical approach, impacted on student learning outcomes and has the potential of improving teaching and learning mathematics in secondary education.

Despite the promising results, more research is recommended to strengthen and extend this study. In this section, some directions for future research are suggested.

- Although modest findings on students' scores from only two hypothetical lessons showed the impact of pre-service teachers' lesson enactment on students' learning outcomes, the question still remains as to what extent the professional development programmes impacted on students' achievements. Therefore it would be worthwhile to undertake further research to investigate the impact of spreadsheet-supported ABL lessons on students' achievement in mathematics.

- Collaborative design activities in design teams may vary among pre-service teachers in various disciplines such as applied sciences, arts and humanities. Therefore further investigation in other disciplines in the university would offer data and present an opportunity to learn technology by collaborative design in design teams.

- The maintenance of a professional learning culture in teacher education programmes will require teacher educators to support institutional change. There is a need for teacher educators themselves to be well informed and updated with the knowledge and skills pre-service teachers need to be able to integrate ICT in their educational practice.

It would be worthwhile to undertake further research to explore how teacher educators in the teacher education programmes in Ghana can apply 
collaborative design in design teams in pre-service teacher education to prepare pre-service teachers for the integration of ICT in their future lessons.

- Adoption of spreadsheets both as a tool for instruction and learning mathematics content was key to a successful intervention in integrating ICT because spreadsheet applications are readily available and user friendly and promoted students' higher-order thinking in mathematics. One important issue was the limited range of potential spreadsheet applications for mathematics education.

Future research can therefore be directed to explore other applications that are readily available, user friendly and fostering higher-order thinking, such as the use of internet resources, to further develop the knowledge and skill of preservice teachers to integrate ICT in designing and enacting mathematics lessons. 


\section{REFERENCES}

AACTE Committee on Innovation \& Technology. (Ed.). (2008). Handbook of Technological Pedagogical ContentKnowledge (TPCK) for Educators. New York: Taylor and Francis Group.

Adamy, P., \& Boulmetis, J. (2006). The impact of modeling technology integration on pre service teachers' technology confidence. Journal of Computing in Higher Education 17(2), 100-120.

Adu-Gyamfi, D., \& Smit, C. P. (2007). Programme Reform and Alignment for increasing Competencies of Teachers and for Improving Comprehension and Application in Learning science and mathematics (PRACTICAL): An inception report on the analysis of standards in subject content mastery in B.Ed programmes in Ghana. Amsterdam: Centre for International Cooperation (CIS), Vrije Universiteit.

Aguti, J. N., \& Fraser, W. J. (2006). Integration of Information Communication Technologies in the DistanceEducation Programme, Makerere University, Uganda. Turkish Online Journal of Distance Education, 7(3), 89-104.

Agyei, D. D., \& Voogt, J. (2011a). ICT use in the teaching of mathematics: Implications for professional development of pre-service teachers in Ghana. Education and Information Technologies, 16(4), 423-439.

Agyei, D. D., \& Voogt, J. (2011b). Exploring the potential of the Will Skill Tool model in Ghana: Predicting prospective and practicing teachers' use of technology. Computers $\mathcal{E}$ Education, 56(1), 91-100.

Agyei, D \& Voogt, J. (2012). Developing Technological Pedagogical Content Knowledge in pre-service mathematics teachers, through Teacher Design Teams, Australiasian Journal of Educational Technology, 28(4), 547-564.

Agyei, D. D., \& Voogt, J. (submitted). Developing pre-service teachers' competencies to use Activity-based learning with technology in mathematics education. Technology Pedagogy and Education.

Alayyar, G. M. (2011). Developing pre-service teachers' competencies for ICT integration through Design Team. Docoral dissertation. Enschede: University of Twente.

Ampiah, J., Akyeampong, A. K., \& Leliveld, M. (2004). Science, Mathematics and ICT (SMICT) secondary education in sub-Saharan Africa - country profile Ghana. Amsterdam: Centre for International Cooperation (CIS), Vrije Universiteit.

Anamuah-Mensah National Education Review Committee Report. (2002). Report of the President's Committee on Review of Education Reforms in Ghana. Accra: Ministry of Education.

Angeli, C., \& Valanides, N. (2005). Preservice elementary teachers as information and communication technology designers: An instructional systems design model based on an expanded view of pedagogical content knowledge. Journal of Computer Assisted learning, 21, 292-302. 
Angeli, C., \& Valanides, N. (2009). Epistemological and methodological issues for the conceptualization, development, and assessment of ICT-TPCK: Advances in technological pedagogical content knowledge (TPCK). Computers \& Education, 52, 154-168.

Association of Mathematics Teacher Educators, A. (2006). Preparing teachers to use technology to enhance the learning of mathematics. Retrieved from http://www.amte.net on August 12,2008 .

Ávila Munoz, P. (2008). ICT and educational policy for the Latin American and Caribbean regions. In J. Voogt, \& G. Knezek (Eds.), International handbook of information technology in primary and secondary education (pp. 1133-1143). New York: Springer.

Bagozzi, R. P., Davis, F. D., \& Warshaw, P. R. (1992). Development and test of a theory of technological learning and usage. Human Relations, 45(7), 660-686.

Baldwin, T. T., \& Ford, J. K. (1988). Transfer of training: A review and directions for future research. Personnel Psychology, 41, 63-105.

Ball, D., \& Cohen, D. (1996). Reform by the book: What is - or might be - the role of curriculum materials in teacher learning and instructional reform? Educational Researcher, 25(9), 6-8, 14.

Bandura, A. (1977). Self-efficacy: Towards a unifying theory of behavioral change. Psychological Review, 84(2), 191-215.

Barab, S. A., \& Squire, K. D. (2004). Design-based research: Putting our stake in the ground. Journal of the Learning Sciences, 13(1), 1-14.

Barton, R., \& Haydn, T. (2006). Trainee teachers' views on what helps them to use information and communication technology effectively in their subject teaching. Journal of Computer Assisted Learning, 22, 257-272.

Bate, F. (2010). A bridge too far? Exploring beginning teachers' use of ICT in Australian schools. Australian Journal of Educational Technology, 26(7), 1042-1061.

Baylor, A. L., \& Ritchie, D. (2002). What factors facilitate teacher skill, teacher morale, and perceived student learning in technology-using classrooms? Computers $\&$ Education, 39, 395-414.

Beauchamp, G., \& Parkinson, J. (2008). Pupils' attitudes towards school science as they transfer from an ICT-rich primary school to a secondary school with fewer ICT resources: Does ICT matter? Education and Information Technologies, 13, 103-118.

Becker, H. J. (2001). How are teachers using computers in instruction? Paper presented the Annual Meeting of the American Educational Research Association, Seattle WA.

Bennett, N., Crawford, M. R. L. D. G., \& Earley, P. (2000). The reality of school development planning in the effective primary school: Technicist or guiding plan? School Leadership and Management, 20, 333-351.

Benson, R., \& Palaskas, T. (2006 ). Introducing a new learning management system: An institutional case study. Australasian Journal of Educational Technology, 22(4),548-567.

Borko, H. (2004). Professional development and teacher learning: Mapping the terrain. Educational Researcher, 33, 3-15.

Bottino, R. M., \& Robotti, E. (2007). Transforming classroom teaching and learning through technology: Analysis of a case study. Educational Technology \& Society, 10(4), 174-186.

Bozionelos, N. (2001). Computer anxiety: Relationship with computer experience and prevalence. Computers in Human Behavior, 17, 213-224. 
Bransford, J. D., Brown, A. L., \& Cocking, R. R. (Eds.). (1999). How people learn. Washington, DC: National Academy Press.

British Educational Communications and Technology Agency (BECTA). (2003). What the research says about using ICT in maths. Retrieved 19th June, 2008 from www.becta.org.uk/research

Brown, D., \& Warschauer, M. (2006). From the university to the elementary classroom: Students' experiences in learning to integrate technology in instruction. Journal of Technology and Teacher Education, 14(3), 599-621.

Brush, T., Glazewski, K., Rutowski, K., Berg, K., Stromfors, C., \& Van-Nest, M. H. (2003). Integrating technology into a field-based teacher training program: The PT3@ASU project. . Educational Technology Research and Development, 51, 57-72.

Bryk, A. S., \& Schneider, B. (2002). Trust in schools: A core resource for improvement. New York: Russell Sage.

Burke, L. A., \& Baldwin, T. T. (1999). Workforce training transfer: A study of the effect of relapse prevention training and transfer climate. Human Resource Management, 38(3), 227-242.

Burke, L. A., \& Hutchins, H. M. (2007). Training transfer: An integrative literature review human resource development review. Sage Journals, 6(3), 263-296. doi: $10.1177 / 1534484307303035$

Burkman, E. (Ed.). (1987). Factors affecting utilization: Foundations. Hillsdale, NJ: Lawrence Erlbaum.

Christensen, R. (1997). Effect of technology integration education on the attitudes of teachers and their students. Doctoral dissertation. University of North Texas. Retrieved from http://courseweb.unt.edu/rhondac

Christensen, R., \& Knezek, G. (2000a). Internal consistency reliabilities for 14 computer attitude scales. Technology in Teacher Education, 8(4), 327-336.

Christensen, R., \& Knezek, G. (2000b). Internal consistency reliability for the technology in education competency survey. Paper presented at the American Educational Research Association Annual Meeting, New Orleans, LA, April 25, 2000.

Christensen, R., \& Knezek, G. (2001). Profiling teacher stages of adoption for technology integration. Computers in New Zealand Schools, 13(3), 25-29.

Christensen, R., \& Knezek, G. (2002). Instruments for assessing the impact of technology in education. Computers in the Schools, 18(2), 5-25.

Christensen, R., \& Knezek, G. (2006). Findings from the spring 2006 Irving laptop surveys for teachers. Retrieved May 12, 2009 from http://iittl.unt.edu/irving/index.htm

Christensen, R., \& Knezek, G. (2008). Self-report measures and findings for information technology attitudes and competencies. In J. Voogt, \& G. Knezek (Eds.), International handbook of information technology in primary and secondary education (pp. 349-366). New York: Springer.

Churchill, D. (2004). Effective use of technology for construction of learners' mental models. In A. Khoo, M. A. Heng, L. Lim, \& R. P. Ang (Eds.), Innovation and diversity in education (pp. 144-159). Singapore: McGraw Hill..

Churchill, D., \& Wong, P. (2002). Design of activity-based eLearning. ICTE2002. Paper presented at the International Conference on Information and Communication Technologies in Education. November 13-16, Badajoz, Spain. 
Clark, K. D. (2001). Urban middle school teachers' use of instructional technology. Journal of Research on Computing in Education, 33(2), 178-195.

Clements, D. H. (2000). From exercise and tasks to problems and projects- unique contributions of computers to innovative mathematics education. The Journal of Mathematics Behaviour, 19(1), 9-47.

Cobb, P., Confrey, J., diSessa, A., Lehrer, R., \& Schauble, L. (2003). Design experiments in educational research. Educational Researcher, 32(1), 9-13.

Cohen, J. (1969). Statistical power analysis for the behavioral sciences. New York: Academic Press.

Cohen, J. (1988). Statistical power analysis for the behavioral sciences (2nd ed.). Hillsdale, NJ: Lawrence Erlbaum Associates.

Cohen, L., Manion, L., \& Morrison, K. (2007). Research methods in education. London, England: Routledge.

Cox, S., \& Graham, C. R. (2009). Diagramming TPACK in practice: Using and elaborated model of the TPACK framework to analyze and depict teacher knowledge. TechTrends, $53,60-69$.

Creswell, J. W., Plano Clark, V. L., Gutmann, M., \& Hanson, W. (Eds.). (2003 ). Advanced mixed methods research designs. Thousand Oaks, CA: Sage.

Davis, E. A., \& Krajcik, J. (2005). Designing educative curriculum materials to promote teacher learning. Educational Researcher, 34(5), 3-14.

Davis, S., \& Wiedenbeck, S. ( 2001). The mediating effects of intrinsic motivation, ease of use and usefulness perceptions on performance in first time and subsequent computer users. Interacting with computers, 13, 549-580.

Dawson, C., \& Rakes, G. C. (2003 ). The influence of principals' technology training on the integration of technology into schools. Journal of Research on Technology in Education, 36, 29-49.

Dettori, G., Garuti, R., \& Lemut, E. (2001), From arithmetic to algebraic thinking by using a spreadsheet. In R. Sutherland, T. Rojano, A. Bell, \& R. Lins (Eds.), Perspectives on school algebra (pp.191-207). Dordrecht, The Netherlands: Kluwer.

Drijvers, P., Doorman, M., Boon, P., Reed, H., \& Gravemeijer, K. (2010). The teacher and the tool: Whole-class teaching behavior in the technology-rich mathematics classroom. Educational Studies in Mathematics, 75(2), 213-234.

Durndell, A., \& Haag, Z. (2002). Computer self-efficacy, computer anxiety, attitude to the Internet and reported experience with the Internet, by gender, in an East European sample. Computers in Human Behavior, 18(5), 521-535.

Ebersole, S., \& Vorndam, M. (2003). Adoption of computer based instructional methodologies: A case study. International Journal of E-Learning, 2(2), 15-20.

Elmore, R. F., \& Burney, D. (1999). Investing in teacher learning. In L. Darling- Hammond, \& G. Sykes (Eds.), Teaching as the learning profession (pp. 236-291). San Francisco: Jossey-Bass.

Ely, D. P. (1990). Conditions that facilitate the implementation of educational technology innovations. Journal of Research on Computing in Education, 23(2), 298-305.

Ely, D.P. (1999). New perspectives on the implementation of educational technology innovations. Paper delivered at the Association for Educational Communications and Technology Annual Conference, Houston, TX, Feb., 1999. 
Enochson, A., \& Rizza, C. (2009). ICT in initial teacher training: Research review. OECD EDU Working paper n38.

Ensminger, C. D., \& Surry, W. D. (2008). Relative ranking of conditions that facilitate innovation implementation in the USA. Australasian Journal of educational Technology, 24(5), 611-626.

Feiman-Nemser, S. (2001). From preparation to practice: Designing a continum to strengthen and sustain teaching. Teachers College Record, 103(6), 1013-1055.

Fishbein, M., \& Ajzen, I. (1975). Belief, attitude, intention and behavior. California: AddisionWesley Publishing Company.

Fisher, M. (2000). Computer skills of initial teacher education students. Journal of Information Technology for Teacher Education, 9(1), 109-123.

Fishman, B., \& Davis, E. (2006). Teacher learning research and the learning sciences. Cambridge: Cambridge University Press.

Fullan, M. (2007). The new meaning of educational change $4^{\text {th }}$ edition. New York: Teachers College Press.

Galanouli, D., Murphy, C., \& Gardner, J. (2004). Teachers' perceptions of the effectiveness of ICT-competence training. Computers \& Education, 43, 63-79.

Garet, M. S., Porter, A. C., Desimone, L., Birman, B. F., \& Yoon, K. S. (2001). What makes professional development effective? Results from a national sample of teachers. American Educational Research Journal, 38(4), 915e945.

Georgenson, D. L. (1982). The problem of transfer calls for partnership. Training and Development Journal, 36, 75-78.

Ghana ICT4AD Policy. (2003). A policy statement for the realization of the vision to transform Ghana into an information-rich knowledge-based society and economy through the development, deployment and exploration of ICT's within the economy and society. Accra, Ghana: Ministry of Education.

Goktas, Y., Yıldırım, Z., \& Yıldırım, S. (2008). A review of ICT related courses in preservice teacher education programmes. Asia Pacific Education Review, 9, 168-179.

Goldstein, I. L., \& Ford, J. K. (2002). Training in organizations. Belmont, CA: Wadsworth.

Groff, J., \& Mouza, C. (2008). A framework for addressing challenges to classroom technology use. AACE Journal, 16(1), 21-46.

Guerrero, S. (2010). Technological Pedagogical Content Knowledge in the mathematics classroom. Journal of Digital Learning in Teacher Education, 26(4), 132-139.

Gurcan-Namlu, A., \& Ceyhan, E. (2003). Computer anxiety: Multidimensional analysis on teacher candidates. Educational Sciences: Theory and Practice, 3(2), 401-432.

Hancock, R., Knezek, G., \& Christensen, R. (2007). Cross-validating measures of technology integration: A first step toward examining potential relationships between technology integration and student achievement. Paper presented at the National Educational Computing Conference, June, 2007, Atlanta, GA.

Harris, J., Grandgenett, N., \& Hofer, M. (2010). Testing a TPACK-based technology integration assessment rubric. Paper presented at the Proceedings of Society for Information Technology \& Teacher Education International Conference 2010, Chesapeake, VA: AACE.

Harris, J., Mishra, P., \& Koehler, A. M. (2009). Teachers' Technological Pedagogical Content Knowledge and learning activity types: Curriculum-based technology integration reframed. Research on Technology in Education, 41(4), 393-416. 
Hartsell, T., Herron, S., Fang, H., \& Rathod, A. (2009). Effectiveness of professional development in teaching mathematics and technology applications. Journal of Educational Technology Development and Exchange, 2(1), 53-56.

Haughey, M. (2002). Canadian research on information and communications technologies: A state of the field. Retrieved from http:// citeseerx.ist.psu.edu/viewdoc/download?doi=10.1.1.84.998\&rep=rep1\&type=pdf

Haydn, T. A., \& Barton, R. (2007). Common needs and different agendas: How trainee teachers make progress in their ability to use ICT in subject teaching. Some lessons from the UK. Computers $\mathcal{E}$ Education, 49, 1018-1036.

Hennessy, S. (2000). Graphing investigations using portable (palmtop) technology. Journal of Computer Assisted Learning, 16, 243-258.

Hennessy, S., Fung, P., \& Scanlon, E. (2001 ). The role of the graphic calculator in mediating graphing activity. International Journal of Mathematics for Education in Science and Technology, 32(2), 267-290.

Hmelo-Silver, C. E., Duncan, R. G., \& Chinn, C. A. (2008). Scaffolding and achievement in problem-based inquiry learning: A response to Kirschner, Sweller, and Clark (2006). Educational Psychologist, 42(2), 99-107.

Hofer, M., Grandgenett, N., Harris, J., \& Swan, K. (2011). Testing a TPACK-based technology integration observation instrument. Paper presented at the Proceedings of Society for Information Technology \& Teacher Education International Conference 2011, Chesapeake, VA: AACE.

Huang, H. M., \& Liaw, S. S. (2005). Exploring users' attitudes and intentions toward the web as a survey tool. Computers in Human Behavior, 21(5), 729-743.

Hughes, J., Thomas, R., \& Scharber, C. (2006). Assessing technology integration: The RAT replacement, amplification, and transformation - framework. Paper presented at the Technology and Teacher Education Annual Conference.

Ittigson, R. J., \& Zewe, J. G. (2003). Technology in the mathematics classroom. In L. A. Tomei (Ed.), Challenges of teaching with technology across the curriculum: Issues and solutions (pp. 114-133). Hershey: Information Science Publishing.

Jang, S. J. (2008). The effects of integrating technology, observation and writing into a teacher education method course. Computers \& Education, 50, 853-865.

Jonassen, D. (2002). Computers as mindtools for schools. New Jersey: Prentice-Hall Inc.

Jones, A. (2004). A review of the research literature on barriers to the uptake of ICT by teachers. UK: Becta.

Jones, K. (2005). Using spreadsheets in the teaching and learning of mathematics: A research bibliography. MicroMath, 21(1), 30-31.

Kay, R. H. (2006). Evaluating strategies used to incorporate technology into pre-service education: A review of the literature. Journal of Research on Technology in Education, 38, 383-408.

Keating, T., \& Evans, E. (2001). Three computers inthe back of the classroom: Pre-service teachers' conceptions of technology integration. Paper presented at the Society for Information Technology \& Teacher Education International Conference 2001, Norfolk, VA: AACE.

Keong, C., Horani, S., \& Daniel, J. (2005). A study on the use of ICT in mathematics teaching. Malaysian Online Journal of Instructional Technology, 2(3), 43-51. 
Kereluik, K., Casperson, G., \& Akcaoglu, M. (2010). Coding pre-service teacher lesson plans for TPACK. In D.Gibson, \& B. Dodge (Eds.), Proceedings of Society for Information Technology \& Teacher Education International Conference 2010, (pp. 3889-3891). Chesapeake, VA: AACE.

Khine, M. S. (2001). Attitudes toward computers among teacher education students in Brunei Darussalam. International Journal of Instructional Media, 28(2), 147-153.

Khorrami-Arani, O. (2001). Researching computer self-efficacy. International Education Journal, 2(4), 17-25.

Knezek, G., \& Christensen, R. (1998). Internal consistency reliability for the teachers' attitudes toward information technology (TAT) questionnaire. In S. McNeil, J. D. Price, S. Boger-Mehall, B. Robin, \& J. Willis (Eds.), Technology and teacher education annual 1998, Vol. 2 (pp. 831-832). Charlottesville, VA: Association for the Advancement of Computing in Education.

Knezek, G., Christensen, R., Hancock, R., \& Shoho, A. (2000, February). Toward a structural model of technology integration. Paper presented at the Hawaii Educational Research Association Annual Conference, Honolulu, HI.

Knezek, G., Christensen, R., Miyashita, K., \& Ropp, M. (2000). Instrument for assessing educator progress. Texas Center for Educational Technology, Denton, TX.

Koehler, M., \& Mishra, P. (2005). What happens when teachers design educational technology? The development of technological pedagogical content knowledge. Journal of Educational Computing Research, 32(2), 131-152.

Koehler M., \& Mishra P. (2008). Introducing TPCK. In AACTE Committee on Innovation and Technology (Eds.), Handbook of technological pedagogical content knowledge (TPCK) for educators, pp. 3-29. New York: Routledge.

Koehler M., \& Mishra P. (2009) What is Technological Pedagogical Content Knowledge (TPACK)? Contemporary Issues in Technology and Teacher Education, 9, 60-70.

Koehler M. J., Mishra, P., \& Yahya K. (2007). Tracing the development of teacher knowledge in a design seminar: Integrating content, pedagogy and technology. Computers E Education, 49, 740-762.

Lambert, N. M., \& McCombs, B. L. (Eds.). (1998). How students learn. Washington, DC: American Psychological Association.

Law, N. (2008). Teacher learning beyond knowledge for pedagogical innovations with ICT. In J. Voogt, \& G. Knezek (Eds.), International handbook of information technology in primary and secondary education (pp. 425-435). New York: Springer.

Law, N., Pelgrum, W. J., \& Plomp, T. (2008). Pedagogy and ICT use in schools around the world. Findings from the IEA SITES 2006 study. CERC Studies in comparative education. Hong Kong: Comparative Education Research Centre, The University of Hong Kong, and Dordrecht: Springer.

Looney, C., Valacich, J., \& Akbulut, A. (2004). Online investment self-efficacy: Development and initial test of an instrument to assess perceived online investing abilities. Paper presented at the 37th Hawaii international conference on system sciences, Honolulu, HI.

Loucks-Horsley, S., Hewson, P. W., Love, N., \& Stiles, K. E. (1998). Designing professional development for teachers of science and mathematics. California: Corwin Press.

Macdonald, R. J. (2008). Professional development for information communication technology integration: Identifying and supporting a community of practice through design-based research. Journal of Research on Technology in Education, 40(4), 429-445. 
Maddux, C., LaMont Johnson, D., \& Willis, J. (Eds.). (2001). Educational computing. Needham Heights: Allyn \& Bacon.

Magnusson, S., Krajcik, J., \& Borko, H. (1999). Nature, sources and development of pedagogical content knowledge for science teaching. Dordrecht: Kluwer Academic Publishers.

Margerum-Leys, J., \& Marx, R. W. (2004). The nature and sharing of teacher knowledge of technology in a student teacher/mentor teacher pair. Journal of Teacher Education 55(5), 421-437.

Marshall, G., \& Cox, M. (2008). Research methods: Their design, applicability and reliability. In J. Voogt and G. Knezek (Eds.), International handbook of information technology in primary and secondary education (pp. 983 - 987). New York: Springer.

Marshall, H. (Ed.). (1996). Recent and emerging theoretical frameworks for research on classroom teaching: Contributions and limitations [Special issue]. Educational Psychologist, 31(3/4).

Maslowski, R. (2001). School culture and school performance: An explorative study into the organizational culture of secondary schools and their effects. Enschede: Twente University Press.

Mayer, R. (2004). Should there be a three-strikes rule against pure discovery learning? The case for guided methods of instruction. American Psychologist, 59(1), 14-19.

McGarr, O., \& Kearney, G. (2009). The role of the teaching principal in promoting ICT use in small primary schools in Ireland. Technology, Pedagogy and Education, 18(1), 87-102.

Mcllroy, D., Bunting, B., Tierney, K., \& Gordon, M. (2001). The relation of gender and background experience to self reporting computer anxieties and cognitions. Computers in Human Behavior, 17(1), 21-33.

McKenney, S. E., Nieveen, N., \& van den Akker, J. J. H. (2006). Design research from a curriculum perspective. In J. Van den Akker, K. Gravemeijer, S. McKenney \& N. Nieveen (Eds.), Educational Design Research (pp. 67-90). New York: Routledge.

Meelissen, M. (Ed.). (2008). Computer attitudes and competencies among primary and secondary school students. In J. Voogt, \& G. Knezek, (Eds.), International handbook of information technology in primary and secondary education (pp. 381-395). New York: Springer.

Miles, M. B., \& Huberman, A. M. (1994). An expanded source book: Qualitative data analysis ( $2^{\text {nd }}$ ed.). London: Sage Publications.

Ministry of Education (MOE). (2000). Teaching syllabus for mathematics. Accra, Ghana: Ministry of Education.

Ministry of Education Science and Sports (MOESS). (2007). Teaching syllabus for mathematics. Accra, Ghana: Ministry of Education.

Mishra, P., \& Koehler, M. J. (2006). Technological Pedagogical Content Knowledge: A framework for integrating technology in teacher knowledge. Teachers College Record, 108(6), 1017-1054.

Mishra, P., \& Koehler, M. J. (2003). Not "what" but "how": Becoming design-wise about educational technology. In Y. Zhao. (Ed.). What teachers should know about technology: Perspectives and practices (pp. 99-122). Greenwich, CT: Information Age Publishing.

Mishra, P., Koehler, M. J., \& Zhao, Y. (2007). Faculty development by design: Integrating technology in higher education. Charlotte, NC: Information Age Publishing.

Morales, C. (2006). Cross-cultural validation of the will, skill, tool model of technology integration. University of North Texas, Denton, TX. Unpublished doctoral dissertation. 
Moseley, D., \& Higgins, S. (1999). Ways forward with ICT: Effective pedagogy using information and communications technology for literacy and numeracy in primary schools. London. Teacher Training Agency.

Mullis, I. V. S., Martin, M. O., \& Foy, P. (2008). International mathematics report: Findings from IEA's Trends in International Mathematics and Science Study at the fourth and eighth grades. Chestnut Hill: TIMSS \& PIRLS International Study Center, Boston College.

Mullis, I. V. S., Martin, M. O., Gonzalez, E. J., \& Chrostowski, S. J. (2004). International mathematics report: Findings from IEA's Trends in International Mathematics and Science Study at the fourth and eighth grades. Chestnut Hill: TIMSS \& PIRLS International Study Center, Boston College.

Mumtaz, S. (2000). Factors affecting teachers' use of information and communications technology: A review of the literature. Journal of Information Technology for Teacher Education, 9(3), 319-342.

Murphy, P., Anzalone, S., Bosch, A., \& Moulton, J. (2002). Enhancing learning opportunities in Africa: Distance education and information and communication technologies for learning. Africa region human development working paper series.

Myers, J. M., \& Halpin, R. (2002). Teachers' attitudes and use of multimedia technology in the classroom: Constructivist-based professional development training for school districts. Journal of Computing in Teacher Education, 18(4), 133-140.

National Council of Teachers of Mathematics. (2000). Principles and standards for school mathematics. Reston, VA.

Niess, M. L. (2005). Preparing teachers to teach science and mathematics with technology: Developing a Technology Pedagogical Content Knowledge. Teaching and Teacher Education, 21, 509-523.

Niess, M. L. (2008). Knowledge needed for teaching with technologies - Call it TPACK. AMTE Connections, Spring, 9-10.

Niess, M. L. (2011). Investigating TPACK: Knowledge growth in teaching with technology. Journal of Educational Computing Research, 44(3), 299-317.

Niess, M. L., Sadri, P., \& Lee, K. (2007). Dynamic spreadsheets as learning technology tools: Developing teachers' technology pedagogical content knowledge (TPCK). Paper presented at the meeting of the American Educational Research Association Annual Conference, Chicago, IL.

Niess, M. L., Suharwoto, G., Lee, K., \& Sadri, P. (2006). Guiding inservice mathematics teachers in developing TPCK. Paper presented at the paper presentation for the American Education Research Association Annual Conference, April 7-11, 2006, San Francisco, CA.

Niess, M. L., van Zee, E., \& Gillow-Wilese, H. (2010-11). Knowledge growth in teaching mathematics/science with spreadsheets; Moving PCK to TPACK through online professional development. Journal of Digital Learning in Teacher Education, 27(2), 42-52.

Ottenbreit-Leftwich, A., Glazewski, K., Newby, T., \& Ertmer, P. (2010). Teacher value beliefs associated with using technology: Addressing professional and student needs. Computers $\mathcal{E}$ Education, 55, 1321-1335.

Ottevanger, W. (2001). Teacher support materials as a catalyst for science curriculumimplementation in Namibia. Doctoral dissertation. Enschede, The Netherlands: University of Twente. 
Ottevanger, W., van den Akker, J. J. H., \& de Feiter, L. (2007). Developing Science, Mathematics and ICT education in sub-Saharan Africa (SMICT): Patterns and promising practices. Paper presented at the World Bank Working Paper.

Özgün-Koca, A., Meagher, M., \& Edwards, M. T. (2010). Preservice teachers' emerging TPACK in a technology-rich methods class. The Mathematics Educator, 19(2), 10-20.

Pamuk, S., \& Peker, D. (2009). Turkish pre-service science and mathematics teachers' computer related self-efficacies, attitudes, and the relationship between these variables. Computers \& Education 53, 454-461.

Paraskeva, F., Bouta, H., \& Papagianna, A. (2008). Individual characteristics and computer self-efficacy in secondary education teachers to integrate technology in educational practice. Computer and Education, 50(3), 1084-1091.

Pelgrum, W. J., \& Anderson, R. A. (Eds.). (1999). ICT and the emerging paradigm for life long learning: A worldwide educational assessment of infrastructure, goals and practices. Amsterdam: IEA.

Penuel, W. R., Fishman, B. J., Yamaguchi, R., \& Gallagher, L. P. (2007). What makes professional development effective? Strategies that foster curriculum implementation. American Educational Research Journal, 44(4), 921-958.

Phillips, D. C. (1998). How, why, what, when, and where: Perspectives on constructivism in psychology and education. Issues in Education, 3, 151-194.

Polly, D., Mims, C., Shepherd, C. E., \& Inan, F. (2010). Evidence of impact: Transforming teacher education with preparing tomorrow's teachers to teach with technology (PT3) grants. Teaching and Teacher Education, 26, 863-870.

Putnam, R. P., \& Borko, H. (2000). What do new views of knowledge and thinking have to say about research on teacher learning? Educational Researcher, 29(1), 1-15.

Reeves, T. (2006). Design research from a technology perspective. In J. J. H. van den Akker, K. Gravemeijer, S. E. McKenney, \& N. Nieveen (Eds.), Educational design research (pp. 5266). New York: Routledge.

Remillard, J. T. (2005). Key concepts in research on teachers' use of mathematics curricula. Review of Educational Research, 75(2), 211-246.

Resta, P., \& Laferrière, T. (2008). Issues and challenges related to digital equity. In J. Voogt, \& G. Knezek (Eds.), International handbook of information technology in primary and secondary education (pp. 765-778). New York: Springer.

Riel, M., \& Becker, H. J., (2008). Characteristics of teacher leaders for information and communication technology. In J. Voogt, \& G. Knezek, (Eds.), International handbook of information technology in primary and secondary education (,pp. 397-417). . New York: Springer. Rojano, T. (1996), Developing algebraic aspects of problem solving within a spreadsheet environment. In N. Bednarz, C. Kieran, \& L. Lee (Eds.), Approaches to algebra: Perspectives for research and teaching (pp. 137-145). Dordrecht: Kluwer Academic Publishers.

Saks, A. M. (2002). So what is a good transfer of training estimate? A reply to Fitzpatrick. The Industrial-Organizational Psychologist, 39, 29-30.

Sandholtz, J., Ringstaff, C., \& Dwyer, D. C. (1997). Teaching with technology: Creating studentcentered classrooms. New York: Teachers College Press.

Sang, G. Y., Valcke, M., Van Braak, J., \& Tondeur, J. (2010). Student teachers' thinking processes and ICT integration: Predictors of prospective teaching behavior educational technology. Computers and Education, 54(1), 103-112. 
Schmidt, D., Seymour, J., Baran, E., \& Thompson, A. (2009). Developing effective Technological Pedagogical And Content Knowledge (TPACK) in PreK-6 teachers. Paper presented at the Society for Information Technology and Teacher Education International Conference 2008, Las Vegas, Nevada, USA.

Schmidt, D. A., Baran, E., Thompson, A. S., Mishra, P., Koehler, M. J., \& Shin, T. S. (2009). Technological Pedagogical Content Knowledge (TPACK): The development and validation of an assessment instrument for preservice teachers. Journal of Research on Technology in Education, 42(2), 123-149.

Shulman, L. S. (1986). Those who understand: Knowledge growth in teaching. Educational Researcher, 15, 4-14.

Simmie, G. M. (2007). Teacher design teams (TDTs) e-building capacity for innovation, learning and curriculum implementation in the continuing professional development of in-career teachers. Irish Educational Studies, 26(2), 163-176.

Smarkola, C. (2008). Efficacy of a planned model: Belief that contribute to computer usage intentions of student teachers. Computers in Human Behavior 24, 1196-1215.

Snoeyink, R., \& Ertmer, P. A. (2002). Thrust into technology: How veteran teachers respond. Journal of Educational Technology Systems, 30(10), 85-111.

So, H. J., \& Kim, B. (2009). Learning about problem based learning: Student teachers integrating Technology, Pedagogy and Content Knowledge. Australasian Journal of Educational Technology, 25(1), 101-116.

Steffe, L. P., \& Gale, J. (Eds.). (1995). Constructivism in education. Mahwah, NJ: Erlbaum.

Stockdill, S. H., \& Morehouse, D. L. (1992 ). Critical factors in the successful adoption of technology: A checklist based on TDC findings. Educational Technology, 1, 57-58.

Surry, D. W., \& Ensminger, D. C. (2003). Perceived importance of conditions that facilitate implementation. E-Journal of Instructional Science and Technology, 6(1).

Surry, D. W., \& Ensminger, D. C. (2004). Development of implementation profile instrument. British Journal of Educational Technology, 34(4), 503-504.

Tearle, P. (2003). ICT implementation: What makes the difference? British Journal of Educational Technology, 34, 567-583.

Tearle, P., \& Golder, G. (2008). The use of ICT in the teaching and learning of physical education in compulsory education: How do we prepare the workforce of the future? European Journal of Teacher Education, 31(1), 55-72.

Tekinarslan, E. (2008). Computer anxiety: A cross-cultural comparative study of Dutch and Turkish university students. Computers in Human Behavior 24, 1572-1584.

Teo, T. (2008). Assessing the computer attitudes of students: An Asian perspective. Computers in Human Behavior, 24, 1634-1642.

Thompson, A., \& Mishra, P. (2007). Breaking news: TPCK becomes TPACK! Journal of Computing in Teacher Education, 24(2), 38-39.

Tilya, F. (2008). IT and educational policy in the sub-Saharan African region. In J. Voogt, \& G. Knezek (Eds.), International handbook of information technology in primary and secondary education (pp. 1145-1159). New York: Springer.

Tondeur, J., Valcke, M., \& Van Braak, J. (2008). A multidimensional approach to determinants of computer use in primary education: Teacher and school characteristics. Journal of Computer Assisted Learning, 24, 494-506. 
Tondeur, J., Van Braak, J., Sang, G., Voogt, J., Fisser, P., \& Ottenbreit-Leftwich, A. (2012). Preparing pre-service teachers to integrate technology in education: A synthesis of qualitative evidence. Computers \& Education, 59(1), 134-144.

Van Braak, J. (2001). Individual characteristics influencing teachers' class use of computers. Journal of Educational Computing Research, 25(2), 141-157.

Van den Akker, J. (1988). The teacher as learner in curriculum implementation. Journal of Curriculum Studies, 20(1), 47-55.

Van den Akker, J., Gravemeijer, K., McKenney, S., \& Nieveen, N. (Eds.). (2006). Educational design research. London: Routledge.

Van Driel, J. H., de Vos, W., \& Verloop, N. (1998). Developing science Teachers' Pedagogical Content Knowledge. Journal of Resaerch in Science Teaching, 35(6), 673-695.

Vankatesh, V. (1999). Creation of favorable user perceptions: Exploring the role of intrinsic motivation. MIS Quarterly, 23(2), 239-260.

Varkking, W. J. (1995). The implementation game. Journal of Organizational Change Management, 8(3), 31-46.

Voogt, J. (2003). Consequences of ICT for aims, contents, processes and environments of learning. Dordrecht: Kluwer.

Voogt, J. (2008). IT and curriculum processes: Dilemmas and challenges. In J. Voogt, \& G. Knezek (Eds.), International handbook of information technology in primary and secondary education (117-132). New York: Springer.

Voogt, J. (2010). A blended in-service arrangement for supporting science teachers in technology integration. Journal of Technology and Teacher Education, 18(1), 79-105.

Voogt, J., Fisser, P., Pareja Roblin, N., Tondeur, J., \& van Braak, J. (2012). Technological Pedagogical Content Knowledge - A review of the literature. Journal of Computer Assisted Learning. doi: 10.1111/j.1365-2729.2012.00487.x

Voogt, J. \& Knezek, G. (Eds.) (2008). International Handbook of Information Technology in Primary and Secondary Education. New York: Springer.

Voogt, J., Mckenney, S., Smits, M., \& Bustraan, W. (Submitted). Teacher's use of educative curriculum materials in an integrated writing and science curriculum. Elementary School Journal.

Wang, F., \& Hannafin, M. J. (2005). Design-based research and technology-enhanced learning environments. Educational Technology Research and Development, 53(4), 5-23.

Webb, M., \& Cox, M. (2004). A review of pedagogy rated to information and communications technology. Technology, Pedagogy and Education, 13(3), 235-286.

Woodrow, J. E. (1992). The influence of programming training on the computer literacy and attitudes of preservice teachers. Journal of Research on Computing in Education, 25(2), 200-218.

Yamnill, S., \& McLean, G. N. ( 2001). Theories supporting transfer of training. Human Resource Development Quarterly, 12(2), 195-208.

Yin, R. K. (1993). Applications of case study research (Vol. 34). Thousand Oaks: CA: Sage.

Zhu, C., \& Engels, N. (in press). Organizational culture and instructional innovations in higher education: Perceptions and reactions of teachers and students. Educational Management Administration \& Leadership. 


\section{ENGLISH SUMMARY}

\section{Preparation of pre-service teachers in Ghana to integrate Information and Communication Technology in teaching mathematics}

\section{INTRODUCTION}

The importance of mathematics in the development of a country cannot be underestimated as it plays a major role in the economy and the social life of its people. Due to its importance the government of Ghana is committed to ensuring the provision of high quality mathematics education. In spite of government efforts, learning mathematics has not undergone much change in terms of how it is structured and presented and among other reasons has resulted in consistently low achievement levels among mathematics students in high schools. Among the reasons for these low achievements, the method of teaching mathematics is considered one prominent factor. The most frequently used strategy in mathematics classrooms is the teacher-centred (chalk and talk) approach in which teachers do most of the talking and intellectual work, while students are passive receptacles of the information provided. Such teachercentred instructional methods have been criticized for failing to prepare students to attain high achievement levels in mathematics (Hartsell, Herron, Fang, \& Rathod; 2009). Although teacher-centred approaches still dominate in mathematics classrooms in Ghana, curriculum and policy documents suggest student-centred constructivist teaching methods in which learners construct and internalize new knowledge from their experiences. For example, the new curriculum in mathematics at the senior high school encourages teachers to make use of the calculator and the computer for problem solving and investigations of real life situations, in order to help students acquire the habit of analytical thinking and the capacity to apply knowledge in solving practical problems. However, there still exists a gap between the intentions expressed in 
curriculum and policy documents and mathematics teaching in practice. Teacher preparation programmes have not focussed on preparing pre-service teachers sufficiently for effective use of ICT in their teaching practice. In this research a set of studies has been conducted with the aim to design and implement a professional development arrangement for pre-service teachers about the use of ICT in a student-centred approach to teaching mathematics.

The professional development arrangement adopted 'learning technology by design' as approach to provide opportunity for pre-service teachers to develop their attitudes, knowledge and skills in ICT integration through the collaborative design and enactment of ICT-based curriculum materials To prepare pre-service teachers it was postulated that meaningful and effective use of ICT requires teachers to develop knowledge and skills that enable them to integrate ICT with a suitable pedagogical approach for teaching specific subject matter in a certain context. This integrated knowledge is referred to as Technological Pedagogical Content Knowledge (TPACK). TPACK assumes an understanding of the specific relationships between three primary domains of knowledge: Technological knowledge (TK), Pedagogical Knowledge (PK) and Content Knowledge (CK) as well as the interplay between these knowledge domains. In this study Technological knowledge was operationalized as knowledge about spreadsheets, a specific ICT application, which could contribute to higher order thinking skills in mathematics and was readily available in Ghana's senior high schools and in the teacher education programme. To make lessons less teacher-centred and more interactive actively involve pupils in their learning of mathematics, pedagogical knowledge was operationalized as knowledge about Activity Based Learning. In the research, pre-service teachers collaboratively designed and enacted spreadsheet-based lesson materials to prepare them to teach specific mathematics content enriched with spreadsheets

\section{AIM AND RESEARCH QUESTIONS}

The research focused on enhancing professional development arrangements in which pre-service teachers collaboratively design and use ICT-supported lesson teaching materials. Based on this purpose, the main research question was formulated as: 
How should collaborative design in design teams be applied in pre-service teacher education to prepare pre-service mathematics teachers for the integration of ICT in their future lessons?

The following sub-research questions guided the research phases:

1. What are barriers, needs and opportunities of pre-and in-service mathematics teachers' use of ICT in teaching mathematics at senior high schools in Ghana?

2. How do ICT attitudes, competencies and access of pre-and in-service mathematics teachers differ and to what extent do the parameters predict teachers' ICT integration levels?

3. What are pre-service mathematics teachers' experiences in developing and implementing technology-enhanced lessons through collaborative design teams?

4. How do pre-service teachers' knowledge and skills in designing and enacting spreadsheet supported activity-based lessons develop and to what extent do the lessons impact on secondary school students learning outcomes?

5. Which impact does a mathematics specific course, in which pre-service teachers collaboratively design spreadsheet-supported mathematics lessons in teams, have on pre-service teachers' technology competencies (attitudes, knowledge and skills)?

6. To what extent is transfer of learning influenced by beginning teachers' learner characteristics, characteristics of the ICT-based innovation, and school environment characteristics in their professional and teaching practice?

\section{RESEACH APPROACH AND DESIGN}

Design based research was adopted to answer the main research question. The main reason to use design based research is its capability to develop creative approaches for solving performance or teaching/learning problems and at the same time constructing a body of design guidelines that informs theory that could be used to guide efforts in future developments of pre-service teachers' experiences in technology integration. The main phases encompassing the design based research structured the studies in this thesis: context and needs analysis, two design and implementation studies, large scale implementation, 
and a transfer study. Through literature review, a needs- and context analysis and evaluation studies valid, practical and effective guidelines for the design of mathematic-specific professional development programmes to prepare preservice teachers to teach with technology were derived.

Based on the outcomes of the context and needs analysis study, a professional development programme based on 'learning technology by design' was conducted in two case studies among pre-service teachers at the teacher education programme at the University of cape Coast in Ghana. The studies focused on in-depth investigation of pre-service teachers' development of knowledge, skill and attitudes needed to design and enact ICT-supported Activity-based lessons. The findings from the studies informed a scale up study (beyond the group case studies) of the professional development arrangement into mathematics-specific Instructional Technology course to foster adoption of the innovation by many pre-service mathematics teachers. The final study was a transfer study, which followed the pre-service teachers who had become practicing teachers to examine whether and how beginning teachers were able to transfer their knowledge and skills to utililize the ICT-based innovation in their professional and teaching practice. Multiple data sources including qualitative and quantitative data have been used in the research. Teachers' selfreports of their knowledge of technology integration were triangulated with performance-based assessment of their instructional practices and artifacts to give a better understanding and nature of pre-service teachers development of technology competencies. The main results of the research are summarized in the next section.

\section{RESULTS}

This study supported the contention that TPACK is a useful analytic lens for studying teachers' integration of technological, content, and pedagogical knowledge as it develops over time in "learning technology by design" settings. The pre-service teachers in the study were able to develop and demonstrate their knowledge and skills adequately in designing and enacting activity-based mathematical lessons supported with spreadsheets as a result of the interventions. The results also showed that activity-based lessons supported with spreadsheets served a useful pedagogical approach, impacted on student 
learning outcomes and have the potential of improving teaching and learning mathematics in secondary education. Pre-service teachers applied their knowledge and skills in designing and enacting spreadsheet-enriched ABL lessons by employing a mix of direct instruction and hands-on activities to guide students and enhance their learning of mathematics.

The findings also showed that the professional development arrangement accounted for the development and improvement of technology integration competencies. In particular scaffolding authentic technology experiences including feedback from teaching try-outs played the most significant contribution to pre-service teachers' development of technology integration competencies. The importance of authentic teaching experiences with technology contributed to the reduction of pre-service teachers' anxieties thereby increasing their enthusiasm to use technology in instruction.

In this study collaborative design in teams helped pre-service teachers to undertake the kind of pedagogical reasoning that was necessary to design lessons to effectively integrate technology in their lessons. Participation in design teams for ICT-based lessons designed improved interaction and interdependence among pre-service teachers; making them discover how to share knowledge and ideas as well as improve communication and brainstorming on relevant information relating to their designs.

With regards to transfer of learning, findings from the transfer study showed that, after several months of finishing their teacher education preparatory programme, the pre-service teachers who had just begun their professional careers still held strong positive pedagogical views about collaboration in design teams to support ICT integration and make attempts to employ aspects of it in their professional and teaching practices. However, collaborative design in design teams to support ICT integration in the classroom situations was a challenge. Lesson observations confirmed that participants faced a complex mix of school-related constraints that when combined, contributed to a lack of creativity in supporting ICT integration through collaborative design. Particularly, lack of access to the ICT infrastructure and an unenthusiastic school culture were pronounced. 


\section{DESIGN GUIDELINES}

A major outcome of the research is a set of design guidelines to shape preservice teacher professional development on meaningful and effective use of ICT in education. These design guidelines are:

- Collaborative Design Teams, in which pre-service teachers work with peers, are an important means to stimulate and support teacher learning. This approach of ICT integration will improve interaction and interdependence among preservice teachers; making them discover how to share knowledge and ideas as well to brainstorm on relevant information relating to their designs.

- Exemplary curriculum materials are an important means as they can inspire teachers to learn and provide a better understanding of an innovation (cf. Van den Akker, 1988). Exemplary curriculum materials will promote a better understanding of what integrating technology in lessons is about, promote pedagogical design capacity, provide concrete how-to-do suggestions and facilitate a better implementation of ICT-based innovations.

- For effective collaboration in design teams and the use of the exemplary materials, an orientation programme is important. Such an orientation programme for pre-service teachers should provide a learning experience where conceptual and theoretical information could be linked to a practical application.

- Adoption of technology that is readily available with the potential of supporting students' higher-order thinking in mathematics is key to a successful intervention in integrating technology. By learning how to use existing hardware and software in creative and situation-specific ways to accomplish their teaching goals, pre-service teachers will be prepared to use ICT in their professional and daily classroom practices.

- Scaffolds and authentic technology experiences, such as teaching try-outs with peers should be an integrated part of a pre-service teacher preparation programme aiming to develop pre-service teachers' technology integration competencies. This allows pre-service teachers to put into practice their designed lesson plans and that through feedback from peers, scaffolds are provided. 


\section{CONCLUSION}

Based on responses and experiences of the pre-service teachers, the research demonstrated that pre-service teachers developed TPACK and that they felt prepared to effectively use ICT in their classroom. The outcomes of the research showed that collaborative design in design teams in pre-service teacher education is a viable and effective approach to prepare pre-service mathematics teachers for the integration of technology and activity-based learning in mathematics lessons. Because pre-service teachers had to design and enact ICTenhanced mathematics lessons opportunities were provided to develop their knowledge and skills and make intimate connections between technology (spreadsheets), content (mathematics) and pedagogy (activity-based learning). While pre-service teachers collaborated during design and enactment, knowledge and attitudes about ICT and activity-based learning became explicit, which helped them to reflect on their experiences, and hence fostered learning. 


\section{DUTCH SUMMARY}

\section{Het opleiden van docenten in opleiding in de integratie van Informatie en Communicatie Technologie in het wiskunde onderwijs in Ghana}

\section{INTRODUCTIE}

Voor de ontwikkeling van een land kan het belang van wiskunde niet worden onderschat, omdat wiskunde een belangrijke rol speelt in de economie en het sociale leven.. Omwille hiervan committeert de regering van Ghana zich aan het leveren van wiskunde onderwijs van hoge kwaliteit. Ondanks de inspanningen van de overheid heeft het wiskunde onderwijs geen grote veranderingen ondergaan in termen van hoe het gestructureerd en gepresenteerd wordt en dit heeft onder meer geresulteerd in voortdurend lage wiskundeprestaties van leerlingen op middelbare scholen. De wijze van lesgeven wordt gezien als een belangrijke factor die bijdraagt aan deze slechte prestaties. De meest gebruikte strategie in de wiskundelessen is de op overdracht gebaseerde benadering, waarin de docent het meest aan het woord is en het intellectuele werk uitvoert, terwijl de leerlingen passieve ontvangers van de geleverde informatie zijn. Er is kritiek op het gebruik van dergelijke op overdracht gebaseerde instructiemethoden omdat ze niet bijdragen aan hoge prestatieniveaus in wiskunde (Hartsell, Herron, Fang, \& Rathod; 2009). Hoewel in Ghana op overdracht gebaseerde benaderingen nog steeds de wiskundelessen domineren, wordt in curriculum- en beleidsdocumenten het gebruik van onderwijsmethoden voorgesteld waarbij leerlingen nieuwe kennis construeren en internaliseren vanuit hun ervaringen. Het nieuwe curriculum voor wiskunde in de bovenbouw van de middelbare school bijvoorbeeld, moedigt docenten aan om gebruik te maken van een rekenmachine en de computer voor het oplossen van problemen, bij wiskundig onderzoek naar levensechte situaties, om leerlingen te helpen analytische vaardigheden te ontwikkelen, en om hen te leren hun kennis toe te 
passen voor het oplossen van praktische problemen. Echter, er is nog steeds sprake van een kloof tussen de intenties die in de curriculum- en beleidsdocumenten zijn opgeschreven en het wiskunde onderwijs in de praktijk. Opleidingsprogramma's voor docenten zijn niet gericht op het in voldoende mate opleiden van toekomstige docenten om effectief gebruik te kunnen maken van Informatie- en Communicatietechnologie (ICT) in hun onderwijspraktijk. In deze studie is een serie onderzoeken uitgevoerd die als doel hebben om een scholingsarrangement voor docenten in opleiding te ontwerpen en te implementeren voor het gebruik van ICT in een student-gerichte benadering in het wiskunde onderwijs.

Er is gekozen om het scholingsarrangement vorm te geven via de'learning technology by design' benadering. Docenten in opleiding ontwikkelen in het scholingsarrangement attitudes, kennis en vaardigheden met het oog op de integratie van ICT door middel van het collaboratieve ontwerp exemplarische curriculummaterialen, waarin ICT is geïntegreerd. Voor het opleiden van toekomstige docenten werd aangenomen dat voor betekenisvol en effectief gebruik van ICT het noodzakelijk is dat docenten kennis en vaardigheden aanleren die hen in staat stellen om ICT te integreren met een passende didactiek voor het lesgeven met domeinspecifieke leerstof in een bepaalde context. Deze geïntegreerde kennis wordt ook wel Technological Pedagogical Content Knowledge (TPACK) genoemd. TPACK gaat uit van het begrijpen van de specifieke relatie tussen drie primaire kennisdomeinen: Technological Knowledge (TK; technologische kennis), Pedagogical Knowledge (PK: didactische kennis) en Content Knowledge (CK; vakinhoudelijke kennis), alsmede de interactie tussen deze kennisdomeinen. In dit onderzoek werd technologische kennis geoperationaliseerd als kennis over het gebruik van spreadsheets, een specifieke ICT-applicatie, die zou kunnen bijdragen aan hogere orde denkvaardigheden in wiskunde. Spreadsheets zijn beschikbaar op middelbare scholen in Ghana en op de lerarenopleiding. Om de lessen minder docent-gericht te maken en om leerlingen meer actief te betrekken bij het interactief aanleren van wiskunde, werd didactische kennis geoperationaliseerd als kennis over Activity Based Learning (ABL). In het onderzoek ontwierpen en gebruikten docenten in opleiding gezamenlijk lesmaterialen ondersteund met spreadsheetst om hen voor te bereiden op het lesgeven in een bepaalde wiskundige inhoud. spreadsheets. 


\section{DOEL VAN ONDERZOEK EN ONDERZOEKSVRAGEN}

De studie richtte zich op het verbeteren van scholingsarrangementen waarin pre-service docenten collaboratief ICT-ondersteunde lesmaterialen ontwerpen en gebruiken. De centrale onderzoeksvraag luidde:

Hoe moet collaboratief ontwerpen in ontwerpteams worden toegepast in de lerarenopleiding om toekomstige wiskundedocenten zodanig op te leiden dat ze ICT zullen integreren in hun toekomstige lessen?

De volgende deelvragen leidden de verschillende fases in het onderzoek:

1. Wat zijn de barrières, behoeften en mogelijkheden voor het gebruik van ICT door toekomstige en praktiserende wiskundedocenten bij het wiskunde onderwijs aan de bovenbouw van middelbare scholen in Ghana?

2. Hoe verschillen attitudes, kennis en vaardigheden ten opzichte van ICT en de toegang tot ICT tussen toekomstige en praktiserende wiskundedocenten en in welke mate voorspellen deze parameters de niveaus van ICT integratie?

3. Wat zijn de ervaringen van wiskundedocenten in opleiding met het gezamenlijk ontwerpen en implementeren van met ICT-verrijkte lessen in ontwerpteams?

4. Hoe ontwikkelt de kennis en vaardigheden van wiskundedocenten in opleiding in het ontwerpen en gebruiken van op activiteiten gebaseerde lessen verrijkt met spreadsheets zich, en in welke mate hebben de lessen een impact op de leerprestaties van middelbare school leerlingen?

5. Welke impact heeft een wiskundespecifieke cursus, waarin docenten in opleiding collaboratief in teams wiskundelessen ontwerpen verrijkt met spreadsheets, op de ICT competenties (attitudes, kennis en vaardigheden) van docenten in opleiding?

6. In welke mate wordt transfer van leren naar de professionele en onderwijspraktijk beïnvloed door de kenmerken van beginnende leraren, de kenmerken van op de ICT gebaseerde innovatie, en de kenmerken van de schoolomgeving? 


\section{ONDERZOEKSBENADERING EN ONTWERP}

De onderzoeksvraag werd beantwoord met behulp van ontwerponderzoek.. Ontwerponderzoek is gericht op het oplossen van problemen uit de onderwijspraktijk en resulteert in de formulering van ontwerprichtlijnen, die bijdragen aan theorievorming, en gebruikt kunnen worden bij de toekomstige ontwikkeling van docenten in opleiding in ICT integratie. De hoofdfases van ontwerponderzoek vormden de structuur van de onderzoeken in dit proefschrift: context- en behoeftenanalyse, twee ontwerp- en implementatieonderzoeken, implementatie op grotere schaal, en een onderzoek naar transfer. Via literatuuronderzoek, context- en behoeftenanalyse en evaluatie-onderzoek, werden valide, praktisch bruikbare en effectieve ontwerprichtlijnen afgeleid voor het ontwerpen van wiskunde-specifieke scholingsarrangementen voor het opleiden van toekomstige wiskundedocenten in het lesgeven met behulp van ICT.

In twee case studies waarin docenten in opleiding van de Universiteit van Cape Coast in Ghana participeerden, werd een scholingsarrangement ontwikkeld en uitgevoerd gebaseerd op 'learning technology by design'. Het betrof een diepgaand onderzoek naar de ontwikkeling van de kennis, vaardigheden en attitudes van docenten in opleiding, die nodig zijn om op activiteit-gebaseerde met ICT verrijkte lessen te ontwerpen en te implementeren.. De bevindingen van de case studies bevatten voldoende informatie voor een vervolgonderzoek naar de implementatie van het scholingsarrangement in een reguliere wiskunde-specifieke instructietechnologie cursus. Het laatste onderzoek betrof een onderzoek naar transfer van leren, waarin werd onderzocht of en hoe de docenten in opleiding, die inmiddels beginnende docenten waren geworden, in staat waren de opgedane kennis en vaardigheden toe te passen in hun professionele lespraktijk.

In het onderzoek zijn kwalitatieve en kwantitatieve data verzameld. De zelfrapportages van de docenten over hun kennis van ICT integratie werden getrianguleerd met de beoordeling van hun instructiepraktijken en van de ontworpen lesmaterialen, om een beter begrip te vormen van de aard en ontwikkeling van ICT competenties van docenten in opleiding. De voornaamste resultaten van het onderzoek zijn in het volgende gedeelte samengevat. 


\section{RESUlTATEN}

Dit onderzoek ondersteunt de bewering dat TPACK een bruikbare analytische lens vormt voor het bestuderen van de integratie van technologische, vakinhoudelijke, en didactische kennis van docenten, zoals het zich in de tijd ontwikkelt in 'learning technology by design' settings. Als resultaat van de interventies bleken de docenten in opleiding in staat om hun kennis en vaardigheden voor het ontwerpen en implementeren van op activiteiten gebaseerde wiskundelessen ondersteund met spreadsheets adequaat te ontwikkelen en te demonstreren. De resultaten toonden ook aan dat op activiteiten gebaseerde lessen ondersteund met spreadsheets een bruikbare didactische benadering is, en impact heeft op de leerprestaties van leerlingen, en mogelijkheid biedt voor de verbetering van het wiskunde-onderwijs. De docenten in opleiding pasten hun kennis en vaardigheden in ontwerpen en implementeren van met spreadsheets verrijkte ABL lessen toe dooreen mix van directe instructie- en hands-on activiteiten te gebruiken om leerlingen te begeleiden bij het leren van wiskunde.

De bevindingen toonden ook aan dat het scholingsarrangement verantwoordelijk was voor de ontwikkeling en de verbetering van competenties om ICT te integreren. In het bijzonder was de aansluiting bij authentieke onderwijservaringen met ICT, waaronder het geven van feedback tijdens onderwijs-try-outs, belangrijk voor de ontwikkeling van competenties die ICT integratie bevorderen. Het belang van authentieke onderwijservaringen met ICT droeg bij aan een afname in angst bij docenten in opleiding waardoor hun enthousiasme om technologie in hun instructies te gebruiken toenam.

In deze studie hielp het collaboratief ontwerpen in teams de docenten in opleiding om het soort didactisch redeneren te ontwikkelen dat nodig is om lessen te ontwerpen waarin ICT effectief wordt geïntegreerd. Participatie in teams bij het ontwerpen van met ICT-verrijkte lessen bevorderde de interactie en onderlinge afhankelijkheid van docenten in opleiding; het zorgde ervoor dat ze ontdekten hoe ze hun kennis en ideeën konden delen en hoe ze tegelijkertijd hun communicatie en brainstormen over relevante informatie voor hun ontwerp konden verbeteren. 
Ten aanzien van de transfer van leren toonden de bevindingen van het transfer onderzoek aan dat, meerdere maanden na het afronden van de lerarenopleiding, de docenten in opleiding die net met hun professionele carrière waren begonnen nog steeds een sterk positieve didactische visie hebben op samenwerking in ontwerpteams om ICT te integreren en dat ze pogingen doen om aspecten hiervan in te zetten in hun professionele en onderwijspraktijk. Echter, het bleek een uitdaging te zijn om collaboratief ontwerpen in ontwerpteams in te zetten om de integratie van ICT in de les te ondersteunen. Observaties van de lessen bevestigden dat beginnende docenten geconfronteerd werden met een complexe mix van school-gerelateerde beperkingen die tezamen bijdroegen aan een gebrek aan creativiteit in het ondersteunen van ICT integratie door middel van collaborative ontwerpen. Een belangrijke reden hiervoor was het gebrek aan toegang tot de ICT infrastructuur en een niet enthousiaste schoolcultuur.

\section{ONTWERPRICHTLIJNEN}

Een belangrijke uitkomst van deze studie zijn ontwerprichtlijnen om de professionele ontwikkeling van docenten in opleiding vorm te geven in het betekenisvol en effectief gebruik van ICT in het onderwijs. Deze ontwerprichtlijnen zijn:

- Collaboratieve ontwerpteams, waarin docenten in opleiding samenwerken met studiegenoten, zijn een belangrijk middel om het leren van docenten te stimuleren en ondersteunen. Deze benadering voor ICT-integratie zal de interactie en onderlinge afhankelijkheid van docenten in opleiding verbeteren; het zorgt ervoor dat ze ontdekken hoe ze kennis en ideeën kunnen delen en hoe ze kunnen brainstromen over relevante informatie gerelateerd aan hun ontwerpen.

- Exemplarische curriculummaterialen zijn een belangrijk middel omdat zij docenten kunnen inspireren om te leren en een beter begrip kunnen opleveren voor een innovatie (cf. Van den Akker, 1988). Exemplarische curriculummaterialen zullen een beter begrip bevorderen over wat het integreren van ICT inhoudt, de didactische ontwerpcapaciteit van docenten bevorderen, concrete 'how-to-do' suggesties leveren, en een betere implementatie van op ICT-gebaseerde innovaties faciliteren. 
- Voor effectieve collaboratie in ontwerpteams en het gebruik van exemplarische curriculummaterialen is een oriëntatie-programma belangrijk. Een dergelijk oriëntatie-programma voor docenten in opleiding zou een leerervaring moeten leveren waarin conceptuele en theoretische informatie gelinkt wordt aan praktische toepassing.

- Adoptie van reeds beschikbare technologie met de mogelijkheid om het hogere orde denken in wiskunde bij leerlingen te ondersteunen is een sleutel tot een succesvolle interventie voor het integreren van ICT in wiskundeonderwijs. Door te leren hoe bestaande hardware en software creatief en situatie-specifiek gebruikt kan worden om leerdoelen te bereiken, zullen docenten in opleiding voorbereid zijn op het gebruik van ICT in hun professionele en dagelijkse lespraktijken.

- Scaffolds en authentieke onderwijservaringen met ICT, zoals onderwijs tryouts met studiegenoten, zouden een geïntegreerd deel moeten uitmaken van een opleidingsprogramma dat als doel heeft om de competenties van docenten in ICT-integratie te ontwikkelen. Dit geeft docenten in opleiding de mogelijkheid om hun ontworpen lesplannen in praktijk te brengen en zorgt ervoor dat scaffolds worden geleverd door feedback van studiegenoten.

\section{CONCLUSIE}

Deze studie, gebaseerd op de reacties en ervaringen van de docenten in opleiding, heeft aangetoond dat docenten in opleiding TPACK ontwikkelden en dat zij zich voorbereid voelden om ICT effectief te gebruiken in hun klaslokaal. De uitkomsten van deze studie lieten zien dat collaboratief ontwerpen in ontwerpteams in de lerarenopleiding een levensvatbare en effectieve benadering is om toekomstige wiskundedocenten op te leiden in het integreren van ICT en het geven van op activiteiten gebaseerde wiskundelessen. Door docenten in opleiding ICT-verrijkte wiskunde lessen te laten ontwerpen en implementeren werden hen mogelijkheden geboden om hun kennis en vaardigheden te ontwikkelen en om verbanden te leggen tussen ICT (spreadsheets), vakinhoud (wiskunde) en didactiek (leren gebaseerd op activiteiten). Terwijl docenten in opleiding samenwerkten tijdens het ontwikkelen en uitvoeren van de lessen, werden kennis, vaardigheden en attitudes over ICT en leren gebaseerd op activiteiten expliciet, wat hen hielp om op hun ervaringen te reflecteren, en waardoor hun leerproces werd bevorderd. 


\section{APPENDICES}

\section{APPENDIX A}

Data collection instruments for Chapters 2 and 3

\section{A1: Questionnaire for mathematics Tutors in Senior High Schools}

\section{A. Introduction}

Dear.

This interview is meant to collect data that will help to empirically ascertain the feasibility of integrating Information Communication Technology as an instructional aid in the teaching of Senior High Schools mathematics in Ghana. In this study, ICT means the integration of web-based or computer-based technologies in teaching of mathematics. They include technologies such as Word Processing Packages, Graphical applications, Multimedia, Java applets, Simulation Programmes, Data bases, Spreadsheets and any Internet activities. In this questionnaire, quite a few questions require you to fill in some information, but for the rest of the questions you are required to just tick (v) items against a specific response that apply to your situation. I wish to let you know that all the information you provide will be used only for the purpose of this study and that it will be treated confidentially.

\section{B. Biographic data}

1. Your age:

2. Sex: male[ ], female[ ]

3. Email/Phone number.

4. School / institute

5. Subject you teach: Core Mathematics [] Elective mathematics[ ] Both [ ]

6. Years of experience in teaching mathematics

7. Rank: Senior Superintendent[ ], Principal Superintendent[ ], Assistant Director 2[ ], Assistant Director 1[ ], Director [ ]

8. Nature of employment: full time[ ], part time[ ] 


\section{Questions}

1. What kind of teaching strategies are you often involved in as a tutor in mathematics at the SHS? (Please mark only one choice in each row)

\begin{tabular}{|l|l|l|l|l|}
\hline \multicolumn{1}{|c|}{ Strategy } & $\begin{array}{c}\text { Nearly } \\
\text { Always }\end{array}$ & often & Sometimes & Never \\
\hline $\begin{array}{l}\text { Chalk and Talk approach (Lecture } \\
\text { method) }\end{array}$ & & & & \\
\hline Use of Course Manuals & & & & \\
\hline Individual Assignments & & & & \\
\hline Use of Group/Team work & & & & \\
\hline Use of ICT & & & & \\
\hline Use of Demonstrations & & & & \\
\hline $\begin{array}{l}\text { other, } \\
\text { namely..................................................... }\end{array}$ & & & & \\
\hline
\end{tabular}

2. What challenges do you encounter in your current teaching strategy in your mathematics lessons? (Please mark only one choice in each row)

\begin{tabular}{|l|c|c|}
\hline \multirow{2}{*}{ Items } & \multicolumn{2}{c|}{ Responses } \\
\cline { 2 - 3 } & yes & No \\
\hline $\begin{array}{l}\text { Providing support to students immediately (e.g. elaboration of } \\
\text { a concept to students) }\end{array}$ & & \\
\hline $\begin{array}{l}\text { Providing effective and immediate feedback on assignments, } \\
\text { tests and examinations }\end{array}$ & & \\
\hline Dealing with large class sizes & & \\
\hline Dealing with diverse groups of students & & \\
\hline Regular communication and interaction with students & & \\
\hline Insufficient and outdated supplementary reading resources & & \\
\hline $\begin{array}{l}\text { Timely delivery of assignments / course materials e.t.c to } \\
\text { students }\end{array}$ & & \\
\hline Other, namely............................................................... & & \\
\hline
\end{tabular}

3. In your teaching of mathematics how often do you engage your students in the following activities? (Please mark only one choice in each row)

\begin{tabular}{|l|l|l|l|l|}
\hline \multicolumn{1}{|c|}{ Students' Activities } & $\begin{array}{l}\text { Nearly } \\
\text { Always }\end{array}$ & often & Sometimes & Never \\
\hline $\begin{array}{l}\text { Students working on the same learning materials } \\
\text { at the same pace and/or sequence }\end{array}$ & & & & \\
\hline $\begin{array}{l}\text { Students explaining and discussing own ideas } \\
\text { with teacher and peers }\end{array}$ & & & & \\
\hline $\begin{array}{l}\text { Reflect on own learning experience review (e.g., } \\
\text { writing a learning log) and adjust own learning } \\
\text { strategy }\end{array}$ & & & & \\
\hline Self and/or peer evaluation & & & & \\
\hline $\begin{array}{l}\text { Students learning and/or working during lessons } \\
\text { at their own pace }\end{array}$ & & & & \\
\hline Give presentations & & & & \\
\hline Determine own content goals for learning & & & & \\
\hline
\end{tabular}


4. Please read the descriptions of each of the six stages related to adoption of Information and Communication Technology and write down the number of the stage that best describes where you are in the adoption of ICT.

\section{Stage 1: Awareness}

I am aware that information and communication technology exists but has not used it - perhaps I'm even avoiding it.

Stage 2: Learning the process

I am currently trying to learn the basics. I am often frustrated using computers. I lack confidence when using computers.

Stage 3: Understanding and application of the process

I am beginning to understand the process of using technology and can think of specific tasks in which it might be useful.

Stage 4: Familiarity and confidence

I am gaining a sense of confidence in using the computer for specific tasks.

I am starting to feel comfortable using the computer.

Stage 5: Adaptation to other contexts

I think about the computer as a tool to help me and I'm no longer concerned about it as technology. I can use it in many applications and as an instructional aid.

Stage 6: Creative application to new contexts

I can apply what I know about technology in the classroom. I am able to use it as an instructional tool and integrate it into the curriculum.

The stage that best describes where I am now is number

5. Does your school have the following ICT facilities? (Please mark only one choice in each row)

\begin{tabular}{|l|c|c|}
\hline \multirow{2}{*}{ Items } & \multicolumn{2}{c|}{ Responses } \\
\cline { 2 - 3 } & \multicolumn{1}{c|}{ Yes } & No \\
\hline Computer Laboratory & & \\
\hline Computers in the Library & & \\
\hline Computers in the Staff Common Room & & \\
\hline Computer(s) in the Mathematics Department (office) & & \\
\hline Computer in your office & & \\
\hline Internet connectivity & & \\
\hline other, namely.................................................................... & & \\
\hline
\end{tabular}


6. To what extent do you integrate the following ICT Application in your instruction? (Please mark only one choice in each row). Mark "NA" if an application is "not available" in your school. If your response for question 6 below is "not at all" or "NA" for all the applications in the table, then skip questions 7 to 9 and continue from question 10.

\begin{tabular}{|l|l|l|l|l|l|}
\hline \multicolumn{1}{|c|}{ Application } & $\begin{array}{c}\text { Not at } \\
\text { all }\end{array}$ & $\begin{array}{c}\text { A } \\
\text { little }\end{array}$ & Somewhat & $\begin{array}{c}\text { A } \\
\text { lot }\end{array}$ & NA \\
\hline Word processing packages (e.g.microsoft word) & & & & & \\
\hline $\begin{array}{l}\text { Database software (e.g.online student results, } \\
\text { online continuous assessment, computerized library } \\
\text { system) }\end{array}$ & & & & & \\
\hline Spreadsheet (e.g. excel) & & & & & \\
\hline Presentation Software (e.g.power point) & & & & & \\
\hline Graphical Application (e.g. derive) & & & & & \\
\hline Graphical Calculators & & & & & \\
\hline Application of multimedia (e.g.video, audio, tv) & & & & & \\
\hline E-mail (e.g.yahoo,outlook express, gmail) & & & & & \\
\hline Internet (e.g.for getting information from website) & & & & & \\
\hline Java applets & & & & & \\
\hline
\end{tabular}

NA - Not Available

7. What barriers do you encounter when integrating ICT in your lessons? (Please mark only one choice in each row)

\begin{tabular}{|l|l|l|l|}
\hline \multicolumn{1}{|c|}{ Items } & \multicolumn{2}{c|}{ Responses } \\
\cline { 4 - 5 } & $\begin{array}{l}\text { major } \\
\text { barrier }\end{array}$ & $\begin{array}{l}\text { Minor } \\
\text { barrier }\end{array}$ & $\begin{array}{l}\text { Not a } \\
\text { barrier }\end{array}$ \\
\hline $\begin{array}{l}\text { Not enough or limited access to computers/computer } \\
\text { lab }\end{array}$ & & & \\
\hline Availability of computer software & & & \\
\hline Lack of time in school schedule for integrating ICT & & & \\
\hline Lack of adequate technical support & & & \\
\hline $\begin{array}{l}\text { Lack of knowledge about ways to integrate ICT in } \\
\text { Lessons }\end{array}$ & & & \\
\hline ICT integration is not a school priority & & & \\
\hline $\begin{array}{l}\text { Not enough training opportunities for ICT integration } \\
\text { knowledge acquisition }\end{array}$ & & & \\
\hline Lack of confidence to try new approaches & & & \\
\hline $\begin{array}{l}\text { Lack of time necessary to develop and implement } \\
\text { activities }\end{array}$ & & & \\
\hline $\begin{array}{l}\text { Lack of knowledge to identify which ICT tools will be } \\
\text { useful }\end{array}$ & & & \\
\hline Lack of digital learning resources in my school & & & \\
\hline
\end{tabular}


8. What kind of technical support do you currently get when using ICT in your teaching?

\begin{tabular}{|l|l|l|c|c|}
\hline \multicolumn{1}{|c|}{ Technical Support } & Not at all & A little & Somewhat & A lot \\
\hline Troubleshooting & & & & \\
\hline Installation of software & & & & \\
\hline $\begin{array}{l}\text { Provision of technical course for operating \& } \\
\text { maintaining computer system }\end{array}$ & & & & \\
\hline Having a technician in the classroom & & & & \\
\hline None & & & & \\
\hline Other, namely................................................. & & & & \\
\hline
\end{tabular}

9. To what extent do the following statements about administrative support to teachers apply to you? (Please mark only one choice in each row).

\begin{tabular}{|l|l|l|l|l|}
\hline Administrative Support & Not at all & A little & Somewhat & A lot \\
\hline $\begin{array}{l}\text { The administrative work arising from the } \\
\text { use of ICT in my teaching (e.g., booking } \\
\text { computer laboratories, changing class } \\
\text { schedules) is easy to do in my school. }\end{array}$ & & & & \\
\hline $\begin{array}{l}\text { The current reward structure adequately } \\
\text { recognize those utilising ICT }\end{array}$ & & & & \\
\hline $\begin{array}{l}\text { When implementing innovations, our school } \\
\text { considers teachers' opinions and adjusts its } \\
\text { action plan as needed }\end{array}$ & & & & \\
\hline
\end{tabular}

10. To what extent are you confident in accomplishing the following?

\begin{tabular}{|l|l|l|l|l|}
\hline Knowledge and Skill of ICT & Not at all & A little & Somewhat & A lot \\
\hline $\begin{array}{l}\text { I can produce a letter using a word } \\
\text { processing programme }\end{array}$ & & & & \\
\hline I can e-mail a file to a colleague & & & & \\
\hline $\begin{array}{l}\text { I can take photos and show them on a } \\
\text { computer }\end{array}$ & & & & \\
\hline $\begin{array}{l}\text { I can produce presentations with simple } \\
\text { animation functions }\end{array}$ & & & & \\
\hline $\begin{array}{l}\text { I can use spreadsheet for student } \\
\text { administration }\end{array}$ & & & & \\
\hline $\begin{array}{l}\text { I can prepare lessons that involve the use of } \\
\text { ICT for instruction }\end{array}$ & & & & \\
\hline $\begin{array}{l}\text { I know which teaching/learning situations } \\
\text { are suitable for ICT use. }\end{array}$ & & & & \\
\hline $\begin{array}{l}\text { I can use the Internet (e.g., select suitable } \\
\text { websites, user groups/discussion forums) to } \\
\text { support my lessons in mathematics }\end{array}$ & & & & \\
\hline $\begin{array}{l}\text { I can find useful curriculum resources in } \\
\text { mathematics on the Internet for teaching }\end{array}$ & & & & \\
\hline $\begin{array}{l}\text { I can install educational software on my } \\
\text { Computer }\end{array}$ & & & & \\
\hline $\begin{array}{l}\text { I can use ICT to give effective } \\
\text { presentations/ } \\
\text { Explanations in my lessons }\end{array}$ & & & & \\
\hline
\end{tabular}


11. Have you participated in any of the following professional development activities? If no, would you wish to attend?

\begin{tabular}{|l|l|l|l|}
\hline \multicolumn{1}{|c|}{ Items } & \multicolumn{3}{c|}{ Responses } \\
\cline { 2 - 4 } & $\begin{array}{l}\text { Yes } \\
\text { I have }\end{array}$ & $\begin{array}{l}\text { No, I do } \\
\text { not wish } \\
\text { to attend }\end{array}$ & $\begin{array}{l}\text { No, I would } \\
\text { like to attend } \\
\text { if available }\end{array}$ \\
\hline $\begin{array}{l}\text { Technical course for operating and maintaining } \\
\text { computer system }\end{array}$ & & & \\
\hline $\begin{array}{l}\text { Introductory course for Internet use and general } \\
\text { applications (e.g., basic word-processing, } \\
\text { spreadsheets, databases, etc.) }\end{array}$ & & & \\
\hline $\begin{array}{l}\text { Subject-specific training with learning software for } \\
\text { specific content mathematics goals (e.g., tutorials, } \\
\text { simulation, etc }\end{array}$ & & & \\
\hline $\begin{array}{l}\text { Course on pedagogical issues related to integrating } \\
\text { ICT into teaching and learning. }\end{array}$ & & & \\
\hline $\begin{array}{l}\text { Course on multimedia operations (e.g., using digital } \\
\text { video and/or audio equipment in mathematics }\end{array}$ & & & \\
\hline
\end{tabular}

12. The following table shows various perceptions of use of computers and varying responses. Read each statement and then circle the number which best shows how you feel.

( $\mathrm{SD}=$ Strongly Disagree $\mathrm{D}=$ Disagree $\mathrm{U}=$ Undecided $\mathrm{A}=$ Agree SA = Strongly Agree $)$

\begin{tabular}{|c|c|c|c|c|c|}
\hline Perceptions & SD & D & $\mathbf{U}$ & A & SA \\
\hline \multicolumn{6}{|l|}{ Part 1: General Computer Use } \\
\hline 1. I enjoy doing things on a computer & (1) & (2) & (3) & (4) & (5) \\
\hline 2. I am tired of using a computer & (1) & (2) & (3) & (4) & (5) \\
\hline $\begin{array}{l}\text { The challenge of learning about computers is } \\
\text { exciting }\end{array}$ & (1) & (2) & (3) & (4) & (5) \\
\hline 4. I concentrate on a computer when I use one & (1) & $(2)$ & (3) & (4) & (5) \\
\hline 5. I enjoy computer games very much & (1) & (2) & (3) & (4) & (5) \\
\hline $\begin{array}{l}\text { I would work better if I could use computers } \\
\text { more often }\end{array}$ & (1) & (2) & (3) & (4) & (5) \\
\hline $\begin{array}{l}\text { 7. I know that computers give me opportunities } \\
\text { to learn many new things. }\end{array}$ & (1) & (2) & (3) & (4) & (5) \\
\hline $\begin{array}{l}\text { K. Knowing how to use a computer is a } \\
\text { worthwhile skill }\end{array}$ & (1) & (2) & (3) & (4) & (5) \\
\hline 9. I enjoy lessons on the computer & (1) & (2) & (3) & (4) & (5) \\
\hline $\begin{array}{l}\text { I have a lot of self confidence when it comes } \\
\text { to working with computers }\end{array}$ & (1) & (2) & (3) & (4) & (5) \\
\hline $\begin{array}{l}\text { I believe that it is very important for me to } \\
\text { learn how to use a computer. }\end{array}$ & (1) & (2) & (3) & (4) & (5) \\
\hline 12. I feel comfortable working with a computer & (1) & (2) & (3) & (4) & (5) \\
\hline $\begin{array}{l}\text { I3. I get a sinking feeling when I think of trying to } \\
\text { use a computer. }\end{array}$ & (1) & (2) & (3) & (4) & (5) \\
\hline $\begin{array}{l}\text { I think that it takes a long time to finish a task } \\
\text { when I use a computer. }\end{array}$ & (1) & (2) & (3) & (4) & (5) \\
\hline 15. Working with a computer makes me nervous & (1) & (2) & (3) & (4) & (5) \\
\hline 16. Using a computer is very frustrating & (1) & (2) & (3) & (4) & (5) \\
\hline
\end{tabular}




\begin{tabular}{|c|c|c|c|c|c|}
\hline $\begin{array}{l}\text { 17. I will do as little work with computers as } \\
\text { possible }\end{array}$ & (1) & (2) & (3) & (4) & (5) \\
\hline 18. Computers are difficult to use & (1) & $(2)$ & (3) & (4) & (5) \\
\hline 19. Computers do not scare me at all & (1) & (2) & (3) & (4) & (5) \\
\hline $\begin{array}{l}\text { 20. I can learn more from books than from a } \\
\text { computer }\end{array}$ & (1) & (2) & (3) & (4) & (5) \\
\hline \multicolumn{6}{|l|}{ Part 2: Computers in Instruction } \\
\hline $\begin{array}{l}\text { Computers are valuable tools that can be used } \\
\text { to improve the quality of education. }\end{array}$ & (1) & (2) & (3) & (4) & (5) \\
\hline $\begin{array}{l}\text { Teachers should know how to use computers } \\
\text { in their classrooms. }\end{array}$ & (1) & (2) & (3) & (4) & (5) \\
\hline $\begin{array}{l}\text { I believe that the more often teachers use } \\
\text { 23. computers, the more students will enjoy } \\
\text { school }\end{array}$ & (1) & (2) & (3) & (4) & (5) \\
\hline $\begin{array}{l}\text { If there is a computer in my future classroom, } \\
\text { It would help me to be a better teacher. }\end{array}$ & (1) & (2) & (3) & (4) & (5) \\
\hline $\begin{array}{l}\text { 25. would like to have a computer for use in my } \\
\text { classroom. }\end{array}$ & (1) & (2) & (3) & (4) & (5) \\
\hline $\begin{array}{l}\text { If there was a computer in my classroom it } \\
\text { would help me to be a better teacher }\end{array}$ & (1) & (2) & (3) & (4) & (5) \\
\hline 27. I enjoy using new tools for instruction. & (1) & $(2)$ & (3) & (4) & (5) \\
\hline $\begin{array}{l}\text { The people who give me the best idea for } \\
\text { 28. improving teaching tend to know a lot about } \\
\text { ICT }\end{array}$ & (1) & (2) & (3) & (4) & (5) \\
\hline $\begin{array}{l}\text { 29. I believe textbooks will be replaced by } \\
\text { electronic media. }\end{array}$ & (1) & (2) & (3) & (4) & (5) \\
\hline $\begin{array}{l}\text { I believe that the roles of schools will be } \\
\text { dramatically changed because of the internet. }\end{array}$ & (1) & (2) & (3) & (4) & (5) \\
\hline $\begin{array}{l}\text { Computers could enhance remedial } \\
\text { instruction }\end{array}$ & (1) & (2) & (3) & (4) & (5) \\
\hline $\begin{array}{l}\text { Computer can be used successfully with } \\
\text { 32. } \\
\text { courses which demand creative activities }\end{array}$ & (1) & (2) & (3) & (4) & (5) \\
\hline $\begin{array}{l}\text { Computers can help accommodate different } \\
\text { teaching styles }\end{array}$ & (1) & (2) & (3) & (4) & (5) \\
\hline $\begin{array}{l}\text { 34. Teacher training should include instructional } \\
\text { applications of computers }\end{array}$ & (1) & (2) & (3) & (4) & (5) \\
\hline $\begin{array}{l}\text { 35. Computers will relieve teachers of some } \\
\text { routine duties }\end{array}$ & (1) & (2) & (3) & (4) & (5) \\
\hline $\begin{array}{l}\text { 36. Incorporate new ways of organizing student } \\
\text { learning }\end{array}$ & (1) & (2) & (3) & (4) & (5) \\
\hline $\begin{array}{l}\text { Computers can help teachers provide more } \\
\text { individualized feedback to students. }\end{array}$ & (1) & (2) & (3) & (4) & (5) \\
\hline $\begin{array}{l}\text { The use of e-mail provides better access to } \\
\text { instructor }\end{array}$ & (1) & (2) & (3) & (4) & (5) \\
\hline $\begin{array}{l}\text { Computers help to incorporate new teaching } \\
\text { methods }\end{array}$ & (1) & (2) & (3) & (4) & (5) \\
\hline $\begin{array}{l}\text { E-mail is an effective means of disseminating } \\
\text { class information and assignments }\end{array}$ & (1) & (2) & (3) & (4) & (5) \\
\hline
\end{tabular}




\begin{tabular}{|c|c|c|c|c|c|}
\hline $\begin{array}{l}\text { 41. I prefer e-mail to traditional class handout as } \\
\text { an information disseminator }\end{array}$ & (1) & (2) & (3) & (4) & (5) \\
\hline \multicolumn{6}{|l|}{ Part 3: Perceived Benefits of ICT use } \\
\hline $\begin{array}{l}\text { The relationship between theory and practice } \\
\text { is strengthened (e.g. through simulations) }\end{array}$ & (1) & (2) & (3) & (4) & (5) \\
\hline $\begin{array}{l}\text { Improvement of communication and } \\
\text { 43. interaction between instructors and students, } \\
\text { and among students }\end{array}$ & (1) & (2) & (3) & (4) & (5) \\
\hline $\begin{array}{l}\text { 44. Lesson delivery is improved and enhanced } \\
\text { (efficiency) }\end{array}$ & (1) & (2) & (3) & (4) & (5) \\
\hline 45. Enhances students learning (effectiveness) & (1) & $(2)$ & (3) & (4) & (5) \\
\hline $\begin{array}{l}\text { Students can access courses, assignments, } \\
\text { 46. course outlines e.t.c regardless of location and } \\
\text { time (flexibility in education) }\end{array}$ & (1) & (2) & (3) & (4) & (5) \\
\hline 47. Improvement of feedback to students & (1) & (2) & (3) & (4) & (5) \\
\hline 48. Learning becomes fun & (1) & (2) & (3) & (4) & (5) \\
\hline 49. Students feel more involved in a lesson & (1) & (2) & (3) & (4) & (5) \\
\hline 50. Provision of a better learning experience & (1) & (2) & (3) & (4) & (5) \\
\hline \multicolumn{6}{|l|}{ Part 4: Perceived Barriers } \\
\hline $\begin{array}{l}\text { 5ack of technical support regarding ICT } \\
\text { integration }\end{array}$ & (1) & (2) & (3) & (4) & (5) \\
\hline 52. Lack of support from administration & (1) & (2) & (3) & (4) & (5) \\
\hline 53. Lack of sufficient ICT training & (1) & $(2)$ & (3) & (4) & (5) \\
\hline $\begin{array}{l}\text { Limited or no programmes as to what is } \\
\text { expected for teaching with ICT }\end{array}$ & (1) & (2) & (3) & (4) & (5) \\
\hline $\begin{array}{l}\text { Schools are unsure as to how effectively to } \\
\text { integrate ICT in teaching }\end{array}$ & (1) & (2) & (3) & (4) & (5) \\
\hline $\begin{array}{l}\text { Teachers do not have sufficient time to } \\
\text { integrate ICT }\end{array}$ & (1) & (2) & (3) & (4) & (5) \\
\hline $\begin{array}{l}\text { Lack of ICT infrastructure (ie computers, } \\
\text { computer lab, internet) in schools }\end{array}$ & (1) & (2) & (3) & (4) & (5) \\
\hline 58. Schools are not interested in integrating ICT & (1) & (2) & (3) & (4) & (5) \\
\hline $\begin{array}{l}\text { Curriculum does not allow enough time to } \\
\text { integrate ICT in teaching }\end{array}$ & (1) & (2) & (3) & (4) & (5) \\
\hline \multicolumn{6}{|l|}{ Perceived Support } \\
\hline $\begin{array}{l}\text { 60. More technical support is needed to keep the } \\
\text { computers working in schools }\end{array}$ & (1) & (2) & (3) & (4) & (5) \\
\hline $\begin{array}{l}\text { Training on pedagogical practices that } \\
\text { 61. } \\
\text { incorporate ICT is needed }\end{array}$ & (1) & (2) & (3) & (4) & (5) \\
\hline $\begin{array}{l}\text { Generic ICT training is irrelevant to teacher } \\
\text { needs }\end{array}$ & (1) & (2) & (3) & (4) & (5) \\
\hline $\begin{array}{l}\text { Current Reward structure must recognize } \\
\text { teachers using ICT }\end{array}$ & (1) & (2) & (3) & (4) & (5) \\
\hline 64. ICT Infrastructure is not easily accessible & (1) & (2) & (3) & (4) & (5) \\
\hline
\end{tabular}

Source: http://www.tcet.unt.edu/pubs/studies/survey/caqdesc.htm 
13. What is your overall perception towards ICT integration in delivering your lesson? (for this question, tick only one item against a response that best describes your perception)

\begin{tabular}{|l|c|c|c|c|c|}
\hline \multirow{2}{*}{ Items } & \multicolumn{5}{|c|}{ Responses } \\
\cline { 2 - 6 } & $\begin{array}{c}\text { very } \\
\text { willing }\end{array}$ & willing & neutral & skeptical & $\begin{array}{c}\text { Highly } \\
\text { skeptical }\end{array}$ \\
\hline $\begin{array}{l}\text { I am..........................................to } \\
\text { integrate ICT in my teaching. }\end{array}$ & & & & & \\
\hline
\end{tabular}

14. Arrange the following ICTs according to your priority for its potential usefulness in teaching and learning mathematics in your school. (hint: use numbers from 1 to 8 , where; $1=$ highest priority and $8=$ lowest priority. Remember to use each number only once)

\begin{tabular}{|l|l|}
\hline \multicolumn{1}{|c|}{ Items } & Priority number \\
\hline Graphical Calculators & \\
\hline Application of Multimedia (e.g. video, audio, tv) & \\
\hline Java Applets & \\
\hline Word Processing Package (e.g.microsoft word) & \\
\hline Graphical Application (e.g. derive) & \\
\hline Spreadsheet (e.g. excel) & \\
\hline $\begin{array}{l}\text { Database Software (e.g.online student results, online continuous } \\
\text { assessment, computerized library system) }\end{array}$ & \\
\hline Presentation Software (e.g.power point) & \\
\hline
\end{tabular}

15. Are you willing to be considered to participate in training on how to design, develop and integrate ICT in your teaching?

[ ] yes,

[ ] undecided,

[ ] no, I like to have more information

16. What are your suggestions regarding content of the training for instructors on ICT use for instruction in a mathematics lesson?

\begin{tabular}{|l|c|c|}
\hline \multirow{2}{*}{ Items } & \multicolumn{2}{c|}{ Responses } \\
\cline { 2 - 3 } & yes & No \\
\hline Support on basic ICT skills & & \\
\hline $\begin{array}{l}\text { Training on how to access available ICT for teaching } \\
\text { mathematics }\end{array}$ & & \\
\hline Support on how to teach mathematics using ICT & & \\
\hline Support on practice to incorporate ICT in mathematics teaching & & \\
\hline Other, namely.................................................................... & & \\
\hline
\end{tabular}


17. What are your suggestions regarding content in mathematics that need some kind of ICT intervention in instruction? (State some specific topics or concept if any)

\begin{tabular}{|l|l|l|l|}
\hline \multirow{2}{*}{\multicolumn{1}{|c|}{ Items }} & \multicolumn{2}{c|}{ Responses } & \multirow{2}{*}{ Specific topic or concept } \\
\cline { 2 - 3 } & yes & No & \\
\hline Algebra & & & \\
\hline Geometry & & & \\
\hline Calculus & & & \\
\hline Trigonometry & & & \\
\hline Statistics & & & \\
\hline Other................. & & & \\
\hline
\end{tabular}

Thanks for your time and cooperation

\section{A2: Questionnaire for Pre-service teachers}

\section{A. Introduction}

\section{Dear student,}

This interview is meant to collect data that will help to empirically ascertain the feasibility of developing students' teachers professionally to be able to integrate ICT in their instruction in mathematics in the SHS. In this study, ICT means the integration of webbased or computer-based technologies in teaching of mathematics. They include technologies such as Word Processing Packages, Graphical applications, Multimedia, Java applets, Simulation Programmes, Data bases, Spreadsheets and any Internet activities. In this questionnaire, quite a few questions requires you to fill in some information, but for the rest of the questions you are required to just tick (v) items against a specific response that apply to your situation. I wish to let you know that all the information you provide will be used only for the purpose of this study and that it will be treated confidentially.

\section{B. Biographic data}

1. Your age:

2. Sex: male[ ], female[ ]

3. Department

4. Program of study.

5. Year of study.

6. Level of Entry at UCC: Cert A [ ], SSS [ ], other, specify

7. Email/ Phone number 


\section{Questions}

1. What kind of teaching strategies have you experienced in your mathematics lessons at pre-university level? (Please mark only one choice in each row)

\begin{tabular}{|l|l|l|l|l|}
\hline \multicolumn{1}{|c|}{ Strategy } & $\begin{array}{c}\text { Nearly } \\
\text { Always }\end{array}$ & often & Sometimes & Never \\
\hline Chalk and Talk approach (Lecture method) & & & & \\
\hline Use of Course Manuals & & & & \\
\hline Individual Assignments & & & & \\
\hline Use of Group/Team work & & & & \\
\hline Use of ICT & & & & \\
\hline Use of Demonstrations & & & & \\
\hline Other,namely................................................... & & & & \\
\hline
\end{tabular}

2. Do you think the following were encountered as a result of the teaching strategies you experienced in your mathematics lessons at the pre-university level? (Please mark only one choice in each row)

\begin{tabular}{|l|c|c|}
\hline \multirow{2}{*}{ Items } & \multicolumn{2}{c|}{ Responses } \\
\cline { 2 - 3 } & yes & No \\
\hline $\begin{array}{l}\text { Providing support to you immediately (e.g. elaboration of a } \\
\text { concept to students) }\end{array}$ & & \\
\hline $\begin{array}{l}\text { Providing effective and immediate feedback on assignments, } \\
\text { tests and examinations }\end{array}$ & & \\
\hline Dealing with large class sizes & & \\
\hline Dealing with diverse groups of students & & \\
\hline Regular communication and interaction with you & & \\
\hline Insufficient and outdated supplementary reading resources & & \\
\hline Timely delivery of assignments / course materials e.t.c to you & & \\
\hline Other, namely.................................................................... & & \\
\hline
\end{tabular}

3. How often did you mathematics tutors in your pre - university education engaged you in the following activities? (Please mark only one choice in each row)

\begin{tabular}{|l|l|l|l|l|}
\hline \multicolumn{1}{|c|}{ Students' Activities } & $\begin{array}{l}\text { Nearly } \\
\text { Always }\end{array}$ & often & Sometimes & Never \\
\hline $\begin{array}{l}\text { Working on the same learning materials at the } \\
\text { same pace and/or sequence during mathematics } \\
\text { lessons }\end{array}$ & & & & \\
\hline $\begin{array}{l}\text { Explaining and discussing your own ideas with } \\
\text { teacher and peers in a mathematics lesson }\end{array}$ & & & & \\
\hline $\begin{array}{l}\text { Reflect on own learning experience review (e.g., } \\
\text { writing a learning log) and adjust own learning } \\
\text { strategy }\end{array}$ & & & & \\
\hline Self and/or peer evaluation & & & & \\
\hline $\begin{array}{l}\text { Students learning and/or working during } \\
\text { lessons at their own pace }\end{array}$ & & & & \\
\hline Giving presentations & & & & \\
\hline Determining your own content goals for learning & & & & \\
\hline
\end{tabular}


4. Please read the descriptions of each of the six stages related to adoption of Information and Communication technology and write down the number of the stage that best describes where you are in the adoption of ICT.

\section{Stage 1: Awareness}

I am aware that information and communication technology exists but has not used it - perhaps I'm even avoiding it.

Stage 2: Learning the process

I am currently trying to learn the basics. I am often frustrated using computers. I lack confidence when using computers.

Stage 3: Understanding and application of the process

I am beginning to understand the process of using technology and can think of specific tasks in which it might be useful.

\section{Stage 4: Familiarity and confidence}

I am gaining a sense of confidence in using the computer for specific tasks.

I am starting to feel comfortable using the computer.

\section{Stage 5: Adaptation to other contexts}

I think about the computer as a tool to help me and am no longer concerned about it as technology. I can use it in many applications and as an instructional aid.

Stage 6: Creative application to new contexts

I can apply what I know about technology in the classroom. I am able to use it as an instructional tool and integrate it into the curriculum.

The stage that best describes where I am now is number

5. Does the Department of Mathematics and Science Education in UCC have the following ICT facilities? (Please mark only one choice in each row)

\begin{tabular}{|l|c|c|}
\hline \multicolumn{1}{|c|}{ Items } & \multicolumn{2}{c|}{ Responses } \\
\cline { 2 - 3 } & Yes & No \\
\hline Computer Laboratory & & \\
\hline Computers in the Library & & \\
\hline Computers in the Staff Common Room & & \\
\hline Internet for Lecturers & & \\
\hline Computer in your Lecture Rooms & & \\
\hline Internet connectivity for you to access & & \\
\hline Other, namely..................................................................... & & \\
\hline
\end{tabular}


6. Which of the following ICT facilities do you have access to? (Please mark only one choice in each row)

\begin{tabular}{|l|c|c|}
\hline \multirow{2}{*}{ Items } & \multicolumn{2}{c|}{ Responses } \\
\cline { 2 - 3 } & Yes & No \\
\hline Computer Laboratory & & \\
\hline Computers in the Library & & \\
\hline Computers in the Staff Common Room & & \\
\hline Internet for Lecturers & & \\
\hline Computer in your Lecture Rooms & & \\
\hline Internet connectivity for you to access & & \\
\hline Other, namely..................................................................... & & \\
\hline
\end{tabular}

7. To what extent do Lecturers in your department apply ICT in their instruction? (Please mark only one choice in each row).Mark "NA" if an application is not available in the department. (if your answer is "Not at all" or "NA" for all the applications in the table below, then skip question 8 and continue from question 9)

\begin{tabular}{|l|l|l|l|l|l|}
\hline \multicolumn{1}{|c|}{ Application } & $\begin{array}{c}\text { Not at } \\
\text { all }\end{array}$ & $\begin{array}{c}\text { A } \\
\text { little }\end{array}$ & Somewhat & $\begin{array}{c}\text { A } \\
\text { lot }\end{array}$ & NA \\
\hline Word processing packages (e.g.microsoft word) & & & & & \\
\hline $\begin{array}{l}\text { Database software (e.g.online student results, } \\
\text { online continuous assessment, computerized library } \\
\text { system) }\end{array}$ & & & & & \\
\hline Spreadsheet (e.g. excel) & & & & & \\
\hline Presentation Software (e.g. power point) & & & & & \\
\hline Graphical Application (e.g. derive) & & & & & \\
\hline Graphical Calculators & & & & & \\
\hline Application of multimedia (e.g.video, audio, tv) & & & & & \\
\hline E-mail (e.g.yahoo,outlook express, gmail) & & & & & \\
\hline Internet (e.g.for getting information from website) & & & & & \\
\hline Java applets & & & & & \\
\hline
\end{tabular}

NA - Not Available 
7. Which of the following in your opinion are barriers lecturers in your department encounter when integrating ICT in their lessons? (Please mark only one choice in each row)

\begin{tabular}{|l|l|l|l|}
\hline \multicolumn{1}{|c|}{ Items } & \multicolumn{2}{c|}{ Responses } \\
\cline { 2 - 4 } & $\begin{array}{c}\text { major } \\
\text { barrier }\end{array}$ & $\begin{array}{l}\text { Minor } \\
\text { barrier }\end{array}$ & $\begin{array}{l}\text { Not a } \\
\text { barrier }\end{array}$ \\
\hline $\begin{array}{l}\text { Not enough or limited access to computers/computer } \\
\text { lab in the department. }\end{array}$ & & & \\
\hline Availability of computer software in the department. & & & \\
\hline Lack of time in school schedule for integrating ICT & & & \\
\hline Lack of adequate technical support & & & \\
\hline $\begin{array}{l}\text { Lack of knowledge about ways to integrate ICT in } \\
\text { Lessons }\end{array}$ & & & \\
\hline ICT integration is not a school priority & & & \\
\hline $\begin{array}{l}\text { Not enough training opportunities for ICT integration } \\
\text { knowledge acquisition }\end{array}$ & & & \\
\hline Lack of confidence to try new approaches & & & \\
\hline $\begin{array}{l}\text { Lack of time necessary to develop and implement } \\
\text { activities }\end{array}$ & & & \\
\hline $\begin{array}{l}\text { Lack of knowledge to identify which ICT tools will be } \\
\text { useful }\end{array}$ & & & \\
\hline Lack of digital learning resources in the department & & & \\
\hline
\end{tabular}

8. To what extent are you confident in accomplishing the following?

\begin{tabular}{|c|c|c|c|c|}
\hline Knowledge and Skill of ICT & $\begin{array}{c}\text { Not at } \\
\text { all }\end{array}$ & A little & Somewhat & A lot \\
\hline $\begin{array}{l}\text { I can produce a letter using a word } \\
\text { processing programme }\end{array}$ & & & & \\
\hline I can e-mail a file to a colleague & & & & \\
\hline $\begin{array}{l}\text { I can take photos and show them on a } \\
\text { computer }\end{array}$ & & & & \\
\hline $\begin{array}{l}\text { I can produce presentations with simple } \\
\text { animation functions }\end{array}$ & & & & \\
\hline $\begin{array}{l}\text { I can use spreadsheet for making my time } \\
\text { table }\end{array}$ & & & & \\
\hline $\begin{array}{l}\text { I can prepare lessons that involve the use of } \\
\text { ICT for instruction in SHS/JHS }\end{array}$ & & & & \\
\hline $\begin{array}{l}\text { I know which teaching/learning situations } \\
\text { are suitable for ICT use. }\end{array}$ & & & & \\
\hline $\begin{array}{l}\text { I can use the Internet (e.g., select suitable } \\
\text { websites, user groups/discussion forums) } \\
\text { to support my learning in mathematics }\end{array}$ & & & & \\
\hline $\begin{array}{l}\text { I can find useful curriculum resources in } \\
\text { mathematics on the Internet for teaching }\end{array}$ & & & & \\
\hline $\begin{array}{l}\text { I can install educational software on my } \\
\text { Computer }\end{array}$ & & & & \\
\hline $\begin{array}{l}\text { I can use ICT to give effective } \\
\text { presentations/ } \\
\text { Explanations in my lessons }\end{array}$ & & & & \\
\hline
\end{tabular}


9. Have you participated in any of the following professional development activities? If no, would you wish to attend?

\begin{tabular}{|l|l|l|l|}
\hline \multirow{2}{*}{ Items } & \multicolumn{3}{c|}{ Responses } \\
\cline { 2 - 4 } & $\begin{array}{c}\text { Yes } \\
\text { I have }\end{array}$ & $\begin{array}{l}\text { No, I do } \\
\text { not wish } \\
\text { to attend }\end{array}$ & $\begin{array}{l}\text { No, I would } \\
\text { like to attend } \\
\text { if available }\end{array}$ \\
\hline $\begin{array}{l}\text { Technical course for operating and maintaining } \\
\text { computer system }\end{array}$ & & & \\
\hline $\begin{array}{l}\text { Introductory course for Internet use and general } \\
\text { applications (e.g., basic word-processing, } \\
\text { spreadsheets, databases, etc.) }\end{array}$ & & & \\
\hline $\begin{array}{l}\text { Subject-specific training with learning software for } \\
\text { specific content mathematics goals (e.g., tutorials, } \\
\text { simulation, etc }\end{array}$ & & & \\
\hline $\begin{array}{l}\text { Course on pedagogical issues related to integrating } \\
\text { ICT into teaching and learning }\end{array}$ & & & \\
\hline $\begin{array}{l}\text { Course on multimedia operations (e.g., using digital } \\
\text { video and/or audio equipment in mathematics }\end{array}$ & & & \\
\hline
\end{tabular}

10. The following table shows various perceptions of use of computers and varying responses. Read each statement and then circle the number which best shows how you feel. $(\mathrm{SD}=$ Strongly Disagree $\mathrm{D}=$ Disagree $\mathrm{U}=$ Undecided $\mathrm{A}=$ Agree $\mathrm{SA}=$ Strongly Agree)

\begin{tabular}{|c|c|c|c|c|c|}
\hline Perceptions & SD & $\mathbf{D}$ & $\mathbf{U}$ & $\mathbf{A}$ & SA \\
\hline \multicolumn{6}{|l|}{ Part 1: General Computer Use } \\
\hline 1. I enjoy doing things on a computer & (1) & (2) & (3) & (4) & (5) \\
\hline 2. I am tired of using a computer & (1) & (2) & (3) & (4) & (5) \\
\hline 3. The challenge of learning about computers is exciting & (1) & (2) & (3) & (4) & (5) \\
\hline 4. I concentrate on a computer when I use one & (1) & (2) & (3) & (4) & (5) \\
\hline 5. I enjoy computer games very much & (1) & (2) & (3) & (4) & (5) \\
\hline 6. I would work better if I could use computers more often & (1) & (2) & (3) & (4) & (5) \\
\hline $\begin{array}{l}\text { 7. I know that computers give me opportunities to learn many } \\
\text { new things. }\end{array}$ & (1) & (2) & (3) & (4) & (5) \\
\hline 8. Knowing how to use a computer is a worthwhile skill & (1) & (2) & (3) & (4) & (5) \\
\hline 9. I enjoy lessons on the computer & (1) & (2) & (3) & (4) & (5) \\
\hline $\begin{array}{l}\text { I have a lot of self confidence when it comes to working } \\
\text { with computers }\end{array}$ & (1) & (2) & (3) & (4) & (5) \\
\hline $\begin{array}{l}\text { I1. believe that it is very important for me to learn how to use } \\
\text { a computer. }\end{array}$ & (1) & (2) & (3) & (4) & (5) \\
\hline 12. I feel comfortable working with a computer & (1) & $(2)$ & (3) & (4) & (5) \\
\hline $\begin{array}{l}\text { 13. I get a sinking feeling when I think of trying to use a } \\
\text { computer. }\end{array}$ & (1) & (2) & (3) & (4) & (5) \\
\hline $\begin{array}{l}\text { I think that it takes a long time to finish a task when I use a } \\
\text { computer. }\end{array}$ & (1) & (2) & (3) & (4) & (5) \\
\hline 15. Working with a computer makes me nervous & (1) & (2) & (3) & (4) & (5) \\
\hline 16. Using a computer is very frustrating & (1) & (2) & (3) & (4) & (5) \\
\hline 17. I will do as little work with computers as possible & (1) & (2) & (3) & (4) & (5) \\
\hline 18. Computers are difficult to use & (1) & (2) & (3) & (4) & (5) \\
\hline
\end{tabular}




\begin{tabular}{|c|c|c|c|c|c|}
\hline 19. Computers do not scare me at all & (1) & (2) & (3) & (4) & (5) \\
\hline 20. I can learn more from books than from a computer & (1) & (2) & (3) & (4) & (5) \\
\hline \multicolumn{6}{|l|}{ Part 2: Computers in Instruction } \\
\hline $\begin{array}{l}\text { Computers are valuable tools that can be used to improve } \\
\text { the quality of education. }\end{array}$ & (1) & (2) & (3) & (4) & $(5)$ \\
\hline $\begin{array}{l}\text { 22. Teachers should know how to use computers in their } \\
\text { classrooms. }\end{array}$ & (1) & (2) & (3) & (4) & (5) \\
\hline $\begin{array}{l}\text { 23. I believe that the more often teachers use computers, the } \\
\text { more students will enjoy school }\end{array}$ & (1) & (2) & (3) & (4) & (5) \\
\hline $\begin{array}{l}\text { If there is a computer in my future classroom, It would help } \\
\text { me to be a better teacher. }\end{array}$ & (1) & (2) & (3) & (4) & (5) \\
\hline 25. I would like to have a computer for use in my classroom. & (1) & (2) & (3) & (4) & (5) \\
\hline $\begin{array}{l}\text { If there was a computer in my classroom it would help me } \\
\text { to be a better teacher }\end{array}$ & (1) & (2) & (3) & (4) & (5) \\
\hline 27. I enjoy using new tools for instruction. & (1) & (2) & (3) & (4) & $(5)$ \\
\hline $\begin{array}{l}\text { The people who give me the best idea for improving } \\
\text { teaching tend to know a lot about ICT }\end{array}$ & (1) & (2) & (3) & (4) & (5) \\
\hline 29. I believe textbooks will be replaced by electronic media. & (1) & (2) & (3) & (4) & 5 \\
\hline $\begin{array}{l}\text { I believe that the roles of schools will be dramatically } \\
\text { changed because of the internet. }\end{array}$ & (1) & (2) & (3) & (4) & (5) \\
\hline 31. Computers could enhance remedial instruction & (1) & (2) & (3) & (4) & $(5$ \\
\hline $\begin{array}{l}\text { Computer can be used successfully with courses which } \\
\text { demand creative activities }\end{array}$ & (1) & (2) & (3) & (4) & (5) \\
\hline 33. Computers can help accommodate different teaching styles & (1) & $(2)$ & (3) & (4) & $(5)$ \\
\hline $\begin{array}{l}\text { 34. Teacher training should include instructional applications } \\
\text { of computers }\end{array}$ & (1) & (2) & (3) & (4) & 5 \\
\hline 35. Computers will relieve teachers of some routine duties & (1) & (2) & (3) & (4) & $(5)$ \\
\hline $\begin{array}{l}\text { 36. Incorporate new ways of organizing student } \\
\text { learning }\end{array}$ & (1) & (2) & (3) & (4) & (5) \\
\hline $\begin{array}{l}\text { Computers can help teachers provide more individualized } \\
\text { feedback to students. }\end{array}$ & (1) & (2) & (3) & (4) & (5) \\
\hline 38. The use of e-mail provides better access to instructor & (1) & (2) & (3) & (4) & 5 \\
\hline 39. Computers help to incorporate new teaching methods & (1) & (2) & (3) & (4) & (5) \\
\hline $\begin{array}{l}\text { E-mail is an effective means of disseminating class } \\
\text { information and assignments }\end{array}$ & (1) & (2) & (3) & (4) & (5) \\
\hline $\begin{array}{l}\text { I prefer e-mail to traditional class handout as an } \\
\text { information disseminator }\end{array}$ & (1) & (2) & (3) & (4) & (5) \\
\hline \multicolumn{6}{|l|}{ Part 3: Perceived Benefits of ICT use } \\
\hline $\begin{array}{l}\text { The relationship between theory and practice is } \\
\text { 42. } \\
\text { strengthened (e.g. through simulations) }\end{array}$ & (1) & (2) & (3) & (4) & (5) \\
\hline $\begin{array}{l}\text { Improvement of communication and interaction between } \\
\text { instructors and students, and among students }\end{array}$ & (1) & (2) & (3) & (4) & $(5)$ \\
\hline 44. Lesson delivery is improved and enhanced (efficiency) & (1) & (2) & (3) & (4) & $(5)$ \\
\hline 45. Enhances students learning (effectiveness) & (1) & (2) & (3) & (4) & $(5)$ \\
\hline $\begin{array}{l}\text { Students can access courses, assignments, course outlines } \\
\text { e.t.c regardless of location and time (flexibility in education) }\end{array}$ & (1) & (2) & (3) & (4) & $(5)$ \\
\hline 47. Improvement of feedback to students & (1) & (2) & (3) & (4) & $(5)$ \\
\hline
\end{tabular}




\begin{tabular}{|c|c|c|c|c|c|}
\hline 48. Learning becomes fun & (1) & (2) & (3) & (4) & (5) \\
\hline 49. Students feel more involved in a lesson & (1) & (2) & (3) & (4) & (5) \\
\hline 50. Provision of a better learning experience & (1) & (2) & (3) & (4) & (5) \\
\hline \multicolumn{6}{|l|}{ Part 4: Perceived Barriers } \\
\hline 51. Lack of technical support regarding ICT integration & (1) & (2) & (3) & (4) & (5) \\
\hline 52. Lack of support from administration & (1) & (2) & (3) & (4) & (5) \\
\hline 53. Lack of sufficient ICT training & (1) & (2) & (3) & (4) & (5) \\
\hline $\begin{array}{l}\text { 5imited or no programmes as to what is expected for } \\
\text { teaching with ICT }\end{array}$ & (1) & (2) & (3) & (4) & (5) \\
\hline $\begin{array}{l}\text { Schools are unsure as to how effectively to integrate ICT in } \\
\text { teaching }\end{array}$ & (1) & (2) & (3) & (4) & (5) \\
\hline 56. Teachers do not have sufficient time to integrate ICT & (1) & (2) & (3) & (4) & (5) \\
\hline $\begin{array}{l}\text { Lack of ICT infrastructure (ie computers, computer lab, } \\
\text { internet) in schools }\end{array}$ & (1) & (2) & (3) & (4) & (5) \\
\hline 58. Schools are not interested in integrating ICT & (1) & (2) & (3) & (4) & (5) \\
\hline $\begin{array}{l}\text { Curriculum does not allow enough time to integrate ICT in } \\
\text { teaching }\end{array}$ & (1) & (2) & (3) & (4) & (5) \\
\hline \multicolumn{6}{|l|}{ Part 5: Perceived Support } \\
\hline $\begin{array}{l}\text { More technical support is needed to keep the computers } \\
\text { working in schools }\end{array}$ & (1) & (2) & (3) & (4) & (5) \\
\hline $\begin{array}{l}\text { Training on pedagogical practices that incorporate ICT is } \\
\text { needed }\end{array}$ & (1) & (2) & (3) & (4) & (5) \\
\hline 62. Generic ICT training is irrelevant to teacher needs & (1) & (2) & (3) & (4) & (5) \\
\hline $\begin{array}{l}\text { 63. Current Reward structure must recognize teachers using } \\
\text { ICT }\end{array}$ & (1) & (2) & (3) & (4) & (5) \\
\hline 64. ICT Infrastructure is not easily accessible & (1) & (2) & (3) & (4) & (5) \\
\hline
\end{tabular}

Source: http://www.tcet.unt.edu/pubs/studies/survey/caqdesc.htm

11. What is your overall perception towards ICT integration in delivering mathematics lesson? (for this question, tick only one item against a response that best describes your perception)

\begin{tabular}{|l|c|c|c|c|c|}
\hline \multirow{2}{*}{ Items } & \multicolumn{4}{|c|}{ Responses } \\
\cline { 2 - 6 } & $\begin{array}{c}\text { very } \\
\text { willing }\end{array}$ & willing & neutral & skeptical & $\begin{array}{c}\text { Highly } \\
\text { skeptical }\end{array}$ \\
\hline $\begin{array}{l}\text { I am.............................................to } \\
\text { integrate ICT in my future teaching. }\end{array}$ & & & & & \\
\hline
\end{tabular}


12. Arrange the following ICTs according to your priority for its potential usefulness in teaching and learning mathematics in SHS. (hint: use numbers from 1 to 8, where; $1=$ highest priority and $8=$ lowest priority. Remember to use each number only once)

\begin{tabular}{|l|l|}
\hline \multicolumn{1}{|c|}{ Items } & Priority number \\
\hline Graphical Calculators & \\
\hline Application of Multimedia (e.g.video, audio, tv ) & \\
\hline Java Applets & \\
\hline Word Processing Package (e.g. microsoft word) & \\
\hline Graphical Application (e.g. derive) & \\
\hline Spreadsheet (e.g. excel) & \\
\hline $\begin{array}{l}\text { Database Software (e.g..online student results, online continuous } \\
\text { assessment, computerized library system) }\end{array}$ & \\
\hline Presentation Software (e.g.power point) & \\
\hline
\end{tabular}

13. Are you willing to be considered to participate in training on how to design, develop and integrate ICT for teaching mathematics?
[ ] yes,
[ ] undecided,
[ ] no, I like to have more information

14. What are your suggestions regarding content of the training for instructors on ICT use for instruction in a mathematics lesson?

\begin{tabular}{|l|c|c|}
\hline \multirow{2}{*}{ Items } & \multicolumn{2}{c|}{ Responses } \\
\cline { 2 - 3 } & yes & No \\
\hline Support on basic ICT skills & & \\
\hline $\begin{array}{l}\text { Training on how to access available ICT for teaching } \\
\text { mathematics }\end{array}$ & & \\
\hline Support on how to teach mathematics using ICT & & \\
\hline Support on practice to incorporate ICT in mathematics teaching & & \\
\hline Other, namely...................................................................... & & \\
\hline
\end{tabular}

15. What are your suggestions regarding content in mathematics that need some kind of ICT intervention in instruction in SHS? (State some specific topics or concept if any)

\begin{tabular}{|l|c|c|c|}
\hline \multirow{2}{*}{\multicolumn{1}{|c|}{ Items }} & \multicolumn{2}{c|}{ Responses } & \multirow{2}{*}{ Specific topic or concept } \\
\cline { 2 - 3 } & Yes & no & \\
\hline Algebra & & & \\
\hline Geometry & & & \\
\hline Calculus & & & \\
\hline Trigonometry & & & \\
\hline Statistics & & & \\
\hline Other................ & & & \\
\hline
\end{tabular}

Thanks for your time and cooperation 


\section{A 3: Interview guide for the Head of Department}

Department of Mathematics \& Statistics- UCC

\section{A. Introduction}

Dear HOD,

This interview is meant to collect data that will help to empirically ascertain the feasibility of developing UCC mathematics student teachers professionally to be able to integrate ICT in their instruction in mathematics in the SHS. In this study, ICT means the integration of web-based or computer-based technologies in teaching of mathematics. They include technologies such as Word Processing Packages, Graphical applications, Multimedia, Java applets, Simulation Programmes, Data bases, Spreadsheets, Graphic Calculators and any Internet activities. I wish to inform you that all the information provided will be used only for the purpose of this study and that it will be treated confidentially.

\section{B. Biographic data}

1. Sex: male[ ], female[ ]

2. Number of years in the post:

\section{Interview questions}

1. What ICT support structures (or units) are there in the department/faculty for use instruction?

2. What is the desired state of ICT support structures (or unit) in the next 5 years?

3. What kind of facilities and resources is the department/university willing to provide towards training of student teachers?

4. Do lecturers have access to computers in the department for instruction?

5. Do student teachers have access to computers and internet in the department or faculty?

6. What is the ratio of computer to lecturer in the department?

7. What is the ratio of computer to the student teachers in the department /faculty?

8. What kind(s) of ICT are currently being integrated in teaching and learning processes at the department? For which courses/programmes are these ICT used?

9. What challenges do lecturers/ instructors encounter in the use of ICT and how do address them?

10. What specific ICT would you like to see lecturers in the department use to complement the current traditional Strategies of teaching in the department?

11. What ICT administration structure is currently there to support ICT integration in teaching and learning in the department?

12. What strategies are in placed to motivate and encourage lecturers and student teachers to use ICT for educational processes?

13. What arrangements for technical support services for both lecturers and student teachers on ICT use is in place at the department?

14. What is the desired state of providing technical support for students and lecturers in the next 5 years?

15. How are student teachers supported pedagogically to prepare them towards effective integration of ICT in their future lessons in mathematics in SHS?

16. What is the desired state of providing pedagogical support in future? Will an introduction of a course such as "Use of ICT in teaching mathematics" in the training programme of mathematics teachers be feasible in UCC in the near future? 


\section{A. Introduction}

Dear......

This interview is meant to collect data that will help to empirically ascertain the feasibility of integrating Information Communication Technology as an instructional aid in the teaching of Senior High Schools mathematics in Ghana. In this study, ICT means the integration of web-based or computer-based technologies in teaching of mathematics. They include technologies such as Word Processing Packages, Graphical applications, Multimedia, Java applets, Simulation Programmes, Data bases, Spreadsheets, Graphic Calculators and any Internet activities. I wish to inform you that all the information provided will be used only for the purpose of this study and that it will be treated confidentially.

\section{B. Biographic data}

1. Sex: male[ ], female[ ]

2. Number of years in the post

\section{Interview questions}

1. What are the current teaching strategies mathematics tutors apply in the teaching of mathematics in your school?

2. What is the challenges/problems mathematics tutors face when they use such approaches/strategies in their lessons?

3. What ICT support structures (or units) are there in your department for use in instruction?

4. What is the desired state of ICT support structures (or unit) in the next 5 years in your department?

5. Do mathematics tutors have access to computers in the department/school for instruction?

6. What is the ratio of computer to students for Instruction/learning purposes?

7. What kind(s) of ICT are currently being integrated in teaching and learning processes at the department?

8. What challenges do tutors encounter in the use of ICT and how do you address them?

9. What specific ICT would you like to see mathematics tutors in the department use to complement the current teaching strategies in the department?

10. What ICT administrative structure currently exists in the department to support ICT integration in teaching and learning?

11. What strategies are in placed to motivate and encourage tutors to use ICT for educational processes?

12. What arrangements for technical support services for tutors on ICT use are in place at the department?

13. What is the desired state of providing technical support for tutors in the next 5 years?

14. How are tutors supported pedagogically to equip them towards effective integration of ICT in their lessons in mathematics?

15. What is the desired state of providing pedagogical support in future?

16. Will mathematics tutors in the department be willing to be part of any professional development to integrate ICT in their teaching lessons? 


\section{A. Introduction}

Dear.

This interview is meant to collect data that will help to empirically ascertain the feasibility of integrating Information Communication Technology as an instructional aid in the teaching of Senior High Schools mathematics in Ghana. In this study, ICT means the integration of web-based or computer-based technologies in teaching of mathematics. They include technologies such as Word Processing Packages, Graphical applications, Multimedia, Java applets, Simulation Programmes, Data bases, Spreadsheets, Graphic calculators and any Internet activities. I wish to inform you that all the information you provide will be used only for the purpose of this study and that it will be treated confidentially.

\section{B. Biographic data}

1. Sex: male[ ], female[ ]

2. Number of years in the post:.

\section{Interview questions}

1. What ICT support structures (or units) are there in the school for use in instruction by tutors? Where are these structures (most classrooms, some classrooms, and computer laboratory and other places)?

2. What is the desired state of ICT support structures (or unit) in the next 5 years?

3. What is the school's main vision and plan towards ICT integration in teaching and learning?

4. Do mathematics tutors have access to computers in the department/school for instruction?

5. What is the ratio of computer to students for Instruction/learning purposes?

6. What kind(s) of ICT are currently being integrated in teaching and learning processes in the school?

7. Which subjects do your school integrate ICT for Instructional purposes or is ICT treated as a separate subject?

8. What challenges do tutors encounter in the use of ICT and how do you address them?

9. What specific ICT would you like to see tutors use to complement the current teaching strategies in the school?

10. What ICT administrative structure currently exists in the school to support ICT integration in teaching and learning?

11. What strategies are in placed to motivate and encourage tutors to use ICT for educational processes?

12. What arrangements for technical support services for tutors on ICT use are in place at the school?

13. What is the desired state of providing technical support for tutors in the next 5 years in your school?

14. 14. How are tutors supported pedagogically to equip them towards effective integration of ICT in their lesson?

15. What is the desired state of providing pedagogical support in future? 


\section{A. Introduction}

Dear......

This interview is meant to collect data that will help to empirically ascertain the feasibility of developing mathematics student teachers professionally to be able to integrate ICT in their instruction in mathematics in the SHS. In particular the focus will be on UCC mathematics student teachers who will graduate to teach in the SHS's in Ghana. In this study, ICT means the integration of web-based or computer-based technologies in teaching of mathematics. They include technologies such as Word Processing Packages, Graphical applications, Multimedia, Java applets, Simulation Programmes, Data bases, Spreadsheets, Graphic Calculators and any Internet activities. I wish to inform you that all the information provided will be used only for the purpose of this study and that it will be treated confidentially.

\section{B. Biographic data}

1. Sex: male[ ], female[ ]

2. Number of years in the post:

3. Regional centre:

4. District.

\section{Interview questions}

1. What is the Ministry of Education main vision and plan towards ICT integration in education in the Senior High Schools?

2. In which way is your Division involved in issues related to ICT integration in education within the Senior High Schools?

3. Why do the Science Resource Centres in the districts not provide for mathematics teaching/learning in the Senior High Schools? Are there any plans to make room for mathematics teaching / learning at the Resource Centres?

4. How has your office been involved in supporting tutors in the SHS pedagogically to equip them towards effective integration of ICT in their lesson in the passed?

5. What is the desired state of providing pedagogical support in future?

6. What arrangements for infrastructure support for SHS on ICT use are in place by the Ministry of Education and Sports(MOES) or CRDD?

7. What is the desired state of providing infrastructure support for SHS in the next 5 years by your office?

8. What arrangements for technical support for SHS on ICT use are in place by the Ministry of Education and Sports or CRDD office?

9. What is the desired state of providing technical support for SHS in the next 5 years by your office?

10. What specific ICT do you think the Senior High Schools should consider integrating in the teaching and learning of mathematics to complement already teaching strategies? Why? (E.g. Graphic Calculus, Application of Multimedia, Java Applets, Word Processing Package, Spreadsheet, Database Software, Presentation Software) 
APPENDIX B

Data collection instruments for Chapter 4

B1 Experimental teachers' evaluation questionnaire-TPACK

\begin{tabular}{|c|c|c|c|c|c|}
\hline & $\begin{array}{l}\text { Strongly } \\
\text { Disagree }\end{array}$ & Disagree & $\begin{array}{l}\text { Neither } \\
\text { Agree or } \\
\text { Disagree }\end{array}$ & Agree & $\begin{array}{l}\text { Strongly } \\
\text { Agree }\end{array}$ \\
\hline \multicolumn{6}{|l|}{ TK (Technology Knowledge) } \\
\hline \multicolumn{6}{|l|}{$\begin{array}{l}\text { 1. I know how to solve my own } \\
\text { technical problems }\end{array}$} \\
\hline \multicolumn{6}{|l|}{ 2. I can learn technology easily. } \\
\hline \multicolumn{6}{|l|}{$\begin{array}{l}\text { 3. I keep up with important new } \\
\text { technologies. }\end{array}$} \\
\hline \multicolumn{6}{|l|}{$\begin{array}{l}\text { 4. I frequently play around the } \\
\text { technology. }\end{array}$} \\
\hline \multicolumn{6}{|l|}{$\begin{array}{l}\text { 5. I know about a lot of different } \\
\text { technologies. }\end{array}$} \\
\hline \multicolumn{6}{|l|}{$\begin{array}{l}\text { 6. I have the technical skills I } \\
\text { need to use technology }\end{array}$} \\
\hline \multicolumn{6}{|l|}{$\begin{array}{l}\text { 7. I have had sufficient } \\
\text { opportunities to work with } \\
\text { different technologies }\end{array}$} \\
\hline \multicolumn{6}{|l|}{$\begin{array}{l}\text { TCK (Technological Content } \\
\text { Knowledge) }\end{array}$} \\
\hline \multicolumn{6}{|l|}{$\begin{array}{l}\text { 8. I know about technologies that } \\
\text { I can use for understanding and } \\
\text { doing mathematics }\end{array}$} \\
\hline \multicolumn{6}{|l|}{$\begin{array}{l}\text { TPK (Technological } \\
\text { Pedagogical Knowledge) }\end{array}$} \\
\hline \multicolumn{6}{|l|}{$\begin{array}{l}\text { 9. I can choose technologies that } \\
\text { enhance the teaching approaches } \\
\text { for a lesson }\end{array}$} \\
\hline \multicolumn{6}{|l|}{$\begin{array}{l}\text { 10. I can choose technologies that } \\
\text { enhance students' learning for a } \\
\text { lesson. }\end{array}$} \\
\hline \multicolumn{6}{|l|}{$\begin{array}{l}\text { 11. My teacher education } \\
\text { program has caused me to think } \\
\text { deeply about how technology } \\
\text { could influence teaching } \\
\text { approaches I use in my } \\
\text { classroom }\end{array}$} \\
\hline \multicolumn{6}{|l|}{$\begin{array}{l}\text { 12. I am thinking critically about } \\
\text { how to use technology in my } \\
\text { classroom }\end{array}$} \\
\hline \multicolumn{6}{|l|}{$\begin{array}{l}\text { 13. I can adapt the use of the } \\
\text { technologies that I am learning } \\
\text { about to different teaching } \\
\text { activities }\end{array}$} \\
\hline $\begin{array}{l}\text { TPACK (Technology Pedagogy } \\
\text { and Content Knowledge) }\end{array}$ & & & & & \\
\hline
\end{tabular}




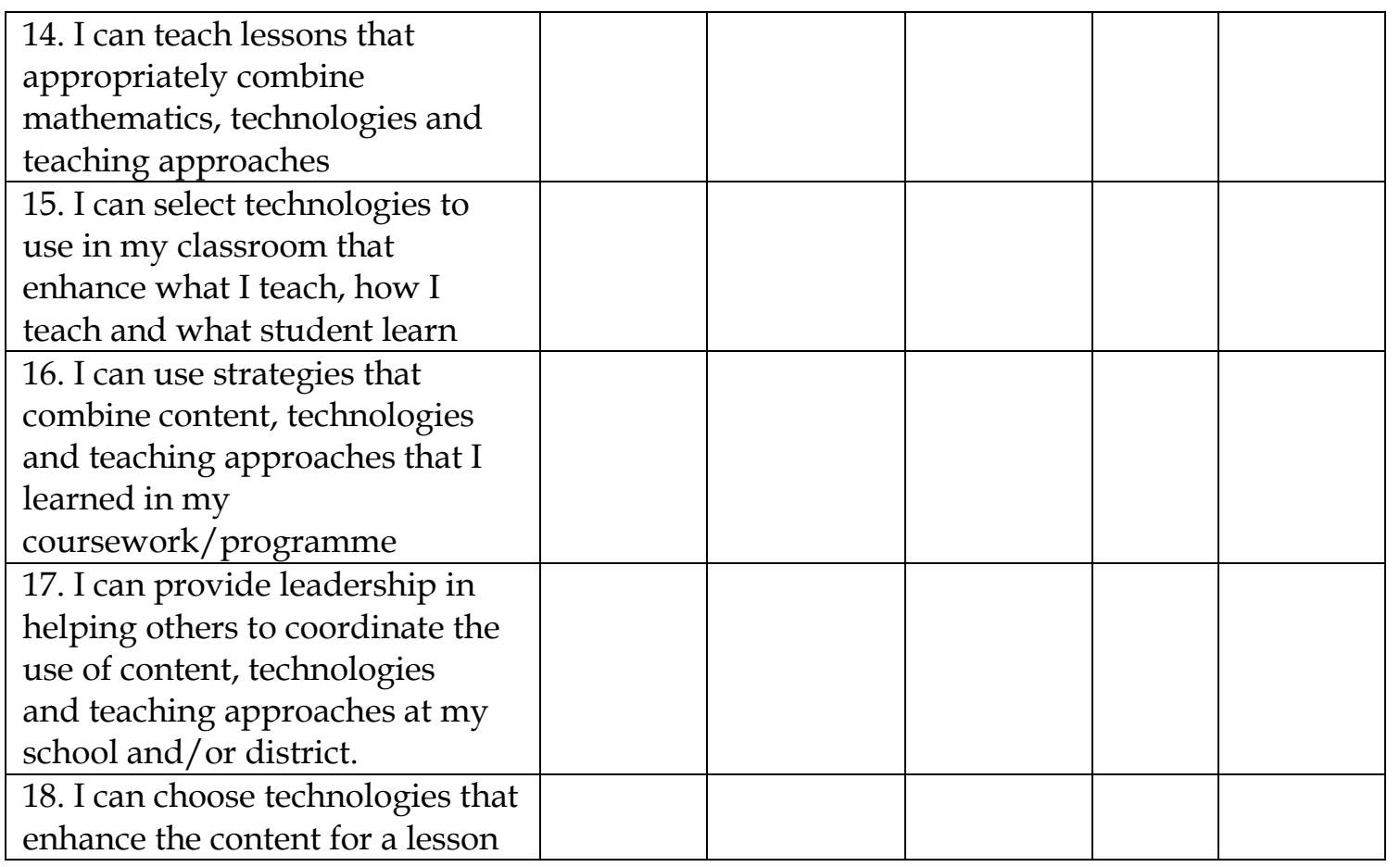

\section{B2 Questionnaire on student teachers experiences with teaching try-out}

Dear student,

This questionnaire is meant to explore your experiences about how you understood the lesson taught. Please provide your genuine responses to each of the questions that follow. Be assured that the information you provide will be treated strictly confidential and will be used only for this research.

\section{A. Biographic data}

1. Age:

2. Gender: Male [ ] Female [ ]

3. Topic treated in the lesson: 


\section{B. Personal experience with teaching tryout}

What is your overall experience with the lesson that was taught?

\begin{tabular}{|c|c|c|c|c|c|}
\hline Experiences & $\begin{array}{l}\text { Strong- } \\
\text { ly dis- } \\
\text { agree }\end{array}$ & $\begin{array}{l}\text { Dis- } \\
\text { agree }\end{array}$ & Neutral & agree & $\begin{array}{c}\text { Strong- } \\
\text { ly } \\
\text { agree }\end{array}$ \\
\hline 1. The lesson is generally interesting & & & & & \\
\hline $\begin{array}{l}\text { 2. The spreadsheet demonstrations helped me } \\
\text { to understand more about the topic }\end{array}$ & & & & & \\
\hline $\begin{array}{l}\text { 3. The lesson explained concepts that I found } \\
\text { difficulty to understand before }\end{array}$ & & & & & \\
\hline 4. The content of the lesson was clear & & & & & \\
\hline $\begin{array}{l}\text { 5. The content of the lesson was well } \\
\text { understood }\end{array}$ & & & & & \\
\hline $\begin{array}{l}\text { 6. The content of the lesson was well } \\
\text { delivered }\end{array}$ & & & & & \\
\hline $\begin{array}{l}\text { 7. The activities in the lesson helped me to } \\
\text { understand the lesson better }\end{array}$ & & & & & \\
\hline $\begin{array}{l}\text { 8. The organization of the lesson is } \\
\text { appropriate, logical and clear }\end{array}$ & & & & & \\
\hline $\begin{array}{l}\text { 9. The delivery of the lesson was well } \\
\text { supported by examples }\end{array}$ & & & & & \\
\hline $\begin{array}{l}\text { 10. The examples given enhanced my } \\
\text { understanding of the lesson }\end{array}$ & & & & & \\
\hline $\begin{array}{l}\text { 11. I have learnt about something new which } \\
\text { was not stated in the lesson outline }\end{array}$ & & & & & \\
\hline $\begin{array}{l}\text { 12. The team work helped me to understand } \\
\text { better }\end{array}$ & & & & & \\
\hline 13. I found the lesson exciting & & & & & \\
\hline $\begin{array}{l}\text { 14. The use of the worksheet made the lesson } \\
\text { interesting }\end{array}$ & & & & & \\
\hline $\begin{array}{l}\text { 15. Enjoyed the class and i wish such teaching } \\
\text { will continue }\end{array}$ & & & & & \\
\hline $\begin{array}{l}\text { 16. There was clarification of some difficult } \\
\text { concepts }\end{array}$ & & & & & \\
\hline $\begin{array}{l}\text { 17. I can relate the concepts to real life } \\
\text { application }\end{array}$ & & & & & \\
\hline 18. The lesson delivery was exceptional & & & & & \\
\hline $\begin{array}{l}\text { 19. Due to clarity I can do my assignment } \\
\text { with ease }\end{array}$ & & & & & \\
\hline $\begin{array}{l}\text { 20. Discussion in the groups helped me to } \\
\text { learn better }\end{array}$ & & & & & \\
\hline $\begin{array}{l}\text { 21. The activities in the lesson helped me to } \\
\text { identify patterns and make generalisations }\end{array}$ & & & & & \\
\hline $\begin{array}{l}\text { 22. The use of the spreadsheet and the power } \\
\text { point presentation motivated my learning }\end{array}$ & & & & & \\
\hline 23. Group presentations were exciting & & & & & \\
\hline
\end{tabular}

Thank you for your cooperation 


\section{B3 Semi-structured interview guides for beginning teachers}

\section{A. Background information}

1. Name:

2.Teacher design team number

3. Topic taught:

\section{Planning and Preparation}

4. What encouraged you to select this topic or concept for integration of spreadsheets?

5. Are the spreadsheets used in the lesson your own creation, or obtained from another source(s)?

6. Have you taught the lesson before (during your off-campus teaching practice)? If you have, how did the incorporation of spreadsheet affect your preparation for the lesson (Did you prepare differently?)

7. What of the professional development program prepared you to teach this content with Spreadsheet?

\section{During the lesson}

8. Do you think students like the approach? Why or why not?

9. What aspects of your teaching of the mathematics topic with spreadsheet went well and supported student learning? Please explain.

10. What aspects of your teaching needed improvement?

11. How comfortable are you with using spreadsheets in teaching mathematics?

12. What unexpected events happened when teaching this lesson with spreadsheets?

13. What were the difficulties in guiding students to use spreadsheets with this mathematics lesson?

14. Describe the student attention in this lesson? Were they engaged? Did they act differently than in regular lessons?

15. What did the students say about learning with spreadsheets in this mathematics lesson?

\section{Post - review of teaching}

16. Do you think the students' conceptual understanding of the mathematics focus of the lesson was improved with the integration of spreadsheets? Please explain

17. Was the integration of the spreadsheet perspective helpful in teaching the mathematics in this lesson?

18. After teaching this lesson, what preparation do you think you need to do for another lesson that integrates spreadsheets as tools for learning?

19. Will you teach other mathematics concepts using spreadsheets? If so which? If not so why not?

20.With the amount of mathematics content to be taught in the SHS each year, how often do you think it is feasible for you to incorporate spreadsheets in your lessons?

21.Do you think that more technology-oriented professional development programmes are needed to improve your teaching of mathematics with spreadsheets?

22. What general comment can you make about using spreadsheet in the SHS mathematics class? 


\section{B4 Guide Interview for student teachers (after teaching try-out)}

\section{Interview questions}

1. What is the general opinion about the lesson?

2. Did you like the approach of the delivery of the lesson?

3. Did you learn the mathematics concepts in the lesson? Was it the same as learning without the use of spreadsheet?

4. Do you think the whole class understood the lesson, or do you think there was some confusion? If so where?

5. Do you think the integration of spreadsheets with learning mathematics is a good idea? Why or why not?

6. Which lesson activity was very interesting to you? Why?

7. Which lesson activity was not interesting to you? Why?

8. How is the lesson different from the normal mathematics lesson in SHS's?

9. How did you like the working in groups?

10. Can you think of any new thing you learned from the lesson?

11. Would you want to teach mathematics using spreadsheet in your future class?

12. With the amount of mathematics content to be taught in the SHS each year, how often do you think it is feasible to incorporate spreadsheets in mathematics lessons? 


\section{APPENDIX C \\ Data Collection instrument for chapter 5}

\section{C1 TPACK Questionnaire for pre-service teachers}

Technology is a broad concept that can mean a lot of different things. For the purpose of this questionnaire, technology is referring to digital technology/technologies. That is, the digital tools we use such as computers, laptops, interactive whiteboards, software programmes, etc. Please answer all of the questions and if you are uncertain of or neutral about your response you may always select "Neither Agree or Disagree"

\begin{tabular}{|l|l|l|l|l|l|}
\hline & $\begin{array}{l}\text { Strongly } \\
\text { Disagree }\end{array}$ & Disagree & $\begin{array}{l}\text { Neither } \\
\text { Agree or } \\
\text { Disagree }\end{array}$ & Agree & $\begin{array}{l}\text { Strongly } \\
\text { Agree }\end{array}$ \\
\hline TK (Technology Knowledge) & & & & & \\
\hline $\begin{array}{l}\text { 1. I know how to solve my own } \\
\text { technical problems }\end{array}$ & & & & & \\
\hline 2. I can learn technology easily. & & & & & \\
\hline $\begin{array}{l}\text { 3. I keep up with important new } \\
\text { technologies. }\end{array}$ & & & & & \\
\hline $\begin{array}{l}\text { 4. I frequently play around the } \\
\text { technology. }\end{array}$ & & & & & \\
\hline $\begin{array}{l}\text { 5. I know about a lot of different } \\
\text { technologies. }\end{array}$ & & & & & \\
\hline $\begin{array}{l}\text { 6. I have the technical skills I } \\
\text { need to use technology }\end{array}$ & & & & & \\
\hline $\begin{array}{l}\text { 7. I have had sufficient } \\
\text { opportunities to work with } \\
\text { different technologies }\end{array}$ & & & & & \\
\hline CK (Content Knowledge) & & & & & \\
\hline Mathematics & & & & & \\
\hline $\begin{array}{l}\text { 8. I have sufficient knowledge } \\
\text { about mathematics }\end{array}$ & & & & & \\
\hline $\begin{array}{l}\text { 9. I can use a mathematical way } \\
\text { of thinking. }\end{array}$ & & & & & \\
\hline $\begin{array}{l}\text { 10. I have various ways and } \\
\text { strategies of developing my } \\
\text { understanding of mathematics }\end{array}$ & & & & & \\
\hline PK (Pedagogical Knowledge) & & & & & \\
\hline $\begin{array}{l}\text { 11. I know how to assess student } \\
\text { performance in a classroom }\end{array}$ & & & & & \\
\hline $\begin{array}{l}\text { 12. I can adapt my teaching } \\
\text { based-upon what students } \\
\text { understand or do not understand }\end{array}$ & & & & & \\
\hline $\begin{array}{l}\text { 13. I can adapt my teaching style } \\
\text { to different learners }\end{array}$ & & & & & \\
\hline $\begin{array}{l}\text { 14. I can assess student learning } \\
\text { in multiple ways }\end{array}$ & & & & & \\
\hline $\begin{array}{l}\text { 15. I can use a wide range of } \\
\text { teaching approaches in a } \\
\text { classroom setting (collaborative }\end{array}$ & & & & & \\
\hline
\end{tabular}




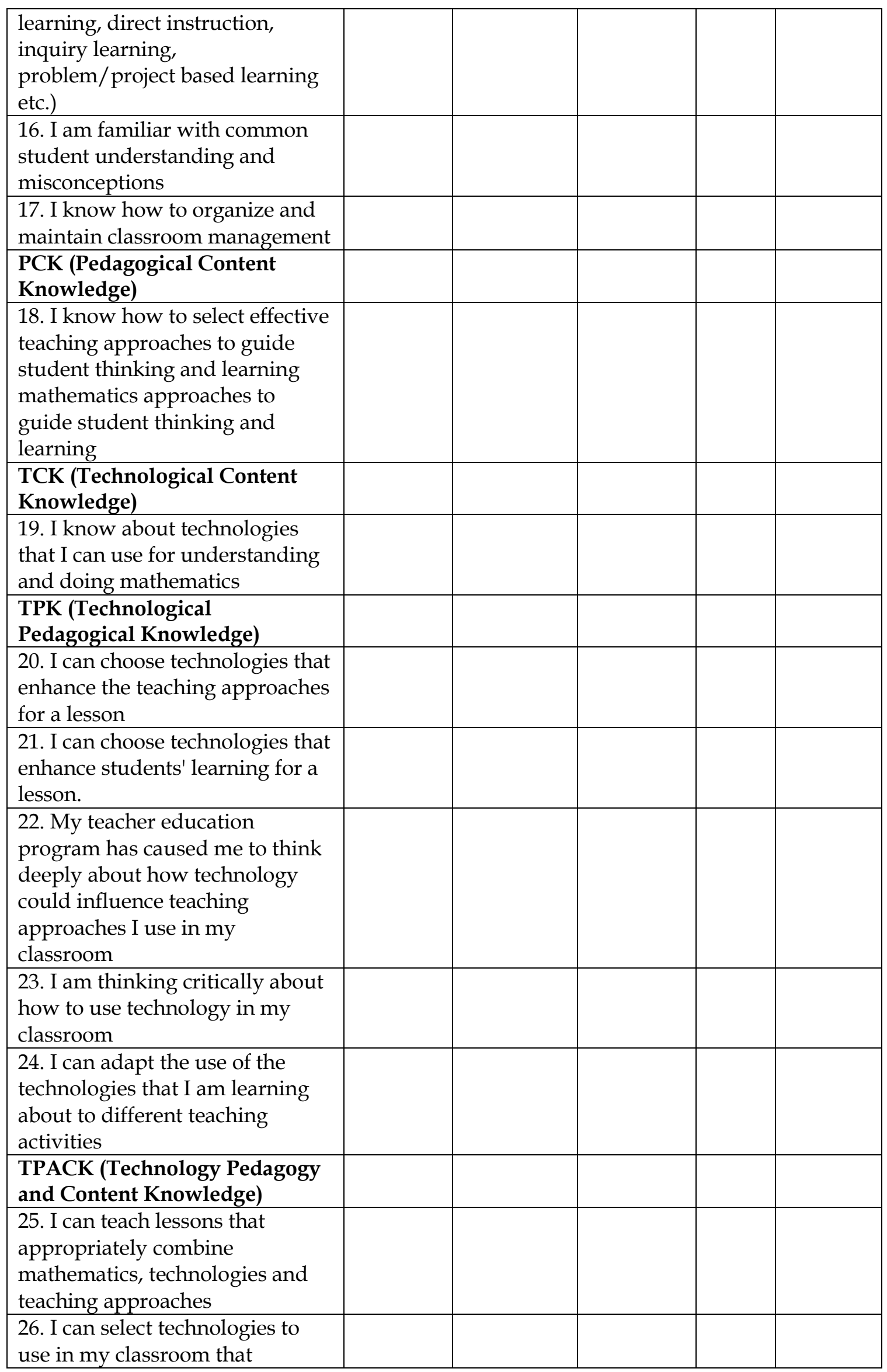




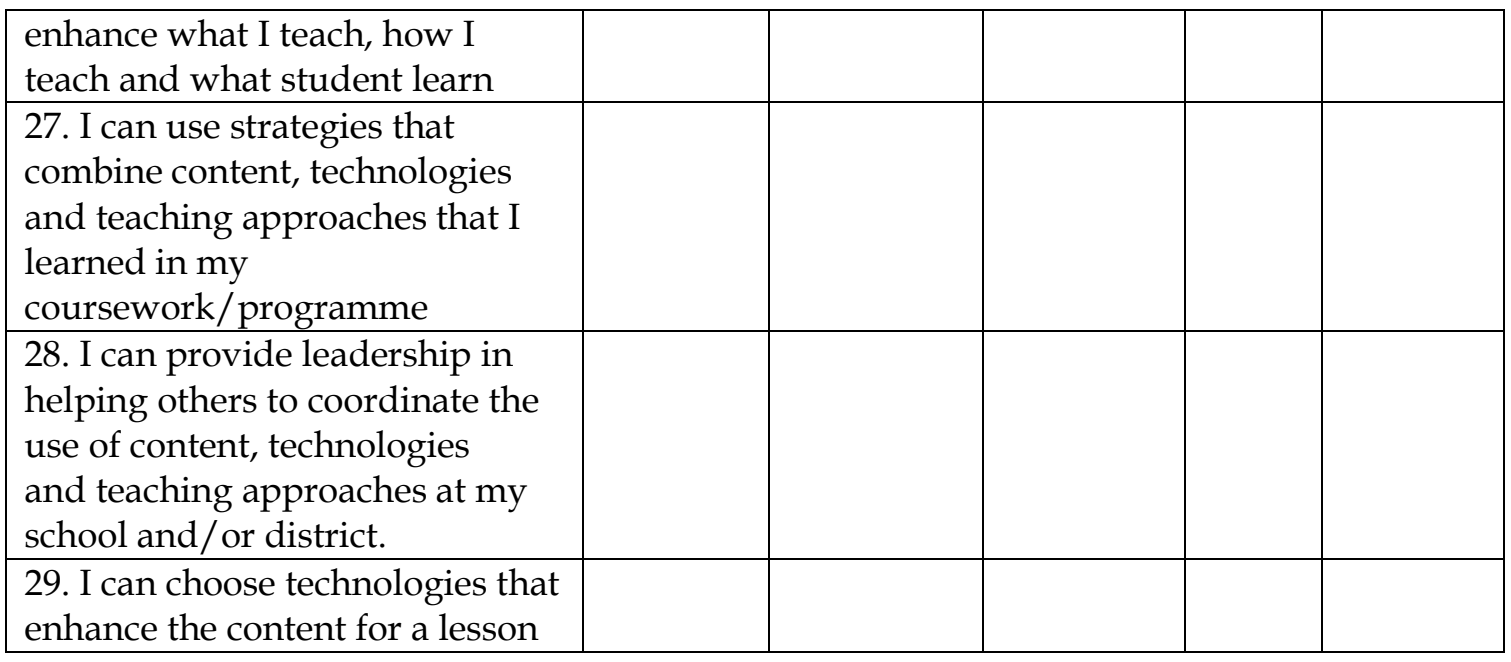

\section{C2 TPACK Lesson Plan Rubric}

Criteria for Analysing Lesson Plan Documents

\begin{tabular}{|l|l|l|l|l|}
\hline Criteria & $\begin{array}{l}\text { Aligned, } \\
\text { support or } \\
\text { observed (3) }\end{array}$ & $\begin{array}{l}\text { Minimal } \\
\text { (2) }\end{array}$ & $\begin{array}{l}\text { Not at } \\
\text { all (1) }\end{array}$ & Example \\
\hline $\begin{array}{l}\text { Appropriately spelt out subject matter } \\
\text { of lesson (CK) }\end{array}$ & & & & \\
\hline $\begin{array}{l}\text { Instructional strategies support to } \\
\text { learning (PK) }\end{array}$ & & & & \\
\hline $\begin{array}{l}\text { Clearly designed technologies that can } \\
\text { support transfer of knowledge(TK) }\end{array}$ & & & & \\
\hline $\begin{array}{l}\text { Instructional strategies support to } \\
\text { lesson goals (PCK) }\end{array}$ & & & & \\
\hline $\begin{array}{l}\text { Alignment of technologies to lesson } \\
\text { goals (TCK) }\end{array}$ & & & & \\
\hline $\begin{array}{l}\text { Support of technologies to } \\
\text { instructional strategies (TPK) }\end{array}$ & & & & \\
\hline $\begin{array}{l}\text { Strength of content, instructional } \\
\text { strategies and technology fit together } \\
\text { within theinstructional plan (TPACK) }\end{array}$ & & & & \\
\hline
\end{tabular}

Adapted from Harris Grandgenett and Hofer (2010) 
C3 TPACK Lesson Observation Rubric

TPACK observation checklist

\begin{tabular}{|c|c|c|c|c|}
\hline $\begin{array}{l}\text { Subject matter (content) } \\
\text { knowledge }\end{array}$ & 3 & 2 & 1 & $\begin{array}{l}\text { Example of observed or partly observed } \\
\text { practice }\end{array}$ \\
\hline $\begin{array}{l}\text { 1. Clearly introduced the topic } \\
\text { and learning goals }\end{array}$ & & & & \\
\hline $\begin{array}{l}\text { 2. Has sufficient knowledge of } \\
\text { mathematics lesson }\end{array}$ & & & & \\
\hline $\begin{array}{l}\text { 3. He/she demonstrates confident } \\
\text { in mathematics concepts related } \\
\text { to lesson }\end{array}$ & & & & \\
\hline $\begin{array}{l}\text { 4. Uses appropriate materials in } \\
\text { relation to given mathematics } \\
\text { lesson being taught }\end{array}$ & & & & \\
\hline Pedagogical knowledge & & & & \\
\hline $\begin{array}{l}\text { 5. Engage students in exploring } \\
\text { real-world issues and solving } \\
\text { authentic problems using } \\
\text { teaching resources. }\end{array}$ & & & & \\
\hline $\begin{array}{l}\text { 6. Address the diverse needs of all } \\
\text { learners by using learner-centered } \\
\text { strategies }\end{array}$ & & & & \\
\hline $\begin{array}{l}\text { 7. Providing equitable access to } \\
\text { appropriate resources }\end{array}$ & & & & \\
\hline Technological knowledge & & & & \\
\hline $\begin{array}{l}\text { 8. Teacher demonstrates } \\
\text { developed knowledge in } \\
\text { spreadsheet skills }\end{array}$ & & & & \\
\hline $\begin{array}{l}\text { 9. Demonstrate fluency in the } \\
\text { transfer of spreadsheet } \\
\text { knowledge to new situations }\end{array}$ & & & & \\
\hline $\begin{array}{l}\text { 10.Demenstrate knowledge on } \\
\text { effective combination of learning } \\
\text { support tools such as LCD and } \\
\text { spreadsheet use }\end{array}$ & & & & \\
\hline Pedagogical content knowledge & & & & \\
\hline $\begin{array}{l}\text { 11. Possess the ability to integrate } \\
\text { teaching approaches that arouse } \\
\text { students' creativity }\end{array}$ & & & & \\
\hline $\begin{array}{l}\text { 12. Apply teaching approaches } \\
\text { which gives more authority to } \\
\text { students in solving mathematics } \\
\text { problem }\end{array}$ & & & & \\
\hline $\begin{array}{l}\text { Technological pedagogical } \\
\text { knowledge }\end{array}$ & & & & \\
\hline $\begin{array}{l}\text { 13. Engage students in } \\
\text { spreadsheet based inquiry } \\
\text { learning activities }\end{array}$ & & & & \\
\hline
\end{tabular}




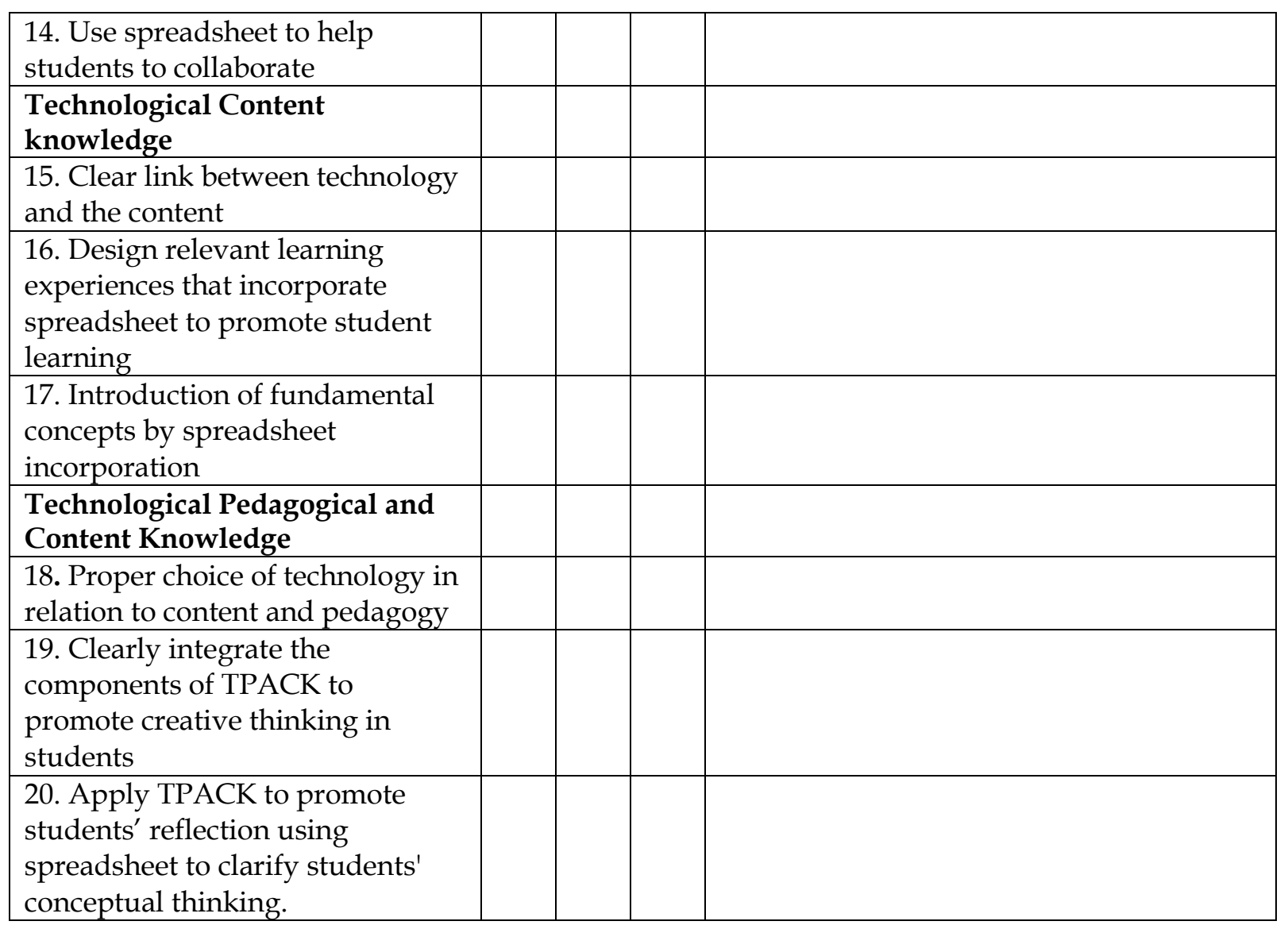

$3=$ observed; $2=$ Partly observed and $1=$ Not obserevd

\section{C4 Semi-structured interview guides for beginning teachers}

\section{A. Background information}

1. Name:

2.Teacher design team number

4. Topic taught:

\section{Planning and Preparation}

4. What encouraged you to select this topic or concept for integration of spreadsheets?

5. Are the spreadsheets used in the lesson your own creation, or obtained from another source(s)?

6. Have you taught the lesson before (during your off-campus teaching practice)? If you have, how did the incorporation of spreadsheet affect your preparation for the lesson (Did you prepare differently?)

7. What of the professional development program prepared you to teach this content with Spreadsheet?

\section{During the lesson}

8. Do you think students like the approach? Why or why not?

9. What aspects of your teaching of the mathematics topic with spreadsheet went well and supported student learning? Please explain.

10. What aspects of your teaching needed improvement? 
11. How comfortable are you with using spreadsheets in teaching mathematics?

12. What unexpected events happened when teaching this lesson with spreadsheets?

13. What were the difficulties in guiding students to use spreadsheets with this mathematics lesson?

14. Describe the student attention in this lesson? Were they engaged? Did they act differently than in regular lessons?

15. What did the students say about learning with spreadsheets in this mathematics lesson?

\section{Post - review of teaching}

16. Do you think the students' conceptual understanding of the mathematics focus of the lesson was improved with the integration of spreadsheets? Please explain

17. Was the integration of the spreadsheet perspective helpful in teaching the mathematics in this lesson?

18. After teaching this lesson, what preparation do you think you need to do for another lesson that integrates spreadsheets as tools for learning?

19. Will you teach other mathematics concepts using spreadsheets? If so which? If not so why

not?

20.With the amount of mathematics content to be taught in the SHS each year, how often do you think it is feasible for you to incorporate spreadsheets in your lessons?

21.Do you think that more technology-oriented professional development programmes are needed to improve your teaching of mathematics with spreadsheets?

22. What general comment can you make about using spreadsheet in the SHS mathematics class? 


\section{APPENDIX D}

\section{Data Collection instrument for chapter 6}

\section{D1 TPACK Questionnaire for pre-service teachers}

Technology is a broad concept that can mean a lot of different things. For the purpose of this questionnaire, technology is referring to digital technology/technologies. That is, the digital tools we use such as computers, laptops, interactive whiteboards, software programmes, etc. Please answer all of the questions and if you are uncertain of or neutral about your response you may always select "Neither Agree or Disagree"

\begin{tabular}{|l|l|l|l|l|l|}
\hline & $\begin{array}{l}\text { Strongly } \\
\text { Disagree }\end{array}$ & Disagree & $\begin{array}{l}\text { Neither } \\
\text { Agree or } \\
\text { Disagree }\end{array}$ & Agree & $\begin{array}{l}\text { Strongly } \\
\text { Agree }\end{array}$ \\
\hline TK (Technology Knowledge) & & & & & \\
\hline $\begin{array}{l}\text { 1. I know how to solve my own } \\
\text { technical problems }\end{array}$ & & & & & \\
\hline 2. I can learn technology easily. & & & & & \\
\hline $\begin{array}{l}\text { 3. I keep up with important new } \\
\text { technologies. }\end{array}$ & & & & & \\
\hline $\begin{array}{l}\text { 4. I frequently play around the } \\
\text { technology. }\end{array}$ & & & & & \\
\hline $\begin{array}{l}\text { 5. I know about a lot of different } \\
\text { technologies. }\end{array}$ & & & & & \\
\hline $\begin{array}{l}\text { 6. I have the technical skills I } \\
\text { need to use technology }\end{array}$ & & & & & \\
\hline $\begin{array}{l}\text { 7. I have had sufficient } \\
\text { opportunities to work with } \\
\text { different technologies }\end{array}$ & & & & & \\
\hline CK (Content Knowledge) & & & & & \\
\hline Mathematics & & & & & \\
\hline $\begin{array}{l}\text { 8. I have sufficient knowledge } \\
\text { about mathematics }\end{array}$ & & & & & \\
\hline $\begin{array}{l}\text { 9. I can use a mathematical way } \\
\text { of thinking. }\end{array}$ & & & & & \\
\hline $\begin{array}{l}\text { 10. I have various ways and } \\
\text { strategies of developing my } \\
\text { understanding of mathematics }\end{array}$ & & & & & \\
\hline PK (Pedagogical Knowledge) & & & & & \\
\hline $\begin{array}{l}\text { 11. I know how to assess student } \\
\text { performance in a classroom }\end{array}$ & & & & & \\
\hline $\begin{array}{l}\text { 12. I can adapt my teaching } \\
\text { based-upon what students } \\
\text { understand or do not understand }\end{array}$ & & & & & \\
\hline $\begin{array}{l}\text { 13. I can adapt my teaching style } \\
\text { to different learners }\end{array}$ & & & & & \\
\hline $\begin{array}{l}\text { 14. I can assess student learning } \\
\text { in multiple ways }\end{array}$ & & & & & \\
\hline $\begin{array}{l}\text { 15. I can use a wide range of } \\
\text { teaching approaches in a } \\
\text { classroom setting (collaborative }\end{array}$ & & & & & \\
\hline
\end{tabular}




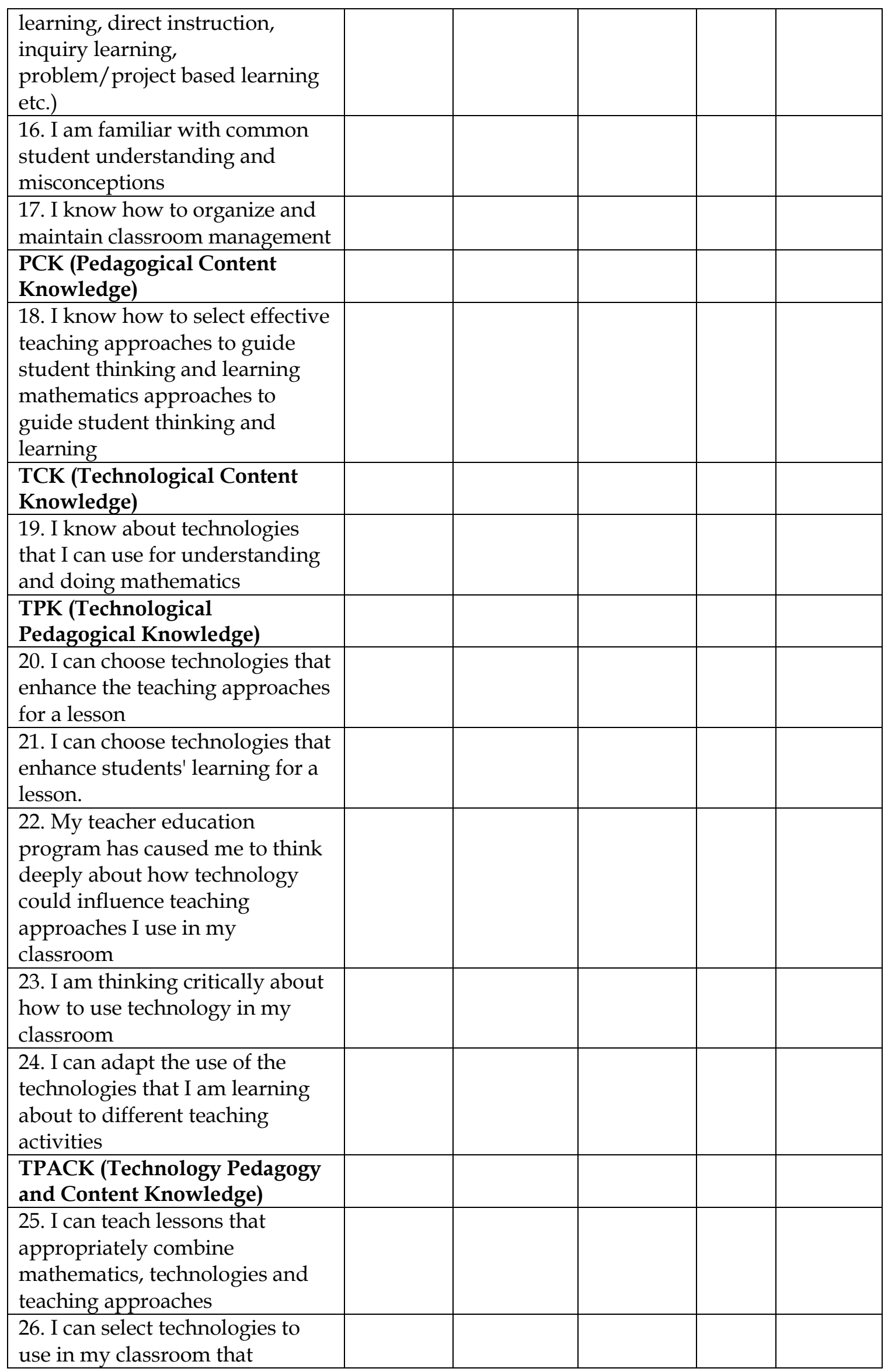




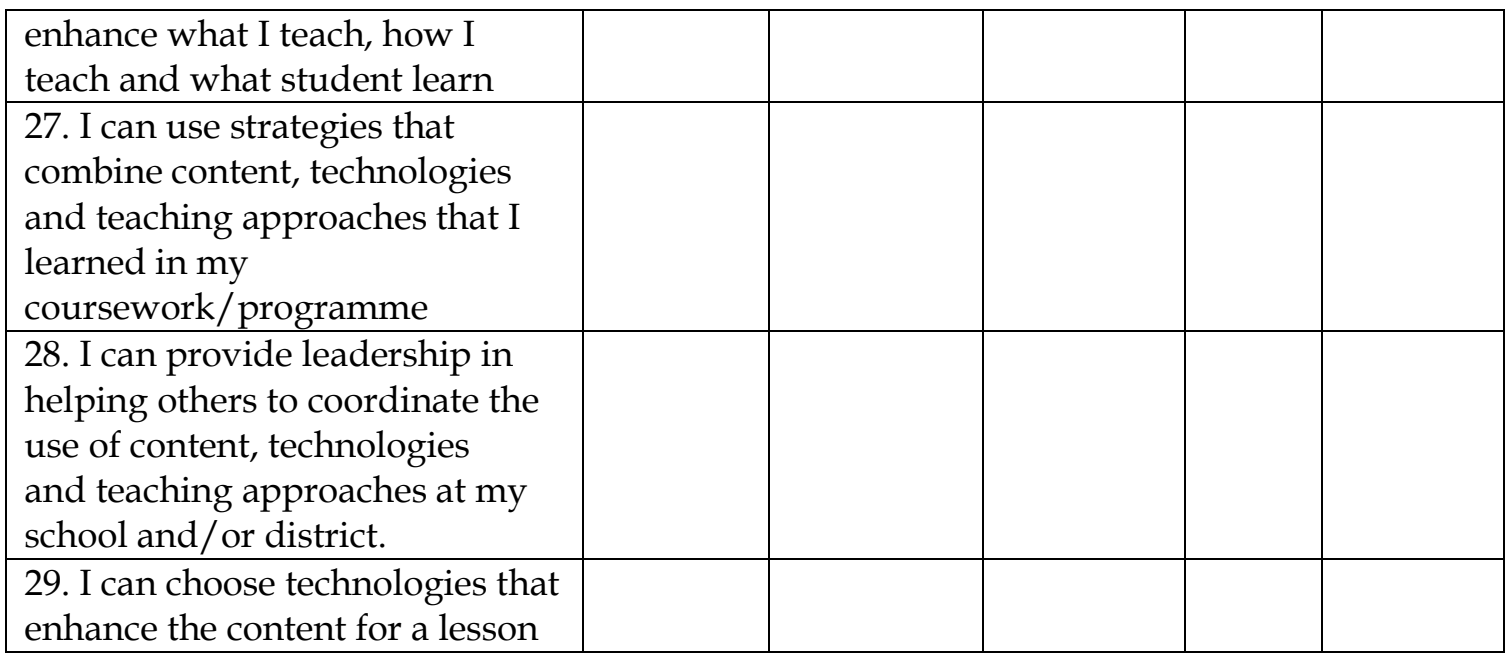

D2 TPACK Lesson Plan Rubric

Criteria for Analysing Lesson Plan Documents

\begin{tabular}{|l|l|l|l|l|}
\hline Criteria & $\begin{array}{l}\text { Aligned, } \\
\text { support or } \\
\text { observed (3) }\end{array}$ & $\begin{array}{l}\text { Minimal } \\
\text { (2) }\end{array}$ & $\begin{array}{l}\text { Not at } \\
\text { all (1) }\end{array}$ & Example \\
\hline $\begin{array}{l}\text { Appropriately spelt out subject matter } \\
\text { of lesson (CK) }\end{array}$ & & & & \\
\hline $\begin{array}{l}\text { Instructional strategies support to } \\
\text { learning (PK) }\end{array}$ & & & & \\
\hline $\begin{array}{l}\text { Clearly designed technologies that can } \\
\text { support transfer of knowledge(TK) }\end{array}$ & & & & \\
\hline $\begin{array}{l}\text { Instructional strategies support to } \\
\text { lesson goals (PCK) }\end{array}$ & & & & \\
\hline $\begin{array}{l}\text { Alignment of technologies to lesson } \\
\text { goals (TCK) }\end{array}$ & & & & \\
\hline $\begin{array}{l}\text { Support of technologies to } \\
\text { instructional strategies (TPK) }\end{array}$ & & & & \\
\hline $\begin{array}{l}\text { Strength of content, instructional } \\
\text { strategies and technology fit together } \\
\text { within theinstructional plan (TPACK) }\end{array}$ & & & & \\
\hline
\end{tabular}

Adapted from Harris Grandgenett and Hofer (2010) 
D3 TPACK Lesson Observation Rubric

TPACK observation checklist

\begin{tabular}{|c|c|c|c|c|}
\hline $\begin{array}{l}\text { Subject matter (content) } \\
\text { knowledge }\end{array}$ & 3 & 2 & 1 & $\begin{array}{c}\text { Example of observed or partly observed } \\
\text { practice }\end{array}$ \\
\hline $\begin{array}{l}\text { 1. Clearly introduced the topic } \\
\text { and learning goals }\end{array}$ & & & & \\
\hline $\begin{array}{l}\text { 2. Has sufficient knowledge of } \\
\text { mathematics lesson }\end{array}$ & & & & \\
\hline $\begin{array}{l}\text { 3. He/she demonstrates confident } \\
\text { in mathematics concepts related } \\
\text { to lesson }\end{array}$ & & & & \\
\hline $\begin{array}{l}\text { 4. Uses appropriate materials in } \\
\text { relation to given mathematics } \\
\text { lesson being taught }\end{array}$ & & & & \\
\hline Pedagogical knowledge & & & & \\
\hline $\begin{array}{l}\text { 5. Engage students in exploring } \\
\text { real-world issues and solving } \\
\text { authentic problems using } \\
\text { teaching resources. }\end{array}$ & & & & \\
\hline $\begin{array}{l}\text { 6. Address the diverse needs of all } \\
\text { learners by using learner-centered } \\
\text { strategies }\end{array}$ & & & & \\
\hline $\begin{array}{l}\text { 7. Providing equitable access to } \\
\text { appropriate resources }\end{array}$ & & & & \\
\hline Technological knowledge & & & & \\
\hline $\begin{array}{l}\text { 8. Teacher demonstrates } \\
\text { developed knowledge in } \\
\text { spreadsheet skills }\end{array}$ & & & & \\
\hline $\begin{array}{l}\text { 9. Demonstrate fluency in the } \\
\text { transfer of spreadsheet } \\
\text { knowledge to new situations }\end{array}$ & & & & \\
\hline $\begin{array}{l}\text { 10.Demenstrate knowledge on } \\
\text { effective combination of learning } \\
\text { support tools such as LCD and } \\
\text { spreadsheet use }\end{array}$ & & & & \\
\hline Pedagogical content knowledge & & & & \\
\hline $\begin{array}{l}\text { 11. Possess the ability to integrate } \\
\text { teaching approaches that arouse } \\
\text { students' creativity }\end{array}$ & & & & \\
\hline $\begin{array}{l}\text { 12. Apply teaching approaches } \\
\text { which gives more authority to } \\
\text { students in solving mathematics } \\
\text { problem }\end{array}$ & & & & \\
\hline $\begin{array}{l}\text { Technological pedagogical } \\
\text { knowledge }\end{array}$ & & & & \\
\hline $\begin{array}{l}\text { 13. Engage students in } \\
\text { spreadsheet based inquiry } \\
\text { learning activities }\end{array}$ & & & & \\
\hline
\end{tabular}




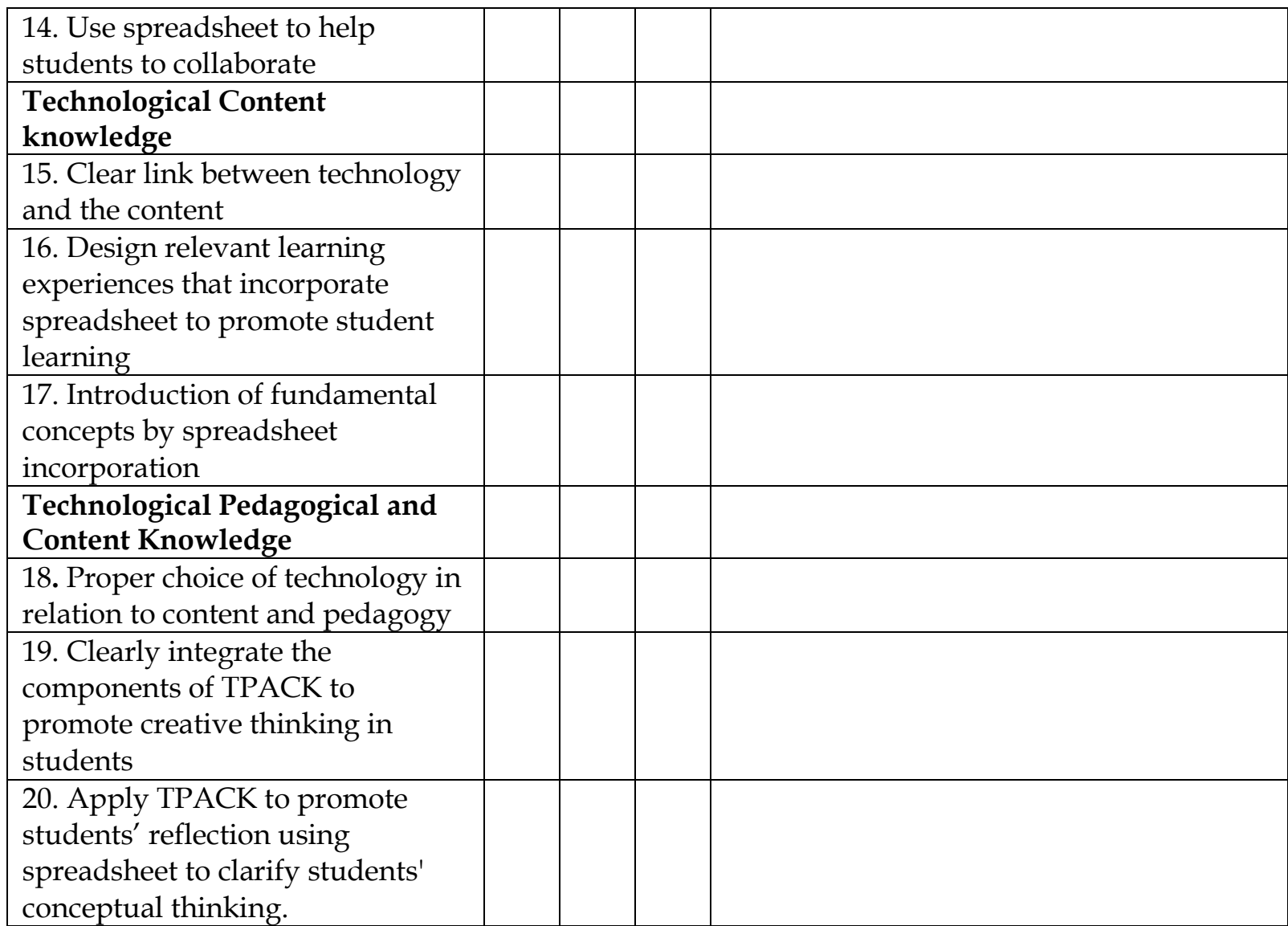

$3=$ observed; $2=$ Partly observed and $1=$ Not obserevd 


\section{D4 Questionnaire on Teacher Attitude Towards computers}

The following table shows various perceptions of use of computers and varying responses. Read each statement and then circle the number which best shows how you feel. (SD = Strongly Disagree, $\mathrm{D}=$ Disagree, $\mathrm{U}=$ Undecided, $\mathrm{A}=$ Agree, $\mathrm{SA}=$ Strongly Agree)

\begin{tabular}{|c|c|c|c|c|c|c|}
\hline & Perceptions & SD & $\mathrm{D}$ & $\mathrm{U}$ & $\mathrm{A}$ & SA \\
\hline & Part 1: General Computer Use & & & & & \\
\hline 1. & I enjoy doing things on a computer & (1) & (2) & (3) & (4) & (5) \\
\hline 2. & I am tired of using a computer & (1) & (2) & (3) & (4) & (5) \\
\hline 3. & $\begin{array}{l}\text { The challenge of learning about computers is } \\
\text { exciting }\end{array}$ & (1) & (2) & (3) & (4) & (5) \\
\hline 4. & I concentrate on a computer when I use one & (1) & (2) & (3) & (4) & (5) \\
\hline 5. & I enjoy computer games very much & (1) & (2) & (3) & (4) & (5) \\
\hline 6. & $\begin{array}{l}\text { I would work harder if I could use } \\
\text { computers more often }\end{array}$ & (1) & (2) & (3) & (4) & (5) \\
\hline 7. & $\begin{array}{l}\text { I know that computers give me opportunities } \\
\text { to learn many new things. }\end{array}$ & (1) & (2) & (3) & (4) & (5) \\
\hline 8. & $\begin{array}{l}\text { Knowing how to use a computer is a } \\
\text { worthwhile skill }\end{array}$ & (1) & (2) & (3) & (4) & (5) \\
\hline 9. & I enjoy lessons on the computer & (1) & (2) & (3) & (4) & (5) \\
\hline 10. & $\begin{array}{l}\text { I have a lot of self confidence when it comes } \\
\text { to working with computers }\end{array}$ & (1) & (2) & (3) & (4) & (5) \\
\hline 11. & $\begin{array}{l}\text { I believe that it is very important for me to } \\
\text { learn how to use a computer. }\end{array}$ & (1) & (2) & (3) & (4) & (5) \\
\hline 12. & I feel comfortable working with a computer & (1) & (2) & (3) & (4) & (5) \\
\hline 13. & $\begin{array}{l}\text { I get a sinking feeling when I think of trying } \\
\text { to use a computer. }\end{array}$ & (1) & (2) & (3) & (4) & (5) \\
\hline 14. & $\begin{array}{l}\text { I think that it takes a long time to finish a } \\
\text { task when I use a computer. }\end{array}$ & (1) & (2) & (3) & (4) & (5) \\
\hline 15. & Working with a computer makes me nervous & (1) & (2) & (3) & (4) & (5) \\
\hline 16. & Using a computer is very frustrating & (1) & (2) & (3) & (4) & (5) \\
\hline 17. & $\begin{array}{l}\text { I will do as little work with computers as } \\
\text { possible }\end{array}$ & (1) & (2) & (3) & (4) & (5) \\
\hline 18. & Computers are difficult to use & (1) & (2) & (3) & (4) & (5) \\
\hline 19. & Computers do not scare me at all & (1) & (2) & (3) & (4) & (5) \\
\hline \multirow[t]{2}{*}{20.} & $\begin{array}{l}\text { I can learn more from books than from a } \\
\text { computer }\end{array}$ & (1) & (2) & (3) & (4) & (5) \\
\hline & Part 2: Computers in Instruction & & & & & \\
\hline 21. & $\begin{array}{l}\text { Computers are valuable tools that can be } \\
\text { used to improve the quality of education. }\end{array}$ & (1) & (2) & (3) & (4) & (5) \\
\hline 22. & $\begin{array}{l}\text { Teachers should know how to use computers } \\
\text { in their classrooms. } \\
\end{array}$ & (1) & (2) & (3) & (4) & (5) \\
\hline 23. & $\begin{array}{l}\text { I believe that the more often teachers use } \\
\text { computers, the more I will enjoy school }\end{array}$ & (1) & (2) & (3) & (4) & (5) \\
\hline 24. & $\begin{array}{l}\text { If there is a computer in my future } \\
\text { classroom, It would help me to be a better } \\
\text { teacher. }\end{array}$ & (1) & (2) & (3) & (4) & (5) \\
\hline 25. & $\begin{array}{l}\text { I would like to have a computer for use in } \\
\text { my classroom. }\end{array}$ & (1) & (2) & (3) & (4) & (5) \\
\hline
\end{tabular}




\begin{tabular}{|c|c|c|c|c|c|c|}
\hline 26. & $\begin{array}{l}\text { If there was a computer in my classroom it } \\
\text { would help me to be a better teacher }\end{array}$ & (1) & (2) & (3) & (4) & (5) \\
\hline 27. & I enjoy using new tools for instruction. & (1) & (2) & (3) & (4) & (5) \\
\hline 28. & $\begin{array}{l}\text { The people who give me the best idea for } \\
\text { improving teaching tend to know a lot about } \\
\text { ICT }\end{array}$ & (1) & (2) & (3) & (4) & (5) \\
\hline 29. & $\begin{array}{l}\text { I believe textbooks will be replaced by } \\
\text { electronic media. }\end{array}$ & (1) & (2) & (3) & (4) & (5) \\
\hline 30. & $\begin{array}{l}\text { I believe that the roles of schools will be } \\
\text { dramatically changed because of the internet. }\end{array}$ & (1) & (2) & (3) & (4) & (5) \\
\hline 31. & $\begin{array}{l}\text { Computers could enhance remedial } \\
\text { instruction }\end{array}$ & (1) & (2) & (3) & (4) & (5) \\
\hline 32. & $\begin{array}{l}\text { Computer can be used successfully with } \\
\text { courses which demand creative activities }\end{array}$ & (1) & (2) & (3) & (4) & (5) \\
\hline 33. & $\begin{array}{l}\text { Computers can help accommodate different } \\
\text { teaching styles }\end{array}$ & (1) & (2) & (3) & (4) & (5) \\
\hline 34. & $\begin{array}{l}\text { Teacher training should include instructional } \\
\text { applications of computers }\end{array}$ & (1) & (2) & (3) & (4) & (5) \\
\hline 35. & $\begin{array}{l}\text { Computers will relieve teachers of routine } \\
\text { duties }\end{array}$ & (1) & (2) & (3) & (4) & (5) \\
\hline 36. & $\begin{array}{l}\text { Incorporate new ways of organizing student } \\
\text { Learning }\end{array}$ & (1) & (2) & (3) & (4) & (5) \\
\hline 37. & $\begin{array}{l}\text { Computers can help teachers provide more } \\
\text { individualized feedback to students. }\end{array}$ & (1) & (2) & (3) & (4) & (5) \\
\hline 38. & $\begin{array}{l}\text { The use of e-mail provides better access to } \\
\text { instructor }\end{array}$ & (1) & (2) & (3) & (4) & (5) \\
\hline 39. & $\begin{array}{l}\text { Computers help to incorporate new teaching } \\
\text { methods }\end{array}$ & & & & & \\
\hline 40. & $\begin{array}{l}\text { E-mail is an effective means of disseminating } \\
\text { class information and assignments }\end{array}$ & (1) & (2) & (3) & (4) & (5) \\
\hline \multirow[t]{2}{*}{41.} & $\begin{array}{l}\text { I prefer e-mail to traditional class handout as } \\
\text { an information disseminator }\end{array}$ & (1) & (2) & (3) & (4) & (5) \\
\hline & Part 3: Perceived Benefits of ICT use & & & & & \\
\hline 42. & $\begin{array}{l}\text { The relationship between theory and practice } \\
\text { is strengthened (e.g. through simulations) }\end{array}$ & (1) & (2) & (3) & (4) & (5) \\
\hline 43. & $\begin{array}{l}\text { Improvement of communication and } \\
\text { interaction between instructors and students, } \\
\text { and among students }\end{array}$ & (1) & (2) & (3) & (4) & (5) \\
\hline 44. & $\begin{array}{l}\text { Lesson delivery is improved and enhanced } \\
\text { (efficiency) }\end{array}$ & (1) & (2) & (3) & (4) & (5) \\
\hline 45. & Enhances students learning (effectiveness) & (1) & (2) & (3) & (4) & (5) \\
\hline 46. & $\begin{array}{l}\text { Students can access courses, assignments, } \\
\text { course outlines e.t.c regardless of location } \\
\text { and time (flexibility in education) }\end{array}$ & (1) & (2) & (3) & (4) & (5) \\
\hline 47. & Improvement of feedback to students & (1) & $(2)$ & (3) & (4) & (5) \\
\hline 48. & learning becomes fun & (1) & $(2)$ & (3) & (4) & (5) \\
\hline 49. & Students feel more involved in a lesson & (1) & (2) & (3) & (4) & (5) \\
\hline 50. & Provision of a better learning experience & (1) & (2) & (3) & (4) & (5) \\
\hline
\end{tabular}




\begin{tabular}{|c|c|c|c|c|c|c|}
\hline & Part 4: Perceived Barriers & & & & & \\
\hline 51. & $\begin{array}{l}\text { Lack of technical support regarding ICT } \\
\text { integration }\end{array}$ & (1) & (2) & (3) & (4) & (5) \\
\hline 52. & Lack of support from administration & (1) & (2) & (3) & (4) & (5) \\
\hline 53. & Lack of sufficient ICT training & (1) & (2) & (3) & (4) & (5) \\
\hline 54. & $\begin{array}{l}\text { Limit or no programmes as to what is } \\
\text { expected for teaching with ICT }\end{array}$ & (1) & (2) & (3) & (4) & (5) \\
\hline 55. & $\begin{array}{l}\text { Schools are unsure as to how effectively to } \\
\text { integrate ICT in teaching }\end{array}$ & (1) & (2) & (3) & (4) & (5) \\
\hline 56. & $\begin{array}{l}\text { Teachers do not have sufficient time to } \\
\text { integrate ICT }\end{array}$ & (1) & (2) & (3) & (4) & (5) \\
\hline 57. & $\begin{array}{l}\text { Lack of ICT infrastructure (ie computers, } \\
\text { computer lab, internet) in schools }\end{array}$ & (1) & (2) & (3) & (4) & (5) \\
\hline 58. & Schools are not interested in integrating ICT & (1) & (2) & (3) & (4) & (5) \\
\hline \multirow[t]{2}{*}{59.} & $\begin{array}{l}\text { Curriculum does not allow enough time to } \\
\text { integrate ICT in teaching }\end{array}$ & (1) & (2) & (3) & (4) & (5) \\
\hline & Perceived Support & & & & & \\
\hline 60. & $\begin{array}{l}\text { More technical support is needed to keep the } \\
\text { computers working in schools }\end{array}$ & (1) & (2) & (3) & (4) & (5) \\
\hline 61. & $\begin{array}{l}\text { Training on pedagogical practices that } \\
\text { incorporate ICT is needed }\end{array}$ & (1) & (2) & (3) & (4) & (5) \\
\hline 62. & $\begin{array}{l}\text { Generic ICT training is irrelevant to teacher } \\
\text { needs }\end{array}$ & (1) & (2) & (3) & (4) & (5) \\
\hline 63. & $\begin{array}{l}\text { Current Reward structure must recognize } \\
\text { teachers using ICT }\end{array}$ & (1) & (2) & (3) & (4) & (5) \\
\hline 64. & ICT Infrastructure is not easily accessible & (1) & (2) & (3) & (4) & (5) \\
\hline
\end{tabular}

Source: http://www.tcet.unt.edu/pubs/studies/survey/caqdesc.htm 


\section{APPENDIX E}

\section{Data Collection instrument for chapter 7}

\section{E1 Teacher Questionnaire for implementing ICT- based instructional innovation}

This questionnaire is meant to collect data that will help to empirically ascertain the implementation of an innovation (use of instructional technology to support Senior High Schools mathematics teaching and learning) in Ghana. In this study, ICT means the integration of web-based or computer-based technologies in teaching of mathematics. They include technologies such as Word Processing Packages, Graphical applications, Spreadsheets and any Internet activities. The information you provide will be treated strictly confidential, and be used for this research only.

\section{Section A}

Teacher Background

1. I am $\quad$ Female $\square \quad$ Male

2. Age

3. My Professional Qualification is:

Degree $\square$ (Specify) Diploma $\square$ (Specify)

Other $\square$ (Specify)

4. Year of graduation from UCC: $2011 \square 2010 \square 2009 \square$ Earlier $\square$

5. Number of years of teaching

6. Name of School

District of School

7. Subject taught :

\section{Section B}

1. How would you characterize the following in current mathematics teaching and learning

practices in the SHS?

\begin{tabular}{|l|l|l|l|l|l|}
\hline Mathematics teaching practices & always & often & sometimes & hardly & never \\
\hline Whole class teaching & & & & & \\
\hline Group assignment or projects & & & & & \\
\hline $\begin{array}{l}\text { Students learning by listening (to } \\
\text { teacher) }\end{array}$ & & & & & \\
\hline $\begin{array}{l}\text { Students learning by doing (e.g. hands- } \\
\text { on activities) }\end{array}$ & & & & & \\
\hline Individual learning of students & & & & & \\
\hline Learning in teams & & & & & \\
\hline $\begin{array}{l}\text { Teachers transferring knowledge (to } \\
\text { students) }\end{array}$ & & & & & \\
\hline $\begin{array}{l}\text { Student active learning (to construct } \\
\text { knowledge) }\end{array}$ & & & & & \\
\hline Teachers teaching to test & & & & & \\
\hline $\begin{array}{l}\text { Teachers teaching towards conceptual } \\
\text { understanding }\end{array}$ & & & & & \\
\hline
\end{tabular}


2. The items in the table below are aimed at collecting your views regarding the traditional and innovative instructional methods. You are hereby requested to provide your genuine responses about each question.(Indicate 1=strongly disagree (SD), 5= strongly agree (SA)).

\begin{tabular}{|c|c|c|c|c|c|}
\hline Item & SD & $\mathbf{D}$ & $\mathbf{U}$ & $\mathbf{A}$ & SA \\
\hline \multicolumn{6}{|l|}{$\begin{array}{l}\text { I believe that current mathematics teaching methods are ineffective in } \\
\text { achieving desired results }\end{array}$} \\
\hline \multicolumn{6}{|l|}{$\begin{array}{l}\text { I think current teaching methods do not support active learning of } \\
\text { students }\end{array}$} \\
\hline \multicolumn{6}{|l|}{$\begin{array}{l}\text { I believe that current teaching methods do not promote teamwork } \\
\text { among students }\end{array}$} \\
\hline \multicolumn{6}{|l|}{$\begin{array}{l}\text { I believe that current teaching methods do not promote students } \\
\text { interactions }\end{array}$} \\
\hline \multicolumn{6}{|l|}{$\begin{array}{l}\text { I believe current teaching methods do not encourage teachers to be } \\
\text { facilitators of students' learning }\end{array}$} \\
\hline \multicolumn{6}{|l|}{$\begin{array}{l}\text { I believe the use of the activity-based pedagogical approach supports } \\
\text { student learning }\end{array}$} \\
\hline \multicolumn{6}{|l|}{$\begin{array}{l}\text { I believe that the uses of spreadsheet techniques supports } \\
\text { mathematical concepts formation }\end{array}$} \\
\hline \multicolumn{6}{|l|}{$\begin{array}{l}\text { I believe that the use of teamwork among students promote } \\
\text { collaborating learning }\end{array}$} \\
\hline \multicolumn{6}{|l|}{$\begin{array}{l}\text { I believe that the use of "interactive demonstration" helps to } \\
\text { encourage teachers to be facilitators of students' learning }\end{array}$} \\
\hline \multicolumn{6}{|l|}{$\begin{array}{l}\text { I believe that the use of a lesson plan help to guide a proper } \\
\text { implementation of a mathematics lesson }\end{array}$} \\
\hline \multicolumn{6}{|l|}{$\begin{array}{l}\text { I believe that it is important to design mathematics lessons in a team } \\
\text { with colleagues }\end{array}$} \\
\hline \multicolumn{6}{|l|}{$\begin{array}{l}\text { I believe that exemplary curriculum materials helps to get a better } \\
\text { understanding on what a spreadsheet-supported activity-based } \\
\text { mathematics lesson could be provided }\end{array}$} \\
\hline \multicolumn{6}{|l|}{ Support from the facilitator was helpful in the design process } \\
\hline $\begin{array}{l}\text { Learning - by -doing was a useful strategy in learning to design the } \\
\text { spreadsheet-supported activity based mathematics lessons }\end{array}$ & & & & & \\
\hline
\end{tabular}


3. Indicate to what extent you are able to use/ or feel confident to apply (components) of the instructional innovation. You are hereby requested to provide your genuine responses about each question.

(Indicate $1=$ strongly disagree (SD), $5=$ strongly agree (SA)).

\begin{tabular}{|c|c|c|c|c|c|}
\hline \multirow{2}{*}{$\begin{array}{l}\text { Item } \\
\text { I feel confident to apply activity-based pedagogical approach to } \\
\text { support student learning }\end{array}$} & SD & D & $\mathbf{U}$ & $\mathbf{A}$ & SA \\
\hline & & & & & \\
\hline $\begin{array}{l}\text { I feel confident to use spreadsheet techniques to support } \\
\text { mathematical concepts formation }\end{array}$ & & & & & \\
\hline $\begin{array}{l}\text { I feel confident using teamwork among students to promote active } \\
\text { learning }\end{array}$ & & & & & \\
\hline $\begin{array}{l}\text { I am able to use "interactive demonstration" to define my role as a } \\
\text { facilitator in mathematics lessons }\end{array}$ & & & & & \\
\hline $\begin{array}{l}\text { I am able to use lesson plan to guide mathematics lesson } \\
\text { implementation }\end{array}$ & & & & & \\
\hline $\begin{array}{l}\text { I am able to apply collaboration in design teams to design } \\
\text { mathematics lessons }\end{array}$ & & & & & \\
\hline $\begin{array}{l}\text { I am able to use curriculum exemplary materials to gain hands-on } \\
\text { experience on what to design }\end{array}$ & & & & & \\
\hline $\begin{array}{l}\text { I know that support from a facilitator/resource person is helpful in } \\
\text { design process }\end{array}$ & & & & & \\
\hline $\begin{array}{l}\text { I am able to apply "learning - by -doing" as a strategy in designing } \\
\text { technology supported lesson }\end{array}$ & & & & & \\
\hline
\end{tabular}

4. To what extent do you implement the following innovations in your classroom instructions and lesson design?

\begin{tabular}{|c|c|c|c|c|c|}
\hline Item & SD & $\mathbf{D}$ & $\mathbf{U}$ & A & SA \\
\hline Activity-driven pedagogical approach to support student lea & & & & & \\
\hline Spreadsheet techniques to support mathematical concepts fo & & & & & \\
\hline Use of teamwork among students & & & & & \\
\hline Use of "interactive demonstration" & & & & & \\
\hline Use of lesson plan to guide lesson implementation & & & & & \\
\hline I collaborate in design teams to design mathematics lessons & & & & & \\
\hline $\begin{array}{l}\text { I use resources and/or exemplary curriculum materials durir } \\
\text { design }\end{array}$ & & & & & \\
\hline $\begin{array}{l}\text { I use a facilitator/resource person to help me in designing } \\
\text { mathematics lessons }\end{array}$ & & & & & \\
\hline $\begin{array}{l}\text { I use "learning - by -doing" approach to design spreadsheet } \\
\text { supported lessons }\end{array}$ & & & & & \\
\hline
\end{tabular}

5. To what extent do you agree that the following factors affect your implementation of activity-based technology enhanced mathematics teaching in your school (Indicate $1=$ strongly disagree (SD), $5=$ strongly agree (SA)).

\begin{tabular}{|l|l|l|l|l|l|}
\hline Factors & SD & D & U & A & SA \\
\hline Not enough computers in the computer lab & & & & & \\
\hline Limited access to computers & & & & \\
\hline Inadequate of computer software (e.g.spread sheet application) & & & & & \\
\hline Lack of time to develop technology supported lessons & & & & \\
\hline Lack of time to implement technology supported lessons & & & & \\
\hline Regular communication with my peers (in my school) about teaching & & & & & \\
\hline
\end{tabular}




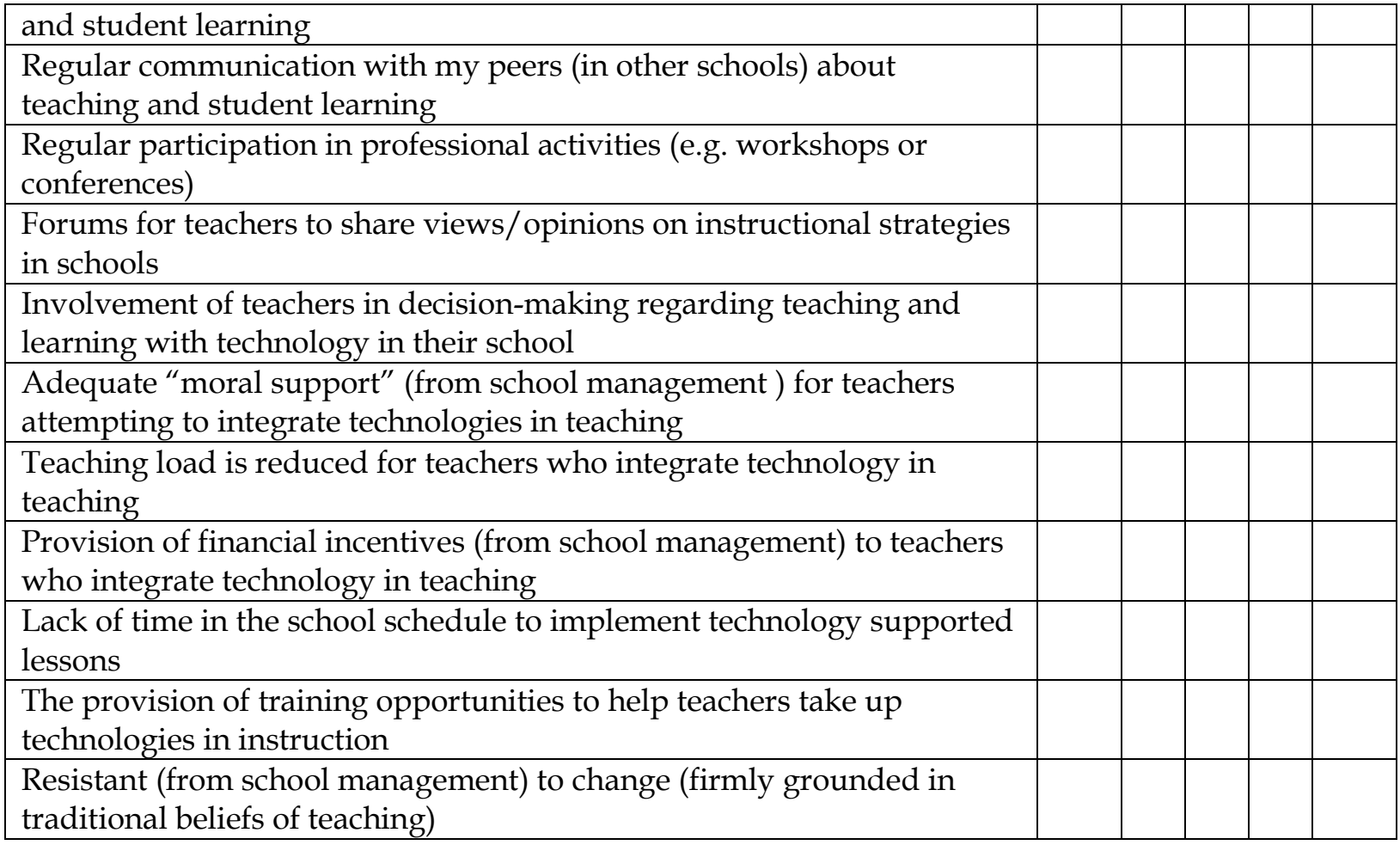

Thank you for your time

\section{E2 Researchers' Observation Lesson Checklist}

Observation Check list

\begin{tabular}{|l|l|l|}
\hline Innovation components & Yes & No \\
\hline Activity-driven pedagogical approach to support student & & \\
\hline Spreadsheet techniques to support mathematical concepts formation & & \\
\hline Use of teamwork among students & & \\
\hline Use of "interactive demonstration" & & \\
\hline Use of lesson plan to guide lesson implementation & & \\
\hline
\end{tabular}

Any other observations

\section{E3 Semi-structured interview guides for beginning teachers}

\section{Interview Guide}

1. Name:

2. Age:.

3. Gender:

4. Subject you teach:

5. Years of teaching 


\section{Section B}

1. How did you value the instructional technology innovation which you took part during your training at UCC regarding

i) the design components : design teams, exemplary materials, facilitator's role, and the learning by doing approach.

ii) the teaching process: activity-based approach, teamwork among students, use of lesson plans, use of spreadsheet and interactive demonstrations.

2 To what extent have you implemented the innovation (or components) in:

i) designing new mathematics lessons in your school?

ii) teaching mathematics lessons

3. How have the following hindered (or supported) your use of technology in your instruction:

- your own belief about teaching mathematics in the traditional settings

- your knowledge and skills regarding teaching mathematics with technology

- ICT facilities in your school

- availability of time in implementing technological instructional methods

- rewards/incentives in implementing technological innovations

- your participation in decision making regarding teaching/learning with innovations

- your own dedication to students learning or professional development

- School factors (e.g. Timetabling, training, supervision etc.).

4. What are your suggestions for successful implementation of technology innovations in

your school?

5. What plans or expectations are in place to use the innovation (or components of it) in their future classrooms? (If a teacher is not using the innovation) 


\section{APPENDIX F}

\section{Example of lesson document designed by pre-service teachers}

Teacher support materials

\begin{tabular}{|lc|}
\hline Topic & Quadratics in Polynomial Form : $y=a x^{2}+b x+k$ \\
School level & SHS 2 \\
Curriculum area & Elective Mathematics \\
Class time & 80 min (approximately 2 periods)
\end{tabular}

Teachers' Guide

In this lesson: Quadratics in Vertex Form: $y=a x^{2}+b x+k$, you are provided with three different support materials: Teachers' guide, the lesson material and student worksheet including student assignment. The activities in the lesson material are planned hand-inhand with the student worksheet. The teachers' guide provides an overview of the lesson and step-by-step support to set up the lesson. Before conducting this lesson, be sure to read through this guide thoroughly, and familiarize yourself with the activities in the lesson plan.

\section{Introduction}

When students are introduced to solving quadratic equations in SHS 1, they often don't identify connections between different quadratic function types. Each function has its own mysterious parameters. The behaviour of each graph is learned in isolation. Through the following investigations, students will compare the graph of quadratic equation in the polynomial form, alter their parameters and observe the changes in the numerical data and in the graphical representation. They then are asked to analyse the results, and to form conclusions about quadratic functions in polynomial form.

\section{Objectives:}

The student will:

- determine how changes in the parameters of a quadratic equation in the polynomial form affects its graph.

- determine how to use the polynomial form of a polynomial quadratic equation to find the location of the vertex on a graph.

- apply the vertex of a quadratic function in a realistic setting.

\section{Prerequisite Knowledge}

Students are able to:

- determine a linear equation from a given set of data.

- evaluate and simplify an expression with variables.

- locate the vertex of a parabola on a graph.

- substitute values into a given relation to find an unknown variable.

\section{Resources}

- This lesson assumes that your classroom has only one computer, from which you can teach. The presence of a projector is an advantage. For classrooms with enough computers for all your students either working individually or in small groups, this 
lesson can still be adapted.

- Spreadsheet such as Excel.

- Pencil, paper, and calculator.

- Copies of the worksheet for each student or small group of students.

\section{Setting up the data and plot windows}

This guide gives you opportunity and support to utilise ICT for the whole class teaching in generating and analysing quadratic patterns. As the instructor, your core task in the lesson execution is to set up the lesson environment and facilitate activities. The following instructions will give you step-by-step directions in preparing quadratic graphs for demonstration in Excel. You may want to bookmark the activity pages for your students. If you like, make copies of the worksheet for each student.

\section{Instructions}

1. Before you conduct this lesson in a spreadsheet, it is important that you know some basic use of the spreadsheet. (i.e. entering data, writing formulas or functions, copying formulas and formatting etc.)

2. Any spreadsheet will allow you to input numerical data and then view a plot of these data.

Most spreadsheets can display the table and the graph onscreen at the same time. This allows you to experiment with changing values in the table and observing the results in the plot.

3. In Microsoft Excel 5.0 the table and plot can be set up in separate windows as shown.

- If the program supports displaying two windows side by side, set the spreadsheet up as follows:

a. With 1 window opened, open a second window. Then select the command which will tile with a vertical split.

b. Type data in the left window.

c. Highlight the cells that contain the data and use the Chart command to create an X-Y Scatter plot in the second window. Make sure to choose to use the data from column 1 as $X$-data.

- If your spreadsheet does not display two windows, you may be able to paste the plot into the spreadsheet. Alternatively, you can toggle back and forth between the plot and table displays.

\section{Quadratic Functions - Working with $y=a x^{2}+b x+k$}




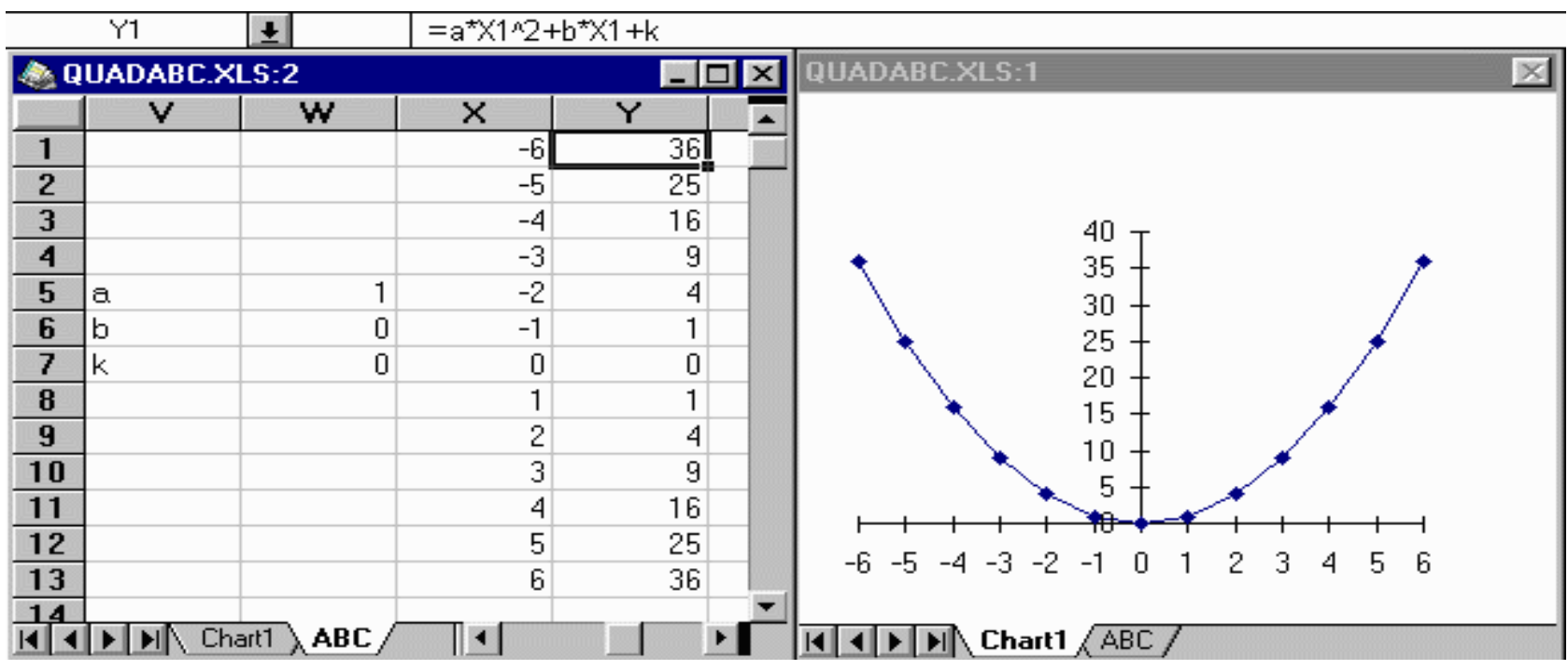

4. Input your $\mathrm{x}$-values you would use in plotting your quadratic graph beginning from cell X1 downwards. (You could choose any other column e.g. D or E, etc. Be sure you make enough columns for all the variables you may need)

5. Make up an equation in the form $y=a^{*}(\mathbf{X} \mathbf{1})^{\wedge} 2+b^{*}(\mathbf{X} \mathbf{1})+k$, and enter the formula in cell Y1 (or in the first cell of the next column you chose). Then use the Fill Down command. Note the values of $a, b$, and $k$ are stored in W5, W6 and W7.

6. Set the cursor over cell $\mathbf{Y} \mathbf{1}$ to note the formula. You should see: $=$ $a^{*}(\mathbf{X} \mathbf{1})^{\wedge} 2+b^{*}(\mathbf{X} \mathbf{1})+k$. (The ${ }^{\wedge}$ symbol is used for exponents in a spreadsheet and the * symbol must be used for multiplication.)

7. Try altering the values of $a, b$, and $k$. It is difficult to see how the parabola changes because the scale automatically adjusts. Therefore, set $a=1, b=0$ and $k=0$ and proceed to execution of the lesson in the lesson plan. (It is important to set up this before the lesson begins.)

Lesson Plan

\begin{tabular}{l}
\hline LESSON 1: Quadratics in Polynomial Form : $y=a x^{2}+b x+k$ (Double Lesson) \\
$\begin{array}{l}\text { Lesson plan and timing } \\
\text { Activity Approximate time (in minutes) }\end{array}$ \\
\hline Introduction \\
\hline Execution of the lesson \\
\hline Conclusion \\
\hline Ending the lesson \\
\hline Total \\
\hline
\end{tabular}


the other. Try to lead students to identify that the movement of the ball is parabolic as shown in the diagram below and help them to link this to a quadratic curve.

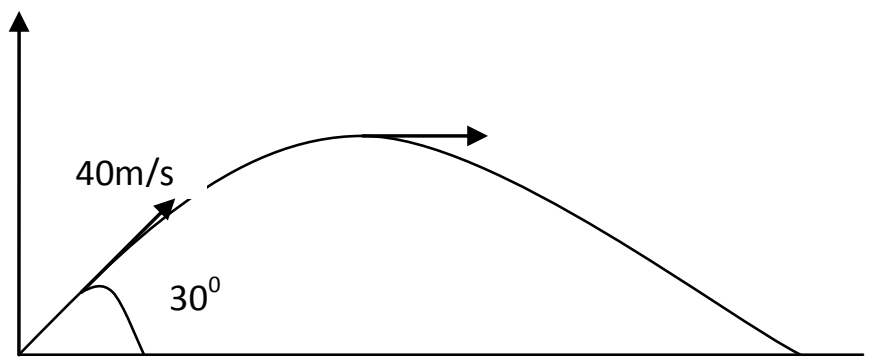

In the second scenario, ask students to predict the path of a ball thrown vertically up and help them to realise that real world phenomena can be modelled with mathematical functions. Prepare students for the following activities (activities: 1.0 - 3.0) by organizing them in small groups (2-3 students per group). Assign specific roles to members in the group e.g. presenter, recorder and chairperson.

Execution of the lesson (60 $\mathrm{min})$

Activity 1 : The shape of the parabola

Prepare the graph $y=a x^{2}+b x+k$ by setting $\mathrm{a}=1, \mathrm{~b}=0$ and $\mathrm{k}=0$ before beginning the lesson on an overhead project. By organizing students in small groups (2-3 students per group), guide them to observe and describe the changes as various parameters of the quadratic equation are altered.

\subsection{Varying the value of $a$ (set $b=0$ and $k=0$ )}

- Direct each group to observe and describe the changes in the graph as we increase the value of a systematically on the spreadsheet (e.g. Set a $=2,4,8,10,20,40)$. Get students to record the observations in the students' worksheet in their groups (it is necessary that the teacher present the different graphs on the same sheet to help bring out the concept).

- Set the values of a in the reverse order $(40,20,10,8,4,2,1,0)$ and get students to record their observations.

- Get students to observe how the graph changes when a changes from positive to negative numbers. Set the value of a to be zero and continue decreasing the value of a to negative numbers.

- Guide groups to compare their observation notes and note down their differences.

- Ask representatives of few groups to report the results to the whole class.

- Discuss group results with students. (Verify results by graphical representations on the spreadsheet if necessary). Some discussion points could be:

i. $\quad$ Increasing the value of a makes the parabola steeper (narrower).

ii. Decreasing the value of a flattens (widens) out the parabola.

iii. When the value of $\mathrm{a}=0$ we have a line on the $\mathrm{x}$-axis (connection between quadratic and linear functions).

iv. As we continue to decrease the value of a through negative values, the parabola opens downwards and gets steeper (narrower).

1.2 Varying the value of $k$ (set $a=1$ and $b=0$ )

Repeat the process for the activity by varying the value of $\mathrm{k}$ and guide students to observe and record changes on graph. Some discussion points could be:

i. Increasing the value of $\mathrm{k}$ moves the graph up (vertically) without altering 


\begin{tabular}{|c|c|}
\hline 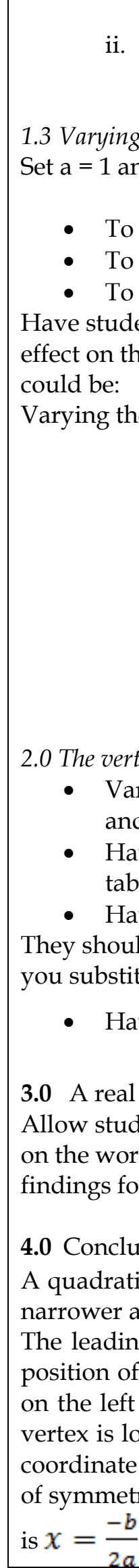 & 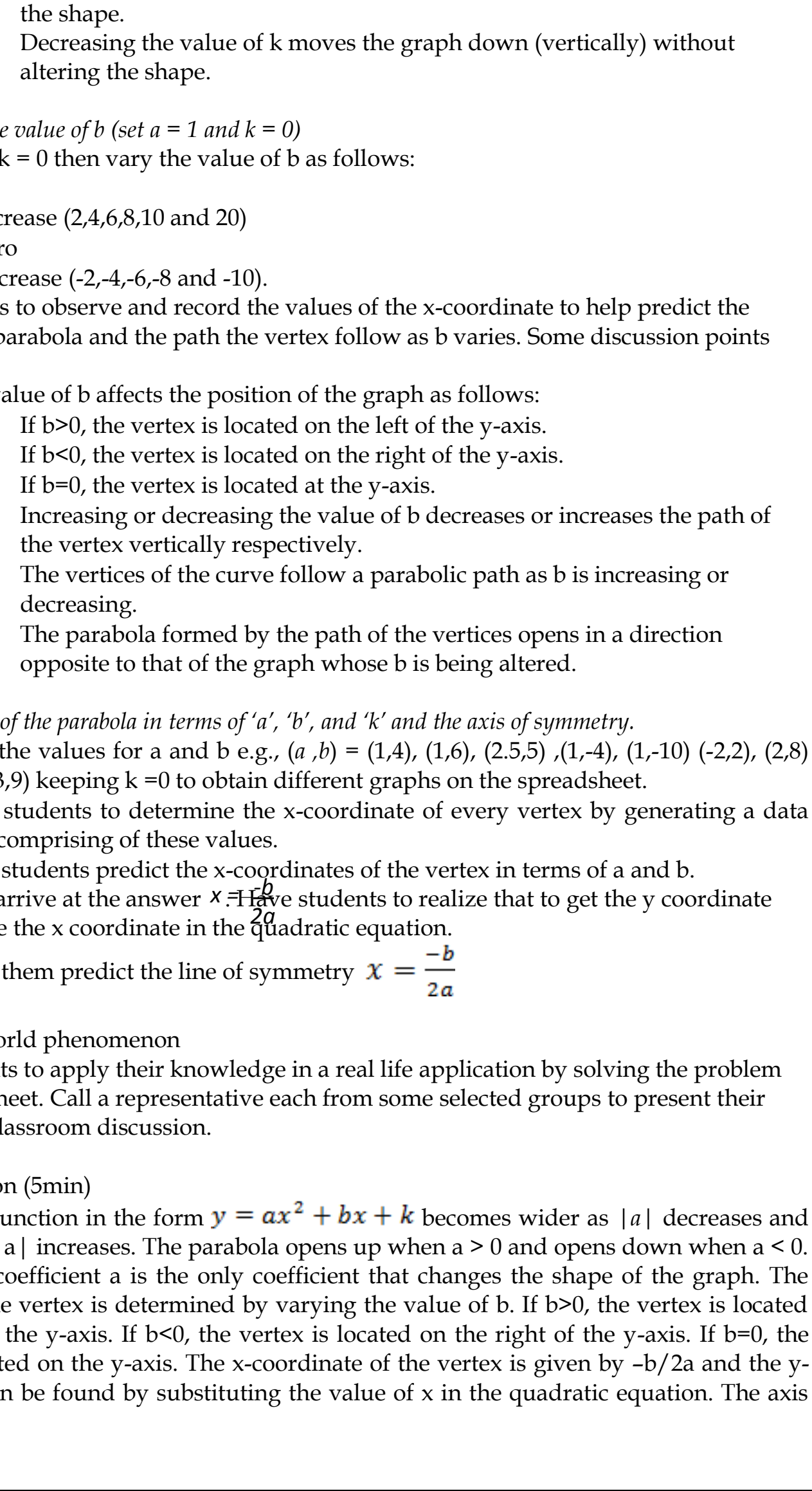 \\
\hline
\end{tabular}


Increasing or decreasing the value of k moves the graph up (vertically) or down (vertically) without altering the shape.

Ending the Lesson (5 min)

Give assignments out to students as indicated on the assignment sheet.

\section{Students' Worksheet}

\section{Introduction}

The graph of the function $y=a x^{2}+b x+k$ has several properties. In this worksheet, you are provided with activities that will help you examine how the shape of the parabola changes as the values of $\mathrm{a}, \mathrm{b}$, and $\mathrm{k}$ are modified. You will also determine how the parameters of the equation will help you find the $\mathrm{x}$ - and $\mathrm{y}$-coordinates of the vertex. You will be introduced to a realistic application of this function illustrating how these properties are useful.

\subsection{The shape of the parabola}

As the parameters are altered in the quadratic equation, observe the slides and notice the changes in the shape of the graph. Record your observations as in the questions below:

\subsection{Varying the value of a}

\section{Question 1.1a.}

How does the graph change when $a$ changes from positive to negative? Sketch.
i. When $a$ is positive
ii. When $a$ is negative

Question 1.1b.

For what values of $a$ will the vertex of the parabola be a maximum (the highest point on the graph)?

Question 1.1c.

For what values of $a$ will the vertex be a minimum (the lowest point on the graph)?

Question 1.1d.

What happens to the graph when $a=0$ ? Why? 
Question 1.1e

How does the graph change as the value of $a$ increases? How does it change if the value of $a$ decreases?

Question 1.1f.

Which of the following parabolas will appear wider: $y=-2 x^{2}+x-5$ or $y=4 x^{2}-2 x+2$ ?

(Check your answer by graphical representation on slide.)

Question 1.1g.

Which of the following parabolas will open downwards: $y=2 x^{2}-x-5$ or $y=-4 x^{2}+2 x+$ 2 ? (Check your answer by graphical representation on slide.)

\subsection{Varying the value of $k$}

Question $1.2 b$

What happens to the graph when the value of $k$ is increased or decreased?

- When $k$ is increased, the graph moves (upwards / downwards). Underline the correct answer.

- When $k$ is decreased, the graph moves (upwards / downwards). Underline the correct answer.

\subsection{Varying the value of $b$}

Question 1.3

Record the value of $x$ in the $\mathrm{x}$-coordinate of the vertex as we alter the values of $\mathrm{b}$ (when $a=1$ and $k=0$ )

\begin{tabular}{|c|c|c|c|c|c|c|c|}
\hline$b$ & 6 & 4 & 2 & 0 & -2 & -4 & -6 \\
\hline$x$ & & & & & & & \\
\hline
\end{tabular}

Question 1.3a

How do changes in the value of $b$ affect the vertex?

When $b>0$, the vertex lie

When $b<0$, the vertex lie

When $b=0$, the vertex lie 
Question $1.4 a$

How far will the vertex of $y=-2 x^{2}+x-5$ be from the vertex of $y=-2 x^{2}+x-$ 1 ?

Question $1.4 b$

Determine a function that is wider, opens in the opposite direction, and has vertex lower than $y=0.5 \times 2+2 x-3$. Explain how you determined this result.

2.0 The $x$ coordinate of the vertex of the parabola in terms of ' $a$ ', ' $b$ ', and ' $k$ ' and the axis of symmetry when $k=0$

Following the changes in the values of $a$ and $b$, fill in the values of x-coordinate of the respective vertices.

\begin{tabular}{|c|c|c|c|c|c|c|}
\hline$a$ & 1 & -1 & 2.5 & 1 & 1 & 2 \\
\hline$b$ & 4 & 6 & 5 & -4 & -10 & 8 \\
\hline$x$ & & & & & & \\
\hline
\end{tabular}

Question 2.1

Determine the value of $x$ in terms of ' $a$ ' and ' $b$ ' in the table.

Question 2.2

Calculate the coordinates of the vertex for the equation $y=-x^{2}+4 x-5$.

Question 2.3

The equation $y=2 x^{2}+8 x+3$ has a vertex at $(-2,-5)$. Without graphing this equation, determine whether the vertex will be the minimum or the maximum $y$-value on the parabola? How?

Question 2.4

Which point on the parabola will the axis of symmetry always pass through? Does the formula for finding the $x$-coordinate of the vertex help you to find the axis of symmetry of a parabola?

Question 2.5

If the quadratic equation $y=x^{2}+b x-3$ has an axis of symmetry at $x=3$, what is the value of $b$ ? Explain how you know. 


\subsection{A real world phenomenon}

The following function describes the vertical position of a falling object as a function of time.

$$
h=\frac{1}{2} g t^{2}+v_{o} t+h_{o}, \text { where }
$$

$h$ represents the height of the ball

$t$ represents the time that the ball is in the air

$g$ represents the gravitational acceleration on the object $\left(-10 \mathrm{~m} / \mathrm{s}^{2}\right.$ on earth)

$v_{o}$ represents the launch velocity (or initial velocity)

$h_{o}$ represents the launch height (or initial height)

\section{Question $3 a$}

Compare this function with $\mathrm{y}=a x^{2}+b x+k$ by completing the table below.

\section{Components of $\quad$ Components of}

$\mathrm{y}=a x^{2}+b x+k \quad h=\frac{1}{2} g t^{2}+v_{o} t+h_{o}$
$y \quad$ is the same as
$x \quad$ is the same as
$a \quad$ is the same as
$\begin{aligned} & \text { is the same as } v_{o} \\ & k\end{aligned} \quad$ is the same as

\section{Question $3 b$.}

What is the leading coefficient of the equation describing the path of the falling object if you are measuring length in meters and time in seconds? Give a numeric value without any letters. Explain how you determined this result.

Question 3c.

A ball is launched vertically 1.85 meters from the ground at a velocity of 20 meters per second. What is the maximum height of the throw? Explain how you determined this result

\section{Assignment}

1. Which of the following parabolas opens upward and appears narrower than $y=-3 x^{2}+2 x-1$ ?
A. $y=4 x^{2}-2 x-1$
B. $y=-4 x^{2}+2 x-1$
C. $y=x^{2}+4 x$
D. $y=-2 x^{2}+x+3$ 
2. Which of the following parabolas is 2 units higher than $y=2 x^{2}-4 x-1$, but has the same shape and opens in the same direction?
A. $y=2 x^{2}-6 x-1$
B. $y=2 x^{2}-2 x-1$
C. $y=2 x^{2}-4 x-3$
D. $y=2 x^{2}-4 x+1$

3. What are the coordinates of the vertex of the parabola $y=x^{2}+2 x-1$ ?
A. $(-2,5)$
B. $(-1,-2)$
C. $(-2,-1)$
D. $(-1,2)$

4. Which of the following equations has an axis of symmetry with the equation $x=1.5$ ?
A. $y=2 x^{2}-6 x-1$
B. $y=2 x^{2}-3 x+1$
C. $y=x^{2}+6 x-3$
D. $y=2 x^{2}+3 x+2$ 


\section{APPENDIX G}

\section{Example of Lesson coding and grading}

G1 Example of Evidence for coding a lesson

Codes-quotations list

Code-Filter: All [7]

Code: CKmaths $\{12-0\}$

\section{Codes: [CKmaths]}

- locate points on the Cartesian plane.

- join points on a Cartesian plane to form a line.

- identify the slope or gradient from a linear function

\section{Codes: [CKmaths]}

- determine how changes in the parameters of a linear function affect its graph.

- determine the $x$ - and $y$-intercepts of a linear function.

\section{Codes: [CKmaths]}

- apply linear functions to real life situations.

they often don't identify connections between effects the changes in the parameters have on the graph of the functions. Each function has its own mysterious parameters

\section{Codes: [CKmaths]}

i. When $\mathrm{m}$ is positive, the graph increases from left to right.

ii. When $\mathrm{m}$ is negative, the graph decreases from left to right.

iii. When the value of $\mathrm{m}=0$ we have a line on the $\mathrm{x}$-axis.

iv. As the absolute value of $m$ increases, the graph becomes more steeper.

$\mathrm{v}$. As the absolute value of $\mathrm{m}$ decreases the line becomes less steeper.

\section{Codes: [CKmaths]}

Write the equation for the final transformed graph:

a. $y=x$; shifts upward 2 units.

b. $y=x$; shifts downward 3 units.

\section{Codes: [CKmaths]}

- Let students complete the table below:

\begin{tabular}{|c|c|c|c|c|c|}
\hline$m$ & 1 & -1 & 2 & 1 & -2 \\
\hline$k$ & 2 & 2 & 1 & -2 & 4 \\
\hline$y$-intercept & & & & & \\
\hline$x$-intercept & & & & & \\
\hline Equation & & & & & \\
\hline
\end{tabular}

\section{Codes: [CKmaths]}

A linear function in the form $y=m x+k$ has many properties as the values of its parameters are altered. When $\mathrm{m}$ is positive, the graph increases to the right and when $\mathrm{m}$ is negative, it decreases to the right. When $\mathrm{m}$ is zero, the graph becomes the line $\mathrm{y}=0$ and lies on the $\mathrm{x}$-axis. As the absolute value of $\mathrm{m}$ increases, the graph becomes steeper. It becomes less steep as the absolute value of $m$ decreases. The line will always pass through the origin, $(0,0)$, when $k=0$. As $k$ increases or decreases, the graph moves vertically upwards or downwards respectively. The $\mathrm{x}$-intercept is determined by $-\mathrm{k} / \mathrm{m}$ while $\mathrm{k}$ represents the $\mathrm{y}$-intercept. 


\section{Codes: [CKmaths]}

Introductory Activity

i. Which of the following equations

$y=3 x+1, y=-4 x+2, y=-2 x+1$, and $y=4 x+3$ will:

a. increase from left to right?

b. decrease from left to right?

ii. Arrange the following equations in increasing order of steepness:

$y=3 x+1, y=-4 x+2$ and $y=-2 x+1$

iii. Which of the following equations will be above the other: $y=-4 x+2$ or $y=-4 x$ ?

\section{Codes: [CKmaths]}

\subsection{The $x$ - and $y$-intercepts}

a. Complete the table below (use the spreadsheet to locate the points and parameters):

\begin{tabular}{|l|l|l|l|l|}
\hline Equation & $m$ & $k$ & $y$-intercept & $x$-intercept \\
\hline$y=3 x+3$ & & & & \\
\hline$y=-3 x-6$ & & & & \\
\hline$y=4 x-2$ & & & & \\
\hline$y=-x+3$ & & & & \\
\hline
\end{tabular}

b. How does the value of $k$ in the function help you to find the $y$-intercept?

c. What is the relationship between the $x$-intercept, $m$ and $k$ ?

d. Complete the table below:

\begin{tabular}{|c|c|c|c|c|c|}
\hline$m$ & 1 & -1 & 2 & 1 & -2 \\
\hline$k$ & 2 & 2 & 1 & -2 & 4 \\
\hline$y$-intercept & & & & & \\
\hline$x$-intercept & & & & & \\
\hline Equation & & & & & \\
\hline
\end{tabular}

e. Sketch, on the $x-y$ plane, the graph of the functions below, not by plotting points, but by starting with the graph of a standard function and applying transformations:
a. $y=2 x+3$
b. $y=-4-2 x$

\section{Codes: [CKmaths]}

Real life application

The wages, $\mathrm{W}$, in Ghana cedis (GH\$), of a sales boy is partly constant, $p$, in Ghana cedis $(\mathrm{GH})$, and partly varies directly as the number of customers acquired per day, $d$, and is given in the function:

$W=d n+p$, where $\mathrm{n}$ is the number of days.

Question 3.1

Which of the variables correspond to $x$ in the linear function?

Question 3.2

From the employer, the sales boy is assured of a daily wage of GH\$20.00. If he earns GH\$50.00 on getting 15 customers, how many days did he worked?

Question 3.3

If he had 25 customers in 5 days, how much will he earn? 
Codes: [CKmaths]

The orientation of the line

Question 1.1a

Draw the orientation of the graph when:
a) $m$ is positive
b) $m$ is negative

Question $1.1 b$

How does the line look like when $\mathrm{m}$ is zero?

Question 1.1c

As the absolute value of $\mathrm{m}$ increases, the line becomes (more steeper / less steeper).

As the absolute value of $\mathrm{m}$ decreases, the line becomes (steeper / less steeper).

Question 1.1d

Which point does the line always pass through when $\mathrm{k}=0$ ?

Question 1.2

How does the graph change as $\mathrm{k}$ increases?

How does the graph change as $\mathrm{k}$ decreases?

Question 1.3

Write the equation for the final transformed graph:

a. $\quad y=x$; shifts upward 2 units.

b. $\quad y=x$; shifts downward 3 units.

Code: PCK $\mathrm{ABL}\{7-0\}$

\section{Codes: $\left[\mathrm{PC} \mathrm{K}_{A B L}\right]$}

In this lesson students will compare the graph of a linear function to its equation, vary the parameters of the equation and explore how the graph changes in response. They then are asked to analyse the results, and to form conclusions about linear functions.

\section{Codes: $\left[\mathrm{PCK}_{A B L}\right]$}

The graph of the function $y=m x+k$ has several properties. In these activities, you will guide students to examine how the orientation of the line changes as the values of $\mathrm{m}$ and $\mathrm{k}$ are altered. You will also assist them determine how the equation will help them find the $x$ and $y$-intercepts.

\section{Codes: $\left[\mathrm{PC} \mathrm{K}_{A B L}\right]$}

In this activity, ask students to indicate (by tick $(\sqrt{ }))$ ) the features of the equations as shown on the Worksheet (without plotting or solving them). Ask the students to keep their results for discussion later in the lesson.

\section{Codes: [PCK $\left.{ }_{A B L}\right]$}

Guide them to identify that:

- The graph moves vertically upwards when $\mathrm{k}$ is increasing.

- The graph moves vertically downwards when $\mathrm{k}$ is decreasing.

Codes: $\left[\mathrm{PCK}_{A B L}\right]$

- Have students determine the relationship between $\mathrm{m}$ and $\mathrm{k}$ and the $\mathrm{x}$-intercept.

- Have students record their observations and findings on the Students' Worksheet and selected groups discuss their results with the whole class.

Codes: $\left[P C K_{A B L}\right]$

Let students sketch, on the $x-y$ plane, the graph of the functions below, not by plotting points, but by starting with the graph of a standard function and applying transformations:
a. $y=2 x+3$
b. $y=-4-2 x$ 
Codes: $\left[\mathrm{PCK}_{A B L}\right]$

Let students apply linear functions to solve questions on a sales boy's wages in a day in the Students' Worksheet.

Code: PK $\mathrm{ABL}\{9-0\}$

Codes: $\left[P K_{A B L}\right]$

Allow students to re-visit the exercise they did at the beginning of the lesson and discuss their results.

Codes: $\left[\mathrm{PK} \mathrm{KBL}_{\mathrm{B}}\right]$

Resources

- This lesson assumes that your classroom has only one computer, from which you can teach. The presence of a projector is an advantage. For classrooms with enough computers for all your students either working individually or in small groups, this lesson can still be adapted.

CD's).

Copies of teacher support materials (including teachers' guide) for teachers (on

- Spreadsheet (e.g. Excel) software.

- Copies of the worksheet for each student or small group of student

Codes: $\left[P K_{A B L}\right]$

As the instructor, your core task in the lesson execution is to set up the lesson environment and facilitate activities. The following instructions will give you step-by-step directions in preparing linear graphs for demonstration in a spreadsheet environment. You may want to bookmark the activity pages for your students. If you like, make copies of the worksheet for each student.

Codes: $\left[P K_{A B L}\right]$

\begin{tabular}{|lc|}
\hline LESSON 1: Linear functions $: \boldsymbol{y}=\boldsymbol{m} \boldsymbol{x}+\boldsymbol{k}$ (Double Lesson) \\
\hline $\begin{array}{l}\text { Lesson plan and timing } \\
\text { Activity }\end{array}$ \\
\hline Introduction & Approximate time (in minutes) \\
\hline Execution of the lesson & 60 \\
\hline Conclusion & 05 \\
\hline Ending the lesson & 05 \\
\hline Total & 80 \\
\hline
\end{tabular}

Codes: $\left[P K_{A B L}\right]$

Prepare students for the following activities (Activities: 1.0 - 3.0) by organizing them in small groups (2-3 students per group). Assign specific roles to members in the group e.g., presenter, recorder and chairperson. Begin the lesson by giving each group a number of linear functions on the Students' Worksheet.

Codes: $\left[P K_{A B L}\right]$

Ask representatives of few groups to report their results to the whole class.

Codes: $\left[P K_{A B L}\right]$

Ask students to do the following in their groups for presentation:

Codes: $\left[P K_{A B L}\right]$

Ask students to do the assignment and present it before the next lesson. 
Codes: [PK $\left.{ }_{A B L}\right]$

Re-visiting the introductory activities

Code: $\mathrm{TCK}_{\text {ss }}\{4-0\}$

Codes: [TCK $\mathrm{Ts}_{\text {ss }}$

Prepare the graph of $y=m x+k$ by setting $m=1$ and $k=0$ before beginning the lesson on an overhead project

Codes: [TCK $\left.K_{s s}\right]$

Input your $x$-values you would use in plotting your linear graph, beginning from cell C1 downwards.

Codes: $\left[\mathrm{TCK}_{\text {ss }}\right]$

Make up an equation $y=x$ (i.e. the standard or basic form of linear equations) in cell D1 (or in the first cell of the next column you chose) by entering the formula $=m^{*} x+k$ and pressing the Enter key.

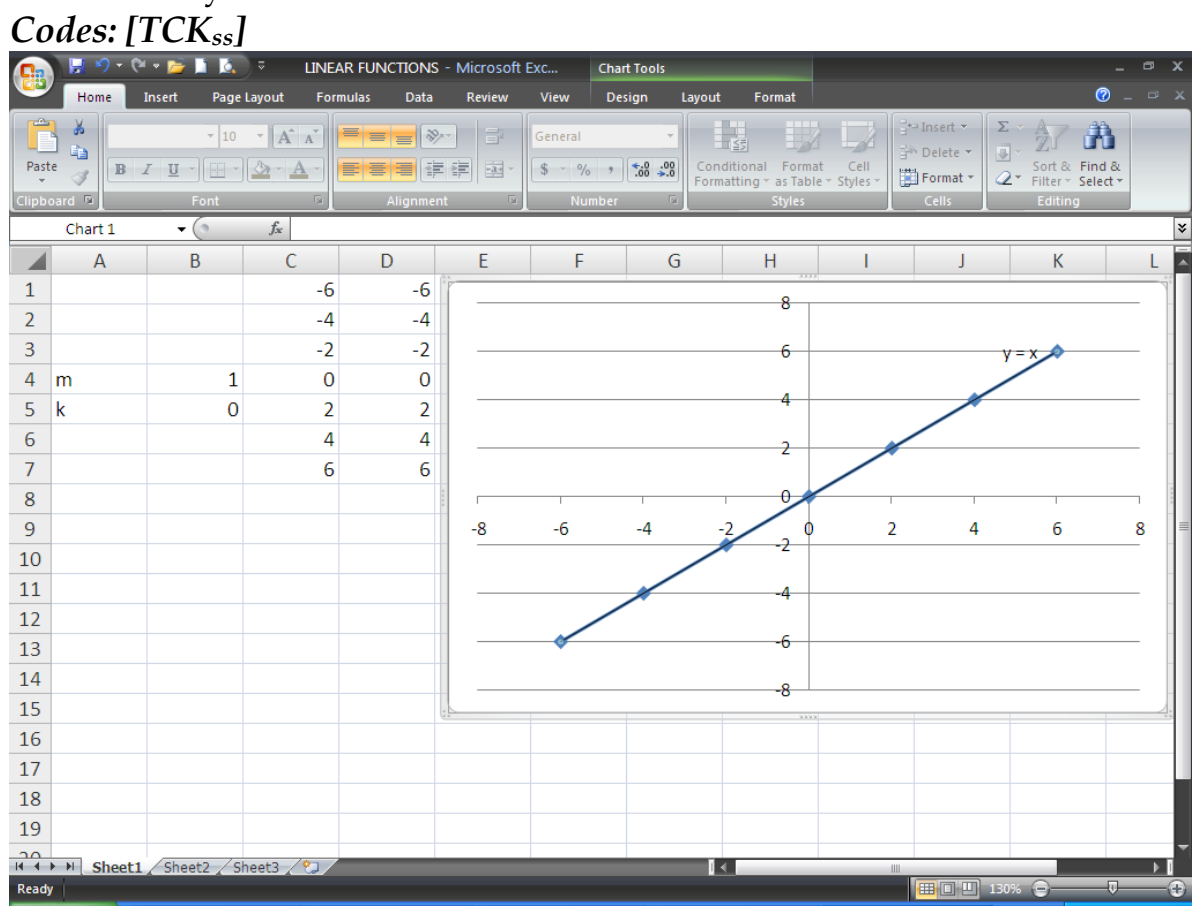

Code: TKss $\{8-0\}$

Codes: $\left[\mathrm{TK}_{s s}\right]$

1. If Microsoft Office Excel 2007 software is installed on the computer, follow these steps to open it:

i. Click the Start menu.

ii. Point your mouse to All Programs.

iii. In the dialog that opens, go to Microsoft Office.

iv. In the dialog that opens, click on Microsoft Office Excel 2007.

This opens the Microsoft Office Excel 2007 window 
Codes: $\left[T K_{s s}\right]$

Define the values of $m$ as 1 and $k$ as 0 in cells B4 and B5 respectively. (This is done by clicking in cell B4. Go to the Name box on the left side of the formula bar and just above cell A1. Type $m$ and press the Enter key. Do this for B5 by naming it as k.) Then type $m$ and $\boldsymbol{k}$ in cells $\mathrm{A} 4$ and $\mathrm{A} 5$ respectively.

Codes: $\left[\mathrm{TK}_{s s}\right]$

(You could choose any other column e.g.D, or E, etc. Be sure you make enough columns for all the variables you may need.)

Codes: $\left[\mathrm{TK}_{s s}\right]$

Any spreadsheet will allow you to input numerical data and then view a plot of these data. Most spreadsheets can display the table and the graph onscreen at the same time.

Codes: $\left[\mathrm{TK}_{\text {ss }}\right]$

Then use the Fill Down command (i.e., point the cursor to the down right corner of cell D1 to get a 'plus' sign, click and drag it down to the row where you have the last $x$-value). This displays all the $y$-values.

Codes: $\left[T K_{s s}\right]$

Set the cursor over cell D1 to note the formula. You should see: $=\mathbf{m}^{*} \mathbf{x}+\mathbf{k}$. (NB: The ${ }^{*}$ symbol is used for multiplication.)

To plot the graph, select (highlight) the set of data by clicking on cell $\mathbf{C} \mathbf{1}$ and dragging to cell D7. Select the Insert menus from the menu bar, click on Scatter, and then click on Scatter with Smooth Lines and Markers. This displays the graph.

Codes: $\left[T K_{s s}\right]$

To display the equation on the line, Right-click on any part of the line and click on Format Trendline. In the dialog, choose Trendline Options and select Display Equation on chart. Then click on Close. This will display the equation on the line.

Codes: $\left[\mathrm{TK}_{\text {ss }}\right]$

(Hint: By clicking and holding the cursor on these points on the graph, the coordinates will be displayed.)

Code: TPCK $_{\text {maths }}\{6-0\}$

Codes: [TPCK $\left.K_{\text {maths }}\right]$

$2.1 \quad$ Plot a number of linear graphs:

$\mathrm{y}=3 \mathrm{x}+3$,

$y=-3 x-6$

$\mathrm{y}=4 \mathrm{x}-2$,

$y=-x+3$.

In each of the plots, guide students to record the $x$-intercept and $y$-intercept as shown in the table on their worksheets

Codes: [TPCK $\left.K_{\text {maths }}\right]$

By organizing students in small groups (2-3 students per group), guide them to observe and describe the changes as various parameters of the linear function are altered in each of the equations you plotted on the spreadsheet.

Codes: [TPCK $K_{\text {maths }}$ ]

Begin with the graph of the standard function: $y=m x$ on the spreadsheet and guide students to observe how the graph changes when $m$ changes from positive to negative numbers. Set the value of $m$ to be zero and continue decreasing the value of $m$ to negative numbers (eg...4,2,1,0,-4,-2,-4,...) 
Codes: [TPCK $\left.K_{\text {maths }}\right]$

Get students in groups to observe and describe the transformations in the graph as we increase the value of $\mathrm{m}$ systematically (e.g. Set $\mathrm{m}=2,4,8)$. Get students to record the observations in the Students' Worksheet in their groups (it is necessary that the teacher present the different graphs on the same sheet to help bring out the concept).

Codes: [TPCK $\left.\mathrm{K}_{\text {maths }}\right]$

Discuss group results with students. (Verify results by graphical representations on the spreadsheet if necessary). Some discussion points could be:

Codes: [TPCK maths $_{\text {s }}$ ]

In each of the plots, guide students to record the $x$-intercept and $y$-intercept as shown in the table on their worksheets. (Hint: By clicking and holding the cursor on these points on the graph, the coordinates will be displayed.)

Code: TPK $_{\mathrm{ABL}}\{5-0\}$

Codes: $\left[T P K_{A B L}\right]$

Before you conduct this lesson in a spreadsheet, it is important that you know some basic use of the spreadsheet (i.e. entering data, writing formulas or functions, copying formulas and formatting, etc.)

Codes: $\left[T P K_{A B L}\right]$

This allows you to experiment with changing values in the table and observing the results in the plot.

Codes: $\left[T P K_{A B L}\right]$

Set the values of $\mathrm{m}$ in the reverse order $(8,4,2,1,0)$ and get students to record their observations.

Codes: $\left[T P K_{A B L}\right]$

Repeat the increasing and decreasing of $m$ with negative numbers (e.g. $-1,-2,-4,-8)$ and let students record their observations.

Codes: $\left[T P K_{A B L}\right]$

Set $m=1$ then vary the value of $k$ and let students record and discuss their findings

\section{G2 Scoring the Coding Categories}

Once the coding had been done for the lesson document, scores were assigned to each category using the criteria for analyzing the spreadsheet supported activity-based lesson plans as shown in Table 1. The average for each category was then determined.

Table 1: Criteria for analysing the spreadsheet supported activity-based lesson plans

\begin{tabular}{|c|c|c|c|}
\hline \multirow{3}{*}{$\begin{array}{l}\text { Appropriately spelt out subject matter of mathematics lesson }\left(C K_{\text {maths }}\right) \\
\text { ABL strategies support to mathematics learning }\left(\mathrm{PK}_{\mathrm{ABL}}\right)\end{array}$} & 3 & 2 & 1 \\
\hline & & & \\
\hline & & & \\
\hline $\begin{array}{l}\text { Clearly designed spreadsheet techniques that can support transfer of } \\
\text { knowledge }\left(T K_{s s}\right)\end{array}$ & & & \\
\hline Support of ABL strategies to mathematics lesson goals $\left(P C K_{A B L}\right)$ & & & \\
\hline $\begin{array}{l}\text { Alignment of spreadsheet techniques to mathematics lesson goals } \\
\left(T C K_{s s}\right)\end{array}$ & & & \\
\hline Support of spreadsheet to ABL strategies $\left(T P K_{A B L}\right)$ & & & \\
\hline $\begin{array}{l}\text { Fit of mathematics content, ABL strategies and spreadsheet techniques } \\
\text { together within the instructional plan }\left(T P A C K_{\text {maths }}\right)\end{array}$ & & & \\
\hline
\end{tabular}

Not at all (1), Minimal (2) and Strong (3) 
Results for the coding categories

\begin{tabular}{|c|l|l|l|l|l|l|l|l|l|l|l|l|l|l|}
\hline Codes & 1 & 2 & 3 & 4 & 5 & 6 & 7 & 8 & 9 & 10 & 11 & 12 & $\mathrm{M}$ & $\mathrm{SD}$ \\
\hline $\mathrm{CK}_{\text {maths }}$ & 3 & 3 & 2 & 3 & 2 & 3 & 2 & 3 & 3 & 3 & 2 & 3 & 2.67 & 0.492 \\
\hline$P K_{A B L}$ & 3 & 3 & 3 & 2 & 3 & 2 & 3 & 3 & 3 & & & & 2.8 & 0.441 \\
\hline $\mathrm{TK}_{\mathrm{ss}}$ & 3 & 2 & 2 & 3 & 3 & 3 & 2 & 2 & & & & & 2.5 & 0.535 \\
\hline$P C K_{A B L}$ & 3 & 2 & 3 & 2 & 2 & 3 & 3 & & & & & & 2.57 & 0.535 \\
\hline$T C K_{S S}$ & 3 & 2 & 2 & 3 & & & & & & & & & 2.5 & 0.577 \\
\hline TPK $_{A B L}$ & 2 & 2 & 3 & 2 & 3 & & & & & & & & 2.4 & 0.548 \\
\hline TPCK $_{\text {maths }}$ & 2 & 3 & 3 & 3 & 2 & 2 & & & & & & & 2.5 & 0.548 \\
\hline
\end{tabular}




\section{APPENDIX H \\ Cirriculum Lesson materials}

H1 Curriculum lesson material designed for the Information technology (IT) course

\begin{tabular}{|c|c|c|}
\hline & $\begin{array}{r}\text { University of Cape Coast } \\
\text { Department of Science and Mathematic } \\
\text { EMA 401: Developing mathematics teaching and lea } \\
\text { Second Semester 2010/2011 }\end{array}$ & $\begin{array}{l}\text { Education } \\
\text { hing activities with ICT }\end{array}$ \\
\hline $\begin{array}{l}1 . \\
2 . \\
3 .\end{array}$ & $\begin{array}{l}\text { Reference Texts } \\
\text { Prestage, S., \& Perks, P. (2001). Adapting and Extendir } \\
\text { Activities: New Tasks for Old. David Fulton, London. } \\
\text { Boaler, J. (1997). Experiencing School Mathematics. Op } \\
\text { Haggerty, L.(2002)Teaching Mathematics in Secondary S } \\
\text { University , London. }\end{array}$ & $\begin{array}{l}\text { Secondary Mathematics } \\
\text { University Press, London. } \\
\text { hools: A Reader .Open }\end{array}$ \\
\hline & Course Description & \\
\hline $\begin{array}{c}\text { The ob } \\
\text { - } \\
\text { - } \\
\text { - } \\
\text { - } \\
\text { - } \\
\text { Pre-rec }\end{array}$ & $\begin{array}{l}\text { Objectives } \\
\text { jectives of the course are: } \\
\text { to provide practical support and guidance for studer } \\
\text { secondary school mathematics with technology } \\
\text { identify various mathematics teaching and learning } \\
\text { secondary schools and criteria for their selection } \\
\text { use technology and activity-based learning approach } \\
\text { understanding of known mathematics concepts and } \\
\text { curriculum } \\
\text { design, develop and implement mathematics lessons } \\
\text { activities. } \\
\text { to reflect on the course in general and on specific act } \\
\text { indicate their understanding of the concepts and skil } \\
\text { quisite: One method course in mathematics }\end{array}$ & $\begin{array}{l}\text { teachers to be able to teach } \\
\text { ctivities for teaching at the } \\
\text { to enhance students teachers' } \\
\text { kills of the secondary school } \\
\text { with teaching learning } \\
\text { ities and approaches to } \\
\text { s learnt }\end{array}$ \\
\hline & $\begin{array}{c}\text { Course Outline } \\
\end{array}$ & \\
\hline Week & Content / Training goal & $\begin{array}{l}\text { Remarks / Expected } \\
\text { students' } \\
\text { task }\end{array}$ \\
\hline 1 & $\begin{array}{l}\text { Objective of Course/ Distribution of Course } \\
\text { Materials }\end{array}$ & $\begin{array}{l}\text { Students form working } \\
\text { groups/ teams }\end{array}$ \\
\hline 2 & $\begin{array}{|rl|}\text { Teaching Learning Activities (1) } \\
\text { - } & \text { Why activity- based learning } \\
\text { - } & \text { Possible ICT alternatives (ICT as a teaching } \\
& \text { tool) } \\
\text { - } & \text { Introduction to TPACK }\end{array}$ & $\begin{array}{l}\text { Introduce students to } \\
\text { possible ICT resources in } \\
\text { maths, websites, } \\
\text { mathematics games etc. }\end{array}$ \\
\hline 3 & $\begin{array}{l}\text { TPACK- Demonstration of Lessons \& Discussion of } \\
\text { Lesson Plans }\end{array}$ & $\begin{array}{l}\text { - Introduce TPACK Rubric \& } \\
\text { Checklist } \\
\text { - Teams evaluate exemplary } \\
\text { lessons - plan \& actual } \\
\text { lessons }\end{array}$ \\
\hline 4 & Introduction to Spreadsheet (Excel )in Mathematics & $\begin{array}{l}\text { Practical Sessions-Basic ICT } \\
\text { skill acquisition }\end{array}$ \\
\hline 5 & $\begin{array}{l}\text { Designing mathematics activities in Spreadsheet } \\
\text { and developing lessons (1) }\end{array}$ & $\begin{array}{l}\text { Practical session at computer } \\
\text { Lab }\end{array}$ \\
\hline 6 & $\begin{array}{l}\text { Designing mathematics activities in Spreadsheet } \\
\text { and developing lessons (2) }\end{array}$ & - do- \\
\hline
\end{tabular}




\begin{tabular}{|c|c|c|}
\hline 7 & $\begin{array}{l}1^{\text {st }} \text { Round of Lesson Implementation (Semesters' } \\
\text { Project) }\end{array}$ & $\begin{array}{l}\text { Peer review of lesson plans } \\
\text { and actual teaching (video- } \\
\text { taped) }\end{array}$ \\
\hline 8 & $\begin{array}{l}\text { Teaching Learning Activities (2) -(TLM) } \\
\text { - } \quad \text { Demonstrations and discussion on Algebra } \\
\text { teaching materials }\end{array}$ & $\begin{array}{l}\text { Team assignment to prepare } \\
\text { TLM on a topic on one of (i) } \\
\text { Geometry or (ii) Numbers } \\
\text { and Number system }{ }^{* *}\end{array}$ \\
\hline 9 & $\begin{array}{l}\text { Teaching Learning Activities (3) - (TLM) } \\
\text { - Demonstrations and discussion on Handling } \\
\text { Data teaching materials }\end{array}$ & - do - \\
\hline 10 & $\begin{array}{l}\text { Team presentation and discussion of designed TLM } \\
\text { (i) Geometry or } \\
\text { (ii) Numbers and Number system }\end{array}$ & Selected teams \\
\hline 11 & $\begin{array}{l}\text { Team presentation and discussion of designed TLM } \\
\text { (i) Geometry or } \\
\text { (ii) Numbers and Number system }\end{array}$ & - do - \\
\hline 12 & $\begin{array}{l}\text { Designing mathematics activities in Spreadsheet } \\
\text { and developing lessons (3) }\end{array}$ & $\begin{array}{l}\text { Practical session at computer } \\
\text { Lab }\end{array}$ \\
\hline 13 & $\begin{array}{l}2^{\text {nd }} \text { Round of Lesson Implementation (Semesters' } \\
\text { Project) }\end{array}$ & $\begin{array}{l}\text { Peer review of lesson plans } \\
\text { and actual teaching (video- } \\
\text { taped) }{ }^{2}\end{array}$ \\
\hline 14 & ICT skill Test & Post Instrumentation \\
\hline $15-16$ & Revision/End of Semester Examination & Students' write their exams \\
\hline \multicolumn{3}{|c|}{$\begin{array}{l}1,2 \text { Assignment due in one (1) week; }{ }^{*}, * * \text { Assignment due before the next lecture } \\
\text { Semesters Project: Choosing a topic (with a problem) in the SHS curriculum and developing a } \\
\text { lesson to be taught with spreadsheet application by a design team member. (to be collected at the } \\
\text { end of the } 13^{\text {th }} \text { week) } \\
\text { Group effort : Members in each group receive the same group mark for their effort } \\
\text { Individual effort : Individual task attract individual marks } \\
\text { Grading: } \\
\text { Group Assignment } \quad 30 \%\end{array}$} \\
\hline
\end{tabular}




\title{
H2 Curriculum lesson material that was used before IT course design
}

\author{
UNIVERSITY OF CAPE COAST \\ DEPARTMENT OF SCIENCE AND MATHEMATICS EDUCATION
}

EMA 401 DEVELOPMENT OF MATHEMATICS TEACHING MATERIALS (3 Credits) FIRST SEMESTER 2009/2010

Lecturer: Prof. Benjamin A. Eshun

\section{Reference Texts}

1. (SP) Banwell, C.S, Saunders, K.D. \& Tahta, D.G. (1972). Starting Points for teaching mathematics in middle and secondary schools.

2. (TLM) Barnett, G. \& Goebel, J. The Impact of Graphing Calculators on the Teaching and Learning of Mathematics. In T.J. Cooney \& C.R. Hirsch (Eds.) (1990). Teaching and Learning Mathematics in the 1990s. National Council of Teachers of Mathematics.

3. (TMA) Smith, S.E., and Backman, C.A. (Eds.) (1982). Teacher-Made Aids for Elementary School Mathematics. National Council of Teachers of Mathematics.

4. (SWM) Welchman-Tischler, R. (1995). Start With Manipulatives. Cuisenaire Company.

\section{Course Description}

The course examines the nature of teaching and learning materials for the secondary (junior and senior high) schools and the criteria for their selection. Materials for teaching the major topics (e.g. Number, Algebra, Geometry) are introduced and activities are designed with specific objectives to enable students acquire the content of the curriculum. The student is required to reflect on the course in general and on specific materials and activities to indicate their understanding and how the course has been of benefit to them.

\section{Objectives}

The objectives of this course are that students will be able to

1. identify various mathematics teaching and learning materials for teaching at the secondary school and the criteria for their selection.

2. design, develop and prepare mathematics teaching and learning materials

3. use teaching and learning materials to learn and understand the content of the secondary school curriculum.

4. use the graphing calculator to enhance understanding of known mathematics concepts and skills and to solve problems in mathematics especially calculus.

5. to reflect on the course in general and on specific materials and activities to indicate their understanding of the concepts and skills learnt.

Prerequisite: One method course in mathematics

\section{Course Outline}

Week 2- What are teaching materials?

TMA 5-12

Aug. 17

Week 3

Aug. 24 
Week 4 Mathematics activities and games

Week 5 Number and Numeration teaching. materials

Sept. 7

Week 6

Sept. 14

Fraction teaching materials

Week 7

Sept. 21

\section{Homework}

Integers and Rational Numbers teaching materials

Week $8 \quad$ Algebra teaching materials

Sept. 28

Week 9 Geometry and Measurement teaching materials

Oct. 5 \#Class Test

Week 10 Statistics and Probability teaching materials

Oct 12

Week 11 Graphing Calculator as a teaching and learning tool

Oct. 19

Week 12 Graphing Calculator Activities

Oct. 26

Week $13 \& 14$

Nov. 2 - 13

The Mathematics Laboratory

\#Journal due

(MSS)

Week 15

Nov 16

\section{Revision period}

Week $16-18$

Nov. 23 - Dec. 11

\section{\#End of Semester Examination}

*Group Effort (Students work in small groups and each group member receives the same group mark.)

\#Individual Effort (Student works individually without consulting other group members.)

Grading $100 \%$

Group Homework

Class Test

$15 \%$

Individual Journal

$15 \%$

End of Semester Examination $60 \%$ 